\title{
THE TRUMP PRESIDENCY, JOURNALISM, AND DEMOCRACY
}

Edited by

Robert E. Gutsche, Jr. 


\section{The Trump Presidency, Journalism, and Democracy}

This book examines the disruptive nature of Trump news - both the news his administration makes and the coverage of it - related to dominant paradigms and ideologies of U.S. journalism. By relying on conceptualizations of media memory and "othering" through news coverage that enhances socio-conservative positions on issues such as immigration, the book positions this moment in a time of contestation. Contributors ranging from scholars, professionals, and media critics operate in unison to analyze today's interconnected challenges to traditional practices within media spheres posed by Trump news. The outcome should resonate with citizens who rely on journalism for civic engagement and who are active in social change.

Robert E. Gutsche, Jr. is Senior Lecturer in Critical Digital Media Practice at Lancaster University, UK. He was Assistant Professor in the Department of Journalism and Media at Florida International University, USA. A journalist since 1996, his scholarship surrounds the cultural and social meanings of news and has appeared in Journalism \& Mass Communication Quarterly, Journalism, and Journalism Studies. 


\section{Routledge Research in Journalism}

For a full list of titles in this series, please visit www.routledge.com.

12 Mindful Journalism and News Ethics in the Digital Era

A Buddhist Approach

Edited by Shelton A. Gunaratne, Mark Pearson, and Sugath Senarath

13 Profile Pieces

Journalism and the 'Human Interest' Bias

Edited by Sue Joseph and Richard Lane Keeble

14 Journalism and the Philosophy of Truth

Beyond Objectivity and Balance

Jesse Owen Hearns-Branaman

15 Democratizing Journalism through Mobile Media

The Mojo Revolution

Ivo Burum

16 News Across Media

Production, Distribution and Cosumption

Edited by Jakob Linaa Jensen, Mette Mortensen, and Jacob Ørmen

17 Pursuing an Ethic of Empathy in Journalism Janet D. Blank-Libra

18 Journalistic Role Performance

Concepts, Contexts, and Methods

Edited by Claudia Mellado, Lea Hellmueller and

Wolfgang Donsbach

19 News of Baltimore

Race, Rage and the City

Edited by Linda Steiner and Silvio Waisbord

20 The Trump Presidency, Journalism, and Democracy

Edited by Robert E. Gutsche, Jr. 


\title{
The Trump Presidency, Journalism, and Democracy
}

\author{
Edited by \\ Robert E. Gutsche, Jr.
}


First published 2018

by Routledge

711 Third Avenue, New York, NY 10017

and by Routledge

2 Park Square, Milton Park, Abingdon, Oxon OX14 4RN

Routledge is an imprint of the Taylor \& Francis Group, an informa business

(C) 2018 Taylor \& Francis

The right of the editor to be identified as the author of the editorial material, and of the authors for their individual chapters, has been asserted in accordance with sections 77 and 78 of the Copyright, Designs and Patents Act 1988.

With the exception of Chapters 6, 7 and 11, no part of this book may be reprinted or reproduced or utilised in any form or by any electronic, mechanical, or other means, now known or hereafter invented, including photocopying and recording, or in any information storage or retrieval system, without permission in writing from the publishers.

Chapters 6, 7 and 11 of this book are available for free in PDF format as Open Access from the individual product page at www.routledge.com. They have been made available under a Creative Commons Attribution-Non Commercial-No Derivatives 4.0 license.

Trademark notice: Product or corporate names may be trademarks or registered trademarks, and are used only for identification and explanation without intent to infringe.

Library of Congress Cataloging-in-Publication Data

CIP data has been applied for.

ISBN: 978-1-138-30738-4 (hbk)

ISBN: 978-1-315-14232-6 (ebk)

Typeset in Sabon

by codeMantra 
For my family, Carolina and Martín Franco 


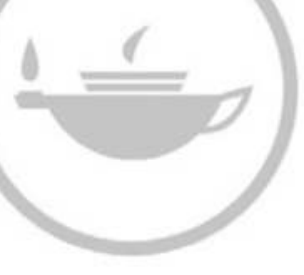

Taylor \& Francis Taylor \& Francis Group

http://taylorandfrancis.com 


\section{Contents}

Introduction: Translating Trump: How to Discuss the Complications of Covering New Presidential Politics

ROBERT E. GUTSCHE, JR.

PART I

Challenges to Journalistic Norms, Practices, and Social Cohesion

1 Donald Trump and the War on the Media: From Election ' 16 into the Trump Presidency

DOUGLAS KELLNER

2 News Boundaries of "Fakiness" and the Challenged Authority of the Press ROBERT E. GUTSCHE, JR.

3 Civil War in Donald Trump's America: Conversations about Media and Mayhem on Main Street, USA

ROBERT E. PIERRE

4 Haktology, Trump, and News Practices LEON BARKHO

PART II

Journalism during Difficult Discourse

5 Who, From Where? TV Network News Coverage of Immigration Narratives during Trump's First 100 Days 
viii Contents

6 By Any Other Name: Media and White-Supremacist Terrorism in the Trump Era

KATHERINE M. BELL

7 The Hell that Black People Live: Trump's Reports to Journalists on Urban Conditions

CAROLYN GUNISS

8 Media Narratives of Gender in the Contentious

Conservative Age of Trump

PAM CREEDON

PART III

Trump, Rhetoric, and Understanding Amid Media

Fragmentation

9 The Origins of Trump's “Alternative Reality": A Brief History of the Breitbart Effect

FRANK DURHAM

10 Advertisements in the Age of Hyper-Partisan Media: Breitbart's \#DumpKelloggs Campaign PRASHANTH BHAT

11 Scapegoater-in-Chief: Racist Undertones of Donald Trump's Rhetorical Repertoire

STEPHEN J. HEIDT

PART IV

Journalistic Recovery Post-Trump: Lessons Learned

12 “Stop Overlooking Us!”: Missed Intersections of Trump, Media, and Rural America

AL CROSS

13 Reeducation or Rejuvenation? Trump's Influence on News Interest and Literacy 
14 Trump, Democracy, and the Extension of Journalism Ethics 282 KATHLEEN BARTZEN CULVER

15 The Effects of Mediatized Hate: Coping with Life in Trumpland

LATASHA DELOACH

Epilogue: Facing Tomorrow in an Age of Trump ROBERT E. GUTSCHE, JR.

List of Contributors

Index 


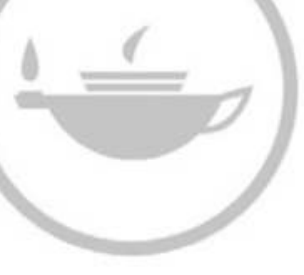

Taylor \& Francis Taylor \& Francis Group

http://taylorandfrancis.com 


\section{Acknowledgements}

This has been a very challenging project. Within a period of months, I asked scholars, practitioners, public officials, and citizens to turn around what would be powerful scholarship, journalism, and reflection in short time about a very painful period of our time. This is one of the most diverse collections of work in the field of journalism studies, and its success is because of the support from many.

Special thanks to Mary Fisher, Moses Shumow, Juliet Pinto, Brian Schriner, Andre Brock, Teresa Ponte, George Pearson and staff at FIU's Hubert Library, Andrew Trabazo, Kristy Hess, and Lanier Holt for a wide array of insights and resources that it takes to produce such a project. I am also thankful for my editors at Routledge and for the many contributors who have left a mark on interpretations of history in the making. Thank you goes to Carina Vo for editing of illustrations for this project.

I also thank my wife, Carolina, my parents, Bob and Jeannie, Vicky and Oscar Estrada, and Mona Robledo for their love and support during the trying time of putting this project together that occurred simultaneously with the birth of Martín Franco. Your patience and care helped me focus both on his wellbeing and on the success of this important project. Special love to Martín's namesake, Frank Durham, and to my brother Mark.

Many thanks to the late Terry Michael, who among other achievements founded The Washington Center for Politics and Journalism, of which I was a participant, who passed during the collection and editing of this work in 2017. He may not have agreed with all of the comments here, and I am sure he would have had many of his own about ones he even agreed with, but as a communicator, educator, and public servant, he is remembered as making a difference at difficult times. 


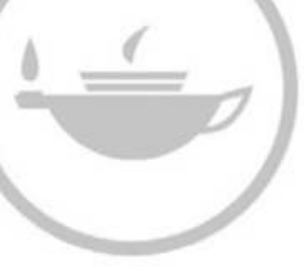

Taylor \& Francis Taylor \& Francis Group

http://taylorandfrancis.com 


\title{
Introduction
}

\section{Translating Trump: How to \\ Discuss the Complications \\ of Covering New Presidential \\ Politics}

\author{
Robert E. Gutsche, Jr.
}

Newspaper headlines from the United States on November 9, 2016, reflected more than just who won the presidential election. "STUNNER," yelled the banner headline of The Record in Stockton, California. "BELIEVE IT," the Montgomery Advertiser headline in Montgomery, Alabama, read below a subhead, "Donald J. Trump becomes 45th President of the United States." On The New York Times, "New media again misreads complex pulse of the nation." Although, Trump's victory wasn't really surprising to people who paid attention to the kinetic energy of the social pendulum that was ramping since Barack Obama first took office and that was fueled by white citizens who felt an ultimate threat to their power. To them, their power was back.

Still, U.S. journalists, by and large, ignored Middle (read, white) and much of America once again, and empowered themselves with traditional approaches to newswork that elevated access and prize journalism over meaningful assessments of systematic power within institutions of government, business, and culture. If decades of televised and now in-real-time white-on-black crime, especially at the hands of militarized police forces against the citizenry, wasn't enough to indicate something was wrong before Trump, it is no wonder that journalists missed the seriousness of a largely white constituency that had all but destroyed any advancements in social and cultural affairs in states such as Wisconsin, Texas, and Florida, as well as an array of local government actions across the country that restrict free speech and personal rights to use a bathroom based on gender identification.

A gay marriage law that can be easily rescinded by governmental executive orders, a Black president, and a socially conscious health care system a liberal society it does not make.

Trump's signs of power to undo these efforts at equal treatment were there the whole time, often hidden in coded jokes, language, and mannerisms. Trump has been open about using news media as free advertising to build his real estate and entertainment empires, and he has also been consistent with audiences and publics - well before his 


\section{Robert E. Gutsche, Jr.}

candidacy - about his humor, his bombastic style, and his ability to shift in populist winds when it suits him. That many knew of his loud mouth following his decades of his controversial real estate deals, his TV fame, and his political speech, helped them to normalize the crazy for mass appeal.

In turn, supporters were able to dismiss any real concerns about Trump's racist tendencies in housing policy, his lavish and over-the-top lifestyle, his reckless financial efforts that sometimes flopped, and his clear connections with powerful Democrats before he was forced by the GOP to join their ranks in order to secure the party's nomination. Put simply, his nonsense approach made his own nonsense, nonsense.

In fact, one of my family members, while watching news coverage of Trump's Milwaukee speech in August 2016 in which he took aim at efforts to increase law enforcement in what he seemed to describe as out-of-control inner cities showed me some insight into the Trumpfollower mindset, whether she supported Trump or not. I didn't ask.

Already in the campaign, Trump had made the following comments:

- "When Mexico sends its people, they're not sending their best. They're not sending you. They're not sending you. They're sending people that have lots of problems, and they're bringing those problems with us. They're bringing drugs. They're bringing crime. They're rapists. And some, I assume, are good people."

- "I watched when the World Trade Center came tumbling down. And I watched in Jersey City, New Jersey, where thousands and thousands of people were cheering as that building was coming down. Thousands of people were cheering."

- "I could stand in the middle of Fifth Avenue and shoot people and I wouldn't lose voters."

- "In the Middle East, we have people chopping the heads off Christians, we have people chopping the heads off many other people. We have things that we have never seen before - as a group, we have never seen before, what's happening right now. The medieval times - I mean, we studied medieval times - not since medieval times have people seen what's going on. I would bring back waterboarding and I'd bring back a hell of a lot worse than waterboarding."

- "[Russia] a very different system and I don't happen to like the system, but certainly, in that system, [Putin's] been a leader, far more than our president has been a leader." (Newsday, 2016)

Such comments were replayed in coverage of the August speech when the following conversation occurred.

"I can't believe he says these things," I said in my living room.

"I wish he wouldn't say those things," my relative said. 
"What's worse is that people actually believe these things," I noted, believing we would be able to discuss how and why Americans have come to believe these ideas to the degree where they would openly support a presidential candidate speaking so plainly.

"It's not that I don't believe those things," my relative told me. "I just don't think he should say them."

And that's where we are.

Maybe where we have always been.

Few people say what they really mean, and maybe politicians are the best at that. With Trump, though, his comments have been in code, where within his plain talk holds hidden meanings.

Trump's comments about the Mexican wall, for instance, and that Mexico "will pay for it," didn't mean that he would seriously seek a check from the Mexican government for building supplies. Instead, the nation would pay (or ease the financial strain of the project for the United States) through types of embargos and taxes that he could conjure up, or in the money lost from rescinded aid to the Mexico, or private and corporate losses as the U.S. government would make it so uncomfortable for U.S.-based industry to do business there.

Trump supporters also understood what Trump really meant in his presidential bid announcement in June 2015 when he discussed issues of Mexico "sending" its citizens across the border. There is no doubt that Trump's many statements about "immigrants" and his own business practices dealing with immigrant workers reveals a disdain for non-American workers (or lives) in the United States. But in the immediate context of this discussion about "sending" people to the United States, Trump was critiquing the Mexican criminal justice system (Washington Post, 2015), in particular, the challenges the government faces in maintaining its prison system (Hanchett, 2015). (Yes, I know the cite for that last point was from Breitbart.) As Trump put it:

And frankly, Mexico doesn't care from the standpoint that they don't want to house these people for a long period of time in their prisons. They say, 'Let the United States take care of them. Let the United States put them in their jails. Why should we pay for it?' And believe me, it's happening and it's happening big league and this country doesn't know.

(Salon, 2015)

Remember that Mexican bad-man "El Chapo" had escaped from Mexican officials and was on the run since 2001 before being captured in 2014 after a massive and international manhunt that led to concern 


\section{Robert E. Gutsche, Jr.}

about the ability of the nation to keep guard (Guardian, 2015). Ironically, "El Chapo" escaped from another Mexican jail in July 2015 and was later captured at which time Mexican officials said that they would extradite him to the United States, which they had once refused to do when U.S. officials expressed concern about his potential to escape (Shoichet, Yan, \& Fantz, 2015).

Trump's comments then and again in his GOP nomination speech in July 2016 (Cariz, Leighton, \& Thorp, 2016), in which he named a murder victim who was killed by an "illegal immigrant" earlier in the month in San Francisco (Mai-Due, 2015), was pushed and parsed together by news media to create a narrative of anti-immigration attributed to Trump.

It's not that the narrative might not be true, but the work of news media to connect news events, language, policy, and social conditions (which, at a normative level, is the role of journalism) ignored the coded comments of the candidate about challenges between the two nations in terms of law enforcement not just in the United States but in Mexico.

Had journalists examined the narrative as Trump presented it (including the overt and coded racism), perhaps stories related to U.S.-Mexico drug cartels and governmental involvement by U.S. forces and officials to spread drugs from below the border into this country's poor neighborhoods and rich suburbs would have been further revealed (i.e. Cockburn \& St. Clair, 1999). Yet, that story wouldn't do well for the media's role of maintaining a socially cohesive nation under the rule of law and order of a fair and free government (Cooke, 2005).

The problem for journalists wasn't that they misquoted Trump. They misunderstood him, and they did so because being against Trump was citing a conflict within a campaign that wasn't about real issues, such as racialized police brutality or corrupt and neoliberal public-private ventures such as the educational system, militarization of our youth, and the government's imperialistic acts across the globe (Gutsche, 2017).

To be clear, I am not supporting rhetoric that is hateful, and I do consider much of Trump's rhetoric to be filled with hate. This brief analysis is not to write away meanings of Trump's rhetoric through complication. Rather, it is the complication I wish to highlight that reveals ideological interactions between political speech, personal philosophies that reinforce such speech, and operations of the press which hide acts of power, subjugation, and oppression.

Indeed, I come from a background where the coded language of hyperbole and metaphor, snide comments and anti-elitist martyrdom is commonplace in conservative Christian communities. And what my family member showed me in August 2016 was that the times haven't changed since I moved away from those communities. The codes are still valid. People are still pissed off about the cultural revolution, and the nation still largely believes prayer in school is more important than justice and fairness on U.S. streets. 
In fact, it was in the Milwaukee speech (which actually was in the suburb of West Bend), that Trump spoke plainly to his base and to the media, to liberals and to the swing voter, understanding that if voters and journalists didn't already like him they never would. And that is OK with him - and his supporters. Speaking of the status quo of U.S. government, Trump said:

It's the powerful protecting the powerful. Insiders fighting for insiders. I am fighting for you.

When we talk about the insider, who are we talking about? It's the comfortable politicians looking out for their own interests. It's the lobbyists who know how to insert that perfect loophole into every bill. It's the financial industry that knows how to regulate their competition out of existence.

The insiders also include the media executives, anchors and journalists in Washington, Los Angeles, and New York City, who are part of the same failed status quo and want nothing to change.

(Politico, 2016)

Here, Trump said what everyone already knew - whether they liked to admit it or not. The United States is a meritocracy run by a power elite. Isn't that why we try so hard to increase our individual wealth or solvency? Do we not work for the next rung of our careers? If you are reading this book, do you not certainly have the disposable time to do so? What would we do to keep things the way they are?

And by identifying (or reminding some of) the audience who is to blame for the threat to our own, individual success - the inner cities, immigrants, government, journalists, and billionaires other than Trump - we become united to fight for whatever we think is right, pitting ourselves against whatever it is that needs to be defeated. In other words, we are all in the same battle. We just have to choose who will fight.

But anyone who has followed Donald Trump as a businessman and as a pop culture icon knows that he will say whatever he wants, whenever he wants to, whether it is true or not, and particularly when fighting is involved. The "You're fired" line from his Apprentice days - even when during the Great Recession the show became about celebrities making money for charity - ignored the ramifications for those who lose their livelihood and elevated the power of the person in charge to rip from someone else their hopes and dreams, bank mortgages and families, savings and futures.

Trump isn't to be blamed for this, though - another mistake anti-Trumpers make. He is simply the voice of reason for those who haven't been able to put food on the table in the Midwest, the voice of the white person in Miami, where I lived from 2012 to 2018 who has seen her neighborhood become more diverse with people who look, sound, and dress less like her than her previous neighbors, the voice for the privileged who think simply because 
they are who they are that they deserve to enter college even if a more qualified, darker-skinned candidate beat them out of the spot. Their spot.

I am taking great risk writing about these issues with such conviction, so much so that one might think I support public policies that disenfranchise. Please know that I am merely tapping into a mentality that is either so foreign to many scholars, journalists, and citizens - or, more likely, that is simply more disgusting - that the choice has been to ignore the less palpable in our society as a means to "think positive" for change. To be clear, I am for change. But I am for real change. When one presidential executive order can be replaced by another or while simply electing enough homophobic representatives to a statehouse can repeal the right of all to marry, we are making progress toward change, but we must realize that these changes are not substantial enough for publics to expect or receive real social justice.

Social movements to reform the "criminal justice system," to financially support public education, and to end rape on college campuses would be so great and so costly to people in power that approved actions and rhetoric frequently diminishes social tension for a time and distracts from those responsible for the disruptive policies and actions. In the end, real change is hard and rarely happens.

Trump might not be real change either.

But, to those who voted for him, Trump is change in their right direction. Realizing this for those who didn't vote for him (or, who like me, do not vote at all) is paramount for upholding what they hold dear while acknowledging the deeper meanings of surface change in this moment and its real consequences.

\section{A Moment of Media Change}

Measurable change has exploded beyond the walls of politics and social discourse since Trump, into the very work that journalists do to maintain the status quo and social control through the veil and rhetoric of the Fourth Estate. As I have written elsewhere (Gutsche, 2017), news media operate as a system of power maintenance, no matter who is in charge. It is the system and its hegemony, grounded in ideological explanations that place some in better social positions than others, that is paramount.

Even in the days of Obama, he wasn't a friend to the press (i.e. Morrison, 2016). Journalists functioned then, too, as a tool for the power elite to provide verifiable and believable explanations for daily life, political decisions, and other news events for the masses. In this way, journalism is a cultural act that surrounds coercion and power that is marked, instead, as social cohesion and civic engagement but that is really about making the powerful (more) powerful by leading citizens to believe they are truly engaged in a sociocultural political process that is American democracy. 
Another problem in discussing the press and politics is that journalism is viewed as a normative practice with little complication as social and cultural functions. In this view - which is not entirely counter to or separate from a cultural perspective - journalism operates as a method by which to engage citizens with governmental and social leaders. Standards of accuracy, transparency, sourcing, and verification have remained past the rejection of pure journalistic objectivity. What also remains are normative attachments to journalism as a realization of a public sphere, of open, free, and fair exchanges of ideas that position citizens as agents of change and determiners of their own existence through governance.

Still, whereas all cultural investigations of journalism do not exclusively lead to issues of coercion, all normative examinations of journalism do not exclusively lead to moments of pure altruism. Instead, cultural and normative explorations reveal complex and layered interactions of power, economy, identity, coercion, engagement, and empowerment. Social order, though, serves as journalism's main function, perpetuated through acts of shaming, legitimization, and surveillance.

This book takes a look at these intersections from both normative and cultural levels at a time of great crisis for both cultural and normative explanations and functions of the press. The following pages examine how Trump's tumultuous - and some might say triumphant - election win and initial months in office have put the political (and the press) world into a spin. His political success has also challenged decades of Civil Rights efforts, recent advancements in sociopolitical arenas of identity, forms and acts of democratic expression, and "known facts" of the everyday.

At the same time, Trump's rise has been a direct attack on mainstream media, particularly mainstream U.S. press, legacy, elite, digital, and otherwise. In addition to charging news media as conspiring against him personally and professionally, Trump's administration has moved to ban reporters from open meetings, making accusations against journalists and politicos on social media and in press conferences without evidence, and rejecting conventional means of communication on and off of Capitol Hill.

At the center of Trump's progress - and the advancement of his supporters - are threats to already subjugated communities and ideologies, the least of which have struggled for mainstream media attention in recent years. Emerging at a time of (publicized) police violence, rape culture, neoliberal economics and social policies, and the defunding of public institutions, Trump's presence in social media, at dinner table conversations, in internet memes, and in both "liberal" and "conservative" media narratives, is the need for critical discourse of explanation, interpretation, resistance, and debate.

Dozens of books have discussed new approaches to journalism in a digital age, how to make journalists better through practice and critique, how to engage citizens with journalism in meaningful ways, and how to increase the democratic aims of the news business. Many of those books 


\section{Robert E. Gutsche, Jr.}

highlight the power of social media to engage journalists with sources and to make more citizens more active sources for shaping the news. Few of those books, however, have been able to prepare us for today's media spheres that have been influenced so quickly and so heavily by Trumpism. My hope is that this book can close some of that gap.

Surely, U.S. democracy will not fall and journalists and citizens will work out the new challenges to the system of gathering and interpreting information, but there are some elements of the system that will not change. The largest? Now that the system's flaws and challenges, its centralized power and elitism have been brought into the political ring, it is (and will be) difficult to argue against and, perhaps, fully recover from where we find ourselves today.

\section{A Common Start to Multiple Explanations}

At one point of agreement among the contributors to this project, "fake news" to "alternative facts" and the rise of Trump and neoliberal democratic values has been at the center of sociopolitical change in the United States since the 2016 election cycle started. The influences are international and personal: concerns surrounding civil liberties, militarization of U.S. forces abroad and at home, and at the center of public discourse today, the potentially destroyed role and existence of a free press in American democracy.

These movements intersected with a rise of tensions between the United States and Russia in the mid-2010s as the Obama administration increased the use of drones and deportations to set standards of U.S. positionality in international affairs, and as media systems worldwide became challenged with practicalities and ethical disruptions related to leaks that gave rise to online media sites focused on undermining the behind-closed-door-ness of U.S. diplomatic and military action.

Domestically, unrest due to media coverage of the Black Lives Matter movement, following the mass murder of U.S. Blacks across the country and residual elements of the Wall Street protests and interpretations of social media to democratize during the Arab Spring all coalesced to further fracture a politically divided nation. Trump was the answer to those struggling with "liberal media" and "talking heads" that for decades have aligned quite well with the country's unison cries of a corrupt Congress and elite media.

This book, therefore, applies critical assessments and examinations of press interactions with fellow institutions of power in the media's battle to maintain mainstream authority when current governmental and police actions of oppression and subversion operate on the nightly news through rhetoric and political action expressed by a new presidential crew and local representations of discontent with progressive actions untaken during the Obama Years. 
Indeed, the rise of Trump and the focus throughout the election and the new administration's positions in changing the very landscape of U.S. social and cultural policies has made an immense impact on our collective futures, changing the focus and the need for a project such as this one that bridges both academic and popular audiences in ways that position the press as key to both the problems that contributed to Trump's contentious rise and to the possible solutions of how to regain press autonomy while shedding some of its oppressive traits.

Great controversy and concern aside, the very public debates about the role of media in covering Trump and proposed neoliberal rhetoric and political acts has put failures of the press to acknowledge Middle America on the front burner. Political pundits, journalists, and scholars alike struggle to explain the meanings for the future of American press in both the short and long terms. Since the beginning of market changes in the 1990s that altered the profitability and sustainability of journalism globally, nothing has challenged the cultural legitimacy and authority of the press like Trump.

In short, my hope is that the contributors to this project highlight for audiences the main elements of journalism's struggle not only with the direct challenges of the Trump administration, but with the underlying social and cultural turns and positions of power that have led to the scary situation in Washington, D.C., which already has lasting implications on everyday lives internationally.

Yet, this project is not just a capturing of current events that will soon be over, but conceptualizes the actions of the press - and the possible legitimate concerns of press critiques - that create a narrative of one of the biggest threats to normalized news understandings the world over. Indeed, scholars and critics have committed journalists to embrace participatory methods of covering particular communities even without understanding whether those communities are actual news audiences and the degree to which the news matters to them. Yet others work to prove the democratic value of the press, arguing about the degree to which today's journalism meets the needs of the public and attempt to place today's media sphere within a normative historical context in which today's media seems much more politicized than the past.

In turn, authors and readers attempt to "make journalism better," with each idea and piece of advice identifying how journalism has lost its way, how objectivity has been replaced by transparency and triangulation, how we should all strive to get back a journalism that we lost. These voices share a common dream that we have as journalists, citizens, and educators - that out there is a watchful eye dedicated to truth and justice and that operates without such subjectivity that the value of the news to help us make decisions about the world has been lost to private interests. 
Still, these voices fail to offer much critical examination of press power and the processes of the press that marginalize. Voices that attempt to alter the journalistic ship, however, provide little meaningful difference in terms of who reports on what and for whom that then appear through soft changes and solutions that people "like." Who doesn't want to have a press free of political influence, at a free or nominal financial cost, and with which members of the public can influence media messages as much as politicians, movie stars, and bank robbers?

Solutions that could get us to each of these outcomes, however, rarely have a deep, cutting cost to how journalists view themselves in terms of power positions and to corporate backers and governmental partners. In other words, popular discourse supports the idea that democracy is for all and led by the people, that the press report the news as though the news is an object to be found rather than constructed by a process of power interests, that journalism, despite its attempt to be value-free still can be categorized as a "good" or "bad" thing for society. The problem is that this might not be the case - and Trumpism has pulled back the veil, to some degree, in ways that allow for a critical debate about the role, function, and processes of U.S. press.

To examine the disruptive nature of Trump news - both the news his administration makes and the coverage of the news itself - related to dominant paradigms and ideologies of U.S. journalism, contributors rely on conceptualizations of recent media memory during the Trump campaign and processes of media "othering" through news coverage that enhances socio-conservative positions on immigration to normative estimates about Trump's impact on journalistic ethics, news literacy efforts, and political rhetoric.

There is no way that this project can include all of the antics, executive orders, changes to media practice, and political meanings associated with Trump's first year in office, though we have tried to put into context intersections of meanings of events that have occurred through November 2017. And while this book has tried to capture these moments comprehensively, we do so not to be a catchall, but to mark within moments of history the conceptualizations, emotions, logics, and effects on lives that are occurring as they occur. History, as we know, has a way of not just placing moments within constructs of clarity and context, but also of delegitimizing the voices of the moments-in-time under study with gloss and revisionism.

As a final point, there may be very few projects like this - one that combines work from scholars, professionals, and media critics that operate in unison to construct an overarching framework of today's interconnected challenges to traditional practices within media spheres, for citizens who rely on journalism for civic engagement, and to those active in social change, from classrooms to city centers. We hope this inclusivity of voices can be an example for future works. 


\section{Book Outline}

This book is presented in four parts. Part 1, Challenges to Journalistic Norms, Practices, and Social Cohesion, examines challenges to dominant journalistic norms and practices during threats to social cohesion within the United States and international communities.

Douglas Kellner launches the book with a critical essay that analyzes power dynamics of the Trump campaign and presidency. His chapter, "Donald Trump and the War on the Media: From Election '16 into the Trump Presidency," pays particular attention to modes of intentionality on part of political operatives and journalists alike to shape a society burgeoning with neoliberalism and authoritarianism.

In Chapter 2, "News Boundaries of 'Fakiness' and the Challenged Authority of the Press," I examine recent iterations of "fake news" and challenges to authority and legitimacy of mainstream news media during coverage of the 2016 presidential election. An analysis of coverage from the United States and the United Kingdom reveals boundary work by mainstream press to position "fake news" within a realm of paradigm maintenance that reinforces normative and social forms and functions of the press. Instead of merely attacking "fake news" rhetoric tossed at mainstream press by candidate and president-elect Trump and undermining "fake news" sites through journalistic investigations, journalists from both nations used the moment to rebuild mainstream authority.

In Chapter 3, "Civil War in Donald Trump's America: Conversations About Media and Mayhem on Main Street, USA," a piece of powerful storytelling, Robert E. Pierre presents the multiple sides of the nation's modern day "Civil War." Through journalism, the voices of Trump supporters and detractors ground this project in the meaningful experiences of the everyday. The chapter is a vital element of information and perspective for a book on journalism and democracy in an age of Trump, providing a space for the voices of citizens trying to decipher reality from reality TV, fake news from real, and who their neighbors really are - and what they believe; Pierre's chapter grounds the project in the "real world."

In Chapter 4, "Hacktology, Trump, and News Practices," Leon Barkho conducts an interesting analysis of "hacktology," the approaches and processes of distracting audiences from violations of personal privacy and independence through press sensationalization of hacking and leaks. Particularly applicable to the rise of Trump and the evolution of press processes related to Trumpism - the distraction of leaks and Russian hacking - "hacktology" provides a method of analysis to identify and critique journalistic practices and internationalities inherent in covering the unseen within a moment of contestation.

In Part 2, Journalism during Difficult Discourse, authors explore news coverage of divisive public policies presented by the Trump 


\section{Robert E. Gutsche, Jr.}

administration and rhetoric of journalists and politicians alike used to explain hatred embedded inside popular ideological stances of immigration, racism, and identity that emerged not just from the White House in these early days but which appeared normal and resonant with many of the population.

Chapter 5, "Who, From Where?: TV Network News Coverage of Immigration Narratives during Trump's First 100 Days," examines variations in coverage among U.S. network news channels ABC, CBS, and NBC related to the emotional and controversial proposals by the president to build a wall on the U.S.-Mexico border. The original trio of video journalism outlets in the United States, the legacy networks, authors Jennifer Hoewe, Geri Alumit Zeldes, and Brian J. Bowe argue, represent various audiences and interests in its coverage, turning to particular tones of discourse, narrative language, and levels of analysis to position the news within an ideological debate.

In Chapter 6, "By Any Other Name: Media and White-Supremacist Terrorism in the Trump Era," Katherine M. Bell provides a rigorous analysis of news media's racialized positionalities that are rooted in whiteness to assess coverage about Trump's approved attacks against non-Christian, non-White, and "un-American" populations, individuals, and rhetoric. Directly, Bell challenges journalists to undermine racist tendencies of journalistic institutions that influence the degrees to which reporters subscribe to political attributions of "terrorism" as being related only to international "others," and not to homegrown, alt-Right, and approved governmental policies of social disorder.

Chapter 7, "The Hell That Black People Live: Trump's Reports to Journalists on Urban Conditions," by Carolyn Guniss, walks us through an analysis by a journalist of Trump's racist rhetoric, as covered by the press. Guniss, the former Executive Editor of Miami's historic black newspaper, The Miami Times, extrapolates meanings of centuries-old narratives of whiteness that appear in Trump's comments and proposed policies related to those of "the inner-city." Her commentary places the reader within the mindset of the dual roles of many Black news outlets in the United States, serving both the local communities of People of Color, particularly African Americans, and maintaining the practices of journalism that frequently function to oppress.

In Chapter 8, "Media Narratives of Gender in the Contentious Conservative Age of Trump," feminist scholar Pam Creedon reflects on the meanings of Trump's rise and the news media's pandering to the lowest common denominator - the conflict and spectacle that the 2016 election became. More than anything, however, Creedon highlights acts of resistance among today's feminist activists and scholars to resist tyranny, and places events such as the Women's March within a context of a Fourth Wave.

Part 3, Trump, Rhetoric, and Understanding Amid Media Fragmentation, articulates meanings associated with the rise of Trumpism via the 
Breitbart Effect, the influence of alt-Right voices and conservative media in a fragmented media sphere. Chapters in this part place the current situation of media ownership, influences of collective values and social norms, and the role of geography and market within a framework that is helpful in expanding perspectives of how journalism shapes Trump and vice versa.

In Chapter 9, "The Origins of Trump's 'Alternative Reality:' A Brief History of the Breitbart Effect," Frank Durham investigates the rise of "fake news" and "alternative explanations" that have plagued the news industry, most recently since the 2016 presidential election, through an epistemological lens that harkens to the nature of emerging press in the United States, the standardization of professionalism from the early 1920 s that was based in scientific interpretation of reality. Durham traces the trajectory of these approaches, landing in the mid-2000s as a foundational moment of change to recent traits of journalistic reporting, verification, and presentation that is focused on ideological manipulation of journalistic information.

Prashanth Bhat, in Chapter 10, "Advertisements in the Age of Hyper-partisan Media: A Case Study of Breitbart's \#DumpKelloggs campaign," examines the critical history of professionalized journalism within the United States alongside adaptations to advertising that came to an interesting head during the era of Trump in 2016. By explicating the \#DumpKelloggs campaign by Breitbart following the food manufacture's call to boycott the news outlet, Bhat discusses the implications for journalism in terms of its economics at contentious political times and during a rise of alternative political and social press, particularly of the alt-Right.

In Chapter 11, "Scapegoater-in-Chief: Racist Undertones of Donald Trump's Rhetorical Repertoire," Stephen J. Heidt provides a fascinating take on how the press covered Trump's scapegoating of all things "un-American" to be positioned within journalistic coverage as a serious candidate for president. Even after the celebrity status shock settled and the mere idea that Trump could win the election became a reality, U.S. press, Heidt argues, turned to narratives other than Trump being a questionable candidate and elected official to explain some of his tirades, his xenophobic language, and the fact that millions of U.S. voters seemed to think Trump would be the best choice. Heidt's analysis provides deeper understandings of presidential rhetoric, particularly Trump's, and the problems of a press that take officials at their word with little examination of their meanings.

Part 4, Journalistic Recovery Post-Trump: Lessons Learned, positions the reader to explore how journalists and scholars already view the influence of Trump's rise - and press coverage of it - and the related social meanings of journalism that reveal cultural aspects of journalism as a reflection (and a force) of power. 
Al Cross, in Chapter 12, “'Stop Overlooking Us!': Missed Intersections of Trump, Media, and Rural America," provides an overview and analysis of the rural vote from the 2016 election. He highlights the divide that national journalists had with rural audiences and residents that was at the center of national political news coverage of Trump. The urban-rural divide is indeed a race- and class-based one that has roots deep into the nation's history, but perhaps few times beyond the 2016 election was the discourse about elite press and the forgotten Middle America so pronounced.

Media historian and media literacy expert Fred Blevens, in Chapter 13, "Reeducation or Rejuvenation?: Trump's Influence on News Interest and Literacy," explicates the history of John Stuart Mill, Matthew Arnold, and Alexis de Tocqueville and media innovations from the Penny Press to the use of social media as a news source and distribution tool to complicate explanations of how the United States came to form its dominant narratives of a free press and democracy. Blevens provides interviews with today's leading journalists and journalism educators, as well, to inject modern rhetoric of press ethics and media literacy evaluative tools of seminal works on the normative role of journalism in U.S. society.

Chapter 14, "Trump, Democracy, and the Extension of Journalism Ethics," examines normative challenges that journalists are facing in a time of Trump. Kathleen Bartzen Culver highlights specific moments of direct attack by Trump and his administration against mainstream journalistic authority that has led to journalists questioning how - and whether - they should adapt to bombastic, authoritarian, and frequently racist rhetoric from the White House. If digital innovations have challenged journalistic practices, values, and ethical standards over the past 20 years, Culver introduces us to the notion that we may not have seen anything yet.

Chapter 15, "The Effects of Mediatized Hate: Coping with Life in Trumpland," sets a tone of urgency for understanding the influence of politics and the press upon society. Focusing on her experiences as a public official, a mother, a social worker, and a Black woman, LaTasha DeLoach extrapolates the daily meanings of living in moments of contestation and overbearing whiteness that the Trump administration and media coverage of it - represents. Hers is an essay that demarcates within spaces of discourse about Trump, journalism, and U.S. democracy the position of everyday citizens who are most influenced by how and what we communicate.

The book concludes with an epilogue, "Facing Tomorrow in an Age of Trump," in which I place within the context of this volume the arguments of journalism as social order and control, a view in which journalism functions to shape dominant ideology, even at times when the journalistic institution appears to be under threat of change or destruction. From this conclusion, I hope readers can examine not just the language of Trump and the actions of journalists as single moments in a challenging time, but as evidence of deeper and, yes, sinister, functions 
of the press to establish racist and classist positions of dominance within society. Trump could not have created (and did not create) the issues of today all by himself. Neither did the press. But as this volume reveals, these changes have been happening (and have happened) with intentionality and consistency for some time. It is up to us to choose to make a change, but are we willing to release the power to do so?

\section{References}

Cariz,J.,Leighton,T.,\&Thorp,A.(2016,July21).DonaldTrump'sGOPacceptance speech, annotated. PolitiFact. Retrieved at www.politifact.com/truth-o-meter/ article/2016/jul/21/donald-trumps-gop-acceptance-speech-annotated.

Cockburn, A. \& St. Clair, J. (1999). Whiteout: The CIA. Drugs and the Press. Brooklyn, NY: Verso.

Cooke, T. E. (2005). Governing With the News: The News Media as a Political Institution. Chicago, IL \& London, UK: University of Chicago Press.

The Guardian.(2015, October 14).ElChapoprisonescape; guardsignoredloudhammering in drug lord's cell. The Guardian. Retrieved at www.theguardian.com/ world/2015/oct/14/hammering-escape-drug-lord-el-chapo-prison-cell-mexico.

Hanchett, I. (2015, July 15). Trump: "Five different sources" say Mexico is sending people to us. Breitbart. Retrieved at www.breitbart.com/video/2015/07/15/ trump-five-different-sources-say-mexico-is-sending-people-to-the-us.

Gutsche, Jr., R. E. (2017). Media Control: News as an Institution of Power and Social Control. New York, NY \& London, UK: Bloomsbury.

Mai-Due, C. (2015, September 4). Deportee accused of killing Kathryn Steinle to stand trial on murder charge. Los Angeles Times. Retrieved at www. latimes.com/local/lanow/la-me-ln-kathryn-steinle-sf-shooting-murder-trial20150904-story.html.

Morrison,S.(2016,September23). Obamaunderminedpressfreedom.Nowhewantsa strong media to stop Trump? The Guardian. Retrieved at www.theguardian.com/ commentisfree/2016/mar/30/barack-obama-press-freedom-strong-media-stopdonald-trump.

Newsday. (2016, November 9). Donald Trump speech, debates and campaign quotes. Newsday. Retrieved at www.newsday.com/news/nation/donald-trumpspeech-debates-and-campaign-quotes-1.11206532.

Politico. (2016, August 17). Donald Trump campaign speech in Wisconsin. Politico. Retrieved at www.politico.com/story/2016/08/full-text-donald-trumpsspeech-on-227095.

Salon. (2015, July 15). Donald Trump's 'Morning Joe' meltdown. Salon. Retrieved at www.salon.com/2015/07/15/donald_trumps_morning_joe_meltdown_the_ epic_immigration_debate_which_riled_mika_halperin_and_the_donald.

Shoichet, C. E., Yan, H., \& Fantz, A. (2015, July 14). After 'El Chapo' escape, Mexico offers reward for fugitive drug lord's capture. CNN. Retrieved at www.cnn.com/2015/07/13/world/mexico-el-chapo-escape.

Washington Post. (2015, June 16). Donald Trump announces a presidential bid. The Washington Post. Retrieved at www.washingtonpost.com/news/postpolitics/wp/2015/06/16/full-text-donald-trump-announces-a-presidentialbid/?utm_term=.1bf10b006283. 


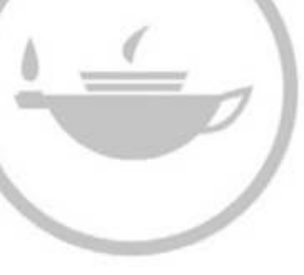

Taylor \& Francis Taylor \& Francis Group

http://taylorandfrancis.com 
Part I

Challenges to Journalistic

Norms, Practices, and Social Cohesion 


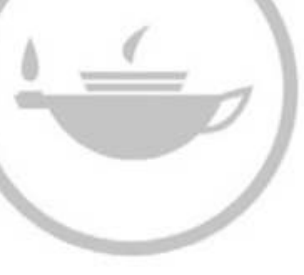

Taylor \& Francis Taylor \& Francis Group

http://taylorandfrancis.com 


\section{Donald Trump and the War on the Media}

\section{From Election ' 16 into the Trump Presidency}

\section{Douglas Kellner}

From early in his improbable presidential campaign, Donald Trump has waged a war against the media. Trump's media bashing and daily attacks via his campaign rallies, Twitter feeds, and off-the-cuff remarks have been a defining feature of both Trump's presidential campaign and the first 200 days of his presidency. When the media criticizes his statements or actions, Trump goes on the attack. When he makes questionable or demonstrably false statements and is confronted with contrary evidence, Trump and his handlers dismiss any critical claims about Trump as "fake news" and "alternative facts." Echoing Chairman Mao and Comrade Stalin, Trump calls the media "the enemy of the people" and rarely does a day go by without a barrage of attacks and rants against the media on his Twitter account.

Ironically, one could argue that Trump won the Republican primary contest and then the 2016 U.S. Presidential Election, in part, because he is the master of media spectacle, a concept that I've been developing and applying to U.S. politics and media since the mid-1990s. ${ }^{1}$ In this study, I will first discuss Trump's use of media spectacle in his business career, in his effort to become a celebrity and reality TV superstar, and his political campaigns. I examine how Trump both uses the media in his campaign and presidency and deploys a war against the media to delegitimize criticism or opposition to his presidency. Yet Trump's war against the media has generated a momentous battle in which segments of the media are fighting back against Trump in what has to be the most contested media spectacle in modern U.S. political history.

\section{Donald Trump and the Politics of the Spectacle}

I first came up with the concept of media spectacle to describe the key phenomenon of U.S. media and politics in the mid-1990s. This was the era of the O.J. Simpson murder case and trial, the Clinton sex scandals, and the rise of cable news networks like Fox, CNN, and MSNBC, and the 24/7 news cycle that has dominated U.S. politics and media since then. ${ }^{2}$ The 1990 s was also the period when the internet and new media 


\section{Douglas Kellner}

took off so that anyone could be a political commentator, player, and participant in the spectacle, a phenomenon that accelerated as new media morphed into social media and teenagers, celebrities, politicians, and others wanting to become part of the networked virtual world joined in.

The scope of the spectacle has thus increased in the past decades with the proliferation of new media and social networking like Facebook, YouTube, Twitter, Instagram, Skype, and the like that increases the scope and participation of the spectacle. By "media spectacles" I am referring to media constructs that present events which disrupt ordinary and habitual flows of information, and which become popular stories which capture the attention of the media and the public, and circulate through broadcasting networks, the internet, social networking, smart phones, and other new media and communication technologies. In a global networked society, media spectacles proliferate instantaneously, become virtual and viral, and in some cases become tools of sociopolitical transformation, while other media spectacles become mere moments of media hype and tabloidized sensationalism.

I've argued since 2008 that the key to Barack Obama's success in two presidential elections is because he became a master of media spectacle, blending politics and performance in carefully orchestrated media spectacles. Previously, the model of the mastery of presidential spectacle was Ronald Reagan who everyday performed his presidency in a well-scripted and orchestrated daily spectacle. Reagan was trained as an actor and every night Ron and Nancy reportedly practiced his lines for the next day's performance like they had done in their Hollywood days. Reagan breezed through the day scripted with a teleprompter and well-orchestrated media events, smiling frequently, and pausing to sound bite the line of the day.

Now in the 2016 election and into his presidency, Trump has emerged as a major form of media spectacle and has long been a celebrity and master of the spectacle with promotion of his buildings and casinos from the 1980s to the present, his reality TV shows, self-promoting events, and then his presidential campaign and election. Hence, Trump was arguably empowered and enabled to run for the presidency in part because media spectacle has become a major force in U.S. politics, helping to determine elections, government, and more broadly the ethos and nature of our culture and political sphere.

Trump's biographies reveal that he was driven by a need to compete and win, ${ }^{3}$ and entering the highly competitive real estate business in New York in the 1980s, Trump saw the need to use the media and publicity to promote his celebrity and image. It was a time of tabloid culture and media-driven celebrity, and Trump even adopted a pseudonym "John Baron" to give the media gossip items that touted his successes in businesses, with women, and as a rising man about town (Fisher \& Hobson, 2016). 
Trump derives his language and behavior from a highly competitive and ruthless New York business culture and an appreciation of the importance of media and celebrity to succeed in a media-centric hypercapitalism. Hence, to discover the nature of Trump's "temperament," personality, and use of language, we should recall his reality TV show The Apprentice and his book The Art of the Deal (Trump \& Schwartz, 1987), ${ }^{4}$ which popularized him into a supercelebrity and made The Donald a major public figure for a national audience. Indeed, Trump is the first reality TV candidate who runs his campaign like a reality TV series, boasting during the most chaotic episodes in his campaign that his rallies are the most entertaining and sending outrageous tweets into the Twitter-sphere which then dominate the news cycle on the everproliferating mainstream media and social networking sites. Hence, Trump is the first celebrity candidate whose use of the media and celebrity star power is his most potent weapon in his improbable and highly surreal campaign. ${ }^{5}$

\section{The Apprentice, Twitter, and the Summer of Trump}

Since Trump's national celebrity derived in part from his role in the reality TV series The Apprentice, we need to interrogate this popular TV phenomenon to help explain the Trump phenomenon. The opening theme music "For the Love of Money," a 1973 R\&B song by The O'Jays, established the capitalist ethos of the competition for the winning contestant to get a job with the Trump organization; obviously, money is the key to Trump's business and celebrity success, although there is much controversy over how rich Trump is. As of this writing, he has not released his tax returns to quell rumors that he isn't as rich as he claims, that he does not contribute as much to charity as he has stated, and that in many years he had paid little or no taxes.

In the original format to The Apprentice, several contestants formed teams to carry out a task dictated by Trump, and each "contest" resulted with a winner and Trump barking, "You're fired" to the loser. Curiously, some commentators believe in the 2012 presidential election that Barack Obama beat Mitt Romney handily because he early on characterized Romney as a billionaire who liked to fire people. This is ironic since firing people is Trump's signature personality trait in his business, reality $\mathrm{TV}$, and now political career, which saw him fire two campaign managers and more advisors by August 2016, and made dramatic firings of key officials a defining feature of his chaotic administration.

The Apprentice's TV Producer Mark Burnett broke into national consciousness with his reality TV show The Survivor, a neo-Darwinian epic of alliances, backstabbing, and nastiness, which provides an allegory of how one succeeds in the dog-eat-dog business world in which Trump has thrived - and spectacularly failed, as many of the books about him 


\section{Douglas Kellner}

document. Both Burnett and Trump share the neo-Darwinian (a)social ethos of nineteenth-century ultracompetitive capitalism with some of Trump's famous witticisms proclaiming:

When somebody challenges you unfairly, fight back - be brutal, be tough - don't take it. It is always important to WIN!

I think everyone's a threat to me.

Everyone that's hit me so far has gone down. They've gone down big league.

I want my generals kicking ass.

I would bomb the shit out of them.

You bomb the hell out of the oil. Don't worry about the cities. The cities are terrible.

(Trump in Pogash, 2016, pp. 30, 152, 153)

In any case, The Apprentice made Trump a national celebrity who became well-known enough to plausibly run for president. Throughout the campaign, Trump used his celebrity to gain media time. In addition to his campaign's ability to manipulate broadcast media, Trump has also been a heavy user of Twitter and tweets out his messages throughout the day and night. Indeed, Trump may be the first major Twitter candidate, and certainly, he is the one using it most aggressively and frequently into his presidency. Twitter was launched in 2006, but I don't recall it being used in a major way in the 2008 election, although Obama used Facebook and his campaign bragged that he had over a million "Friends" and used Facebook as part of his daily campaign apparatus. I don't recall, however, other presidential candidates using Twitter in a big way like Trump, although many have Twitter accounts.

Twitter is a perfect vehicle for Trump as you can use its 140-character framework for attacking, bragging, and getting out simple messages or posts that engage receivers who feel they are in the know and involved in TrumpWorld when they get pinged and receive his tweets. When asked at an August 26, 2015, Iowa event as to why he uses Twitter so much, Trump replied that it was easy, it only took a couple of seconds, and that he could attack his media critics when he "wasn't treated fairly." Trump has also used Instagram - an online mobile photo-sharing, video-sharing, and social networking service that enables its users to take pictures and videos, and share them on a variety of social networking platforms, such as Facebook, Twitter, Tumblr, and Flickr.

Twitter is perfect for General Trump who can blast out his opinions and order his followers what to think. It enables Businessman and Politician Trump to define his brand and to mobilize those who wish to consume or support it. "Trump Twitter" gratifies the need of Narcissist Trump to be noticed and recognized as a Master of Communication who can bind his warriors into an online community. Twitter enables 
the Pundit in Chief to opine, rant, attack, and proclaim on all and sundry subjects, and to subject TrumpWorld to the indoctrination of their Fearless Leader.

Hence, Trump has mastered social media as well as perfecting the domination of television and old media through his orchestration of media events as spectacles and his daily Twitter feed. In Trump's presidential campaign kickoff speech on June 16, 2015, when he announced he was running for president, Trump and his wife, Melania, dramatically ascended down the stairway at Trump Tower. Trump strode up to a gaggle of microphones and henceforth dominated media attention for days with his dramatic pronouncements and the controversy they provoked. The opening speech of his campaign made typically inflammatory remarks that held in thrall news cycles:

The United States has become a dumping ground for everybody else's problems.

[Applause]

Thank you. It's true, and these are the best and the finest. When Mexico sends its people, they're not sending their best. They're not sending you. They're not sending you. They're sending people that have lots of problems, and they're bringing those problems with us. They're bringing drugs. They're bringing crime. They're rapists. And some, I assume, are good people.

These comments ignited a firestorm of controversy and a preview of things to come concerning vile racism, xenophobia, Islamophobia, and the other hallmarks of Trump's Cacophony of Hate. Debate over Trump's assault on undocumented immigrants would come to dominate daily news cycles of the Republican primaries and would continue to play out in the general election in fall 2016. In the lead-up to the first Republican primary debate in fall 2015, Trump received the majority of media time, and his daily campaign appearances and the Republican primary debates became media spectacle dominated by Trump.

Every day that Trump had a campaign event, the cable news networks would hype the event with crawlers on the bottom of the TV screen proclaiming, "Waiting for Trump," with airtime on cable TV dominated by speculation on what he would talk about. Trump's speeches were usually broadcast live, often in their entirety, a boon of free TV time that no candidate of either party was awarded. After the Trump event, the rest of the day the pundits would dissect what he had said and his standing - vis-à-vis the other Republican candidates. If Trump had no campaign event planned, he would fire off a round of tweets against his opponents on his highly active Twitter account, which then would be featured on network cable news discussions as well as social media. 


\section{Douglas Kellner}

Hence, Trump's orchestration of media spectacle and a compliant mainstream media was a crucial factor in thrusting Trump ever further into the frontrunner status in the Republican primaries and winning for him the overwhelming amount of media attention and eventually the Republican nomination. The first major quantitative study of news media coverage of major candidates indicated that from mid-June 2015, after Trump announced he was running, through mid-July 2015, Trump appeared in 46 percent of the news media coverage of the Republican field, based on Google News hits; he also received 60 percent of Google News searches (Somiya, 2015). I will bet that later academic studies will show how Trump dominated all media from newspapers to television to Twitter and new media to social networking during the Republican primaries and then during the general election.

Trump bragged during the primary campaign about how one major media insider told him that it was the "Summer of Trump," and that it was amazing how he was completely dominating news coverage. Trump also explained, correctly I think, why he was getting all the media attention: "RATINGS," he explained in a tweet, "it's ratings, the people love me, they want to see me, so they watch TV when I'm on." And I do think it is the ratings that lead the profit-oriented television networks to almost exclusively follow Trump's events and give him live TV control of the audience.

Trump rose to prominence in New York during the Reaganite 1980s as an embodiment of wild, entrepreneurial cowboy capitalism in an era of deregulation, the celebration of wealth, and the "greed is good" ethos of Wall Street enabled by the Reagan administration. Trump's success was tied to an unrestrained finance capital that loaned him immense sums of money, often with minimal and problematic collateral, to carry through his construction projects. Trump was an extravagant consumer with a three-story penthouse at the top of Trump Tower, a 118-room mansion in Palm Beach, Florida, called Mar-a-Lago that he immediately opened for TV interview segments and an obscene array of properties. He flaunted a yacht bought from Saudi arms dealer Adnan Khashoggi and a personal airplane to jet-set him around the world to luxury resorts. Trump was featured on TV shows like Life Styles of the Rich and Famous, and his lifestyle was the subject of multi-page spreads in fashion and other popular magazines, making Trump the poster boy for excessive "conspicuous consumption," of a degree that I doubt Thorstein Veblen (1994) could have imagined.

Trump's financial fortunes hit the economic slowdown that followed the Reagan orgy of unrestrained capitalism in the late $1980 \mathrm{~s},{ }^{6}$ and in the 1990s Trump almost became bankrupt. Fittingly, Trump had overinvested in the very epitome of consumer capitalism, buying a string of luxury gambling casinos in Atlantic City. The financial slump hit Trump's overextended casinos, driving him to put them on the market. 
The banks called in loans on his overextended real estate investments, and he was forced to sell off properties, his yacht, and other luxury items. Having temporarily lost his ability to borrow from finance capital to expand his real estate business, Trump was forced to go into partnerships in business ventures and then sold the Trump name that was attached to an array of consumer items ranging from water to vodka and men's clothes to fragrances.

Most significantly, Trump has been particularly assiduous in branding the Trump name and selling himself as a businessman, a celebrity, and now as a presidential candidate (see Klein, 2017). Indeed, Trump's presidential campaign represents an obscene branding of a hypercapitalist pig into a political candidate whose campaign is run on bombast, dominating on a daily basis the mediascape, and gaining the attention of voters/ consumers. Obviously, Trump is orchestrating political theater. His theatrics are sometimes entertaining, and, as I noted earlier, his candidacy represents another step in the merger between entertainment, celebrity, and politics (here, Ronald Reagan played a key role, our first actor president). Yet Trump is arguably the first major candidate to pursue politics as entertainment and thus to collapse the distinction between entertainment, news, and politics, so that the 2016 presidential election and then the Trump presidency can be seen as a form of infotainment.

\section{The Trump Presidency, "Fake News," and the War against the Media}

Just as Trump ran his presidential campaign like a reality TV show, so too has he run his presidency as a theatrical performance, playing to his base and the media which he continues to dominate, perhaps more than any previous president in history. Yet the Trump presidency has been clearly one of the most controversial in recent times, in part, because from the beginning, the Trump presidency has been a war against the media.

Trump began his presidency with a big lie concerning the numbers of people attending the Obama vs. Trump inaugurations, claiming that his inauguration was the biggest ever. When TV pictures showed that there were many more people at the 2008 Obama inauguration, with comparative pictures of crowds on the mall and lining parade routes, Trump sent out his hapless press secretary Sean Spicer to read a carefully and nastily written attack on the media for misrepresenting the amount of people who had attended Trump's inauguration. Spicer threatened that the media would be held responsible for their lies and distortions, signaling that Trump's War Against the Media was "Game on!" Spicer correctly argued that the Federal Parks Service does not do crowd estimates, but falsely claimed that many more people took the Metro rail system the day of Trump's inauguration than on Obama's inauguration 


\section{Douglas Kellner}

and provided what turned out to be completely false numbers in his false claim that Trump's inauguration was the biggest in history.

D.C. Metro quickly released inauguration day rider statistics for the Trump and Obama events, and reported that many more took the Metro the day of Obama's inauguration, thus leading CNN and other media to report that the Trump administration began its reign with bald-faced lies on its first day in office and had launched an attack on the media for allegedly lying, while available statistics and facts indicated that the media had in fact basically told the truth about comparative crowd size, Metro usage, and comparative pictures of the Obama and Trump administration inaugurations, which showed that many more attended the former.

On Sunday morning of Inauguration Weekend, more evidence emerged that the Trump administration had gone full-out post-factual as President Trump tweeted: "Wow, television ratings just out: 31 million people watched the Inauguration, 11 million more than the very good ratings from 4 years ago!” The still functioning media quickly pointed out, however:

Nielsen reported Saturday that 30.6 million viewers watched inaugural coverage between 10 a.m. and 6 p.m. on Friday. That figure is higher than Obama's second inauguration in 2013, which drew 20.6 million viewers. But it's lower than that of Obama's first inauguration in 2009, when 38 million viewers tuned in, according to Nielsen. The record is held by Ronald Reagan, when 42 million watched his inaugural festivities in 1981.

(Battaglio, 2017)

The same morning, on Meet the Press, the Trumpsters multiple, and multiplying by the minute, misrepresentations of inauguration numbers were cited by moderator Chuck Todd in his questions to Kellyanne Conway, counselor to the president.

"Why put him (Press Secretary Sean Spicer) out there for the very first time, in front of that podium, to utter a provable falsehood?," Todd asked. "It's a small thing, but the first time he confronts the public, it's a falsehood?"

"Don't be so overly dramatic about it, Chuck," Conway responded. "You're saying it's a falsehood, and they're giving - our press secretary, Sean Spicer, gave alternative facts to that. But the point really is -"

Todd jumped in and retorted.

"Wait a minute," he said. "Alternative facts!? Alternative facts!? Four of the five facts he uttered... were just not true. Alternative facts are not facts; they're falsehoods."

Trumpsters have obviously come to believe that they can define facts and reality, and that if the media doesn't validate their truths, Trump and his post-factual brigade of media flacks will take them on, presenting a 
challenge to the media to subject every word of Trumpspin to rigorous scrutiny, and if necessary, critique. It will be interesting to see how long Trump's minions will continue to tell bold and brazen lies that they and their media critics and informed audiences know to be untrue.

In any case, Trump spinster Kellyanne Conway will evermore be remembered in the Post-Truth Hall of Infamy as "Alternative Facts" Conway, and Sean Spicer earned the title of 4L4M Spicer (as in "Four Lies Four Minutes" Spicer"), and everything they say should be subjected to the same rigorous scrutiny and criticism that should be applied to the ultimate source and King of Lies, Donald John Trump.

During the early days of the Trump presidency, 4L4M Spicer riled the media by his aggressive hectoring tone, threats that the media would be held responsible for its lying reporting, and then after loudly and aggressively repeating his litany of lies, he shouted: "And that's what you should be reporting!" The media does not like to be told what to report any more than politicians and their spinners like to be confronted with alternative facts that trump their facts. Democracy requires a separation of powers, and the press serves classically as the "Fourth Estate" to provide part of a system of checks and balances against excessive, misused, or corrupt state power, including speaking truth to lying liars.

In the first full day of the Trump administration, Trump bragged of his "running war against the media" in front of CIA employees before the fabled CIA "Wall of Fame" and sent his flunkeys out to battle the press in the media for the next days, but the barrage of ridicule, criticism, and anger they stirred up suggest that Trump and Co. lost the battle of Day One. Of course, Trump's daily tweets, that he promised to continue despite contrary advice, and his "running" war against the media, could be a distraction in the real war to push through a rightwing and militarist agenda while the press is distracted chasing down the Daily Lies and shooting down "fake news" and alternative facts that are the epistemological novum of the newly minted Trump administration.

Indeed, never before had an administration run on a daily dosage of "alternative facts" as the Trumpsters while attacking media counterreports as "fake news." Indeed, to this day, Trump and his minions shoot down stories they don't like as "fake news," and for their rabid followers have labeled the mainstream and increasingly anti-Trump media as "false news" tout court, marking the first time that a president has so broadly attempted to delegitimize the mainstream media.

As the Donald J. Trump White House Reality Show moved into its first weeks in office, there were weekly shocks, internal chaos, and national, indeed global, anxiety as the Trump administration veered from one drama to another. The stock market declined for five days straight before the inauguration, lost all of its gains for the year, and continued to go down, although there would no doubt be roller coasters to come. Indeed, by summer 2017, Wall Street indexes were at an all-time high as 


\section{Douglas Kellner}

finance capital speculated in an orgy of irrational exuberance, as if they were entering the Last Days. The Earth's temperature had risen to alltime highs for the third year in a row and a Trump administration full of climate deniers and contemptuous of science would no doubt continue to heat things up and would indeed shock the world some months later when Dumbass Donald announced that the United States was leaving the Paris Climate Accord.

Inauguration weekend had seen extreme weather events from coast to coast as heavy rain continued to pound California after a severe drought and rational minds were undergoing shock and trauma at the unthinkable thought of a Trump presidency. Yet as in classic authoritarian movements, the followers accepted the pronouncements of the leader as gospel truth, and although Trump lied more outrageously than any candidate in recent U.S. history, his followers turned out in droves throughout the country shouting hateful slogans and repeating Trump's lies and deception. Like classical authoritarian demagogues, Trump produced scapegoats and others who were seen as threats against whom Trump could mobilize his followers. The scapegoats Trump projected were not only Muslims and immigrants, but "the establishment" and a shadowy cabal of global capital with which Trump identified Hillary Clinton, successfully making her part of the enemy against which Trump railed. Trump played the "forgotten men and women" card effectively, and presented himself as the people's savior, although it was not clear what he would actually deliver to his followers.

\section{The Trump Administration, Russia, and the Media War Over the Trump Presidency}

In putting together his transition team, cabinet, and administration, Trump went further than any previous U.S. president in confirming Marx's view of capitalism and embodying Eisenhower's warning against the military-industrial complex, choosing an assortment of generals, billionaires, rightwing ideologues, and cronies for top positions in his government, often without qualifications in the area in which they were chosen to serve. They also included some of the worst racists, Islamophobes, sexists, homophobes, and creatures of the swamp imaginable, suggesting that rather than draining the swamp, Trump was constructing a morass of swamp creatures who were likely to create an era of unparalleled disruption, nastiness, conflict, crisis, precarity, and warfare that would put U.S. democracy and global organizations to their more severe tests in its history (see Kellner, 2017).

What was also totally bizarre was the number of strongly pro-Russian figures who Trump chose for the inner circle of his government and how Trump himself spoke so positively of Russian dictator Vladimir Putin and the Russians during his campaign and presidency going against 
Republican Cold War orthodoxy that villainized Russia, the Evil Empire, and The Enemy Red Menace during the Cold War. Many of us grew up in a Cold War culture which included many films and TV shows with evil Russians, and experienced broadcast and print media, schooling, and other institutions that presented the Cold War as a battle between good and evil with the United States representing good, democracy, and freedom, while the Soviet Union represented evil, with its authoritarian Communism, dictators, and collectivism. In particular, Republicans vilified the Soviet Union with Ronald Reagan decrying the "evil empire" and every Republican presidential candidate in my lifetime taking a hard anti-communist and anti-Soviet line.

Enter Trump with his famously friendly words toward Vladimir Putin during the election and a strikingly Russian-friendly inner circle of his campaign and administration. Trump initially chose as National Security Director, General Michael Flynn, who was one of a cadre of close Trump associates who had fond relations with Putin and the Russians, as pictures circulated throughout the media of Flynn next to Putin in Moscow at an event celebrating Russian Television (RT); Flynn was paid for this event, but he did not report Russian contacts on security forms and was fired, only belatedly admitting and signing documents which confirmed he was a foreign agent for Russia and a Russian-friendly group in Turkey. After Flynn exited as these stories circulated in the press, Trump fired FBI Director James Comey who confirmed in congressional hearings that Trump, not known for friendship or loyalty, went out of his way to try to get Comey to lay off of the Flynn-Russia investigations, and told the FBI director that he expected "loyalty" to himself, leading to charges of possible obstruction of justice and impeachment.

In addition, there hasn't been adequate discussion of how former ExxonMobil CEO Rex Tillerson, Trump's choice for secretary of state, was one of several powerful positions within the Trump administration who had especially close relations with Vladimir Putin and the Russians. In over 30 years of service with ExxonMobil, Tillerson had particularly warm relations with Putin and Russian leaders, cutting big business deals, becoming a personal friend of Vladimir, and even receiving Russia's Order of Friendship (for more, see Coll, 2013). ${ }^{7}$ Typical anti-Russian Republicans were worried about the too-cozy relationship between Tillerson and the Russians:

'Let's put it this way: If you received an award from the Kremlin, order of friendship, then we're gonna have some talkin'. We'll have some questions,' Senator Lindsey Graham (Rep.-S.C.) said upon hearing Tillerson was going to be Trump's choice for the key Secretary of State office.

(Boccagno \& Schultheis, 2016) 
As president of ExxonMobil, Tillerson was attempting to negotiate with Putin and Russian oil companies a major oil deal to explore areas of the Arctic believed to contain vast mineral wealth, when President Obama imposed sanctions on Russia because of their intervention in the Ukraine and Crimea (for more, see Myers, 2016). If the Trump administration could eliminate these sanctions, Tillerson and his cronies could profit immensely, but such conflicts of interest did not bother Trump, himself a walking and talking cauldron of conflicted interests, ranging from his hotel near the Capitol in Washington, D.C., to the outposts of his farflung and largely mysterious business empire.

Trump's pro-Russian cabinet was unnerving to many because not only was Trump himself excessively well-disposed toward Putin and Russia, but Michael Flynn, Trump's national security adviser, was also close to Putin and the Russians, as was Tillerson. Tillerson's nomination was especially unsettling because the major story of the week of Tillerson's designation to lead the State Department was an uproar over alleged Russian hacking of the 2016 election and a story in The Washington Post that Russians had intervened to help Trump get elected (Entous, Nakashima, \& Miller, 2016). Trump himself denied that Russians had hacked the Democrats and had released selected information to help Trump and to hurt Clinton, whereas major figures in both parties, the U.S. intelligence services, and sectors of the media were all convinced that Russia had intervened in the U.S. election. Moreover, President Obama had announced in the last weeks of his presidency a commission that would put out a report on the alleged Russian intervention as soon as possible (Entous, Nakashima, \& Miller, 2016).

Of course, it would be wrong to claim that the United States was an innocent who had never intervened in foreign elections in the light of an entire history of the U.S. incursions in foreign elections, starting in a post-war Italy where the CIA did everything in its power to make sure the Christian Democrats beat the Italian Communist Party (for more, see Agrawal, 2016; Osnos, Remnick, \& Yaffa, 2017). During the Reagan era, William Casey's CIA intervened in a number of Latin American countries, and after failing to oust the Nicaraguan Sandinistas through the electoral process, funded an illegal Contra war that embarrassed the Reagan administration and destroyed the careers of some of its officials when it was uncovered that an illegal deal selling arms to Iran was funding the Contra war (Travis, 2016).

Yet, given that Republicans had been Cold War super-adversaries of Russian Communism, it was highly bizarre to see so many of Trump's inner circle and Trump himself so enamored with Putin and the Russians. These included Paul Manafort, Trump's campaign manager for six months; Carter Page, who Trump described as a key foreign policy advisor and who U.S. intelligence claimed was the target of a Russian intelligence operation; and Donald J. Trump, Jr., who had made contact 
with a Russian lawyer who claimed she had "dirt" on Hillary Clinton and arranged a meeting in Trump Tower between Trump Jr., Russians, Manafort, and Trump's son-in-law, Jared Kushner, who fell under investigation for Russian connections that he did not disclose on security forms necessary for White House government positions (Kirchgaessner, 2017).

What can we make of the Trump-Russia connections currently the focus of Special Counsel Robert Mueller and many congressional committees that are investigating the linkages, as well as an intense focus of global investigative media? While more and more information comes out every day concerning Trump-Russia connections, and much still remains to be revealed, we can reach some preliminary conclusions and advance some hypotheses concerning the role of Putin and Russian hackers in the context of the 2016 U.S. presidential election, the shocking and surprising victory of Trump, and even more startling scandals of his administration.

\section{Concluding Comments: Trump, Russia, and the Media}

From a globalist perspective, the 2016 election and Trump presidency needs to be interpreted in terms of Cold War and U.S.-Russia relations. The Russian hack and intervention in the U.S. election can be seen as revenge and blowback for U.S. interventions in Russian elections, as well as what Russians saw as U.S. interference in elections and political upheaval in satellite countries, and other elections and countries around the world in which Russia had interests. During the Cold War, both Russia and the United States regularly intervened in elections throughout the world to support, in the case of the United States, pro-U.S. candidates while attacking leftist and progressive national candidates who would be conceived as supporting the Soviet Bloc or world socialism and Communism. In turn, the former Soviet Union supported parties in its orbit while attacking governments seen as U.S. allies.

While both the United States and Russia have intervened in elections throughout the Cold War, as far as we know, Election 2016 is the first time the Russians intervened massively and perhaps effectively in a U.S. presidential election and may have influenced the outcome, although there is not yet enough evidence to make this claim. It is significant, however, that the revelations of Trump-Russia connections in the election make it clear that Russia intervened on behalf of the Trump campaign and that high-level members of the Trump team had many contacts with various and sundry Russians, although we do not know the nature of the collusion or the extent of their coordination. There are, however, many questions to still be raised and some assertions that we can make as of the time of writing this text in mid-July 2017.

But why did the Russian government allegedly intervene in favor of Trump in the 2016 election? While there were reports that Trump had 


\section{2}

secret business connections with Russia and that Russians had compromising material on Trump, it is clear that Putin and his crowd hated Hillary Clinton and preferred Trump, although we still don't know why they seemed to like Trump so much and why Trump gushed with enthusiasm over Putin during the election and then fawned over him at the G-20 conference in Hamburg when they allegedly first met in July 2017. U.S.-Russia-Trump relations are now at the center of many House and Senate investigations, as well as Special Counsel Robert Muller's investigation of Trump and the election, so presumably we will eventually learn much more about this "special relationship." In addition, the Trump-Russia connection is the focus of U.S. media doing its job investigating shady government actions, and it appears that mainstream media like The New York Times, The Washington Post, The Wall Street Journal, and some of the cable news networks are working feverishly to break new and startling daily revelations of the Trump-Russia saga, which is emerging as the most astonishing and jaw-dropping political spectacle of my lifetime.

There are also books published that help explain why Putin and Russia would take the risk of intervening in the 2016 election. Martha Gesson's The Man Without a Face: The Unlikely Rise of Vladimir Putin, initially published in 2012, argues that Putin was devastated by the collapse of the Soviet Union in 1989 when he was a KGB agent assigned to an embassy/Russian government job in Dresden, probably spying for the KGB. Hence, Putin himself was close to seeing the Berlin Wall go down, the Soviet Empire collapse, and George H. W. Bush and others proclaiming that Russia lost the Cold War. ${ }^{8}$

From this optic, Putin was a super sore loser, who wanted revenge and made the choice to disrupt the 2016 election to delegitimize the U.S. electoral system and to attempt to help defeat Hillary Clinton, who he blamed for helping stir up anti-Russia revolts in the Ukraine, Crimea, and other parts of Russia when she was secretary of state under Obama. From this standpoint, the election of Trump could be seen as Putin's revenge for the U.S. role in helping take down the Soviet Union and undermining the USSR/Russia during the long Cold War period, and then interfering in Putin's affair during his reign. ${ }^{9}$ I'm bracketing the issue, explored in my book The American Horror Show, whether Trump is Putin's Poodle, a Manchurian candidate, a Russian agent, or someone with deep financial Russian interests subject to blackmail or something else, some of which we'll hopefully learn more about before it's too late.

The question then arises: How did Putin get his revenge, and what are its nature and consequences? My thesis is that the Russian hacking of the 2016 election and helping to get Trump elected is rooted in long-time Russian Cold War policies and the psyche of its product Vladimir Putin. Note that I'm saying "helping to get Trump elected" and not causing, or directly influencing the outcome, as we obviously lack such evidence. 
In analyzing Election 2016 and most complex historical events, we need multi-causal analysis that explicates the multiple causes and deep layers of economic, political, cultural, media, and other factors that help explain as of 2017 why Trump won the 2016 presidential election - which I attempt to do in The American Horror Show, published after the election and first 30 days of the Trump administration (Kellner, 2017).

We do know, however, that the Democratic National Committee email server, and that of Clinton's campaign manager, John Podesta, among others, were hacked by the Russians, and that Putin and the Russians used WikiLeaks and various global internet networks to circulate "fake news," bots, and anti-Hillary stories. ${ }^{10}$ From this perspective, key global digital networks helped Trump win, which along with the antiglobalization discourse with which Trump conned his followers, makes Election 2016 the first U.S. presidential election where global actors, networks, and global politics played a significant and perhaps decisive role.

Part of Trump's appeal for both the Russian government and his devoted followers, who Trump claimed would vote for him even if he shot someone on Fifth Avenue, was that at least in his campaign rhetoric Trump presented himself as anti-establishment and anti-globalist. On one hand, this is total BS as Trump is part of the global establishment with business connections throughout the world. Moreover, Trump's administration is full of the worst swamp creatures from the political and economic establishment, and his policies have so far only helped the 1 percent while he has done nothing for his working-class supporters angry about globalization and an establishment apparently hostile or blind to their interests. Yet, it appears that Trump was against the U.S. political establishment and institutions of U.S. democracy. Trump loaded his cabinet and administration with establishment businessmen, generals, and Republican politicians, but he has acted from the beginning as a wrecking ball for the political institutions of liberal democracy and has arguably diminished severely the United States' role and standing in the world.

Highlights of the Trump administration's attack on the institutions of liberal democracy and the U.S. political system during his first eight months in office, which arguably weakened the U.S. polity and its position in the world include:

- Trump's Travel Ban and attack on the judiciary during the opening days of his administration, a war still intensely being fought into his first year in office

- Trump's daily Twitter war, assaulting all and sundry aspects of the political, media, and global establishment which offend him in some way

- Trump's attack on Obamacare (aka the Affordable Care Act) and the U.S. health system 


\section{Douglas Kellner}

- Trump's attacks on the North Atlantic Treaty Organization (NATO) and alienating of the United States from NATO and other allies and efforts to weaken the U.S. alliances and the United States' role as a global superpower, with German Chancellor Angela Merkel stating that the United States can no longer be counted on for leadership

- Trump's shocking pulling out of the Paris Climate Accord and unleashing devastation on the environment, marked by attempts to defang the Environmental Protection Agency, signing executive orders to cut regulations, build pipelines through sensitive environmental areas, intensify oil exploration, and even coal production, generating dangerous threats to climate change

Yet perhaps the most distinctive feature so far of the Trump presidency is his daily attacks on the mainstream media, and on the truth, itself. Mass media have been theorized in the modern era as the Fourth Estate, a necessary pillar of democracy where the people can speak truth to power and debate issues of the day. Yet Trump's Twitter war against the media presented them in one tirade as the media as "the enemy of the American people," a phrase that Comrade Stalin used to use against bourgeois media, a phrase resurrected by Comrade Trump that puts him in the Stalinist anti-media camp. Trump's equation of the media as a site of "fake news" is an attack on the truth itself, for it is the media that functions at its best to expose the lies, deceits, and corruption of those in power.

Other assaults on the political establishment include firing James Comey and carrying out attacks on the FBI, the CIA, and U.S. intelligence services, astonishingly posing Trump against top institutions of U.S. intelligence and crime detection and prevention. I might note that Trump's alt-Right consigliere Steve Bannon has called the Trump project a "deconstruction of the administrative state," a use of the term by a barbarian who would appall the urbane Jacques Derrida. From this perspective, the Trump presidency, so far, might be seen as the greatest victory for Russia in the Cold War, leaving the United States more divided, weakened, and traumatized than at any time in its recent history.

Indeed, the war against the Justice Department and FBI continued into July 2017 with an interview with The New York Times where Trump attacked Attorney General Jeff Sessions for recusing himself from the Trump-Russia investigation (and thus not being able to halt the inquiry or fire the Special Counsel Robert Mueller), even though all legal experts and most members of Congress affirmed that Sessions had to recuse himself because of his role in the Trump campaign and contacts with Russians. Nonetheless, through late July, Trump continued to attack Sessions in daily Twitter insults, which also included other top Justice Department and FBI officials, as if Trump was trying to blow up the judicial, law-making, and enforcing branch of the government. ${ }^{11}$ 
While the war against Sessions heated up by the day and speculation broiled over how long Sessions could survive such attacks - although Trump's base was divided over his war against Sessions, a darling of the conservative movement - Trump inexplicably and without warning launched a war against the military itself as he unleashed another Twitter barrage of attacks on July 26, this time insisting that transgender people could no longer serve in the military, reversing the Pentagon's 2016 decision to lift the ban. Trump's tweet caught the Pentagon offguard and the Secretary of Defense "Mad Dog" Mattis who was on vacation, opening with a lie that "after consulting with my generals" (with no evidence of which generals he consulted with), and in light of the "great expense" of transgender operations (quickly revealed to be another lie), Trump declared that henceforth transgender people could not serve in the military.

Apparently, thousands of transgender people were in the military, and the defense establishment saw this as an assault on national security and the military itself, as the White House and Pentagon scrambled over how to deal with Trump's demented Twitter War against the LGBT community who Trump had repeatedly promised during the campaign he would defend. At the same time, Trump and his Republican allies' attempt to destroy the health care system appeared to be going down in startling defeat as more and more medical organizations and a growing number of Trump supporters turned against the bill and that despite Republican control of the House and Senate the hapless Republicans and increasingly unhinged president could not marshal a majority vote even for what was derisively called a "skinny repeal" bill with no replacement. Hence, whereas Trump had promised his supporters "cheaper" and "better" health care, the actual bills were deemed by all informed critics as "more expensive" and worse, denying at least 21 million Americans any health care.

As I am concluding his article in August 2017, a media uproar has exploded over Trump's failure to condemn neo-Nazi, Klan, and white supremacist groups until more than two days after deadly alt-Right demonstrations in Charlottesville, Virginia, over the weekend of August 11 to 13, 2017, which produced three deaths, many injuries, and tremendous outrage over the extremist demonstrations. In a news conference on August 15 that was strongly denounced by the media and political establishment, Trump symmetrized the white supremacist forces that had gathered in Charlottesville with protestors against neo-fascism and white supremacism, arguing they were equally responsible for violence, while defending Confederate hero Robert E. Lee and the Confederacy!

The next day, Trump continued his war against the Union and for the Confederacy, mourning the loss of "beautiful statues and monuments" in the wake of demands for the removal of statues depicting Lee in the Charlottesville spectacle, followed by demands among citizens for 
removal of other monuments of the Confederacy throughout the country. As Trump hardened his support of far-right groups, executives from major corporations began resigning from advisory panels, leading Trump to cancel the panels, while major military leaders and some Republican members of Congress denounced white supremacism and the president's failure to more sharply criticize extremist groups.

The media responded with all-out war against an increasingly embattled Trump who was finding out that war against the media cuts two ways. Bowing to pressure, and perhaps wanting to change the media narrative, Trump fired Steve Bannon, the center of the alt-Right in the White House on August 18, 2017, who then promised that he would wage all-out media war against the Republican establishment and his enemies in the Trump administration. Hence, while one cannot foresee the trajectory of the Trump presidency, one can be certain that it will involve continuing war with the media of huge intensity and consequence.

\section{Notes}

1 On my concept of media spectacle, see Kellner (2001, 2003a, 2003b, 2005, 2012, 2016, 2017). This article draws upon and updates my two Trump books Kellner $(2016,2017)$.

2 I provide accounts of the O.J. Simpson trial and the Clinton sex/impeachment scandal in the mid-1990s in Kellner (2003b), engage the stolen election of 2000 in the Bush/Gore presidential campaign in Kellner (2001), and describe the 9/11 terrorist attacks and their aftermath in From 9/11 to Terror War in Kellner (2003a).

3 See D’Antonio (2015), Blair (2000), and Kranish and Fisher (2016). Blair's chapter on "Born to Compete," (p. 223) documents Trump's competitiveness and drive for success at an early age.

4 Trump's book The Art of the Deal, co-written with Tony Schwartz (2005 [1987]), helped introduce him to a national audience and is a key source of the Trump mythology; see Blair (2000, p. 380).

5 For my take on celebrity politics and the implosion of entertainment and politics in U.S. society, see Kellner (2015, pp. 114-134). See also Wheeler (2013). On Trump, the media, and his long cultivation and exploitation of celebrity, see O'Brien (2016 [2005]).

6 For the story of Trump's financial downfall and near collapse in the 1980s and 1990s, see the detailed and well-documented narratives in Barrett (2016), O’Donnell and Rutherford (1991), D’Antonio (2015), and Kranish and Fisher (2015).

7 Coll, whose book Private Empire: ExxonMobil and American Power, 2013, is considered a major book on ExxonMobil, claimed: "reporting on Exxon was not only harder than reporting on the bin Ladens, it was harder than reporting on the CIA by an order of magnitude," adding, "They have a culture of intimidation that they bring to bear in their external relations, and it is plenty understood inside the corporation too. They make people nervous, they make people afraid" (Coll cited in Schwartz, 2012).

8 This account is similar to that in the excellent overview of Putin's career in Myers (2016). 
9 Putin has long believed that Hillary Clinton was the spearhead of U.S. interference in Russian affairs during her role as secretary of state under Obama; see Herszenhorn and Barry (2011).

10 The hacking is documented in Nance (2016), and many mainstream media sources, although it is denied in Kovalik (2017) and pro-Trump sources from the swamps and whacko-worlds of "alternative facts" which may be the enduring legacy of the Trump presidency. For a comprehensive analysis of how the Russian hacking interfered in the 2016 election and dangers for the future of U.S. democracy, see Calabresi (2017, pp. 30-35).

11 On July 11, 2017, The Rachel Maddow Show spent long segments on how Trump administration policies constitute "Russia's Wish List" and how Trump has consistently carried out policies in Russia's interests, as I have also argued in The American Horror Show (Kellner, 2017).

\section{References}

Agrawal, N. (2016, December 22). U.S. disrupts elections too. Like Russia, America has a long history of meddling in foreign votes. Los Angeles Times.

Barrett, W. (2016). Trump: The Greatest Show on Earth: The Deals, the Downfall, the Reinvention. New York, NY: Regan Books.

Battaglio, S. (2017, January 19). Trump's inauguration is watched by 30.6 million viewers -7 million fewer than Obama's first ceremony. Los Angeles Times.

Blair, G. (2000). The Trumps. New York, NY: Simon and Schuster.

Boccagno, J., \& Schultheis, E. (2016, December 13). Secretary of state pick Rex Tillerson faces some Senate GOP criticism. CBS News. Retrieved at www. cbsnews.com/news/state-pick-rex-tillerson-faces-some-senate-gop-criticism

Calabresi, M. (2017, May 29). Hacking democracy: Inside Russia's social media war on America. Time.

Coll, S. (2013). Private Empire: ExxonMobil and American Power. Baltimore: Penguin Books.

D’Antonio, M. (2015). Never Enough. Donald Trump and the Pursuit of Success. New York, NY: Thomas Dunne Books.

Entous, A., Nakashima, E., \& Miller, G. (2016, December 9). Secret CIA assessment says Russia was trying to help Trump win White House. The Washington Post. Retrieved at www.washingtonpost.com/world/nationalsecurity/obama-orders-review-of-russian-hacking-during-presidentialcampaign/2016/12/09/31d6b300-be2a-11e6-94ac-3d324840106c_story. html?utm_term=.bb175270bfde.

Fisher, M., \& Hobson, W. (2016, May 13). Donald Trump 'pretends to be his own spokesman to boast about himself.' The Independent. Retrieved at www.independent.co.uk/news/world/americas/us-elections/donald-trumppretends-to-be-his-own-spokesman-to-boast-about-himself-a7027991.html.

Herszenhorn, D. M., \& Barry, E. (2011, December 8). Putin contends Clinton incited unrest over vote. The New York Times. Retrieved at www.nytimes. com/2011/12/09/world/europe/putin-accuses-clinton-of-instigating-russianprotests.html.

Kellner, D. (2001). Grand Theft 2000. Media Spectacle and a Stolen Election. Lanham, MD: Rowman \& Littlefield.

Kellner, D. (2003a). From September 11 to Terror War: The Dangers of the Bush Legacy. Lanham, MD: Rowman \& Littlefield. 


\section{Douglas Kellner}

Kellner, D. (2003b). Media Spectacle. London, UK \& New York, NY: Routledge.

Kellner, D. (2005). Media Spectacle and the Crisis of Democracy. Boulder, CO: Paradigm Press.

Kellner, D. (2012). Media Spectacle and Insurrection, 2011: From the Arab Uprisings to Occupy Everywhere. London, UK \& New York, NY: Bloomsbury.

Kellner, D. (2016). American Nightmare: Donald Trump, Media Spectacle, and Authoritarian Populism. Rotterdam: Sense Publishers.

Kellner, D. (2017). The American Horror Show: Election 2016 and the Ascendency of Donald J. Trump. Rotterdam: Sense Publishers.

Kirchgaessner,S.(2017, April23). Russia 'targeted Trumpadviser in bid to infiltrate campaign.' The Guardian. Retrieved at www.theguardian.com/us-news/2017/ apr/23/russia-tried-to-use-trump-advisers-to-influence-us-election-report.

Klein, N. (2017). No is Not Enough. Resisting Trump's Shock Politics and Winning the World We Need. Chicago, IL: Haymarket Books.

Kovalik, D. (2017). The Plot to Scapegoat Russia. How the CIA and the Deep State Have Conspired to Vilify Russia. New York, NY: Skyhorse Publishing.

Kranish, M., \& Fisher, M. (2016). Trump Revealed: An American Journey of Ambition, Ego, Money and Power. New York, NY: Scribner.

Myers, S. L. (2016). The New Tsar: The Rise and Reign of Vladimir Putin. New York, NY: Vintage Books.

Nance, M. (2016). The Plot to Hack America. How Putin's Cyberspies and WikiLeaks Tried to Steal the 2016 Election. New York, NY: Skyhorse Publishing.

O'Brien,T.L.(2016[2005]).TrumpNation:TheArtofBeingtheDonald.New York, NY: Grand Central Publishing.

O’Donnell, J., \& Rutherford, J. (1991). Trumped!: The Inside Story of the Real Donald Trump-His Cunning Rise and Spectacular Fall. New York, NY: Simon \& Schuster.

Osnos, E., Remnick, D., \& Yaffa, J. (2017, March 6). Trump, Putin, and the new Cold War. What lay behind Russia's interference in the 2016 electionand what lies ahead? The New Yorker. Retrieved at www.newyorker.com/ magazine/2017/03/06/trump-putin-and-the-new-cold-war5.

Pogash, C. (2016). Quotations from Chairman Trump. New York, NY: Rosetta Books.

Schwartz, M. (2012, May). An extended interview with Steve Coll. Texas Monthly.Retrievedatwww.texasmonthly.com/articles/an-extended-interviewwith-steve-coll.

Somaiya, R. (2015, July 24). Trump's wealth and early poll numbers complicate news media's coverage decisions. The New York Times. Retrieved at www. nytimes.com/2015/07/25/business/media/donald-trumps-wealth-and-pollnumbers-complicate-news-medias-coverage.html.

Travis, P. W. (2016). Reagan's War on Terrorism in Nicaragua: The Outlaw State. Lexington, KY: Lexington Books.

Trump, D. J., \& Schwartz, T. (2005 [1987]). The Art of the Deal. New York, NY: Ballantine Books.

Veblen, T. (1994 [1899]). Theory of the Leisure Class: An Economic Study in the Evolution of Institutions. New York, NY: Dover.

Wheeler, M. (2013). Celebrity Politics. Cambridge, UK: Polity. 


\title{
2 News Boundaries of "Fakiness" and the Challenged Authority of the Press
}

\author{
Robert E. Gutsche, Jr.
}

Edgar Welch walked into the Washington, D.C., pizza shop in October 2016 armed with an assault rifle. His goal was to free young children he thought were held there as part of a sex ring led by U.S. presidential candidate Hillary Clinton and the Democratic Party (Kang \& Goldman, 2016). How had Welch come to this conclusion? The news. Pizzagate another media-centric narrative with hints of political conspiracy, dangerous threats to U.S. democracy, and the assumed power of the press to save the day - held a mess of current events news and controversies: Hints at a child sex ring lingered for some in emails of high-ranking Clinton insider John Podesta that were leaked to WikiLeaks; the emails were central to police investigations of former U.S. Congressman Anthony Weiner's sexting scandal. Debate that spread about the possible connections between the pizza joint, an alleged sex ring, Clinton, underground tunnels, human trafficking, Barack Obama, and social media created the perfect storm for a perfect news story - for news outlets both true and fake (Aisch, Huang, \& Kang, 2016).

Tales of children held hostage then appeared on what would later be categorized as "fake news" websites - a list that ranges (depending on the critic) from SubjectPolitics to Brietbart News to The New York Times. To investigate Pizzagate, journalists that traditionally are pitted against each other as being "liberal," "conservative," and even "clickbate-ish" rallied around the Times, Fox News, and Snopes.com, each of which led fact-checking efforts to debunk the pizzeria child sex ring and celebrated the role "real" journalism can have on society - providing "truth." In the end, "legitimate" news was on attack against that which wasn't.

Beginning in fall 2016, this national news story of violence, fear, and "conspiracy," "fake news" - generally defined as (mis)information presented as traditional journalism by outlets outside of dominant, mainstream news spheres and that works with an intention to deceive - had appeared in press and political discourses largely surrounding the U.S. presidential election between Clinton and Donald Trump (Holan, 2016; Mullin, 2017). Statements by Trump (late in the campaign and repeatedly 
after the election) that mainstream U.S. journalism is "fake news" and comments by a Trump White House advisor over the legitimacy of journalistic and "official" information, particularly about how many attended Trump's inauguration, contributed to rifts between official source information and information journalists believed to be true and verifiable (Ball, 2017; Blake, 2017). There were also hurt feelings on the side of the press - and legal concerns about publishing information journalists "knew" to be false. CNN, for instance, refused to run a Trump presidential advertisement in mid-2017 because of a graphic that referred to mainstream news media as "fake" (Gold, 2017).

On an international scale - from crisis in the Ukraine to threats of nuclear strikes in conflict between Pakistan, Syria, and Israel (Goldman, 2016) - and moments of panic about potential relationships between fake news, hacking, and Western political systems (Waterson, 2016) led to calls for Facebook, social mediaites, and citizens to maintain truthful order through verification and altered journalistic practices (ie Easton, 2016). In effect, "fake news" has presented challenges to United States and international press corps to explain to audiences - and to themselves - how they stand apart from what isn't "real" or "true" (see also, Chapter 4). This chapter, therefore, conducts a critical textual analysis of coverage in agenda-setting legacy newspapers in the United States and U.K. to explore journalistic explanations of "fake news" in an age of "post-truth," when emotion and personal belief overtake objective facts in terms of influencing public opinion (Holan, 2016).

By and large, I argue, mainstream news coverage critical of "fake news" during and after the 2016 U.S. presidential election focused on how audiences, the marketplace and technology, and Donald Trump fueled the genre while celebrating the role of professional journalists to investigate and uncover "untruths." Simultaneously, coverage ignored what may have contributed to a rise in "fake news," including (1) personnel cuts and emptied newsrooms that hinder journalists from covering "all sides of the story," (2) conflict between traditional (read, boring) and "satire journalism" (read, fun) that turned the former unpopular, and (3) public critique of mainstream news media sensationalism and access journalism surrounding politics and business that has diluted single notions of journalistic legitimacy as a truth-teller and as an outsider-looking-in.

Themes of explanation about truth and untruth in journalism in news articles in late 2016 not only wished to distinguish between what is "fake" and what is "real," but attempted to counter public opinion that mainstream legacy news media has slipped in its status as an institution of social authority. By placing responsibility for the spread of "fake news" sites on what one newspaper referred to as "gullible" readers, on the conflict between using robot automation rather than human editors, and on Trump and conservative, anti-media rhetoric, journalists attempted to maintain legitimacy of and for mainstream press by infusing 
media memory of journalism with aims of covering the truth. I begin by providing a brief background on fake journalism and the struggle of journalists today to fight against it.

\section{Fakiness and Journalistic Interpretations: A Briefing}

Once largely reserved for the National Enquirer, People, or U.K. (and some United States) tabloids and for stories of celebrity crisis, "soft news," and UFO sightings, labels of sensationalized news and "tabloid journalism" (Bird, 1990; Hartley, 2009; Nadler, 2016; Zelizer, 2009) might not have been moved up from the lowest of the low in terms of journalistic quality, but by 2017, it seemed to share the journalistic bottom rung with "fake news." Despite a history of "fake news" that is as old as journalism itself (McLeod, 2014; Soll, 2016), the genre continues to be associated, however slightly, with normative notions of conspiracy and propaganda (i.e., Haigh, Haigh, \& Kozak, 2017) in that the genre holds to "untruths" that are determined so because the information operates so far afield from dominant interpretation. ${ }^{1}$

Today's fake news wave, media critics and scholars state, is different than previous iterations, directly set at influencing politics and governance and creating divides specific to social and cultural politics. Past fakiness was either designed to test the limits of technology, to entertain, or to create attention and financial profit, and great concern for mediates today is that current "fake news" deals more directly with lies, not interpretation.

Today's dissections of "fake news" delve deeper beyond examining notions of objective and subjective interpretations of information and rarely include debate about what are dominant understandings or interpretations that inform "facts." Instead, focus is on the reliability of the very information or "facts" that are either funneled to, through, or by professional communicators (Goodman, 2008; Schwartz, 2015). Based within dominant articulations of truth reality shared among journalistic communities and fellow social institutions of government, business, and social order, examinations of "fake news" surround surmised intentionality of communicators relaying information that is either expressly "true" or "false" (for more, see Cooke, 2017; Schudson, 1997). The question, however, remains: What is truth, and whose truth is it?

\section{Journalism and Knowledge Subjectivities}

Issues of subjectivities of journalism, information that informs journalism, universal notions of "truth," and the degree to which journalism is an approach able to accomplish ideals of "truth" remain constricted within power dimensions of select interpretation (Aare, 2016; Broersma, 2010). For Boudana (2011), for instance, definitions of truth and objectivity 
in journalism interact in ways that reflect alterations in audience expectations of truth - and of the press - at a particular moment in time. Expectations for and of specific truths change during major cultural and social turns throughout history, influenced by war and economic developments to conversions in collective morals and norms, what is similar to what Zelizer (2017) refers to as "the shelf life of ideas" (p. 61).

Alterations to "factual" characterizations and explanations of social desirables, mores, and behaviors in journalism and political rhetoric assist social and financial efforts of the elite (i.e., Gutsche, 2015; Heidt, 2014). Identifying a single truth that exists across time and collectives, then, is an impossible feat beyond acknowledging that of natural law (though, these interpretations change, too) and that which has been verified to an nth degree within which the verification has addressed fallacies or failures of challenges to the fact, or within which alternative explanations have been subjugated.

To be sure, challenges to what may be considered a singular fact through the performance of journalism and fact-finding is not "evading the fact that there certainly is falsehood in which outright fictitious narratives are presented as actualities" (Adeduntan, 2017, p. 7). Yet, the process of examining issues of "truth" in journalism "has to do with the implications such factors as ideology and culture have for journalistic texts that are based on facts yet bear discordant narratives" (p. 7). Indeed, journalists are aware of issues related to truths and lies and of what explanations of the world are acceptable or defendable in order to successfully navigate avenues and intersections of meaning-making when gathering and explicating information (Gutsche, 2017).

Knowledge-creation within journalism - processes by which journalists determine what is newsworthy and within that category what is believable, true, and accurate - allows that despite a sense of "journalistic skepticism" of what is true and what is not, journalists remain unable to verify each piece of information, thereby providing a layer of unknown elements within reported known knowledge (Godler \& Reich, 2017). Furthermore, journalists' personal experiences with information-gathering and interpretations of information blend with a professionalized sense of basing journalistic judgements on "testimony-based" information, that which can be verified, measured, and questioned (Gans, 2004; Reid, 2000; Shapiro, Brin, Bedard-Brule, \& Mychajlowycz, 2013; Tuchman, 1972).

Still, professional news standards in the United States and U.K. allow for alterations to information provided to and passed on by journalists. Processes of access and prize journalism and spin remain acceptable despite the role that access to the powerful and financial benefits of journalism prizes has on influencing interpretations of "fact" and "truth" and the alterations to interpretations of information that spin plays in driving particular pieces of information or interpretations (Conboy, 2013; Gutsche, 2017; Macnamara, 2016). 


\section{Satire Journalism \& 'Post-Truth Society'}

Satire journalism in the 2000s revealed layers of "truthiness" within which falsehoods remain truths both confused roles of journalism as legitimate and journalists as authorities on dominant interpretations of daily life (Berkowitz \& Gutsche, 2012; Gutsche, Naranjo, \& Martinez-Bustos, 2014). Satire journalism such as The Onion, The Colbert Report, and The Daily Show serve as direct competition to establishment journalism in terms of further fragmenting the financial and information marketplaces. Satire journalism publications and television programs also mirror the social authority of mainstream journalists with language, visuals, and personalities that resemble delivery, tone, and discourse of mainstream news (Baym, 2009).

In effect, humor, irony, and political bent of information shared in satire journalism increased its popularity among non-traditional news audiences (such as youth) and contributed to a sense of a "post-truth" society, "an era in which audiences are more likely to believe information that appeals to emotions or existing personal beliefs, as opposed to seeking and readily accepting information regarded as factual or objective" (Cooke, 2017, p. 212). More specific threats to journalistic authority in such a post-truth society are discussed below.

\section{Modern Threats to Journalistic Authority}

In a fragmented news world, increased threat to journalistic authority in the rise of "fake news," websites designed to make money from increased web traffic by publishing information ranging from satire to outright lies, provides not only financial competition but also dangers to democracy. "If we [journalists] do not understand how we are being manipulated [by fake news]," writes mediaite Jeff Jarvis (2017), "we become the manipulators' agents." The (re)entrance of "fake news" into press and public discourses has called attention of media critics who are attempting to explain just what fake news is and why.

First Draft News's Claire Wardle (2017) identifies seven types of "mis and disinformation" upon which one may measure "fake news." Perhaps the most rigorous in its range, hers is worth mentioning in length. Here, "fake news" sits on a spectrum beginning with information created with a level of no intention to harm through the manipulation of information and increases to where the manipulation of information is done with an intention to deceive. The range appears thusly:

- Satire or parody in which can "fool," but is published without intention to harm

- Misleading information designed to "frame an issue or individual"

- Imposter content that impersonates genuine sources

- Fabricated content that is false and is published with the intent to harm 
- False connections in which captions, headlines, and visuals do not match the story's content

- False context which reshapes genuine content

- Manipulated content that is reshaped with intent to deceive

While this range identifies the role of intention and of "truth," similar to much discourse on "fake news," there remains little attention to the subjectivities of personal experience, individual values, and, yes, "alternative facts" of daily issues and events rather than what it means to deceive, who it is that is being deceived, and for what purpose. In other words, focusing on the "truth" only suggests that the truth itself is on the side of the press and that there are "two sides to a story" but only one side or interpretation of "fact" exists.

Explanations of how "fake news" comes to be beyond that of sociopolitical or socioeconomic gain come from within the journalistic community and the political elite, institutions rarely open to interpretation from the "outside," but that are informed by popular culture and narratives of news work. Even technology and an uneducated or "gullible" (perhaps even culpable) audience has been to blame for allowing information from "fake news" to be confused with information from the real (Mihailidis \& Viotty, 2017). This is not to say that information from "real news" isn't subject to multiple interpretations of accuracy or truthfulness, as countercultures, counter-narratives, and contested meanings of news articulations abound (Gutsche, 2014; Heider, 2004; Lester, 1996; Robinson \& Culver, 2016). In this study, however, I am interested in how journalists explained the role of truth in discussions of "fake news."

\section{Culling Meanings of News Texts}

To identify news items that not only discussed issues of "fake news" among dominant news voices in the United States and the U.K. but that defined the genre and addressed the challenges and solutions within the journalistic community, I searched for "fake news" within digital archives of two U.S. newspapers, The Washington Post and The New York Times, and two U.K. newspapers, The Guardian and The Daily Telegraph. The four newspapers are journalism outlets considered agenda-setting in each country (Carlson \& Berkowitz, 2014; Gans, 2004; Godefroidt, Berbers, \& d'Haenens, 2016; McNair, 2003). I focused on dates between January 1, 2016 - before "fake news" made its debut in the U.S. presidential election - and December 31, 2016, to include immediate news coverage of "fake news" and its relationship to the fall election.

After removing duplicate texts and those that merely described cases of "fake news," the final selection of articles, including stories by newspaper columnists and editorials that best represented explanations of "fake 
news" and how it relates to other news genres, 36 articles remained - 9 from The Washington Post, 12 from The New York Times, 2 from The Daily Telegraph, and 13 from The Guardian. To cull meaning from the articles, I approached journalistic texts as industry and ideological discourse (Gutsche, 2017) and to extrapolate what Wahl-Jorgensen (2013) refers to as "unavoidable subjective appraisals" made by journalists "that are carefully managed through a distinctive series of discursive strategies" (p. 306) that appear through "reordering and reshaping events, facts and information" (p. 308).

In this way, Wahl-Jorgensen writes, subjectivities in journalism can be culled through analysis of a news item's use of language, dramatic tension and vantage points of stories that suggest moral judgements, and narratives and/or subject matters that may evoke emotional responses from audiences (for more see (i.e., Gürsel, 2009; Krippendorff, 2004; Martin \& Rose, 2003; Matheson, 2000; Richardson, 2007). Below, I identify subjectivities in coverage of "fake news" that explain the genre's position in journalistic society and its relationship to dominant journalistic interpretive communities of both countries.

\section{Binaries of Truth and Lies and Attacks on Anti-media Trump}

Journalists in the United States and U.K. associated binaries of truth vs lies with anti-Trump rhetoric about "fake news" to establish mainstream journalists as the bar against which to measure alternative media messages. With the headline, "Truth and lies in the age of Trump," a December 2016 editorial in The New York Times claimed that the election of Trump had brought (or would soon bring) the end of "a shared public reality built upon widely accepted facts." The Times continued: "The institutions that once generated and reaffirmed" a shared reality, including "the church, the government, the news media, the universities and labor unions - are in various stages of turmoil or even collapse." At the moment, Americans, the editorial stated, "gobble up" "fake news" and have seemed to turn against a sense of shared reality of facts, according to the Times, that excused former U.S. President Clinton, in the middle of impeachment, who presented "public contortions" of truth about his sexual relations with an intern by saying, "It depends on what the meaning of the word 'is' is."

By the time this editorial appeared, mainstream news media in the United States was embroiled over how to deal with a president-elect Trump who, in their terms, flat-out lied about the number of illegal votes that contributed to Hillary Clinton's popular vote numbers in the election, his empire's net worth, and a " $\$ 500$ billion a year trade deficit with China" (Lippman, Samuelsohn, \& Arnsdorf, 2016). National journalists, namely with The New York Times and cable news networks, 
such as MSNBC, took the lead in daily discourse questioning Trump's truthiness. The Washington Post, as will be discussed below, tended to focus on other issues related to "fake news" - such as the influence of truth and falsehoods that make way into mainstream news and fuel the potential for citizens to be duped by "fake news" sites and social media posts. It was the Times, however, that took Trump to task as a main facilitator of "fake news" - a position Trump tossed back at mainstream media.

In the end, attacks by the Times focused on legitimizing the role of the press in providing the facts - and even profiting from it. "Newspapers," the paper's media columnist wrote, "have reached online readership highs that would have been unimaginable just a few years ago" (Rutenberg, 2016a). Still, the columnist wrote, there is a battle to be won over "fake news" that "couldn't be happening at a worse moment in American public life" with "a host of faux-journalistic players to pollute the democracy with dangerously fake news items." Panic and cultural trauma within the journalistic community that "fake news" would degrade Western politics and society - both in the United States and in the U.K. - resembles boundary work of legacy press to maintain legitimacy through attack of emerging media, similar to traditional responses of establishment press at the rise of new media technologies (Carlson, 2017), changes in popular public ideas (Zelizer, 2017), and satire news (Baym, 2009). Journalistic explanations in these moments position approved, dominant journalistic interpretive communities and their boundaries as the norm against which to measure newcomers or opposition forces.

The Guardian, for instance, set a difference between right and wrong by outlining issues of what was believable and not within the news. "Until recently," the newspaper wrote, "there was news and "not news..." (Hunt, 2016), highlighting, however, that understanding the boundaries of what was real and what was might be harder to assess, as "the news format is easy to imitate and some true stories are outlandish enough to beggar belief." Variations of how true or how real the real news is, however, is still questioned: "If it is published on the Guardian just for example," the newspaper wrote, "it may well not be news, but it won't be fake news. (Sorry, Breitbart)." The newspaper linked its Breitbart reference to a Guardian piece focused on the alternative news site's conservative positions (Carroll, 2016).

Juliet Samuel (2016) in the U.K.'s Sunday Telegraph expressed a more defined binary of real news and fake news - or at the very least argued that the binary of truth and lie is able to be identified. "[A]lthough trying to sort the fake from the real might sometimes feel fruitless, it's not," Samuel wrote, and that there remain questions about whether audiences are "willing to put in the effort" to examining the truth of fakeness or the fakeness in the truth, or as Samuel puts it, to "distinguish trash from truth." A similar tone of distain for "fake news" was 
simultaneously assigned to Trump's public "slurring" of news media as being the true "fake news" in 2016 as journalists showed concern that fake news (and a president) might be more powerful in relaying authoritative messages than mainstream media (i.e., Wolffe, 2016). Notions of "the real" possessed journalists' approaches to aligning audiences with whose journalism is "right" and whose is "wrong" in direct attacks against the presidential candidate and then-president-elect Trump (i.e., Woolf, 2016). ${ }^{2}$

At the end of 2016, for example, The Guardian provided fodder for media fights against Trump, arguing for a strict true/false binary between press and official sources of information from the president-elect, largely by collecting more than 100 "falsehoods" made by Trump leading up to the November 8 election (Yuhas, 2016). Trump statements identified by the newspaper and countered with the journalist's own commentary, included:

- "crime is always rising (the national rate fell for decades)"

- "African Americans are 'living in hell' (they are not)"

- "migrants are flooding in (more Mexicans are leaving than arriving)"

- "and they bring violence (there is no evidence that they do)"

The Guardian's list goes on - without, however, "facts" of what Trump actually said and the newspaper's actual evidence or data to counter the statements.

Even though the Trump statements as published by the newspaper revolved around issues of accuracy and perhaps dislike of the president's hate speech (or commentary), the measure of the statement's in terms of truth, however, left much to be desired. In fact, The Guardian's presentation of "facts" promotes a binary of truth and falsehoods that are limiting in terms of deeper meanings. Questions in their assessment of truth from above include (save for the last one, which is harder to argue against:

- All crime rates fell?

- Is there a single African American community?

- Mexicans are the only "migrants" entering the United States?

To position itself on the side of "real news" in a constant battle of mainstream and tabloid journalism in the U.K., a December 2016 media column in The Guardian attacked the U.K.'s Mail Online for using quotation marks to discuss "fake news," a style choice approved, The Guardian writes, by Breitbart, "the unofficial cheerleader of the 'alt right,"” "designed to imply that the concepts of fake news and fact checking are themselves disputed" (Jackson, 2016). But if "fake news" is to be disputed, mainstream journalists wrote, following Trump's rise 
to power, "real" journalists are there to find the facts (Carroll, 2016; Herrman, 2016a; Kristof, 2016) against Trump, who the Times refers to as "a president-elect who has shown a willingness to attack the press" during "a proliferation of fake news that has shaken the public's confidence" (Fandos, 2016).

\section{Building Authority by Calling for Increased, Authoritative Presence}

Journalists mixed criticisms and critiques of "fake news" and of Donald Trump with explanations that the news genre's success at spreading falsehoods reveals a need for an increase in human editors at mainstream news outlets. Journalism read for this study also revealed tension among journalists to assess relationships between news media and social media, namely Facebook, which has come to dominate how some users access fake and real news. Together, these discussions positioned traditional, mainstream news as the formal and only authority with an approved strategy of organizational structure and standards, while also seeking economic solvency by delivering and "making news" via social networks.

Despite increased reliance on social media to heighten journalism's role in everyday life, journalists didn't mince words related to the ills of social media in terms of harboring "fake news": One Guardian story (Rawlinson, 2016), for instance, quoted a Columbia University journalism researcher who wrote (in 2015), "Within minutes or hours, a claim can morph from a lone tweet or badly sourced report to a story repeated by dozens of news websites...." Repetition of these messages, journalists in 2016 claimed, influence audiences to believe falsehoods and, therefore, to make decisions as consumers and citizens that might be against their best interest. As a result, the Guardian writes (Rawlinson, 2016), journalists should argue that "a critical eye is becoming more, not less crucial." To fix what was considered by journalists writing about "fake news" to be a shortfall of editors - ironically, likely caused by massive downsizing by media outlets over the past decade - journalists, such as at The Washington Post (i.e., Sullivan, 2016a), called for hiring more of themselves.

Other journalists, including at The New York Times, called for increased human intervention at social media companies, including Facebook, to engage in warfare against "fake news." In large part, journalists argued, while the social media giant might be liable for publishing known falsehoods, there is also an increased moral component in spreading what possibly may be lies. Media columnist Jim Rutenberg's (2016b) article, "Mark Zuckerberg and Facebook must defend the truth," for instance, represents the general tone of moral panic that emerged in articles at the end of 2016 related to the potential social, cultural, and economic dangers of "fake news." He wrote: "The moment calls for some sort of hyperfactual $[s i c]$ counterinsurgency that treats every false meme as a baby Hitler to be killed in its crib with irrefutable facts." 
But it was an overarching argument about business ethics and the future of democracy via social networks such as Facebook, that gathered the most steam in coverage read for this study. The Guardian, for instance, focused largely on covering the "fake news" crisis in the United States as a business issue between journalists and Facebook. Initially, Facebook founder Mark Zuckerberg argued that "fake news" likely hadn't influenced the presidential election in favor of Trump by providing falsehoods about Clinton. As advertisers pushed against the company for running "fake news" that hadn't been verified by the company, Zuckerberg reversed and presented plans to hire human editors to fight the genre. In the U.K, for example, The Guardian's Jon Bernstein (2016) wrote that Facebook should "[t]reat fake news with the same importance as quality journalism" and should take responsibility for serving to publish such items for "fake news" companies.

Journalists in the United States and U.K. have expressed concerns elsewhere about the accuracy of social media information and news (i.e., Weaver \& Willnat, 2016), about governments becoming news providers themselves and bypassing traditional news flows (Garland, Tambini, \& Couldry, 2017), and the degree to which "fake news" may set mainstream news agendas (Vargo, Guo, \& Amazeen, 2017). As these concerns led "fake news" coverage and commentary in 2016, such a public debate in articles designed to be read not only by journalists but by wider news audiences revealed journalists' interior and exterior attempts to maintain, build, or rebuild notions of legitimacy and authority that have eroded in recent year during the fragmentation of media audiences.

The tone of journalists' attacks against "fake news" took one of positioning "real" journalists as heroes, exemplified by a November 2016 article in The Washington Post (Dvorak, 2016a) that took aim with a direct headline, "Fake news writers need to meet the real reporters who die trying to do their jobs." The story features the death of Charnice Milton, a 27-year-old who died after covering a late-night meeting in Southeast Washington, D.C., in 2015, who was also one of "at least 72 journalists [who] were killed around the world," covering war zones, riots, and "deadly tornadoes while everyone else ran in the other direction." Dvorak writes to readers and reporters of fake news: "Puhleeze, guys. You don't get to call yourselves any kind of journalists.”

\section{“Fake News” Fallout: Scapegoating Sources, "gullible” Audiences}

In a third theme of explanation for the rise and social role of "fake news," journalists in the United States and U.K. attempted to (re)build a reputation for truth-telling for an alleged media illiterate audience blamed for "fake news" because they do not know context of news information nor are they able to determine who is a "real" journalist (i.e., Deacon, 2016; Greenslade, 2016; Hern, 2016). An editorial by The 
Guardian, for example, stated that the function of social media in relaying serious information about serious issues related to governance and economy should be revisited by journalists and citizens alike to measure the medium's "role in a democracy," which is focused on citizen participation (The Guardian, 2016). Put simply, journalists at The Guardian and elsewhere argued that media giants vying for attention and advertising in a fragmented information marketplace - within which "fake news" outlets have become profitable - taint a public grasping for anything interesting, even if false. It is on the citizens, then, to fix a problem that they created.

In one of several columns, The Washington Post's Margaret Sullivan (2016b), for instance, wrote that citizens are suffering from "news fatigue" that moves them to want to hear positive and even soft news, possibly despite the news source, rather than new political, social, or cultural developments. The New York Times explained the operation of "fake news" as an issue of social media - namely Facebook - functioning as a "real [sic] new mass media" (Herrman, 2016b). Audiences, the Times wrote, are taking their money to online spaces other than traditional news sources, as personalizable and interactive sites:

explicitly place the individual at the center of his or her media universe, recording, amplifying and perpetuating their preferences into complete, customized media experiences that no traditional news provider can rival.

By blaming audiences for emerging "fake news" journalists cast themselves as truth-seekers and positioned the process of verification as a journalistic property (Hermida, 2015) that only journalists can provide. In fact, in December, The Washington Post (Dvorak, 2016b), in writing about the pizza shop shooting, argued that items that make way into "fake news" would rarely make way into mainstream news because of journalistic "standards" that protect audiences from mis- and disinformation. In her piece, Dvorak writes that without such "standards," "[t]hose who run our social media companies and internet search engines needs to find a way to help a gullible country differentiate between fake news and real news." Playing off Trump's "Make America Great Again" campaign slogan, she ends her column with a new mantra for journalism: "Let's make America believe in facts again."

To assist audiences with confusion around what's real, The Washington Post published two separate "guides" for fact-checking possible "fake news" (Kessler, 2016; Rosenberg, 2016), including how to identify if the news story is from "a legitimate website," whether the news reporter is real, and how to go about "scrutinizing the sources," such as questioning the degree to which the news story appears from a single tweet "with no additional confirmation" (Kessler, 2016). And while audiences - as 
"gullible" consumers or as victims of "news fatigue" - were cast by journalists to have succumbed to a smarter day and age that is a threat to the world as we know it, as one Washington Post editorial (Washington Post, 2016) stated, today's internet is a "wild west" within which the freedom of expression as an "irresponsible exercise can distort and destabilize our politics." Journalism, the Post concludes, "is a job for people, not algorithms" and, surely, only real journalists can present the news that's real.

\section{Discussion \& Conclusion}

This study examined how journalists in the United States and the U.K. explained the rise and meanings of "fake news" as a threat to mainstream journalistic authority. Beyond describing the themes that emerged in the coverage of "fake news," I wish to present a discussion of the theoretical meaning and normative realizations that journalistic explanation revealed. First, in these emotional and political times surrounding the election of Donald Trump, particularly in the United States, I sense I will not be able to convince those who consider this analysis of "fake news" as more than a splitting of hair as being something more. There is simply truth and untruth, many scholars and journalists state, and anything that comes from Trump is on the side of falsehood. I also sense that in today's political climate this writing might also somehow be seen as being in support of Donald Trump. It is not. Rather, I wish to extrapolate meanings of how this coverage of threats to legacy press in both countries was an opportunity for journalists to reestablish themselves as a sole authority for truthtelling, even though, quite frankly, they did so without great evidence.

The issues of truthiness and fakiness, from satire journalism scholarship to today's "fake news," holds a much greater meaning than whether journalists are accurately covering information or, in fact, whether journalists are receiving accurate information in the first place. That journalists across both sides of the ponds found it necessary in columns, news articles, and editorials to argue the same thing - that mainstream, real journalists are still of value because they bring to light the "truth" - provides a notion of how journalists see themselves perhaps in coverage of other issues, as well.

Increased dissatisfaction by news audiences that has contributed to fragmented media spheres and economic challenges to traditional forms of the press at the rise of personalized and interactive media is only one of the reasons why journalists find themselves in the space of maintaining a sense of social and cultural value. Journalists have been captured in this moment of Trumpism - in which an elected official, supposedly with the backing of a wide and large constituency speaks truth to power about the closemindedness of elite press, about power systems that he is very much openly part of, and about the inadequacy of journalism to "tell all sides of the story." 


\section{Robert E. Gutsche, Jr.}

Yet, rather than facing issues of power inherent in close relationships between the press and police, business, government, and ideologues while at the same time destroying newsrooms (consider the removal of all photographers at the Chicago Sun-Times, a 2017 shedding of editors at The New York Times, and public recognition of gender disparity at The Wall Street Journal with little to show for a solution), journalism continues to be seen by giant swaths of the audiences as being, perhaps not fake, but certainly not owners of the news of the day.

And, interestingly enough, news commentary about "fake news" that attacked audiences for being "gullible" or unable to read the news for issues of journalistic "truth" is a sad moment of inadvertent recognition that journalists simply don't trust readers. The result is twofold. First, journalists are able to use that argument to elevate themselves in a moment of securing themselves as an overarching authority that has lost touch with the needs and interests of the masses. But that assumes audience members really aren't able to dissect the "real" from the "fake."

On the other hand, if the press really does play that pivotal role, they have opened themselves up to questions about their ideological purpose and position in society. What keep the messenger from being merely a mouthpiece? Without adequate transparency of sourcing, for instance, including what doesn't make its way into final, published work, and true diversity that positions profits and reporter pay, engagement in communities that is targeted at more than increasing newsstand sales, and journalism that attacks the wrongs of fellow social institutions, journalism as we know it today will remain an eco-chamber of elite ideologies. Ask a member of a disenfranchised community what they think about the local press. The reasons why the press isn't to be believed isn't because journalists don't report the truth. It's that they only report what's true to them.

This analysis also brings to light the need for journalists (and their bosses) to determine the degree to which technology or news drives the industry. Journalists and scholars must come to terms with the limitations in creating unity through social media and acknowledge the divides that the medium creates, particularly in inner-city and rural areas of the U.K. and the United States. Facebook, for instance, regardless of its "social networking" focus, is a business which has a primary goal of being profitable, regardless of how many people connect with one another. It is untenable for journalists to spend time demanding Facebook stop "fake news" when the goal of Facebook is to keep audiences coming back for more. If journalists (and their bosses) want to stop fake news, they must take action themselves to change who they are as truth-tellers by questioning the very truths they report.

\section{Notes}

1 Scholars differentiate between "conspiracy" as being falsehoods rooted in mythical narratives and distrust of dominant sociopolitical systems and 
"conspiracy theory" as being a discursive means by which to ostracize and delegitimize alternative explanations to dominant thought (for more, see Byford, 2011; deHaven-Smith, 2013; Gutsche, 2017).

2 One cannot help by note that discussions of "the real" in "fake news" also operates alongside debates with Trump, whose Twitter handle is, ironically, @RealDonaldTrump.

A version of this chapter was presented at the Future of Journalism Conference 2017 at Cardiff University.

\section{References}

Aare, C. (2016). A narratological approach to literary journalism: How and interplay between voice and point of view may create empathy with the other. Literary Journalism Studies, 8(1), 106-139.

Adeduntan, A. (2017). Truth, nothing but the performative truth. Journalism Studies. doi:10.1080/1461670X.2017.1299587.

Aisch, G., Huang, J., \& Kang, C. (2016, December 10). Dissecting the \#PizzaGate conspiracy theories. The New York Times. Retrieved at www.nytimes.com/ interactive/2016/12/10/business/media/pizzagate.html?_r=0.

Ball, M. (2017, April). Kellyanne's alternative universe. The Atlantic.

Baym, G. (2009). From Cronkite to Colbert: The Evolution of Broadcast News. New York, NY: Oxford University Press.

Berkowitz, D., \& Gutsche, Jr., R. E. (2012). Drawing lines in the journalistic sand: Jon Stewart, Edward R. Murrow and memory of news gone by. Journalism and Mass Communication Quarterly, 89(4), 643-656.

Bernstein, J. (2016, July 28). Facebook's dominance in journalism could be bad news for us all. The Guardian. Retrieved at www.theguardian.com/ media-network/2016/jul/28/facebook-dominance-journalism-world-view.

Bird, S. E. (1990). Storytelling on the far side: Journalism and the weekly tabloid. Critical Studies in Mass Communication, 7(4), 377-389.

Blake, A. (2017, January 22). Kellyanne Conway says Donald Trump's team as "alternative facts." Which pretty much says it all. The Washington Post. Retrieved at www.washingtonpost.com/news/the-fix/wp/2017/01/22/kellyanneconway-says-donald-trumps-team-has-alternate-facts-which-pretty-muchsays-it-all/?utm_term $=.54 \mathrm{e} 9 \mathrm{~d} 22 \mathrm{~b} 0 \mathrm{deb}$.

Boudana, S. (2011). A definition of journalistic objectivity as performance. Media, Culture \& Society, 33(3), 385-398.

Broersma, M. (2010). The unbearable limitations of journalism. International Communication Gazette, 72(1), 21-33.

Byford, J. (2011). Conspiracy Theories: A Critical Introduction. Hampshire, UK: Palgrave MacMillan.

Carlson, M. (2017). Journalistic Authority: Legitimizing News in the Digital Era. New York, NY: Columbia University Press.

Carlson, M., \& Berkowitz, D. (2014). “The emperor lost his clothes”: Rupert Murdoch, News of the World and journalistic boundary work in the UK and USA. Journalism, 15(4), 389-406.

Carroll, R. (2016, December 15). How Breitbart and the conservative right opened a new front in the war over fake news. The Guardian. Retrieved at www. theguardian.com/us-news/2016/dec/15/breitbart-fake-news-right-trump. 


\section{Robert E. Gutsche, Jr.}

Conboy, M. (2013). Journalism Studies: The Basics. London, UK \& New York, NY: Routledge.

Cooke, N. A. (2017). Posttruth, truthiness, and alternative facts: Information behavior and critical information consumption for a new age. Library Quarterly: Information, Community, Policy, 87(3), 211-221.

Deacon, M. (2016, November 17). No more facts! I'm off to become a fake news media baron. The Daily Telegraph. Retrieved at www.pressreader.com/uk/ the-daily-telegraph/20161217/282376924224433.

deHaven-Smith, L. (2013). Conspiracy Theory in America. Austin: University of Texas Press.

Dvorak, P. (2016a, November 21). Fake news writers need to meet the real reporters who die trying to do their jobs. The Washington Post. Retrieved at www.washingtonpost.com/local/fake-news-writers-need-to-meet-the-realreporters-who-die-trying-to-do-their-jobs/2016/11/21/2d116308-afdc-11e68616-52b15787add0_story.html?utm_term =.5f6c99f4c122.

Dvorak, P. (2016b, December 5). t a D.C. pizzeria, the dangers of fake news just got all too real. The Washington Post. Retrieved at www.washingtonpost. com/local/at-a-dc-pizzeria-the-dangers-of-fake-news-just-got-all-too-real/ 2016/12/05/b8ae43b8-baf4-11e6-94ac-3d324840106c_story.html?utm_ term $=.7819 \mathrm{~d} 4 \mathrm{cfccd} 4$.

Easton, L. (2016, December 15). The fight against fake news. Associated Press. Retrieved at https://blog.ap.org/announcements/the-fight-against-fake-news

Fandos, N. (2016, December 7). Nonprofit journalism groups are gearing up with flood of donations. The New York Times. Retrieved at www.nytimes. com/2016/12/07/business/media/nonprofit-journalism-groups-are-gearingup-with-flood-of-donations.html.

Gans, H. (2004). Deciding What's News: A Study of CBS Evening News, NBC Nightly News, Newsweek and Time. Evanston, IL: Northwestern University Press.

Garland, R., Tambini, D., \& Couldry, N. (2017).Has government been mediatized?: A UK perspective. Media, Culture \& Society. doi:10.1177/0163443717713261

Godefroidt, A., Berbers, A., \& d'Haenens, L. (2016). What's in a frame?: A comparative content analysis of American, British, French, and Russian news articles. The International Communication Gazette, 78(8), 777-801.

Godler, Y., \& Reich, Z. (2017). Journalistic evidence: Cross-verification as a constituent of mediated knowledge. Journalism, 18(5), 558-574.

Gold, H. (2017, May 2). CNN: "We didn't run Trump ad because of 'fake news' graphic". Politico.com. Retrieved at www.politico.com/blogs/on-media/ 2017/05/02/cnn-no-run-trump-ad-237877.

Goldman, R. (2016, Dec. 24). Reading fake news, Pakistani minister directs nuclear threats at Israel. The New York Times. Retrieved at www.nytimes.com/ 2016/12/24/world/asia/pakistan-israel-khawaja-asif-fake-news-nuclear.html.

Goodman, M. (2008). The Sun and the Moon: The Remarkable True Account of Hoaxers, Showmen, Dueling Journalists, and Lunar Man-Bats in Nineteenth-Century New York. New York, NY: Basic Books.

Greenslade, R. (2016, November 23). Here's the truth: 'Fake news is not social media's fault. The Guardian. Retrieved at www.theguardian.com/media/ greenslade/2016/nov/23/heres-the-truth-fake-news-is-not-social-medias-fault.

Gürsel, Z. D. (2009). U.S. newsworld: The rule of text and everyday practices of editing the world. In S. Elizabeth Bird (Ed.), The Anthropology of News and Journalism (pp. 35-53). Bloomington: Indiana University Press. 
Gutsche, Jr., R. E. (2014). A Transplanted Chicago: Race, Place and the Press in Iowa City. Jefferson, N.C.: McFarland.

Gutsche, Jr., R. E. (2015). Boosterism as banishment: Identifying the power function of local, business news and coverage of city spaces. Journalism Studies, 16(4), 497-512.

Gutsche, Jr., R. E. (2017). Media Control: News as an Institution of Power and Social Control. New York, NY \& London, UK: Bloomsbury.

Gutsche, Jr., R. E., Naranjo, C., \& Martinez-Bustos, L. (2014). 'Now we can talk': The role of culture in journalistic boundary work during the boycott of Puerto Rico's La Comay. Journalism Practice, 9(3), 298-313. doi:10.1080/1 7512786.2014.963358.

Haigh, M., Haigh, T., \& Kozak, N. I. (2017). Stopping fake news: The work practices of peer-to-peer counter propaganda. Journalism Studies. doi:10.10 80/1461670X.2017.1316681.

Hartley, J. (2009). Journalism and popular culture. In K. Wahl-Jorgensen \& T. Hanitzsch (Eds.), The Handbook of Journalism Studies (pp. 310-324). New York, NY \& London, UK: Routledge.

Heider, D. (2004). Class and News. Lanham, MD: Rowman \& Littlefield.

Heidt, S. (2014). The mobile savage: Presidential peace rhetoric and the perpetuation of enemies. Dissertation, Georgia State University. Retrieved at http:// scholarworks.gsu.edu/communication_diss/49.

Hermida, A. (2015). Nothing by the truth: Redrafting the journalistic boundary of verification. In M. Carlson \& S. C. Lewis (Eds.), Boundaries of Journalism: Professionalism, Practices and Participation (pp. 37-50). London, UK \& New York, NY: Routledge.

Hern, A. (2016, November 25). Facebook doesn't need to ban fake news to fight it. The Washington Post. Retrieved at www.theguardian.com/technology/2016/ nov/25/facebook-fake-news-fight-mark-zuckerberg.

Herrman, J. (2016a). Fixation on fake news overshadows waning trust in real reporting. The New York Times. Retrieved at www.nytimes.com/2016/11/19/ business/media/exposing-fake-news-eroding-trust-in-real-reporting. html.

Herrman, J. (2016b, November 8). What we've learned about the media industry during this election. The New York Times. Retrieved at www.nytimes. com/2016/11/09/business/media/what-weve-learned-about-the-mediaindustry-during-this-election.html.

Holan, A. D. (2016, December 13). 2016 lie of the year: Fake news. Politifact. com. Retrieved at www.politifact.com/truth-o-meter/article/2016/dec/13/2016lie-year-fake-news.

Hunt, E. (2016, December 17). What is fake news? The Guardian. Retrieved at www.theguardian.com/media/2016/dec/18/what-is-fake-news-pizzagate.

Jackson, J. (2016, December 23). Why is Mail Online going after the fact checkers? The Guardian. Retrieved at www.theguardian.com/media/2016/dec/23/ why-is-mail-online-going-after-fact-checkers-snopes.

Jarvis, J. (2017). Our problem isn't 'fake news.' Our problems are trust and manipulation. Medium.com. Retrieved at https://medium.com/whither-news/ our-problem-isnt-fake-news-our-problems-are-trust-and-manipulation5 bfbcd716440.

Kang, C., \& Goldman, A. (2016, Dec. 5). In Washington pizzeria attack, fake news brought real guns. The New York Times. Retrieved at www.nytimes. 
com/2016/12/05/business/media/comet-ping-pong-pizza-shooting-fakenews-consequences.html.

Kessler, G. (2016, November 22). The Fact Checker's guide for detecting fake news. The Washington Post. Retrieved at www.washingtonpost.com/news/ fact-checker/wp/2016/11/22/the-fact-checkers-guide-for-detecting-fakenews/?utm_term=.1cd07939b90e.

Krippendorff, K. (2004). Content Analysis: An Introduction to its Methodology. Thousand Oaks, CA: Sage.

Kristof, N. (2016, November 12). Lies in the guise of news in the Trump era. The New York Times. Retrieved at www.nytimes.com/2016/11/13/opinion/ sunday/lies-in-the-guise-of-news-in-the-trump-era.html

Lester, P. M. (1996). Images That Injure: Pictorial Stereotypes in the Media. Westport, CT: Praeger.

Lippman, D., Samuelsohn, D., \& Arnsdorf, I. (2016, March 13). Trump's week of errors, exaggerations and flat-out falsehoods. Politico.com. Retrieved at www. politico.com/magazine/story/2016/03/trump-fact-check-errors-exaggerationsfalsehoods-213730.

Macnamara, J. (2016). The continuing convergence of journalism and PR: New insights for ethical practice from a three-country study of senior practitioners. Journalism \& Mass Communication Quarterly, 93(1), 118-141.

Martin, J. R., \& Rose, D. (2003). Working with Discourse. London, UK \& New York, NY: Continuum.

Matheson, D. (2000). The birth of news discourse: Changes in news language in British newspapers, 1880-1930. Media, Culture \& Society, 6(4), 557-573.

McLeod, K. (2014). Pranksters: Making Mischief in the Modern World. New York \& London, UK: New York University Press.

McNair, B. (2003). News and Journalism in the UK. London, UK \& New York, NY: Routledge.

Mihailidis, P., \& Viotty, S. (2017). Spreadable spectacle in digital culture: Civic expression, fake news, and the role of media literacies in 'post-fact' society. American Behavioral Scientist, 61(4), 441-454.

Mullin, B. (2017, May 4). What causes fake news, and what are its solutions?: Journalists from NPR, CNN and the founder of PolitiFact weigh in. Poynter. org. Retrieved at www.poynter.org/2017/what-causes-fake-news-and-whatare-its-solutions-journalists-from-npr-politifact-and-cnn-weigh-in/458582.

Nadler, A. M. (2016). Making the News Popular: Mobilizing U.S. News Audiences. Urbana, Chicago \& Springfield: University of Illinois Press.

Rawlinson, K. (2016, April 25). How newsroom pressure is letting fake stories on to the web. The Guardian. Retrieved at www.theguardian.com/ media/2016/apr/17/fake-news-stories-clicks-fact-checking.

Reid, T. (2000). Inquiry Into the Human Mind: On the Principles of Common Sense. Edinburgh, UK: Edinburgh University Press.

Richardson, J. E. (2007). Analysing Newspapers: An Approach from Critical Discourse Analysis. Basingstoke, UK \& New York, NY: Palgrave Macmillan.

Robinson, S., \& Culver, K. B. (2016). When White reporters cover race: News media, objectivity and community (dis)trust. Journalism. doi:10.1177/146 4884916663599.

Rosenberg, A. (2016, December 1). Should you trust that news story you're reading? Here's how to check. The Washington Post. Retrieved at www.washingtonpost. 
com/news/act-four/wp/2016/12/01/should-you-trust-that-news-story-yourereading-heres-how-to-check/?utm_term=.4cc6a0a2ea4a.

Rutenberg, J. (2016a, December 18). By attacking the press, Donald Trump may be doing it a favor. The New York Times. Retrieved at www.nytimes. com/2016/12/18/business/media/by-attacking-the-press-donald-trump-maybe-doing-it-a-favor.html.

Rutenberg, J. (2016b, November 20). Mark Zuckerberg and Facebook must defend the truth. The New York Times. Retrieved at www.nytimes. com/2016/11/21/business/media/zuckerberg-and-facebook-must-defend-thetruth.html.

Samuel, J. (2016, December 18). Searching for truth in the rubble of 'fake news' from Aleppo. The Sunday Telegraph. Retrieved at www.telegraph.co.uk/ news/2016/12/17/searching-truth-rubble-fake-news-aleppo/.

Schudson, M. (1997). Toward a troubleshooting manual for journalism history. Journalism \& Mass Communication Quarterly, 74(3), 463-476.

Schwartz, A. B. (2015). Broadcast Hysteria: Orson Welles's War of the Worlds and the Art of Fake News. New York, NY: Hill and Wang.

Shapiro, I., Brin, C., Bédard-Brûlé, I., \& Mychajlowycz, J. (2013). Verification as a strategic ritual: How journalists retrospectively describe processes for ensuring accuracy. Journalism Practice, 7(6), 657-673.

Soll, J. (2016, December 18). The long and brutal history of fake news. Politico.com. Retrieved at www.politico.com/magazine/story/2016/12/fakenews-history-long-violent-214535.

Sullivan, M. (2016a, November 20). Real editor could fight Facebook's fake news. The Washington Post.

Sullivan, M. (2016b, December 8). Sick of the news? This is not time to tune out. The Washington Post. Retrieved at www.washingtonpost.com/lifestyle/style/ sick-of-the-news-this-is-no-time-to-tune-out/2016/12/08/97ff1e70-bd6111e6-91ee-1adddfe36cbe_story.html?utm_term=.c54c08f997b3.

The Guardian. (2016, November 15). The Guardian's view on social media. The Guardian.

The New York Times. (2016, December 10). Truth and lies in the age of Trump. The New York Times. Retrieved at www.nytimes.com/2016/12/10/opinion/ truth-and-lies-in-the-age-of-trump.html.

Tuchman, G. (1973). Making news by doing work: Routinizing the unexpected. American Journal of Sociology, 79(1), 110-131.

Vargo, C. J., Guo, L., \& Amazeen, M. A. (2017). The agenda-setting power of fake news: A big data analysis of the online media landscape from 2014 to 2016. New Media \& Society. doi:10.1177/1461444817712086.

Wahl-Jorgensen, K. (2013). Subjectivity and story-telling in journalism: Examining expressions of affect, judgement and appreciation in Pulitzer Prizewinning stories. Journalism Studies, 14(3), 305-320.

Wardle, C. (2017, February 16). Fake news. It's complicated. Medium.com. Retrieved at https://medium.com/1st-draft/fake-news-its-complicated-d0f $773766 \mathrm{c} 79$.

Waterson, J. (2016, Nov. 22). Labour is promising a long campaign against fake news. BuzzFeed.com. Retrieved at www.buzzfeed.com/jimwaterson/labouris-promising-a-long-campaign-against-fake-news?utm_term=.gy 2 W Kvyq\#. wcZqOGWnQ. 


\section{Robert E. Gutsche, Jr.}

Weaver, D. H., \& Willnat, L. (2016). Changes in U.S. journalism: How do journalists think about social media? Journalism Practice, 10(7), 844-855.

Wolffe, R. (2016, December 21). Do you care about the truth? The Guardian. Retrieved at www.theguardian.com/membership/2016/dec/21/guardianmembership-fake-news.

Woolf, N. (2016, November 17). As fake news takes over Facebook feeds, many as taking satire as fact. The Guardian. Retrieved at www.theguardian.com/ media/2016/nov/17/facebook-fake-news-satire.

Yuhas, A. (2016, November 7). How does Donald Trump lie? The Guardian. Retrieved at www.theguardian.com/us-news/2016/nov/07/how-does-donaldtrump-lie-fact-checker.

Zelizer, B. (2009). The Changing Faces of Journalism: Tabloidization, Technology and Truthiness. London, UK \& New York, NY: Routledge.

Zelizer, B. (2017). What Journalism Could Be. Cambridge \& Malden, MA: Polity. 


\title{
3 Civil War in Donald Trump's America
}

\section{Conversations about Media and Mayhem on Main Street, USA}

\author{
Robert E. Pierre
}

On the evening Donald Trump was elected the 45th President of the United States, I watched the results intently and as it became clear that Trump would win the Electoral College, I posted this on Facebook:

\section{Civil War is indeed possible again, for real}

If it was a bit of hyperbole at the time, it doesn't feel that way now. Here's a little slice of how it's playing out in the orbit of Samar Ali, a Nashville lawyer and third-party negotiator and election observer throughout the Middle East. All of the characters are either friends, family members, colleagues, or associates of Ali, primarily those who are aggrieved by Trump's victory.

It was summer after whirlwind of Donald Trump's initial months as president. He and his surrogates - rejecting everything related to his predecessor - had come out swinging. They picked fights with reporters, with allies, with Democrats and Republicans. They publicly chastised America's longtime political allies and threw convention out the window to the glee of those who had voted for a change. There were loud and messy recriminations over the failed repeal of the Affordable Care Act, the repeated rejection by the federal courts of a travel ban on Muslims from certain countries and over the ongoing saga of Russian interference in the 2016 presidential campaign.

News and even foreign policy were being made during early morning Twitter rants and senior administration officials were repeatedly following the president's remarks to explain that he didn't really mean what he said. World leaders vowed that they could no longer look to America to be the shining light on the hill and they might have to look for world leadership in some other place. Samar Ali is a prominent international lawyer at one of Nashville's oldest firms. Her orbit includes liberalleaning friends, Republicans, immigrants and native born, world travelers and homebodies, city dwellers and rural residents, black and white, Latino and Arab - all of whom are figuring out how to survive and thrive in Donald Trump's America. Instead of rallying together toward a common cause, Ali said that everyone appears to be pulling away, becoming more tribal. 
It was in this context late in the summer of 2017 that, while on a work trip to London, a longtime friend pulled Ali aside and asked, "Is America imploding? Are you guys going to be OK?" The answer, depending on who is asked, will be an immediate thumbs-up, an immediate thumbs-down, or more likely a shrug of the shoulders and an eyeroll that says, "Who the hell knows?"

July 2017 marked the sixth month of Trump's presidency and, as usual, hotdogs, hamburgers, and slabs of ribs seared on grills across America and fireworks burst in the skies on the fourth, synchronized to the patriotic songs that remind of us of our common struggles and triumphs. But signs of common ground were difficult to find. The internet exploded with vitriol, hastening the destruction of decades long-relationships that had been forged over family dinners, at Parent-Teacher Association meetings and on ballfields, golf courses and basketball courts. "RESIST" became both a rallying cry and, to Trump supporters, a symbol of liberal fealty to tired and trite protest because they lost an election.

America was at war itself. Democrats fighting Republicans. Democrats fighting Democrats. Republicans fighting Republicans. Hardly anyone - even the politically agnostic - held "the media" in high regard, especially those outlets whose viewpoints they disagreed with. Infighting is built into the nation's fabric as Native Americans, Southerners, Northerners, African Americans, immigrants, Tea Partiers, and others have battled to gain or retain their rights. Even newspapers were said to be at war with each other. In mid-August, actual blood was spilled during a rally in Charlottesville, Virigina by people espousing Nazi and white supremacist ideologies. One of their sympathizers rammed his car into a crowd protesting against the rally, killing one victim. President Trump fanned the flames by equating the hate groups with those who protested them - drawing condemnation from Republicans and Democrats alike (Phillips, 2017).

Perhaps no president in modern history has run for office and started his presidency with such fury as Donald J. Trump, telling his predecessors Democratic and Republican - that none had been as worthy, strong, and capable of saving America. He alone, he said, would stand up to dictators, secure our borders, bring back long-gone jobs, and make anyone who challenged our authority cower in his presence.

There was no call for moderation, no reaching out of hands to those who didn't vote for him. It was, in short, a continuation of the way that Trump campaigned - with a bludgeon. He rejected soaring rhetoric about America's promise and the need for a melting pot that makes us all better. Every interaction is us against them - and the "them" is anyone who doesn't agree exactly with his world view.

Trump's temperament spilled into the electorate, not only his supporters but seemingly the entire nation. It's no secret that there are at least two Americas who look at the same set of facts and come out with wholly different 
interpretations. Donald Trump, the billionaire reality TV star, tapped into this disconnect, labeling anything that didn't fit his worldview as fake news, putting the already beleaguered mainstream media on its heels.

He won accolades from small farmers, factory workers, a majority of white women, and Ku Klux Klan wizards who felt like they were losing control of their lives to Democrats and Republicans in Washington who no longer understood them. The slightly bigger half of the electorate was horrified that Trump became the leader of the free world. Friends stopped talking to one another. Husbands and wives broke up. Parent groups at schools frayed as people looked anew at neighbors and family members and said, "I thought I knew you."

Trump's campaign - and election - forced the nation to reckon again with what it means to be an American and whether Muslims, African Americans, gays and lesbians, and others who have been marginalized should have an equal place under that tent. Many liberal whites were having trouble reconciling the America that elected Barack Obama with the one that embraced Donald Trump. But for me - and many others there was merely the sobering recognition that the dream and hope of America has always lived side by side with the ugly realities of systemic racism, sexism, and economic isolation.

But their co-existence is, and has always been, fragile.

\section{People Are People}

Grieving is part of it. And I understand it. We grieve, not because of DT, but because of neighbors and friends who saw no disqualifiers when we saw nothing at all redeeming. Many are pushing for understanding but not sure what there is to understand except we got work to do today and we have to do it without a lot of brethren. Disheartening to have to erect additional walls around some who we thought we understood. But our own safety and security demands it. We are all we got.

November 12, 2016

The day after the election Amy Wood's seven-year-old son was beside himself when he told his mom, "Donald Trump is a bully. Bullies are not supposed to win." As they walked into school together, Wood noticed that the Muslim and Hispanic children at the school were fearful and reserved. Chants of "Build That Wall. Build That Wall" rang out from other children that day. Her daughter, five, asked, "Well does this mean that we're not equal anymore?" Wood's children said and asked what many Americans were thinking on The Day After: How did this happen? What will it mean for my life?

Amy Wood had been taught that people were people and instilled that in her young children. Her mother was raised poor near Jackson, 


\section{Robert E. Pierre}

Tennessee, sharecropping alongside African American families. As a child, Wood didn't realize that her family was different - in the eyes of most of their neighbors - than black families. But as she grew into a young woman, other white people spoke freely around her. She was shocked to learn that many were upset as black people started to progress to higher status in society - the ultimate manifestation being the election of Barack Obama as the first African American to the hold the highest office in the land.

From Wood's point of view, the 2016 presidential election outcome was similar to a market correction for many white Americans. The red and white MAKE AMERICA GREAT AGAIN baseball caps peddled by Trump's campaign were a primal scream that said prioritizing minorities and immigrants, challenging police authority, and putting other religions on par with Christianity had gone too far. But for many African Americans the shock and disappointment expressed by many liberal-leaning white Americans was neither new nor shocking. My family, for instance, didn't leave Alice C Plantation near Franklin, Louisiana, until 1975, and we weren't the last one to leave. People like my grandfather knew that casually crossing racial lines was dangerous for him and his family and a tiny misstep could be the difference between life and death. They had seen it with their own eyes.

Amy Wood knows that her whiteness shielded her from this danger.

"There is so much entitlement in white America," Wood said.

When they started to see people of any color or difference either become professionals, make a higher wage, have a title, or be involved in politics, I feel like a lot of people started feeling threatened that there wasn't a guarantee anymore.

She added:

People said I don't want them to have what I have, whether it was education or healthcare, all these things that people want as human beings. With Trump, people were like 'Oh, he's going to make us entitled again.' I just look at it and it saddens me. Because my kids are still little, they treat and accept everybody as equal. We've taught them that people are people and humanity is humanity.

\section{America at War}

I grew up in Trump Country. And David Duke country. I know his people. They aren't right and the world they want so much to come back is gone. 
America is a perpetual dichotomy. The men who penned the words, "We hold these truths to be self-evident that all men were created equal," also owned men, women, and children as their personal property and subjected them to their whims and needs. After a bloody Civil War, through Jim Crow and Civil Rights, the nation settled into an uneasy détente, one that eventually allowed the first American of African descent to ascend to the U.S. presidency. For many, Barack Obama's ascension was a cleansing of America's original sin of slavery. And then came the election of Donald Trump.

During the campaign, none of the broadcast outlets could look away from the spectacle of Trump. He was engaging. He belittled his opponents. He took controversial stances. And he busted through barriers, gleefully saying things that were untrue and often laughable except for the fact that millions and millions of people liked what he said. Many pundits and opponents laughed off the idea that he could win, even as he vanquished one Republican after another during the primaries. Once he won, however, there was a virtual arms race among the big news organizations to staff up and really understand what kind of president Trump would be and how to acclimate to a new normal in which statements that might have sunk one of his predecessors were forgotten within hours. The new normal requires public, and daily, fights.

Our latest civil war - and there's nothing civil about it - came into full view on the first Tuesday in November 2016. Nearly every day since has felt like a national soap opera, filled with villains, wanna-be heroes, and daily plot twists and turns: firings, Twitter outbursts, the "Muslim Ban," the courts overturning the Muslim bans, threats to friends and enemies, and the ever-present investigation into potential collusion by the Trump campaign with Russia to help achieve his electoral victory.

Calls for Trump's impeachment started on Day One and grew louder as detractors worried that the new president might literally get everyone killed. His approval ratings sunk to 37 percent in late July, the lowest in modern history, according to Gallup (2017). Even so, he held solid majorities among Republicans, losing little, if any, support among those who put him in office. This conflagration has been a boon for media outlets, boosting ratings and setting off what has been dubbed by Vanity Fair as the last "great newspaper war" (Warren, 2017) between The Washington Post and The New York Times as they have fought for supremacy in breaking story after story about Donald Trump and potential collusion with Russia.

But the breathless reporting is often far removed from the lives of Main Street America in Nashville where Samar Ali lives. Ali's office is perched high above the party that rages every day in the honkytonks on Lower Broadway, alongside the Cumberland River. Nashville is a dot of blue in a deep-red state. And from her office, Ali can peer into both worlds: the blue one that is afraid of what is to come and the red one that is cautiously relieved that help may be on the way. 
Ali is an optimist at heart but she is also worried. She serves as a thirdparty mediator to help create a "steady state" in Syria and joined President Jimmy Carter to monitor the 2012 presidential elections in Egypt. So, she knows what happens when a nation's institutions fall apart. She worries that America is losing touch with the ties that bind us, or that should bind us.

"We are in the middle of a social civil war where everybody is shouting at each other from their own silos," Ali said.

It's a crossfire, literally a crossfire. There are fundamental values of America that are not just American values. They're human rights, including freedom of speech, access to due process of law, democracy in general, the right to vote. The right to vote is the right to choose who it is that's going to impose legislation on you about how you live your life.

\section{Welcome to Trump Country}

We live in two Americas where we are careening away from one another...I am not even sure we have a common language from which to start talking about what caused the level of outrage that the majority, and it is the majority, are feeling right now about what our new president has unleashed to the world... this election has fundamentally altered how Americans see one another and it feels like we are just heading further and further in our own separate corners. Reproductive rights, healthcare, understanding and acceptance of the LGBT community, fair treatment of Muslims, etc. In the most populous areas of our country, these things are a given and there is no going back. You can't un-ring the proverbial bell. And so while this president and this administration have pledged, and in fact, started to whittle away at rights and norms in these areas, the other We The People, the majority, won't retreat today or ever.

January 21, 2017

Music City, as Nashville is known, is a magnet for dreamers from around the country who come here seeking their shot at stardom in the music industry. I visited here to get away from the East Coast and the comfort of living in a place, Washington, D.C., where I can go months without interacting with someone, for work or play, who voted from Trump. As with Hollywood or New York or Chicago, the young end up bartending and serving this city's famous Hot Chicken to thrill-seeking tourists. For those who live a tank of gas or less away, Nashville is their big city, the place to go for special weekends and to experience food and entertainment not available in their own communities. Ali grew up in one of those communities, Waverly, a city of 4,000 about 70 miles and a world away from Nashville. 
Waverly is Trump Country.

On a Saturday afternoon in June 2017, Waverly's town square was mostly quiet, with children filing into the town's one-screen theater to see Disney's Cars 3 and shop owners eagerly chatting up the rare customer who sauntered through their door. One of the shops was a twoyear-old store that caters to "preppers" who prepare for calamities by stocking up on food and survival gear. Business had been brisk leading up to the November 2016 presidential election.

Here and throughout much of small-town America, there was fear that Hillary Clinton would win and that she would further erode the way of they know and love. This staunchly conservative enclave of 4,500, the hometown of county music legend Loretta Lynn, voted overwhelmingly for Donald Trump. But his win was bad for this particular business, at least temporarily. "People aren't prepping as much," the owner said.

High school is the end of the road for education for many in Waverly. High schoolers still cruise through the McDonald's and Sonic after a big game - the same as when Samar Ali, 35, was in high school. She remains partial to her hometown.

As a child, hers was the only Muslim family in a town full of Baptists and Catholics. She attended religious schools, and people there constantly tried to convert her and her family to Christianity so they wouldn't go to hell. But Ali's family, who moved to town in 1976, was nearly universally respected because her parents, both doctors, were the town's healers. They knew everyone and everyone knew them. There was skepticism about their religion and culture, of course, but, over time, they were just the Alis, the town doctors, with three growing daughters.

"In Waverly, we tried from day one to be good neighbors, business people who want to be good citizens," said Subhi Ali, Samar's father, who grew up in Palestine. Maysoon Ali, Samar's mother, who grew up in a prominent family in Syria, said was an outsider at first in Waverly, as a Muslim and as a woman. Some patients did not want to be seen by a woman, so she went to their churches, told them about her culture, food, and clothing. She approached skepticism with compassion, she said. "What helped me most is that my children were very active in the community and people realized that this is a family that really cares," Maysoon Ali explained. "My patients realized that I am there to make my family survive and to take care of them."

When Dr. Ali had a bout with non-Hodgkin's lymphoma in 1994, the town wrapped its collective arms around the family. "That's the South," Maysoon Ali said.

People visited. All the churches reached out. People offered food. Yes, I was an outsider and a Muslim woman, but when it came to sickness, they saw my husband and they saw me as somebody with a family and children and somebody who had worked in the community. This is why I say you have to invest in people. 
Trump's election has taken a toll for people involved in this story. On the internet, it is easy to discard and fight with people who you only meet online. It's harder when you are in line at the grocery store, passing each other at the local diner, or, in the case of the elder Alis, visiting with a sick patient and their family. Some longtime friends are less talkative and actively avoid any discussion of politics. The Alis mostly oblige. Quiet, sometimes, is better than speaking when the wounds remain raw. The way forward, Dr. Maysoon Ali said, involves eventually listening to one another and engaging around points of agreement instead of points of disagreement.

The question is how to jumpstart this conversation in the Trump era when no one is listening to anyone.

\section{Searching for Peace}

People know what the other side thinks and why. There just isn't much common ground, at least for those on the opposite ends of the political spectrum. We will see if the middle can (hold). Clearly his people love the spectacle of it all.

February 21, 2017

Samar Ali toggles between the nostalgia of her youth, the South that wrapped its arms around her family and welcomed them to town, and parts of the South that embrace policies that are detrimental to many people and causes that she fights for daily. Now, she too, is a healer. Unlike many of her schoolmates, she did not feel bound by the often, self-imposed constraints of Waverly and other small towns. Her parents were world travelers and, so too, were their children. Waverly was where she was born, but the idea that it would be the whole of her life never occurred to her. She traveled overseas and she dreamed bigger than many of her peers who thought - or were told - that the state's flagship university was off limits. She is a daughter of small-town Tennessee but not bound by it because of the way she was raised.

Ali was elected student body president at Vanderbilt University as an undergraduate and attended Vanderbilt Law School. As a White House Fellow under President Barack Obama, Ali served as a counterterrorism adviser and worked with U.S. Homeland Security Secretary Janet Napolitano. She also worked as a senior international adviser to Republican Tennessee Gov. Bill Haslam.

At Vanderbilt, Ali received death threats for advocating against Confederate memorials when she was the student body president at Vanderbilt and later during her role with state government by people who accused her of being a radicalized Muslim. The 2016 presidential election, and the run up to it, were distressing for many reasons, 
adding another level of emotional strain on her. Two days before the election, Ali published an essay in The Hill, titled, "As a Muslim American from the South, I know unity is everything." She wrote, in part:

Watching the presidential campaign unfold, I have found myself praying many times for the soul of our country. In all of my astonishment, I have hoped that every American would take a closer look at the currency in their pocket to ponder the same motto that guided our Founding Fathers centuries ago. This election, sadly, has gone beyond the normal differences of partisanship. It has turned my childhood lessons upside down. Entire groups of Americans have been demonized and used as scapegoats for economic ailments, fear, and general uncertainty. These tactics have proven effective in changing polls, and they have also unleashed a Pandora's Box of vitriol that may endure long after November passes.

And the vitriol that Ali mentions has, indeed, endured.

A month after the election, Ann Marie McNamara, a Nashville nonprofit volunteer and philanthropist, said the election strained her relationship as a Democratic activist with relatives and friends. They often disagreed about politics but something about the last election took it to another level. McNamara couldn't take what she saw as people blatantly passing along falsehoods about President Obama, immigrants and the Muslim community specifically. In what has become a common refrain around the country: McNamara has had to unfriend some people on Facebook because she couldn't endure the labeling of Trump protesters as whiners and sore losers or posts that she considered uninformed and discriminatory against Muslims and others.

"It is not just about an election and its results, it is rather about a ratification of a view of the world that is truly disturbing to many, including myself," she said. And she continued:

I do not ask you to agree with this opposing view from the one that you and your friends hold - just to say it is very difficult for me to think that you really approve of a leader with the actions and attitudes which have been voiced and acted upon by him. But since you do, I have to say that I really don't feel that we have the same world view - the same hopes for the world and on something this broad and comprehensive it is very difficult for me to relate to you.

But family ties are not broken that fast. The women remain in touch but something extraordinary has occurred when an election shakes ties built over many decades, marriages, births, and deaths. 


\section{'He Goes Right into Charge Mode'}

Democrats and non-Trumpers, in general, are aghast at something Trump does daily. They can't believe that he was ever allowed into the White House, let alone become a fixture there for four or even eight years.

Countless news articles have examined how families have become fatigued and forced themselves to take breaks from the news to keep themselves from going crazy or worrying themselves to death. As further evidence of the emotional strain of today's new civil war, a Pew Research Center survey released in June found that the hate associated with the election and new White House administration extends far beyond Trump himself and his policies to the actual intent of his supporters. Here's an excerpt from a Washington Post story about the survey (Blake, 2017):

Liberals don't just hate President Trump; lots of them don't even like being in the company of his supporters. That's the big takeaway from a new Pew Research Center survey, which is just the latest indicator of our remarkably tribal and partisan politics. And when it comes to Trump, it's difficult to overstate just how tribal the left is and how much distaste he engenders. Indeed, that distaste apparently extends even to people who decided they would like to vote for Trump.

The poll shows almost half of liberal Democrats - 47 percent - say that if a friend supported Trump, it would actually put a strain on their friendship. Among Democrats and Democratic-leaning voters more broadly, the number is 35 percent. White and more-educated Democrats are more likely to feel that it's tough to even be friends with a Trump supporter.

This poll and others like it caused eyerolls among Republicans and particularly among those who support President Trump. They have grown weary of the Russia investigation and the coverage of every single tweet as breaking news. Trump opponents, they contend, have become irrationally obsessed with booting him from office.

In right-leaning media outlets, liberal elites are lousy losers and hysterical snowflakes, upset because they lost an election to someone who wasn't supposed to win, according to all the pundits. Barack Obama and Hillary Clinton remain the reason for everything bad. And Trump is a revolutionary, shaking up the political operatives and throwing a punch on behalf of the common man who has been abandoned by Democrats and Republicans alike. A recurring question from whiplashed viewers those who are paying attention, at least - is whether this pace of activity and angst can continue for four or eight years.

In Tennessee, Steve Gill has his finger on the pulse of what Republicans think. He is a lawyer and broadcast personality who has spent time in Washington and has also run unsuccessfully for the U.S. House of 
Representatives. Gill also started The Tennessee Star, an online publication that he describes at the "Breitbart of Tennessee."

Since the Civil War, Tennessee, Kentucky, and Mississippi have been Democrat controlled legislatures, and all that shifted in the last 10 or 12 years. Tennessee has gone from literally having Democratic control of the legislature since the Civil War to Republican super majorities in the state House and the state Senate. The fights now in Tennessee are now in the Republican primary.

The same is true largely at the national level. The two major parties are fighting each other, but the divisions are just as strong inside of both parties. "The Bernie Sanders crowd is still fighting with Hillary," Gill said.

The same is true for the Republicans. Trump has people who are Trumpsters who are not necessarily Republicans, so he doesn't necessarily have sway over Republicans. You can't control people like you did in the boss days, on either side.

Gill is no Trump apologist but he thinks a lot of the hysteria about the danger Trump poses to the nation is overblown. What he admires about the president is that he understands the art of fighting like a soldier who must survive on instinct rather than being driven by expected political norms.

"He gets in a fight with the media, with a political opponent and he goes right into charge mode," said Gill, whose Breitbart-ish site drew 700,000 unique visits in May 2017, a few months after launch. "I often said during the campaign that I can't tell if the guy is an idiot or the most genius political operative in history. Maybe it's a little of both. I think [Trump] can take catastrophe and find his way out. This is why I think some of the mainstream media are just so flummoxed by it. Typically, somebody says something stupid, you call them on it, they back off. Trump won't back off."

During a poll taken in June 2017, Trump's approval rating among Republicans in the state was above 80 percent. The biggest issue of concern: illegal immigration, an issue that resonates across party lines and appears to be a safe space for the president - even as it drives liberals and rights activists crazy.

What does concern Gill is that hardly anyone recognizes the news media as a neutral party who can referee disputes about what constitutes a fact. There has long been plenty to dislike about the Washington Press corps, the annual 'Nerd Prom' also known as the White House Correspondents Dinner, the hautiness, the entitlement, the selfaggrandizing questions at news conferences, and the reporting on drivel. But Trump has given people a license to go even further. During the 
campaign, he made the media just as much of a villain as his Republican rivals and Democratic nominee Hillary Clinton, labeling their reports as fake news. Mainstream outlets like The New York Times and The Washington Post have engaged in a mini-war to determine who could get the biggest scoop on the Russia investigation.

Senior editors of both papers have publicly argued that they are not out to get payback against Trump for trashing their organizations in the media. Washington Post Editor Marty Baron says the newspaper is approaching the Trump administration as it would any administration, with curiosity not open animosity. "The way I view it is we're not at war with the administration, we're at work. We're doing our jobs," Baron told a crowd at the Code Media conference in February 2017 in California (Townsend, 2017).

But Gill, at The Tennessee Star believes - and so do his readers and listeners - that the so-called mainstream media is out to bring down Trump because he is a conservative and because he doesn't fit their idea of what a president ought to be. Gill explains:

I think the anti-Trump media has done almost irreparable harm to the media's capability of actually helping us thrive and work as a democracy. You've got just such a clear "We're going to bring him down!" bias that's coming from the CNNs and MSNBCs and The New York Times that nobody believes the national media. We've reached the point where we're not believing what we read. We're not believing what they tell us on TV. There was an audiotape of something and people were still saying, 'Well, I just don't believe it. I don't believe it happened. They could fake that up. How do we have a democracy work that depends on an engaged and involved and informed public when we're not going to be engaged, involved, and informed because we don't believe what the media tells us?'

And it's not just about the fight between Democrats and Republicans, he said:

There are conservatives who watch Fox who are not buying what Fox tells them anymore. I mean, you've got folks who are getting their news from Instagram or Alex Jones or from Rachel Maddow or from the comedy shows. How does a democracy work if we're not informed and at least have the same factual basis to debate the policy issues?

\section{'People Are Not Well Informed'}

They can miss me with the "oh that's hyperbole" argument. I grew up in the South and the vestiges are strong. The biggest problem, quite frankly, is our neighbors. I feel strongly that we can mobilize 
outside of the political parties and, in fact, those efforts are beginning already, far removed from the anger. We have to move on from many of the friends and associates who seek to normalize this. They will figure it out or they won't and I'm fine with either result. No time to try to figure out what people meant. We can leave that to the pols. We have to band together, pool resources, mental and others, and fortify all the places that we can. There is no backward, despite this election.

November 13, 2016

Amr Husseini, Samar Ali's husband, grew up in Beirut, watching channels such as the BBC, CNN International, and Al Jazeera, which piped in news from all corners of the globe. He has lived and spent a significant amount of time in Kuwait, Amman, Dubai, Malaysia, Doha, and Cambridge, Massachusetts, before moving to Nashville. He remembers vividly a Michael Jackson trial being televised for nine hours even as the U.S. waged war in Iraq and Afghanistan.

Entire days and weeks of coverage on cable news can focus on a single topic like Princess Diana's funeral, the O.J. Simpson trial, or a single nugget of breaking news about the president that gets stretched into hours of discussion by talking heads. Husseini's criticism is not that what news media discuss isn't true or important but that such singular focus leaves people unaware of what's going on in the rest of the world.

"I put myself in the position of someone sitting there watching that one thing all day," Husseini said. "What does that do to their perspective? If you live here and that's what you see for your whole life, every day and evening, how can you feel prepared to vote on foreign policy or anything like that. It is not fair to the people of America. When I look at this country, I see a majority of people who are super nice and so good at the core, including the people who voted for Trump." He continued:

But this population doesn't have the 360 degree access of what's going on in the world because of what the media is focusing on. People are engrossed in their families and their work and their only access to the world is through the TV. Democracy depends on having an informed electorate, but the media, especially television media, is providing them with very little useful information. Because people are not well informed, they vote based on emotion. A lot of people are hoping that even if Trump is crazy, maybe he can shake things up.

And the new president is certainly doing that, announcing a Muslim Ban, rolling back Civil Rights protections throughout the government and military, and taking world leaders and members of his own party to task on Twitter to press his agenda. And the administration is having 
trouble getting out of its own way. Infighting and damaging leaks to reporters are reported daily. And Trump has been in a perpetual state of distress about the investigation in Russian collusion in the 2016 presidential race. Robert Mueller, was appointed by the Justice Department as special counsel overseeing the investigation, inching closer to the White House as his investigation proceeds. If that weren't sucking up enough oxygen, the Trump White House has been a communications nightmare, with Sean Spicer beleaguered and combative with the press from Day One and another communications director hired to stop leaks who lasted 10 days before being booted from the job for berating other staffers publicly and generally wreaking havoc.

Those stumbles, however, pale in comparison to the lack of legislative achievements, including the promised 'repeal and replace' of the Affordable Care Act, tax reform, and a pledged infrastructure package.

But by July, the president's single largest accomplishment was the installation of a new Supreme Court justice in a seat that Democrats continue to argue was stolen by Republicans who refused to even hold a hearing for an opening during Barack Obama's final year in office. Even by end of summer 2017, before Congress recessed, there were no major legislative wins, either. However, the administration was enacting policy changes that were significantly altering policies around global warming, criminal justice, and affirmative action in college entrance - actions that could have lasting impacts for generations to come.

Still, on Main Street, USA, the direct impact of Trumps initial six months in office were muted for developer D. J. Wootson, a relatively recent transplant to Nashville.

A native of Wilmington, Delaware, who used college basketball to escape from a crime-ridden neighborhood, Wootson is attempting to revive Jefferson Street, a historic neighborhood near the city's three historically black colleges and universities - Tennessee State University, Fisk University, and Meharry Medical College. Trump is not his primary concern. Wootson wants to bring amenities commonplace elsewhere to African American communities that have long gone without them. Wootson is determined not to be deterred from his goals of raising his family, building his business and changing his community despite the upheaval surrounding Trump. One positive, he said, is long-simmering tensions have been exposed for all to see.

"The Trump election helped us to take the mask off," he said. "It's not new. It revealed a silent volcano that was already under the surface and waiting to erupt."

\section{This Will be Good for America}

Trump's election has had more of a direct impact for activists like Kasar Abdullah, who has been trying to allay the fear of Muslims who are 
worried about being vilified and even pushed out of the country by changing policies.

She knows what Civil War looks like. The United States is not there but it could be.

In 1988, at the age of six, Abdullah left her native Kurdistan with her family on foot as Saddam Hussein waged war on the Kurdish people. Her family crossed mountains and valleys for three days to reach Turkey, where they remained until 1992 when they were settled in North Dakota. They later moved to Nashville. The United States she knew then isn't the same as it is now.

"At first we were culturally shocked and faced many obstacles to integration. It was especially difficult for my parents to integrate and find work," Abdullah told styleblueprint.com (Marchetti, n.d.). "When my parents learned of Nashville, they visited and fell in love. The mountainous valleys reminded us of Kurdistan, and because it was an agricultural state, my parents could grow figs and pomegranates. We aligned with the values here and appreciated the friendly neighbors and sense of community. To us, Nashville is the Little Kurdistan.”

Abdullah's work sends her all over Tennessee and, as such, she wasn't surprised that Trump prevailed in the election. "I could sense the whole movement was getting a lot of momentum," she said. "I believe that is will be good for America. Trump has made the invisible visible, so we can no longer say racism doesn't exist. That part of it, I was actually excited about."

Not all of her thoughts are positive, though. "The part that terrifies me is that he has also made racism okay," Abdullah said.

People feel that it is okay to be racist. You would think that the United States, we've come so far that we would never be going backwards. But it was a good reminder that if you don't continuously check who you are, check your rights, they could be taken away any time.

The current situation brings back memories of being a refugee in Iraq.

"As a new American, you think the United States is a utopia," she said. "(Trump's) presidency has made it even more difficult to be a human being, simply a human being who wants a normal life. Even when 9/11 happened, I wasn't as guarded as I am right now."

Guarded and fearful are terms that get used more frequently in the months that Trump has been in office - even by people like Wootson and Abdullah who come from communities that are accustomed to living in a constant state of guardedness.

That troubles Samar Ali, who wants to do something about it before everyone retreats into themselves. "Part of saving our democracy," Ali said, "is making sure that we can all see each other instead of the caricatures that are created about us. Too many people are operating 


\section{Robert E. Pierre}

from a point of fear, particularly when it comes to the perception of Muslims."

Ali is now spearheading a national fundraising effort that she hopes will culminate in a campaign to help change how Muslims are depicted and discussed in popular culture - always as the dangerous and mysterious Other, even when their families established roots in America many generations ago. Ali's goal is to change the narrative formed in the wake of $9 / 11$ and other terrorist attacks that have come to define for many Americans the entirety of what they know about Muslims. She has friends in the current White House and those still stung by Hillary Clinton's defeat, and she has enlisted many of them to join her cause and help bridge divisions that are being exacerbated daily.

"You have to fight the internalization of the stigma that's all around you," she said.

If we don't address it, then we will have a lot of Americans who are not realizing their full potential. I see this all the time with Muslims who are being investigated because their neighbors called law enforcement because they were fearful. And the law enforcement takes the call very seriously. But then they start unraveling and investigating a Muslim family who then has their lives spun into a spiral of fear and intimidation. And then they start thinking, 'Well this system's not set up for me to win. The system is set up for me to lose. So they start playing defense constantly.'

Steve Gill, the Republican operative who started the Tennessee Star, shares Ali's sentiments. "Some of my best Democrat friends, we've reached the conclusion that we all want the same thing," Gill said. "We want healthy kids and educated kids and safe neighborhoods. The battle is over how you get there. But if we can't even debate the facts, or we can't even agree on the facts and then debate how we use those facts to form policy? It's not just the political apparatus - it's the media is not seen as a fair referee, and so every game looks fixed. If everybody believes that the American political process and the policy process has devolved to professional wrestling, where it's all fake, then how does a democracy work?"

This is the question our nation grapples with today.

\section{The Path Forward}

Call it what it is.

August 13, 2017

The nation has not come to a standstill under Donald Trump, and journalists have not stopped covering him. But the world before he arrived on the scene as a serious candidate has been altered and journalists are 
still finding their footing. They have gone out into the nation to find out what people are thinking, turning around narratives, not unlike the people from Nashville and the surrounding area. Some of these stories have been trite, speaking to white economic aggrievement without comparing and contrasting that with the feelings of people of color who are in similar economic straits. Almost all continued to tiptoe around - sometimes ignoring - the central role that race played during his election, the rhetoric early in Trump's presidency and in the rollback of policies meant to combat systemic discrimination. Republicans had been just as reluctant.

Until Charlottesville. On August 12, 2017, the news throughout the day was filled with images that might have come right out of the 1960s: white men and women screaming white power while carrying Confederate flags and Nazi paraphernalia. President Trump issued a mealy mouthed statement denouncing "hatred, bigotry and violence on many sides" (Phillips, 2017) - the kind of amorphous statement that he has made in the past in an effort not to directly call out white nationalists and delusional white supremacists. But there was near unanimity the day after Charlottesville, when one woman protesting a white supremacy march was intentionally mowed down and killed by a motorist who espoused Nazi teachings. Two other police officers died when their helicopter crashed.

None other than former KKK Grand Wizard David Duke said that they were there, at least in part, because of Donald Trump's pledge to "Take our country back" and to "Make America great again." The denunciations from Democrats, Republicans, and news organizations across the political spectrum was immediate: this is a step too far, they said; this is not America, they said.

Perhaps on cue, Donald Trump said hate from "many sides" was the problem - a position he abandoned two days later after being pummeled in the media and by Democrats, Republicans, and Independents alike. There aren't many things about which all these groups agree except for the fact that overt racists and Nazi sympathizers have no save place in civil society. There was a lesson in this exchange for journalists: stick to the facts, don't engage in hyperbole, and don't cheer for a particular outcome.

The truth is enough and there are still people out there who want to find some semblance of truth. There are many Samar Ali's in our vast nation and, in their communities, residents are grappling with about how to relate to one another during a Trump presidency. Most of them don't want it all to fall apart because they have too much invested. Speak to those people.

Whether Donald Trump is impeached or serves out a full term or two, what happens with our nation depends far more on how we deal with one another in our divided nation. Barack Obama is who we are. Donald Trump is also who we are. And as the Charlottesville incident showed, we can expect no leadership from the White House to help us grapple with those dichotomies. 


\section{References}

Ali, S. (2016, November 11). As a Muslim American from the South, I know unity is everything. The Hill. Retrieved at http://thehill.com/blogs/punditsblog/presidential-campaign/303956-im-a-muslim-american-from-asouthern-state-i-know.

Blake, A. (2017, July 20). Nearly half of liberals don't even like to be around Trump supporters. The Washington Post. Retrieved at www.washingtonpost. com/news/the-fix/wp/2017/07/20/half-of-liberals-cant-even-stand-to-bearound-trump-supporters/?utm_term=.1c7380804715.

Gallup. (2017). Presidential Job Approval Center. Retrieved at www.gallup. com/interactives/185273/presidential-job-approval-center.aspx?g_source= WWWV7HP\&g_medium=topic\&g_campaign=tiles.

Marchetti, A. (n.d.). Kasar Abdulla: FACES of Nashville. StyleBlueprint. Retrieved at https://styleblueprint.com/nashville/everyday/kasar-abdulla-faces.

Phillips, K. (2017, August 13). Trump didn't call out white supremacists. He was rebuked by members of his own party. The Washington Post. Retrieved at https:// www.washingtonpost.com/news/the-fix/wp/2017/08/13/trump-didnt-callout-white-supremacists-he-was-rebuked-by-members-of-his-own-party/?hpid=hp_hp-top-table-main_fix-1230 pm\%3Ahomepage\%2Fstory\&utm_ term $=.289$ ac1bfe 829 .

Townsend, T. (2017, February 14). Washington Post's Marty Baron: 'We're not at war with the administration, we're at work.' Recode. Retrieved at www. recode.net/2017/2/14/14615824/marty-baron-not-at-war-trump.

Warren, J. (2017, September). Is The New York Times vs. The Washington Post vs. Trump the last great newspaper war? Vanity Fair. Retrieved at www.vanity fair. com/news/2017/07/new-york-times-washington-post-donald-trump. 


\title{
4 Haktology, Trump, and News Practices
}

\author{
Leon Barkho
}

Hacked and leaked content has become a major source of information for the mainstream news, particularly in the years since Donald Trump snatched the official Republican presidential nomination in 2016. This chapter seeks to identify some salient policies and practices the news media have adopted in their coverage of the rise of Trump to power. Indeed, there is a plethora of literature on the role hackers and leakers as well as news fakers play in today's journalism (Eggen, 2006; Gunkel, 2005; Jaworski, Fitzgerald, \& Morris, 2004; Lievrouw, 2011; Roberts, 2012; Son, 2002; Vegh, 2003). We even have a new theory with a set of principles designed to test, interpret, and predict the phenomenon. Called "haktology," the theory examines the processes of gaining illegal and unauthorized access to information, its subsequent disclosure to reporters and activists, its transmutation into news reports, and the impact such reports leave on public opinion.

"Haktology" is tentatively defined "as the intentional and willful attempt to gather, collect, and disclose information hidden from the public sphere without the source's approval and spread it via the media" (Barkho, 2017, p. 6). The term "haktology" has its roots in the Middle English word "hakken" and its modern derivative "hack," which in computer programming language refers to attempts seeking to gain access illicitly and illegally, and "ontology," the Greek word for the field of knowledge concerned with the nature of being or existence. A study of "haktology" should involve all aspects and processes related to hacking, leaking, and faking of information, and its impact on journalism as practice and discipline. Hackers, leakers, and news fakers are playing a domineering role in the world of the media. With the emergence of Donald Trump on the political scene, both as a presidential candidate and later as the president of the United States, the theme of hacking and leaking as well as his Twitter memes and codes have overwhelmed the news media in the United States and beyond.

"Haktology," as theory, starts from the premise of a host of tentative trends characterizing the phenomenon within journalism in ways that makes established changes related to normalization of hacking culture. The trends include (Barkho, 2017): 
- News media attention may shift to the act of hacking, leaking, or news faking rather than the content of the information that is being hacked, leaked, or faked

- News media attention may gloss over the act of leaking and hacking and concentrate on its aftermath

- Those affected by the leaks usually reinforce the fact that the act of hacking and leaking is illegal

- News media rarely ask questions about whether governments and institutions have the right to deny citizens information or the validity of the reasons they cite to have it concealed

- Leaks and hacks are usually followed by "tumultuous" coverage with focus steadily shifting to whether it is right or wrong to reveal the information rather than the content of what has been divulged

- Applying balance routines, the media spend more time focusing on those holding the secrets than the impact the secrets have had and the consequences of their disclosure

Using this guide, this chapter examines the trends that have characterized "haktology" in the Trump era and the role of hacking, leaking, news faking, and tweeting in related news coverage. It studies the impact of the phenomenon on the world of journalism and those practicing it and looks into how and why leaks and tweets have characterized Trump's presidency, and more importantly, the discursive patterns and practices journalists resort to when publishing them. The chapter begins with a review of literature related to the role of journalism in the 2016 election and Trump's presidency and related issues such as "fake news."

\section{“Fake News," Social Media, and the Onslaught of Information}

When hacks, leaks, and "fake news" start having such an impact on Western democracies, media practitioners are supposed to emphasize professional standards of journalism practice, especially those related to verification of news content. In order not to fall into the trap of "fake news" providers, media workers need to adopt and apply methods on how to validate content non-professionals, whether hackers, leakers, or news "fakers," create and distribute via the internet. Fake news may need more vetting than hacks and leaks. Hackers and leakers divulge secrets they see as authentic, despite the "illegality" of the process. They do not attempt to apply the standards, values or ethical guidelines of professional journalism. Fake news is intrinsically and intentionally false. News fakers' content is a false replication and reproduction of serious journalism.

If intrinsically false, how come fake news is thriving and having such an impact? "Fake news" and "alternative facts" prosper when audiences see the quality of the content they come across on the internet and the 
content media professionals create and distribute as equal in terms of verification, veracity, and validation. Today, the lines between substantiated and unsubstantiated content on the internet are not so clear. The 2016 U.S. election and the period since Donald Trump was sworn in as President of the United States in 2017 have demonstrated how "fake news" can influence public opinion and western democracies (Allcott $\&$ Gentzkow, 2017). Ordinary people lack the ability to apply professional standards of news content production, particularly validation of facts, which Schwalbe, Silcock, and Candello (2015) see as "critical to truth telling in the news ecosystem" (p. 478).

With borders between bogus and genuine journalism getting somewhat blurred, particularly on the internet, clickbait journalism is slowly but steadily emerging as a winner. Page views on the internet do not necessarily depend on high-standard, quality news employing robust methods to validate and verify content. "Exaggerated headlines, twisting of words and biased writing are sure to get more page views," writes McDonnell (2016), despite the fact that they are detrimental to democracy, deceive the public, and harm society.

Allcott and Gentzkow (2017) define "fake news" as "news articles that are intentionally and verifiably false, and could mislead readers" (p. 213). The term "fake news" has probably become one of the trendiest phrases in the media during and after the 2016 U.S. presidential elections (for more on "fake news," see Chapter 2). Although the appellation is used mainly in reference to content circulating on social media outlets, empirical evidence shows continuous decline in trust and confidence in news, in general, even "when it comes to reporting news fully accurately and fairly" by mainstream media outlets (Allcott \& Gentzkow, 2015, p. 207). Certainly, truth and reliability are among "the major components of social capital" (Nah \& Chung, 2012, p. 716), and their breach makes a dent in audiences' trust in news content.

The flood of information available via social media outlets has prompted news media practitioners to develop their own ways of questioning the authenticity of amateur content. Some journalists have measures in place to assess whether such content should be published or discarded (Paulussen \& Ugille, 2008). However, two trends have emerged in relation to user-generated content, which the internet carries, or which finds its way directly to the newsroom. First, many news media, mainly due to economic considerations, no longer have the capacity to apply their own verification procedures on the "facts" they want to publish. Second, it is extremely hard for audiences, amid the flood of digital news and information, to work out whether "facts" are verified. Thus, it is surprising to see news consumers perceiving user-generated content on the internet to be "equally trustworthy" and occasionally "more trustworthy" than content provided by professional news media (Puustinen \& Seppaenen, 2011, p. 189). 
When it emerged again in 2016, the term "fake news" was there for the media to cover and for scholarly communities to investigate; the term only turned into an effective buzzword in mass communication and scholarly studies investigating news coverage in the Trump era. It is to be noted that literature on "fake news" surfaced even before the emergence of the Trump phenomena and its special way of dealing with the press. Nearly five years before Trump launched his campaign to win Republican nomination for U.S. presidency, for instance, there were fears of "fake news" turning into "real news" (McBeth \& Clemons, 2011). The Scholars then investigated the influence of "fake news" on news coverage as well as on public policy and politics. Using a case study of the 2008 United States presidential campaign, they found that "fake news" exerted a profound influence on news practices to the extent that it has probably become more real than "real" news itself.

There are ethical lessons to be learned from that earlier bout of "fake news," including what was a rousing for satire news in the 2000s. For Borden and Tew (2007), who examined the seriousness of humor and satire journalism, the term "fake news" applies to content whose creators do not abide by journalists' ethical standards and moral commitments. The scholars state that content that does not adhere to these commitments is merely an attempt to imitate or replicate serious and quality journalism.

In an article in the prestigious British science journal Nature, Adam Kucharski (2016) examines the spread of "fake" news in the wake of the 2016 U.S. presidential election and the U.K. vote to leave the European Union. Finding similarities between the diffusion of "fake news" and the transmission of infectious diseases, Kucharski writes that analyses on disease transmission dynamics can help us understand how "fake news" spreads online and competes with verified, substantiated, and morally gathered information. Kucharski draws parallels between the way disease strains grow and compete in their host populations and the manner online social contacts diffuse misinformation.

Besides its being a fertile ground for misinformation, the internet provides the opportunity to counter official narratives serving interests of powerful agents. Khaldarova and Pantti (2016), for instance, scrutinize attempts by a fact-checking Ukrainian website to expose Russian television's narratives of allegedly fake news about Ukraine. For instance, Marchi (2012) reveals a propensity for news discourse loaded with opinion and defense of what audiences stand for. Objective news coverage that pursues the basic tents of professional journalism is no longer the best way to digest information about world events.

Investigating the role of social media websites prior to the 2016 U.S. presidential election, Allcott and Gentzkow (2017) present new evidence that runs contrary to the common notion that the spread of fake news influenced election results. Relying on audience data, the authors found that social media was an important but not a crucial source for news in the run-up to U.S. presidential elections. 


\section{Trumping Mainstream Media via the Social}

To bypass mainstream media throughout the campaign and his presidency, Trump resorts to social media, which gives him the opportunity to connect directly first with his supporters and second with the wider public. But despite his apparent "hostility" to mainstream press, Trump's tweets get wide coverage, and the way the media deal with them is ushering in new practices on how to turn digital communication in primarily 140 characters into journalistic content. Trump defends his use of social media in series of Twitter storms. "My use of social media is not presidential - it's modern day presidential," Trump tweeted in response to criticism of his excessive reliance on social media to convey his message. "The FAKE \& FRAUDULENT NEWS MEDIA is working hard to convince Republicans and others I should not use social media,' he said, reminding his audience that he won the 2016 election with interviews, speeches and social media" (Cited in Graham, 2017).

Trump has repeatedly called the media "fake news" and has labelled CNN, for instance "FNN" -Fraudulent News Network - and branded BuzzFeed a "failing pile of garbage" (Graham, 2017). In his first 100 days in office, Trump tweeted nearly 500 times from his personal account (Pasha-Robinson, 2017). Trump's tweets "skyrocketed from a measly 56 in 2009 to a flabbergasting 9,182 in 2015" (Espinoza, 2017). Many of Trump's tweets fuel anger, ridicule, and even revulsion for most of the mainstream media and tens of millions of Americans who did not vote for him. However, the tweets are something like music to the ears of his supporters in the United States. His staff defend his 140-character, early morning Twitter barrages. So, too, do the mainstream media with consistent conservative views and ideology (Espinoza, 2017; Pew, 2016).

In short, Trump's tweeting practices have redefined a particular role social media can play in coverage of modern-day politics. Tweets of 140 characters on social media have ushered in journalistic practices, which may keep media scholars busy for years to come. Trump has proved that social media can work as an effective discursive tool. No matter how "unfamiliar" his commentaries, the chief executive and commander in chief of the United States has influenced journalism practice through his social media practices (Zurcher, 2017b). Trump's tweets are not confined to 140 characters. Most recently, he stepped up his feud with the mainstream media, posting a mock video showing him beating $\mathrm{CNN}$, prompting the broadcaster to accuse him of "encouraging violence against reporters" (Garrido \& Chung, 2017).

\section{The (New) U.S. Mainstream Media Scene in Trump's Era}

The term "mainstream media" is rather problematic because it is difficult to provide an exact inventory of which media outlets are "mainstream" and which are not. When Donald Trump assails mainstream 


\section{Leon Barkho}

media, he certainly does not have in mind the conservative outlets, which spring to his defense in his frequent spats with the press. Trump's problems mainly have been with what a study from the Pew Research Center (2016) has called "mostly liberal" or "consistently liberal media" and not with "mostly conservative" or "consistently conservative media." The center's study shows that U.S. audiences in Trump's era draw their information from mainly partisan and/or ideological news outlets depending on their leaning on the right or the left.

Most conservative Americans, Pew finds, get their news from Fox News and other conservative leaning media like Breitbart, TheBlaze, the Sean Hannity Show, the Rush Limbaugh Show, the Glenn Beck Program, and Drudge Report. Most liberal Americans, Pew says, get their news from The Guardian, National Public Radio (NRP), The New York Times, The Colbert Report, The Daily Show, The New Yorker, and Slate.

Pew's research sheds new light on average ideological placement on a 10-point scale of ideological consistency of major news sources and their audiences, and it shows that most mainstream media sources, whether more liberal or more conservative, attract a slightly left-of-center audience. Pew places 17 of the 32 mainstream media outlets in this category, among them are CNN, The Wall Street Journal, MSNBC, Bloomberg, USA Today, BuzzFeed, Huffington Post, The Washington Post, Yahoo! News, and NBC News.

However, the study provides a few surprises. For instance, of the 32 mainstream media, there are only seven with an average conservative ideological placement and eight with a slightly liberal ideological placement and the rest middle-of-the-road placement.

Trump's right leaning attracts middle of the ground audience. When Trump goes on attack against the media, his target may not be all the outlets, which Pew finds as the most liberal in the eyes of audiences. Ideology is not pivotal across the board. For instance, Trump has heaped praise on the British Broadcasting Corporation (BBC), a liberal-leaning outlet, according to Pew's research. At a news conference in February 2017, President Trump described the BBC, following a question from its North America editor, Jon Sopel, as: "another beauty." (Sommers \& Graeme, 2017). However, most of Trump's rows with mainstream media have been with outlets which are more consistently liberal, that is 25 of the 32 U.S. mainstream news outlets included in Pew's research. This chapter employs the term "mainstream media" mostly to refer to the 25 of the 32 outlets cited in Pew's research (2016).

\section{Influences of Trump on Media Studies}

The debate on role of hacks and leaks on news practices has intensified in Trump's era. However, the bulk of Trump-related media literature 
comprises studies in which hacking and leaking take a backseat. Nonetheless, and like previous U.S. election campaigns, the coverage of 2016 presidential election has been a source of inspiration for scholars from different disciplines. In a paper prepared for the American Political Science Association Annual meeting, Oates and Moe (2016) use the election's early campaign as a case study. They find that Trump and his Republican Party did not seek setting up any brand for their campaign on their own websites. It was the traditional media, they argue, which played a pivotal part in establishing particular brands for Trump's campaign. Oates and Moe show how the mainstream press amplified Trump's immigration policy, turned it into a brand, and in the process, attracted voter attention to it.

Beckwith and Sorscher (2016) carry a textual analysis of content in eight major U.S. media outlets three months before the 2016 U.S. general election. The authors' investigation attempts to unpack Trump's relationship with the media and find out which media are most fascinated with him and which media show their outrage of him. The authors' analysis reveals two trends: First, contrary to expectations, three out of four major conservative U.S. media outlets included in the study were not positive about Trump. Second, conservative media in general showed the same degree of dissatisfaction with Trump as their liberal counterparts.

Trump's impact on the media has not escaped the critical eye of data scientists. David Robinson (2016) has examined the type of electronic gadget Trump uses for his tweets and the impact it is having on content. The author applies tidy-text package, which associates words with different tones and sentiments. The author's quantitative analysis shows that Trump's Android tweets are angrier, and more negative than counterparts tweeted by his managers via iPhones, which are mostly pleasant, positive, and joyful.

Trump's discourse has been a topic of interest to scholars outside media and journalism studies. Marketing scientists have subjected Trump's discourse to textual analysis to glean insights into his thinking and possible guidelines on how he will behave or react as president of the United States. Geoff Copps (2017), head of research at Mediabrands Marketing Sciences, examines Trump's inaugural speech and finds that 83 percent of his sentences were 140 characters or fewer, rendering the majority of what he said tweetable. Copps writes: "All of this seems to confirm the breeziness of manner, sloganeering and to misquote a creative agency - brutal simplicity of thought that were Trump's ace cards during his campaign. He looks set to continue in this vein."

Additionally, Weifeng Zhong (2016) weighs Trump's candidacy against that of Hillary Clinton on a quantitative textual basis. The author analyses 33,000 words in 20 primary debates by both candidates. Despite the so many negative things said about Trump during the election trail, 
Zhong's study finds that Hillary Clinton and Donald Trump "use similar political speech in comparison with their party rivals: (1) their policy positions are quite moderate (2) their political sentiments are not too negative, and (3) their simple language delivers content to the audience rather effectively."

\section{Fake News and Practitioners}

Media practitioners differentiate between hacking and fake news. They generally present a negative image of hackers, while producers of fake news are in a sense glorified if their content fits news media's strategy. The focus on fake news content comes despite the fact that leaked and hacked content has mostly proved to be authentic. As a result, the fakenews ecosystem is flourishing and becoming more and more influential. The Washington Post's Caitlin Dewey (2016), for example, describes Paul Horner, whose fake news posts were said to have helped Donald Trump win the 2016 election, as the wonder of "a Facebook fake-news empire" to the extent that Trump's associates and family members cited his material to support their case. The newspaper even quotes Horner as saying, "I think Donald Trump is in the White House because of me."

Horner told the paper that Trump followers passed his work around without the slightest effort to check for its authenticity and that they would not care or change their attitude if they found out that the story they read was a hoax. For Horner, Dewey says, the content he posts on Facebook is "satire" rather than "fake news," and adds that he could not believe how people trusted some of the craziest things he wrote about Trump, which he in reality had not said, like putting badges on Muslims, or banning them from airports and from their own queues. Horner said he earns around $\$ 10,000$ a month from Googles AdSense that is connected to his "fake news."

The Guardian's Hannah Jane Parkinson (2016), on the other hand, points to the "influence of verifiably false content" on social media - and specifically on Facebook. Parkinson says the world can no longer overlook the impact of the propagation of unsubstantiated content on social media since it has turned into a tough competitor to the mainstream media in terms of audience reach and readership. According to Gottfried and Shearer of the Pew Research Center (2016) more than 60 percent of U.S. adults get news on social media. The largest and dominant social media network, the authors say, is Facebook with 66 percent of its nearly two billion users getting news on the site. Parkinson (2016) - and others - attributes the rise of social media as a source of news to public's low trust in mainstream media.

Meanwhile, Suzanne More (2016) digs up the history of Trump's former chief strategist, Steve Bannon, for insights into Trump's presidency and his view of the press. She mentions how Bannon, as Breitbart's executive chairman, oversaw the publication of articles by the conservative 
news and opinion website, which "signed up the meme-makers of misogyny." More says Bannon and Trump see eye-to-eye on attitude towards major mainstream media outlets bent on holding their discourse and deeds to account.

According to Silverman and Alexander (2016), there was in the run-up to the 2016 presidential election more than 100 pro-Trump websites operating from one single small town in the former Yugoslav Republic of Macedonia. The scholars describe the proliferation of U.S. politics (and "fake news") websites during the elections as "a digital gold rush." These digital entrepreneurs, they say, cared little for Donald Trump and his policies. Their aim, they add, was to cash in on royalties Facebook offers per-click display advertising. To lure readers, the websites had "American sounding-domain names WorldPoliticus.com, TrumpVision365.com, USConservativeToday.com, DonaldTrumpNews. co, and USADailyPolitics.com".

The "digital gold rush" was not confined to the Balkans or Russia, however. Scott Shane (2017) of The New York Times writes about a 23-year-old former U.S. college quarterback and fraternity leader and a devout fan of the Republican Party and Trump, called Cameron Harris, who builds his own politics website in the small kitchen of his flat. Shane quotes the student as saying that Trump supporters during the election would click on "anything that parroted Trump's talking points" and that it did not matter for them whether the statement was true or false.

With the advent of Trumpism, the mainstream media in general could not resist social media's onslaught on their territory, and some almost surrendered their "journalism" to microblogging (Cockburn, 2016; Fisk, 2016). Trump's camp employed (and it still does) social media to advance its causes and interests. As a result, a substantial part of mainstream media has become suspicious of social media. However, the mistrust the mainstream media have shown about Trump and his reliance on social media have fueled the same degree of mistrust among his supporters about almost anything the mainstream media publish against him. In fact, the mistrust has turned Trump supporters into devout followers who believe him whether right and wrong. Harris, the pro-Trump student The New York Times interviewed says he invested in this mistrust and picked some of Trump's unverified statements and turned them into what looked like "authentic" news.

Further, Harris tells the newspaper that those who supported Trump were predisposed to believe most of his unfounded accusations of his rival Hillary Clinton. What drove Harris to write bogus news, however, as is the case with most "digital gold rush hunters", was not politics but money. Shane, the Times reporter, writes that it took Harris only a few days since he had published his bogus story on which he only spent 15 minutes to earn about $\$ 5,000$. "That was a sizable share of the $\$ 22,000$ an accounting statement shows he made during the presidential 
campaign from ads for shoes, hair gel and web design that Google had placed on his site," Shane writes. Shane also mentions in his reporting that one of the "fake news" stories published by Harris, which went viral and had immense impact and coverage, included a digitally altered photograph to "prove" that Democratic candidate Hillary Clinton and her campaign had rigged the ballot boxes in Ohio.

\section{The Hacking of News Practices}

The advent of the Trump Phenomenon has shifted mainstream media attention to a host of codes in need of unfolding, utterances and statements in need of context, and language in need of interpretation. In a democracy, the press mirrors the political discourse it covers. The media scrutinize Trump, his discourse, his body language, and the things members of his administration say about him. The scrutiny is occasionally so detailed that it borders on forms of textual analysis one may come across in scholarly research. When it becomes hard to read into the political discourse and difficult to predict policies through an analysis of the language uttered, the press resort to certain practices to make it easy for audiences to follow.

A survey of press coverage of the Trump era, overwhelmed by hacks and leaks, reveals a number of journalistic practices that have become a characteristic of mainstream media when reporting on Trump. In the following, I will briefly discuss the most salient features of the journalistic practices that have become a discursive hallmark of Trump's era coverage, and which I believe, through the lens of "hacktology," are in need of further research.

\section{Twitter's Anti-and Pro-bots}

Twitter emerges as one of the winners in the era of Trump, and journalism practitioners lean on Twitter. With Trump's rise to power, journalism practitioners for the first time find social media as the main source of news when covering the leader of the mightiest nation in the world. Twitter is probably Trump's main arena to air his voice. The media strive to unravel Trump's practice of early morning tweets that have taken traditional journalism practices by surprise (Cassidy, 2016). The press analyzes, interprets, and categorizes Trump's penchant for early morning tweets through recourse to unhinged frames. Most of Trump's tweets fall under the category of irrelevant hypotheticals in which he "conjures up imaginary cases that are barely conceivable" (Thaler, 2016). One good example is Trump's famous "Covfefe" Tweet, which though an apparent typo, shows a propensity towards a social reality with certain orientations. The BBC (2017), in its coverage of the world interest in Trump's "Covfefe," says the invented and imaginary word was close to melting the internet and tearing it apart. 
Journalism practitioners find themselves in the midst of a multifaceted Twitter storm, which Trump initiates, and an environment in which bots, whether hostile or friendly, intensify. Digital communication systems are in the midst of what one may call "a bots revolution" fueled by bot armies who are shaping campaigns on Twitter, other social media outlets, and influencing news practice as well as the comment pages of newspapers. The bots are no longer a phenomenon restricted to social media. Although most of bots are the product of software applications running automated scripts, they fuel mainstream press interest, prompting journalism practitioners to make them part of content in their coverage of stories trending on social media (Jones, 2017). Bots took a new turn with Trump's ascent to power. According to Steve Dempsey (2016) of The Irish Independent, they have become a hot topic for both digital technology, and the media and at the same time have started influencing media practice.

\section{Vitriolic Discourse}

One can make a few insightful observations about the nature of what I call "vitriolic discourse" practice. Trump-related media discourse is personalized and vitriolic at the same time. It is occasionally cheap and mostly negative, particularly in the spats pitting him against the mainstream liberal media. I call it "vitriolic discourse," because it obscures truth and deflects attention from the target of criticism (Trump, himself), by resorting occasionally to blunt and direct Twitter diatribes. "Vitriolic discourse" turns serious coverage, a cornerstone of which is holding power to account, into cheap, negative, crude, and personalized discursive practice. "Vitriolic discourse" forces prominent officials and prominent media to engage in discursive practices that are beneath their standing, paying no heed to decorum and expression of politeness verbally or in writing. "Vitriolic discourse" usually involves two prominent opposing poles, but in the case of Trump, it is the world's most prominent and most powerful personality deriding the mainstream media and much less prominent people who are not of his caliber. Finally, "vitriolic discourse" booms in politically charged situations.

A careful examination of the press coverage in Trump's era will show that "vitriolic discourse" has become a striking feature and practice of the press. The most recent example occurred when Trump responded with vitriolic Twitter diatribes to the co-presenters of the MSNBC breakfast show, which has continuously been mocking the U.S. president. Mika Brzezinski and Joe Scarborough, in one of their June 2017 shows, called Trump a "bumbling dope" and likened him to "a kind who pooped in his pants." They also derided his staff as "lobotomized." Trump's Twitter response was vitriolic, harsh, cheap, and personalized. He called Brzezinski "low IQ crazy Mika," pointed to her "bleeding 
badly from a facelift," and struck out at her co-presenter Scarborough (Stelter, 2017; Thrush \& Haberman, 2017). The dual "vitriolic discourse" earned extensive coverage.

\section{Collusion}

The Trump era has thrust the press, and particularly its investigative arm, into the sort of coverage and journalistic practice in which reporters themselves raise doubts about the authenticity, credibility and impartiality of their own coverage. There is much talk about "collusion" in the press and the attempt to spread lies. There are allegations, mainly in liberal press, of Fox News colluding with Trump administration even at the expense of promulgating "a malicious lie" (Rajan, 2017). On the other hand, there are counter-allegations of anti-Trump media colluding with liberal groups and personalities. CNN was found to have fed presidential debate questions to Trump's rival, Hillary Clinton (Schultz, 2016).

\section{Vulgar Discourse}

The Trump era has ushered in a torrent of vulgar discourse, which the press has covered extensively. Some outlets, known for their refined discourse, focus on the occasional vulgar tirades of Trump's administration and even cross their ethical lines in bringing them to the public's attention as was the case with Scaramucci's "furious, foul-mouthed attack on White House rivals" (Smith, 2017). Examples of Trump's discursive fury represented in his uttering or tweeting rude and extraordinary attacks are plenty the last of which he launched against MSNBC host Mika Brzezinski (Buncombe, 2017). The Guardian's columnist Jonathan Freedland (2017) has described the vulgar discourse from Trump and some of his officials, and which has found its way into the news practices, as "expulsive behavior," saying that the conduct "needs to be shaped into a coherent political argument." The anti-Trump media is of course not innocent and reporters, particularly opinion writers, may descend to what the Trump camp sees as "profanity discourse" when covering the president. University of California Riverside and CNN's Reza Aslan resorted to swearing at Trump when tweeting and was forced to apologize for the profanity (Tadayon, 2017).

\section{Leaks and Hacks as "Journalistic Culture"}

The number of leaks during the Trump era is staggering. If hacking, allegedly by Russia, has thrown the Trump administration into disarray, leaks have thrust it into an embarrassing situation of ineffectiveness and malfeasance (Kinery, 2017). Leaks and hacks have prompted action on the part of the Trump administration and at the same time have led 
to the emergence of specific journalistic practices on how to deal with them. The embarrassing disclosures have compelled the U.S. attorney general to charge four people over leaks and contemplated issuing subpoenas to the news media (Savage \& Sullivan, 2017).

Hackers and leakers seek information which authorities hold secret or confidential. The pattern is for hackers to share the information with the media for public interest. However, it is wrong to believe that hackers' aims are always to get at secrets and divulge them for public interest. Jones (2017) notes a shift in hacking "toward espionage-for-hire." A good case in point, according to Jones, is the hacking of Qatari's news agency's website to publish stunning content and attributing it to the country's emir. In the "fake" report posted on the Qatari news agency, the emir was quoted as recommending approaching Iran, praising Palestinian groups the U.S. brands 'terrorist', citing "tensions" with Trump administration and showing that he is friendly to Israel. The report, though proved to be fake and posted after the hacking of Qatari news agency website, sparked a diplomatic row that led to four Arab states withdrawing their ambassadors from Qatar and imposing punitive sanctions on the emirate.

The news media, for which gathering information is a basic value and method, are generally happy with the abundance of hacks, and leaks and the culture they have ushered in in news reporting. The Qatar spat, which essentially originated through hacking, is part of an "information war" in which the spate of high-profile hacks has become among the main actors in the provision of information (Jones, 2017).

\section{Comparative Discourse}

With Trump, we see a focus on a journalistic practice that relies on comparative news discourse. Reporters use discursive parallels and comparisons in a bid to put Trump's tweets and practices in context. There are, for instance, comparisons between Trump, his obedient associates and cabinet members with "Beijing-like obeisance" (Fish, 2017). Fish (2017) draws parallels between "Emperor Trump's sycophantic cabinet ... staff members and even some Republican lawmakers" who find it part of their job to praise the president publicly. Mainstream media's emphasis on discursive parallels with China are most interesting.

The press occasionally depicts actions and statements by Trump's cabinet officials and staff members, including a few Republicans as reminiscent of the Chinese practice of kowtowing, which required touching the ground with one's forehead in deference to the emperor. It draws parallels between some public statements by some of Trump's senior officials and public statements by counterparts in China, who always attribute achievements to the wisdom and sound leadership of the man at the helm of the Chinese communist party. As Fish (2017) writes: "The modern American act of kowtowing requires absurdly praising 
President Donald Trump" in response to his "prodding his underlings in Washington towards Beijing-like levels of obeisance, opacity, prevarication and corruption."

\section{Mocking Discourse}

There are attempts at mocking or mimicking Trump discursively not only by the press but also by foreign government leaders and staff, particularly in Scandinavia. Two pictures, one depicting a meeting by a Swedish government official and another by Nordic leaders are reported to have been arranged in a manner in which participants discursively ridicule Trump in photographs mock his cabinet meetings or his encounter with Middle East leaders (Reilly, 2017a; 2017b). Reporters examine Trump's pictures, gestures, and videos, his discourse in general, and see them as metaphors, which they try to interpret to guess his plans and strategy (Beauchamp, 2017). The practice, which I call "mocking discourse," occupies a prominent position in press coverage.

The practice is two-ways. Sometimes, Trump initiates the practice; evidenced by his mocking of a New York Times reporter with a disability, the practice that spawned an avalanche of press coverage (Camron, 2016). Trump has likewise provided U.S. talk shows with plenty of information that has revitalized the late-night programs, with the practice propelling some hosts to international limelight (Stolworth, 2016).

\section{"Inventory" Discourse}

Journalism practice in the Trump era has concentrated on what one might call "inventory discourse," or discourse of listing. Mainstream media now and then produce content in which they first provide an introduction on the topic of the inventory they are writing about and then bullets or lists "inventory" of recurrent themes in Trump discourse. Major media outlets have inventories, which they update regularly on following themes.

This list is not exhaustive, but includes Trump's:

- $\quad$ lies (Leonhardt \& Thompson, 2017)

- attacks on the media (Khazan, 2017)

- "dirty words" (Zurcher, 2017a)

- offensive comments on women (Cohen, 2017)

- “most outrageous" sayings (Marie Clair, 2017)

- most "scariest things" he has ever said (Atkin, 2016)

- sayings that "would have doomed" others (Bump, 2016)

- sayings about Putin (Kaczynski, Massie, \& McDermott, 2017)

- "dumbest" sayings (Mahalia, 2017)

- craziest things (Glass, 2015)

- sayings about Muslims (Zurcher, 2017b)

- most "outrageous" sayings on Latinos (Moreno, 2016) 
Newspapers present "justification" for providing these inventories, which they update regularly. Politico, for example, says media's interest in Trump's "falsehoods" and the attempt to have them catalogued is due to their "sheer frequency, spontaneity and seeming irrelevance". Trump's "lies", the magazine adds, "come not singly but in constant stream" (Konnikova, 2017).

The news practice of "inventory discourse" relies heavily on databases to produce running lists of "Trump's lies and other bullshit" with a vow to keep track of any untrue statements he makes in the future (Georgantopoulos, 2017). Digitization has helped the media to provide inventories of different sorts. For example, The New York Times' stock list of "lies" has a variety of discursive features demonstrating a skillful use of the internet and ushering in a new practice in journalism which one may label as "inventory discourse." (Leonhardt \& Thompson, 2017). Its major discursive features include short sentences, nominalizations, quotes, strings of noun phrases as well as reliance on color and other orthographic features language provides like italics and bold types. The discourse itself is distinctive as it economizes on the use of words, producing the type of content that is more relevant and suitable to headline writing.

The other important feature is that the inventory-style story is left open in the sense that the editors add to the inventory any "lies," old and new, they can verify or Trump might make. The Times verifies every instance of a "lie" or "falsehood" in its inventory, providing the hyperlink, the date, the place and event during which it was uttered, and links to information demonstrating why the newspaper sees the statement as a "lie." However, the editors decide to categorize the piece under "Opinion" and not news, features, or current affairs. The Times explains to its readers the reason for publishing the inventory:

Many Americans have become accustomed to President Trump's lies. But as regular as they have become, the country should not allow itself to become numb to them. So we have catalogued nearly every outright lie he has told publicly since taking the oath of office. Leonhardt and Thompson (2017)

The newspaper likewise attempts to define the word "lie," a practice which other newspapers adopt in similar pieces: "We are using the word 'lie' deliberately," the Times writes and adds: "Not every falsehood is deliberate on Trump's part. But it would be the height of naïveté to imagine he is merely making honest mistakes. He is lying” (Leonhardt and Thompson, 2017).

\section{Body Language Discourse}

A politician's body language has probably not been as politically and psychologically important as with President Trump. A stream of articles 
follows any handshake or other conscious or even unconscious movements, including gestures, postures, facial expressions, mannerisms, and even innuendos that reporters catch on camera. Occasionally, the press shows more interest in what Trump may communicate through his body language than through his words. "With Trump, struts, scowls and pouts reveal every bit as much as what tumbles from his lips, which is a lot less trustworthy," writes Frank Bruni (2017) with The New York Times. "His words can be counterfeit. His gestures are genuine." For instance, Trump's handshakes with world leaders attract wide range coverage, which, if discursively analyzed, may reveal some salient discursive features of their own. One handshake, which went viral in the press, generating extensive coverage, is the one he had with the French President Emmanuel Macron (Cummings, 2017; Friedman, 2017; Holmes, 2017; Uri, 2017).

\section{Trump's Linguistics}

The press devotes large spaces to discuss and interpret Trump's linguistics. A glance at reporting involving Trump's language reveals a practice with some discursive points of its own. There is for instance the issue of "mystery" terms, which he coins himself, and sometimes have the internet and online press creaking out. A good case in point is his tweeting of "covefefe" that caused a Twitter frenzy and made the word a number-one topic on the microblog (Fox News, 2017). Trump's misspellings, unconventional capitalizations, unusual use of quotation marks, excessive and unconventional use of punctuation, bizarre spellings, and grammar errors have also become a topic of interest to the mainstream press (North, 2017).

Trump's use of language has likewise provided the press with the opportunity to delve into Trump's thinking and mentality through a discursive or psychological analysis of his unconventional use of language (Conrad, 2017). The press borrows from linguists and social justice movements with terms like "noun-free syntax, gibberish, rhetorical style, untethered from both meaning and reality, frivolous abstraction, political correctness" in its textual analysis of Trump's language (West, 2017).

Trump is known for using his Twitter feeds to react to his critics, often through harsh language, sometimes replete with threats and taunts. Tweets like these have become a good source of information for the press and particularly analysis and opinion pieces. Reporters go to lengths in analyzing Trump's language, which they describe as "muscular," "untampered," "unrestrained," "fiery," "jingoistic," "over the-top rhetoric," "kind of blustery and provocative," and "inflammatory". (Blow, 2017a, 2017b; Davis, 2017). 


\section{Conclusion}

The news media mirror the political systems in which they operate. It is no exaggeration to say Western democracies are passing through a tumultuous political period. And there is no doubt that the media are in the throes of turbulent times. A theory of haktology may help us understand both systems better. The discussion in this chapter has revealed the emergence of news practices with a bearing on hacks and leaks as well as the ascendance of President Donald Trump to power. These media practices, along with hacks and leaks and the role of the Internet have opened new paths for academic research that may keep media scholars busy for generations to come.

\section{References}

Allcott, H., \& Gentzkow, M. (2017). Social media and fake news in the 2016 election. Journal of Economic Perspectives, 31(2), 211-236.

Atkin, C. (2016, May 6). Donald Trump quotes: The 10 scariest things the presumptive republican nominee has ever said. The Independent. Retrieved at www.independent.co.uk/us/donald-trump-quotes-the-10-scariest-things-thepresumptive-republican-nominee-has-ever-said-a7015236.html.

Barkho, L. (2017). Towards a theory of "haktology." Journal of Applied Journalism \& Media Studies, 6(1), 3-10.

BBC. (2017, May 31). 'Covfefe': Trump invents new word and melts internet. $B B C$. Retrieved at www.bbc.com/news/world-us-canada-40104063.

Beauchamp, Z. (2017, May 22). The hilarious Trump orb photo is a nearly perfect metaphor for his foreign policy. Vox. Retrieved at www.vox.com/ world/2017/5/22/15674782/trump-orb-what.

Beckwith, J., \& Sorscher, N. (2016). Trump and the media: A text analysis. The Data Face. Retrieved on September 1, 2017 at http://thedataface.com/ trump-media-analysis.

Blow, C. M. (2017a, July 17). Trump savagely mauls the language. The New York Times. Retrieved at www.nytimes.com/2017/07/17/opinion/donald-trumpenglish-language.html.

Blow, C. M. (2017b, May 1). Trump's degradation of the language. The New York Times. Retrieved at www.nytimes.com/2017/05/01/opinion/donaldtrump-degradation-of-the-language.html.

Borden, S. L., \& Tew, C. (2007). The role of journalist and the performance of journalism: Ethical lessons from "fake news" (Seriously). Journal of Mass Media Ethics, 22(4), 300-314.

Bruni, F. (2017, May 26). The awkward body language of Donald Trump. The New York Times. Retrieved at www.nytimes.com/2017/05/26/opinion/sunday/ the-awkward-language-of-donald-trumps-body.html?_r=0.

Bump, P. (2016, July 17). 23 things Donald Trump has said that would have doomed another candidate. The Washington Post. Retrieved at www.washingtonpost. com/news/the-fix/wp/2016/06/17/23-things-donald-trump-has-said-that-wouldhave-doomed-another-candidate/?utm_term=.3abc98866477. 
Buncombe, A. (2017, June 29). Donald Trump accuses ‘crazy' MSNBC host Mika Brzezinski of 'bleeding badly from a face-lift.' The Independent. Retrieved at www.independent.co.uk/news/world/americas/us-politics/donaldtrump-morning-joe-hosts-twitter-mika-brzezinski-mar-a-lago-face-lift-joescarborough-a7814731.html.

Camron, I. (2016, August 11). Donald Trump's worst offense? Mocking disabled reporter, poll finds. $A B C$ NEWS. Retrieved at www.nbcnews.com/ politics/2016-election/trump-s-worst-offense-mocking-disabled-reporterpoll-finds-n627736.

Cassidy, J. (2016, September 30). The meaning of Trump early-morning tweet storm. The New Yorker. Retrieved at www.newyorker.com/news/johncassidy/the-meaning-of-trumps-early-morning-tweet-storm.

Cockburn, P. (2016, December 16). There is more propaganda than news coming out of Aleppo this week. The Independent. Retrieved at www.independent. co.uk/voices/aleppo-crisis-syrianwar-bashar-al-assad-isis-more-propagandathan-news-a7479901.html.

Cohen, C. (2017, July 14). Donald Trump sexism tracker: Every offensive comment in one place. The Telegraph. Retrieved at www.telegraph.co.uk/ women/politics/donald-trump-sexism-tracker-every-offensive-commentin-one-place.

Conrad, P. (2017, May 9). How Trump thinks: His tweets and the birth of a new political language. The Guardian. Retrieved at www.theguardian.com/ books/2017/may/09/how-trump-thinks-tweets-birth-new-political-languagepeter-oborne-tom-roberts-review.

Copps, G. (2017, January 24). Theresa, Trump and textual analysis. Mediatel Newsline. Retrieved at http://mediatel.co.uk/newsline/2017/01/24/ theresa-trump-and-textual-analysis.

Cummings, W. (2017, July 14). Trump and Macron share their strangest handshake yet. USA Today. Retrieved at www.usatoday.com/story/news/politics/ onpolitics/2017/07/15/trump-macron-handshake/481465001.

Davis, J. H. (2017, August 8). Trump's harsh language on North Korea has little precedent, experts say. The New York Times. Retrieved at www. nytimes.com/2017/08/08/us/politics/trumps-harsh-language-on-northkorea-has-little-precedent-experts-say.html?hp\&action=click\&pgtyp $\mathrm{e}=$ Homepage $\&$ clickSource $=$ stor $y$-heading $\&$ module $=b$-lede-package region\&region=top-news\&WT.nav=top-news\&_r=0.

Dempsey, S. (2016, April 17). Are bots the next big thing in marketing and media - or just more hot air? Irish Independent. Retrieved at www.independent.ie/business/media/are-bots-the-next-big-thing-in-marketing-and-mediaor-just-more-hot-air-34633090.html.

Dewey, C. (2016, November 17). Facebook fake-news writer: 'I think Donald Trump is in the white house because of me.' The Washington Post. Retrieved at www.washingtonpost.com/news/the-intersect/wp/2016/11/17/facebookfake-news-writer-i-think-donald-trump-is-in-the-white-house-because-ofme/?utm_term=.149828b7d552.

Eggen, D. (2006, March 5). White house trains efforts on media leaks. The Washington Post. Retrieved at www.washingtonpost.com/wp-dyn/content/ article/2006/03/04/AR2006030400867.html.

Espinoza, R. (2017, June 18). Donald J. Trump presidential Twitter library a smash for 'The Daily Show.' Forbes. Retrieved at www.forbes.com/sites/ 
russespinoza/2017/06/18/donald-j-trump-presidential-twitter-library-asmash-for-the-daily-show/\#66c467aa6e0c.

Fish, I. S. (2017, June 13). Emperor Trump's sycophantic cabinet meeting stinks of Beijing-like obeisance. The Guardian. Retrieved at www.theguardian. com/commentisfree/2017/jun/13/emperor-trumps-sycophantic-cabinetmeeting-stinks-beijing-obeisance.

Fisk, R. (2016, December 29). We are not living in a 'post-truth' world, we are living the lies of others. Independent. Retrieved at www.independent.co.uk/ voices/donaldtrump-post-truth-world-living-the-lies-of-others-a7500136.html.

Fox News. (2017, May 31). Trump tweets 'covfefe,' causes Twitter frenzy. Fox News. Retrieved at www.foxnews.com/politics/2017/05/31/trump-tweets-covfefecauses-twitter-frenzy.html?utm_source=feedburner\&utm_medium=feed\&utm_ campaign $=$ Feed $\% 3 \mathrm{~A}+$ foxnews $\% 2$ Fpolitics+ $\% 28$ Internal+-+Politics +-+ Text $\% 29$.

Freedland, J. (2017, July 28). With Trump it's time to go beyond mere disgust. The Guardian. Retrieved at www.theguardian.com/commentisfree/2017/ jul/28/trump-disgust-president-repulsive-behaviour.

Friedman, U. (2017, July 14). The Trump-Macron handshake: A play in four acts. The Atlantic. Retrieved at www.theatlantic.com/international/ archive/2017/07/trump-macron-handshake/533688.

Garrido, D., \& Chung, A. (2017, June 3). Trump provokes anger over mock video showing him 'beating CNN.' Sky News. Retrieved at http:// news.sky.com/story/cnn-accuses-trump-of-encouraging-violence-againstreporters-10934472.

Georgantopoulos, M. A. (2017, March 20). Here's a running list of President Trump's lies and other bullshit. BuzzFeed. Retrieved at www.buzzfeed.com/ maryanngeorgantopoulos/president-trump-lie-list?utm_term=.uyzkxLOzx\#. jxo3АMyjA.

Glass, N. (2015, July 7). The 7 craziest things Trump has said. Politico. Retrieved at www.politico.com/story/2015/12/donald-trump-ban-muslims-216513.

Gottfried,J., \&Shearer,E.(2016, May 26). News use across social media platforms 2016. Retrieved at www.journalism.org/2016/05/26/news-use-across-socialmedia-platforms-2016.

Graham, C. (2017, July 2). 'Modern day presidential': Donald Trump defends use of social media in Twitter storm. Daily Telegraph. Retrieved at www. telegraph.co.uk/news/2017/07/01/modern-day-presidential-donald-trumpdefends-use-social-media.

Gunkel, D. J. (2005). Editorial: Introduction to hacking and hacktivism. New Media \& Society, 7(5), 595-597.

Holmes, J. (2017, July 14). Shake hands like a normal person. Esquire. Retrieved atwww.esquire.com/news-politics/videos/a56326/trump-macron-handshake.

Jaworski, A., Fitzgerald, R., \& Morris, D. (2004). Radio leaks: Presenting and contesting leaks in radio news broadcasts. Journalism, 5(2), 183-202.

Jones, M. (2017, June 7). Hacking, bots and information wars in the Qatar spat. The Washington Post. Retrieved at www.washingtonpost.com/news/ monkey-cage/wp/2017/06/07/hacking-bots-and-information-wars-in-theqatar-spat/?utm_term $=.640050 \mathrm{dc} 5 \mathrm{ab} 8$.

Kaczynski, A., Massie, C., \& McDermott, N. (2017, March 3). 80 times Trump talked about Putin. CNN. Retrieved at http://edition.cnn.com/ interactive/2017/03/politics/trump-putin-russia-timeline. 
Khaldarova, I., \& Pantti, M. (2016). The narrative battle over the Ukrainian conflict. Journalism Practice, 10(7), 891-901.

Khazan, O. (2017, January 23). What Trump could mean for journalism. The Atlantic. Retrieved at www.theatlantic.com/international/archive/2017/01/ what-trump-means-for-journalism/514160.

Kinery, E. (2017, August 4). As Jeff Sessions announces leak crackdown, here are 12 major leaks of the Trump era. The Washington Post. Retrieved at www. usatoday.com/story/news/politics/onpolitics/2017/08/04/here-12-majorleaks-donald-trump-era/539674001.

Konnikova, M. (2017, January/February). Trump's lies vs. your brain. Politico. Retrieved at www.politico.com/magazine/story/2017/01/donald-trumplies-liar-effect-brain-214658.

Kucharski, A. (2016, December 21). Post-truth: Study of epidemiology of fake news. Nature. Retrieved at www.nature.com/nature/journal/v540/ n7634/full/540525a.html?WT.feed_name=subjects_epidemiology $\&$ foxtrotcallback=true.

Leonhardt, D., \& Thompson, S. (2017, June 23). Trump's lies. The New York Times. Retrieved at www.nytimes.com/interactive/2017/06/23/opinion/100000005182490.mobile.html.

Lievrouw, L. (2011). Alternative and Activist New Media. Oxford, UK: Polity. Marchi, R. (2012). With Facebook, blogs, and fake news, teens reject journalistic "objectivity." Journal of Communication Inquiry, 36(3), 246-262.

Marie Claire. (2017, July 29). Yes, The President of the United States really has said this. Marieclaire. Retrieved at www.marieclaire.co.uk/entertainment/ people/donald-trump-quotes-57213.

McBeth, M. K., \& Clemons, R. S. (2011). Is fake news the real news? The significance of Stewart and Colbert on democratic discourse, politics, and policy. In A. Amarasingam (Ed.), The Stewart-Colbert effect: Essays on the real impact of fake news (pp. 63-78). Jefferson, NC: McFarland.

McDonnell, J. (2016, October 4). Quality journalism vs. the clickbait culture. The Odyssey Online. Retrieved at www.theodysseyonline.com/qualityjournalism-clickbait-culture.

More, S. (2016, November 14). With Steve Bannon, Trump signed up the meme-makers of misogyny. The Guardian. Retrieved at www.theguardian. com/commentisfree/2016/nov/14/steve-bannon-trump-misogyny-roev-wade-threat.

Moreno, C. (2016, November 9). 9 outrageous things Donald Trump has said about Latinos. Huffington Post. Retrieved at www.huffingtonpost. com/entry/9-outrageous-things-donald-trump-has-said-about-latinos_us_ 55e483a1e4b0c818f618904b.

Nah, S., \& Chung, D. S. (2012). When citizens meet both professional and citizen journalists: Social trust, media credibility, and perceived journalistic roles among online community news readers. Journalism, 13(6), 714-730.

North, A. (2017, May 31). Donald Trump's Twitter comedy. The New York Times. Retrieved at www.nytimes.com/2017/05/31/opinion/donald-trumps-twittercomedy.html action $=$ click \&pgtype $=$ Homepage $\&$ clickSource $=$ story-heading $-\&$ module=opinion-c-col-right-region \& region=opinion-c-col-right-region $\& \mathrm{WT}$. nav=opinion-c-col-right-region. 
Oates, S., \& Moe, W. W. (2016). Donald Trump and the 'oxygen of publicity': Branding, social media, and mass media in the 2016 presidential primary elections. Paper prepared for the American Political Science Association Annual Meeting 2016. Retrieved at https://ssrn.com/abstract=2830195 or http:// dx.doi.org/10.2139/ssrn.2830195.

Parkinson, H. J. (2016, November 14). Click and elect: How fake news helped Donald Trump win a real election. The Guardian. Retrieved at www.theguardian.com/commentisfree/2016/nov/14/fake-news-donaldtrump-election-alt-right-social-media-tech-companies.

Pasha-Robinson,L.(2017, April28). Breaking down the 500 tweets Donald Trump has sent in his first 100 days as president. Independent. Retrieved at www. independent.co.uk/news/world/americas/us-politics/donald-trump-100-daysus-president-twitter-social-media-communications-a7704371.html.

Paulussen, S., \& Ugille, P. (2008). User generated content in the newsroom: Professional and organisational constraints on participatory journalism. Westminster Papers in Communication and Culture, 5(2), 24-41.

Pew Research Center. (2016). Ideological placement of each source's audience. Pew Research Center. Retrieved at www.pewresearch.org/pj_14-10-21_ mediapolarization-08-2.

Puustinen, L., \& Seppänen, J. (2011). In amateurs we trust: Readers assessing non-professional news photographs. In K. Andén-Papadopoulos and M. Pantti (Eds.), Amateur images and global news (pp. 175-192). Bristol, UK \& Chicago, IL: Intellect.

Rajan, A. (2017, August 8). Fox News, Hannity and the meaning of 'collusion.' BBC. Retrieved at www.bbc.com/news/entertainment-arts-40856436.

Reilly, K. (2017a, February 4). Swedish deputy prime minister appears to mock president Trump with all-female photo. Fortune. Retrieved at http://fortune. com/2017/02/04/swedish-deputy-prime-minister-all-women-trump.

Reilly, K. (2017b, July 14). See the evolution of Donald Trump and Emmanuel Macron's awkward handshakes. Time. Retrieved at http://time.com/4856558/ donald-trump-emmanuel-macron-handshake-evolution.

Roberts, A. (2012). WikiLeaks: The illusion of transparency. International Review of Administrative Sciences, 78(1), 116-133.

Robinson, D. (2016). Text analysis of Trump's tweets confirms he writes only the (angrier) Android half. Variance Explained. Retrieved at http://varianceexplained.org/r/trump-tweets.

Savage, C., \& Sullivan, E. (2017, August 4). Leak investigations triple under Trump, sessions says. The New York Times. Retrieved at www.nytimes. com/2017/08/04/us/politics/jeff-sessions-trump-leaks-attorney-general.html.

Schultz, M. (2016, October 31). CNN drops Brazile for feeding debate questions to Clinton. New York Post. Retrieved at http://nypost.com/2016/10/31/ cnn-drops-brazile-for-feeding-debate-questions-to-clinton.

Schwalbe, C. B., Silcock, B. W., \& Candello, E. (2015). Gatecheckers at the visual news stream. A new model for classic gatekeeping theory. Journalism Practice, 9(4), 465-483.

Shane, S. (2017, January 18). From headline to photograph, a fake news masterpiece. The New York Times. Retrieved at www.nytimes.com/2017/01/18/us/ fake-news-hillary-clinton-cameron-harris.html. 
Silverman, C., \& Alexander, L. (2016, November 4). How teens in the Balkans are duping Trump supporters with fake news. BuzzFeed. Retrieved at www. buzzfeed.com/craigsilverman/how-macedonia-became-a-global-hub-for-protrump-misinfo?utm_term=.yf1W8rAYx\#.oe0RMLzwa.

Smith, D. (2017, July 28). Scaramucci in furious, foul-mouthed attack on White Houserivals. The Guardian. Retrievedatwww.theguardian.com/us-news/2017/ jul/27/anthony-scaramucci-white-house-reince-priebus-steve-bannon.

Sommers, J., \& Demianyk, G. (2017, February 16). Donald Trump had the most extraordinary press conference of his life, clearing a high bar. Huffington Post. Retrieved at www.huffingtonpost.co.uk/entry/donald-trump-press-conference uk_58a5eb5fe4b037d17d25d1ef.

Son, T. (2002). Leaks: How do codes of ethics address them? Journal of Mass Media Ethics, 17(2), 155-173.

Stelter, B. (2017, June 29). Trump tweets shocking assault on Brzezinski, Scarborough. CNN. Retrieved at http://money.cnn.com/2017/06/29/media/mikabrzezinski-donald-trump-tweet/index.html.

Stolworth, J. (2016, February 16). Donald Trump helps Stephen Colbert become most-watched late-night talk show host. Independent. Retrieved at www. independent.co.uk/arts-entertainment/tv/news/donald-trump-stephencolbert-late-night-us-talk-show-jimmy-fallon-a7582986.html.

Tadayon, A. (2017, June 4). Reza Aslan of CNN and UC Riverside apologizes for swearing at Trump on Twitter. The Press Enterprise. Retrieved at www. pe.com/2017/06/04/reza-aslan-of-cnn-and-uc-riverside-apologizes-forswearing-at-trump-on-twitter.

Thaler, M. (2016). Unhinged frames: Assessing thought experiments in normative political theory. British Journal of Political Science. doi: 10.1017/ S0007123416000259.

Thrush, G., \& Haberman, M. (2017, June 29). Trump mocks Mika Brzezinski; says shewas 'bleeding badly from a face-lift. The New York Times. Retrieved at www. nytimes.com/2017/06/29/business/media/trump-mika-brzezinski-facelift. html?_r=0.

Vegh, S. (2003). Hacking for democracy: A study of the internet as a political force and its representation in the mainstream media. American Quarterly, 55(4). Retrieved at https://search.proquest.com/openview/ce01cfbd4ec4 b85007ec4e7bfcf15ca9/1?pq-origsite $=$ gscholar $\& \mathrm{cbl}=42071$.

West, L. (2017, April 25). 100 days of gibberish - Trump has weaponised nonsense. The Guardian. Retrieved at www.theguardian.com/commentisfree/2017/apr/25/trump-100-days-gibberish-weaponised-white-houselanguage-presidency.

Zhong, W. (2016, April 14). The candidates in their own words: A textual analysis of 2016 Presidential primary debates. AEI Economic Perspectives. Retrieved at www.aei.org/wp-content/uploads/2016/04/The-candidates-intheir-own-words.pdf.

Zurcher, A. (2017a, July 2). Why CNN 'assault' tweet should surprise no-one. BBC. Retrieved at www.bbc.com/news/world-us-canada- 40475448 .

Zurcher, A. (2017b, February 7). What Trump team has said about Islam. BBC. Retrieved at www.bbc.com/news/world-us-canada-38886496. 


\section{Part II}

\section{Journalism during Difficult Discourse}




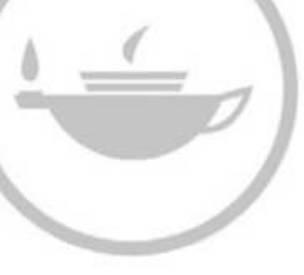

Taylor \& Francis Taylor \& Francis Group

http://taylorandfrancis.com 


\title{
5 Who, From Where? TV \\ Network News Coverage of Immigration Narratives during Trump's First 100 Days
}

\author{
Jennifer Hoewe, Geri Alumit Zeldes, \\ and Brian J. Bowe
}

Less than a week after he took office, U.S. President Donald Trump addressed a gathering at the Department of Homeland Security (DHS). Signaling one of the signature priorities of his young administration, he told the gathered crowd that "a nation without borders is not a nation" (Parker, Nakamura, \& Rucker, 2017, para. 18). In the first 100 days of Trump's presidency, he began to make good on some of his highly controversial campaign promises related to tightening immigration policies.

In his campaign rhetoric, Trump rebuked the seemingly softer mandates of President Barack Obama. However, the reality on the ground was more complicated. Obama was no immigration dove - he was known in some circles as the "Deporter-in-Chief" for his strong focus on deporting gang members, felons, and those identified as security risks. Obama moderated that position by delaying the deportation of those without criminal records. Beginning in January 2017, Trump issued a series of executive orders that allocated more resources to the DHS and directed Immigration and Customs Enforcement (ICE) agents to expand deportation efforts and tighten immigration controls. Trump's deportation directives targeted unauthorized immigrants regardless of lawlessness and vowed to do away with the "catch and release" policy that resulted in capturing then releasing unauthorized immigrants while they awaited the results of asylum requests.

Shortly after winning the presidential election, Trump promised to deport two to three million undocumented immigrants with criminal records in what would have amounted to a stunning increase in deportees. Yet from January 20 until March 13, 2017, ICE deported 54,741 undocumented immigrants, which amounted to a 1.2 percent decrease in the number of undocumented immigrants deported during the same period in 2016 under Obama (Gidda, 2017). Two of Trump's executive orders impacted mostly nationals from Mexico. However, Executive Order 13769 ("Protecting the Nation from Foreign Terrorist Entry into the United States") - known in many circles as the "Muslim ban" - also required ICE agents to single out nationals from several other countries: Iran, Iraq, Libya, Somalia, Sudan, Syria, and Yemen (Kulish et al., 2017; Sargent, 2017). 
Because journalists play a key role in providing interpretive cues to audience members about contentious social issues such as immigration, it is important to unpack the way information is relayed to the public through the news. This chapter examines television news coverage of immigration and deportation policies in President Trump's first 100 days in office. It also looks at the differences among the major TV networks in their coverage of Trump's directives.

The chapter focuses on the three legacy U.S. television networks $\mathrm{ABC}, \mathrm{CBS}$, and NBC - because they remain a key journalistic source of governmental information and a primary source for news consumption, even though the public's media options have expanded to include internet news sites, mobile media, and social media. In its examination of Nielsen Media Research data, the Pew Research Center reported that the combined viewership of the networks remained steady in 2016 from the previous year at 24 million (Network News Fact Sheet, 2017). For comparison purposes, the major cable news channels - CNN, Fox News, and MSNBC - had a combined viewership of 5 million in 2016 (Pew Research Center, 2017); in fact, advertising revenue for the traditional broadcast networks grew by 12 percent when compared to the previous year (Network News Fact Sheet, 2017). As such, this research will examine how the legacy networks under study covered President Trump's stance on immigration and if that coverage differed among the networks, revealing any possible political and/or topical biases.

Previous research on ABC, NBC, CBS and the cable networks suggests that each has its own distinct pattern of coverage, even providing more coverage of one political party than another (Diddi, Fico, \& Zeldes, 2014; Rosenstiel, Mitchell, \& Jurkowitz, 2012; Schaefer \& Fordan, 2014). TV news content can influence voter decisions. Gross, Porter, and Wood's (2017) research showed those who watched debate and post-debate coverage on Fox News and MSNBC - especially moderate partisans - assessed the performance of the supported by that particular network more favorably, and those perceptions lingered for more than a week. Martin and Yurukoglu (2017) found those who watched Fox News an extra 2.5 minutes each week increased the likelihood to vote for a Republican by 0.3 points.

Another reason to analyze TV news coverage is to scientifically examine content for narrative patterns and ideological bents, as research indicates Americans believe the "liberal" news media are biased against Trump. An NBC News/Wall Street Journal survey showed 51 percent found coverage of the president "too critical" and 53 percent found coverage exaggerated missteps by the Trump administration. Moreover, separate studies, one at Harvard and the other conducted by the Media Research Center (a politically conservative nonprofit organization that content analyzes media), reported that more than 80 percent of news coverage in Trump's first 100 days in office was negative, even "hostile" 
toward the president (Harper, 2017). Given this body of prior research indicating the differing coverage among networks, this analysis will provide context for their coverage of immigration during Trump's first 100 days in office.

\section{Immigration and Deportation - Debates}

The issue of immigration within the United States reached a fevered pitch during the 2016 presidential election cycle, emerging as one of the most salient issues for voters, particularly among Republicans (Huang, Jacoby, Strickland, \& Lai, 2016; Pew Research Center, 2016). In fact, some research suggests the two major party candidates in 2016 Republican Trump and Democrat Hillary Clinton - used their most polarized language of the campaign on issues related to immigration, with Trump using overwhelmingly negative terms and Clinton using a similar degree of positive language (Vasile, 2017).

Anxieties about immigration are nothing new for the American public, as the issue has been identified in polls as one of the top five problems facing Americans every month for nearly two decades (Newport \& Brands, 2016). Felter and Renwick (2017) contextualized the immigration debate as a decades-long Congressional failure to enact comprehensive immigration reform, forcing the judicial and executive branches to fill this gap. The authors argued that the debate is highly contentious because of the difficulties in reconciling competing U.S. interests that include labor force needs as well as border and domestic security in an electorate with an increasing foreign-born population. Immigrants make up 13 percent - or 43 million people - of the U.S. population, and if one considers their American-born children, those figures rise to 27 percent, doubling the population. This number includes roughly 11 million individuals who are undocumented (Felter \& Renwick, 2017).

Internationally, immigration tends to be a topic that receives a great deal of attention from journalists, in part because of the inflamed emotions that accompany the issue. Previous research suggests that commercial television broadcasts tend to focus on the negative and sensational aspects of immigration and that audience members who prefer commercial to public broadcast outlets tend to hold more negative attitudes about immigration (Jacobs, Meeusen, \& d'Haenens, 2016). In the United States, Santa Ana (2016) found that network TV depictions of immigrants were informed by cinematic and literary myths of cowboy mavericks and intrepid goddesses, arguing "news reports present the events of the day by dressing up traditional morality tales that justify a political order" (p. 111).

World events may have heightened concerns about global migration in some parts of the U.S. electorate. In 2015, the world saw dramatic 
images of Syrian, Iraqi, and Afghan refugees risking - and sometimes losing - their lives crossing the Mediterranean in an attempt to reach Europe. More than a million refugees reached European soil that year, while 3,700 died in the process (Feinstein \& Storm, 2017). Media outlets heavily covered these heart-wrenching stories, exacting a heavy toll on some of the journalists reporting the story (Feinstein \& Storm, 2017). Adding to the media cacophony was a series of terrorist attacks in the United States and across Europe that rattled the public. Attacks in Paris, Brussels, Nice, San Bernardino, and Orlando were attributed to the terror groups known alternately as ISIS, ISIL, the Islamic State, or Daesh. Some commentators spuriously connected these attacks to the refugee crisis as they called for a forceful political response.

The relationship between the United States and Mexico has been tumultuous as well, including a recent push from President Trump to make the Mexican government pay for a wall between the two countries. This controversy brought increased attention to immigrants from that country. U.S. news media has not framed Mexican immigration in a positive light either. Prior research has shown that the news media perpetuates negative stereotypes related to Mexican immigrants, where these individuals are repeatedly mentioned alongside issues of crime, and the majority of the stories focus on Mexican immigrants without documentation (Chavez, Whiteford, \& Hoewe, 2010). Moreover, Chavez (2001) concluded that Mexican immigrants were portrayed in U.S. news magazines through "alarmist imagery" (p. 260).

If the immigration issue itself isn't new, the strongly nationalistic tone of the Trump administration in its response to the topic is a development that hasn't been seen in recent decades. Two of the main topics of immigration angst in the 2016 campaign and the early days of the Trump administration were related to Mexico and a variety of Muslim-majority nations.

\section{Immigration from Mexico - "Build the wall"}

One of Trump's signature campaign promises was that he would build a wall between Mexico and the United States' southern border. Chants of "build the wall" were common features of his campaign rallies as Trump decried the dangers posed by foreign drug traffickers and other threatening types - murderers and criminals and "bad hombres," as Trump referred to them (McCann \& Bromwich, 2016; Parker et al., 2017). These chants were symbols of a certain atavistic catharsis evident in the campaign rallies, rather than sober statements about a preferred policy. They established who belonged within the American in-group, and who was to be excluded. Leary (2017) noted that "the wall, in other words, is as much about who it keeps in as who it supposedly keeps out" (p. 146). 


\section{Muslim Migration - Fleeing War and Fears of Terrorism}

In addition to a proposal to build a wall on the Mexican border, one of the most provocative of Trump's policy proposals was to enact what he called on the campaign trail a "total and complete shutdown of Muslims entering the United States" (Zapotosky, 2017). The proposal was consistent with a growing preoccupation with the idea of "radical Islam" as a movement that poses an ideological threat to the security of the U.S. (Hoewe \& Bowe, 2017). Discussing the "hateful ideology of radical Islam," Trump told a campaign rally it should not be "allowed to reside or spread within our own communities" (Shane, Rosenberg, \& Lipton, 2017, para. 3).

\section{The State of News during the Trump Administration}

Faced with these polarizing issues, news consumers increasingly hunger for fair and balanced news coverage and are spending more time with media they agree with politically or believe have little bias (e.g., Hoffner \& Rehkoff, 2011; Kaye \& Johnson, 2016). The behavior to navigate toward news media in which individuals feel more ideologically matched with is a phenomenon across generations and political affiliations (Hoffner \& Rehkoff, 2011). Depending on how the question is asked, certain public opinion polls find trust in the news media has hit an all-time low and that attitudes are significantly different along party lines (Barthel \& Mitchell, 2017).

Several years after the Watergate scandal, a 1976 Gallup poll reported that 72 percent of Americans trusted newspapers, TV, and radio to report the news in a fair, balanced, and complete manner. That figured plummeted in 2016 to 32 percent, an all-time low (American Press Institute, 2017; Swift, 2016). Providing historical context to explain this decrease in trust, the American Press Institute (2017) found that in the 1980s and 1990s, cable news and talk radio became part of the news media family, slowly eroding trust to the 50-percentile mark. That decline continued in the 2000 s, reaching the 30-percentile range.

Partisan differences also are palpable, showing that only 14 percent of Republicans trust the news media - a deep divide echoed in a similar poll by the Pew Research Center (Barthel \& Mitchell, 2017). In 1985, the Center started asking Americans their thoughts on the watchdog function of the media. It asked "whether news organizations' criticism of political leaders primarily keeps them from doing things they shouldn't or keeps them from doing their job.” In 2017, 89 percent of Democrats believed in the new media's watchdog role, which is much higher than Republicans at 42 percent, making it the largest gap since the poll began (Barthel \& Mitchell, 2017). Given the historic lows in confidence in the news media, it is important to revisit the value system at the core of 
journalism reportage that explores how journalism is made and whether U.S. journalists are covering certain countries because of closeness to country borders and if organizational influences, particularly at the TV networks, are influencing news coverage.

\section{From Media Provocateur to President: Making News}

Like P.T. Barnum in the nineteenth century, Trump created a spectacle during the presidential campaign, and current political communication researchers are congregated under his tent to prognosticate or at least ponder what Trump's ride to the presidency means to journalism and society (Schmidt, S., 2017). Then-candidate Trump trumpeted during his campaign that he earned billions in free news media coverage by creating a circus, largely by provoking journalists and agitating his political rivals (Confessore, 2016). Media Quant, a firm that calculates the monetary value of news and commentary coverage, estimates that in the last year of their campaigns Trump received $\$ 4.96$ billion to Clinton's $\$ 3.24$ billion across print, broadcast, and online news as well as social media (Harris, 2016).

Wells et al. (2016) built a timeline using Trump's data points from staged events, such as rallies and debates, together with non-staged events, such as call-ins to radio and TV shows, as well as Trump's tweets. His campaign activity predicted news coverage in print and online media, and the authors concluded - even before his eventual election - that Trump had engineered a hybrid multi-platform campaign to co-opt media attention. Other researchers found Trump's bombastic and populist social and legacy media approach to set the news agenda in stark contrast with Hillary Clinton's "professionalized" methods - the use of research and other methods to create a standardized message (Enli, 2017; Oliver \& Rahn, 2016; Schmidt, V. A., 2017). But how did Trump's strategy for media coverage translate into broadcast news coverage of issues related to immigration and deportation, in particular?

This chapter's overall theoretical approach relies on and tests assumptions about news work graphically illustrated in Reese and Shoemaker's (2016) hierarchical model. This model presents higher-level factors such as social systems, which can influence lower level factors such as social institutions and organizational levels. These influential factors can include organized religions or government, media organizations as embodied in a network such $\mathrm{ABC}$ and $\mathrm{CNN}$, media routines such as pack journalism and interviewing experts, and journalists' individual characteristics, namely openly shared political beliefs, race/ethnicity, and gender. In this approach, a cacophony of forces ultimately produces news content.

The current research zeros in on the influence of two of these levels: (1) media routines, specifically the standardized ways news coverage imposes a particular order on reality; and (2) the news media's 
organizational influences that predict news coverage. To begin, this research considers the entire corpus of network broadcast news stories from the first 100 days of the Trump administration to look for overarching themes:

RQ1: How did the three U.S. network news channels portray immigration and deportation issues during Trump's first 100 days in office?

Prior research on the TV networks under study - ABC, CBS, and NBC suggests each reports the news differently in terms of amount and political bent. Diddi et al. (2014) showed that while the three broadcast networks in the 2008 presidential campaign favored Republican presidential candidate John McCain in terms of amount of coverage, ABC had the greatest imbalance between coverage favoring the Republicans at 58 percent when compared to the Democrats at 34 percent. Considering the coverage in terms of segments - or a group of stories between the commercial breaks during the evening news - the pattern is even more pronounced: $\mathrm{ABC}$ favored the Republicans in 61 percent versus Democrats in 26 percent of its coverage. During the next presidential campaign, though, Rosenstiel et al. (2012) found ABC differed substantially from the other networks in that it favored Democratic candidate Barack Obama over Republican rival Mitt Romney.

CBS and NBC gave each candidate almost the same negative coverage. Schaefer and Fordan (2014) conducted a content analysis of ABC, CBS, and NBC's coverage of the U.S. president's State of the Union speeches from 1982 to 2013 and found ABC differed from CBS and NBC, but in the opposite direction. ABC was more balanced in its coverage of the president and those quoted from the opposing party. Taken together, it seems clear that ABC is often at odds with its two network rivals; however, it is difficult to discern a clear partisan pattern to the difference.

There has been a traditional consistency in the content broadcast by the legacy TV networks since ABC, CBS, and NBC all launched in and around the 1940s. In the 2010s, however, as competition for eyeballs on small and large screens and across hundreds of channels increased, the networks diversified their products. Ben Sherwood, president of ABC, said in a 2012 interview with The New York Times that today's viewers "make their own choices. They pick what matters most to them, and we are trying to be adaptive and responsive to those sweeping changes" (Stelter, 2012). These disparities and varying strategies in network coverage across time periods and topics led to the second research question:

RQ2: What were the similarities and differences among U.S. network news coverage of Trump's immigration and deportation narratives? 


\section{Method}

The transcripts of all stories broadcast on the three U.S. network news channels were collected for analysis. The timeframe ran from Trump's inauguration day until 100 days later. Stories were located on Lexis-Nexis through keyword searches for "Trump" and "immigration" broadcasted on ABC, CBS, or NBC. This search resulted in 287 news stories broadcast about Trump's policies on immigrations in his first 100 days in office. $\mathrm{ABC}$ and CBS published an equal number of stories $(\mathrm{N}=$ 106 each), and NBC published slightly fewer $(N=75)$.

To analyze the text in these stories, Linguistic Inquiry and Word Count (LIWC) - a computer-assisted content analysis program - was used. The LIWC dictionary includes numerous categories, some of which have been analyzed for reliability and validity (Cohn, Mehl, \& Pennebaker, 2004; Newman, Pennebaker, Berry, \& Richards, 2003; Pennebaker, Chung, Frazee, Lavergne, \& Beaver, 2014). This study, in particular, focuses on the use of narrative words in news stories about Trump's treatment of immigration issues in his first 100 days in office. First, the analytical thinking category focuses on the usages of words related to "formal, logical, and hierarchical thinking" (Pennebaker, Booth, Boyd, \& Francis, 2015, p. 21), where higher scores indicate greater usage of these words and lower scores indicate more informal tone that is more personal and includes elements of narrative thinking. Scores could range from zero to 100 , and the mean of the stories included in this sample suggest a strong usage of analytical thinking in these news stories $(M=87.46, S D=8.96)$.

Second, the category related to the authenticity of the words used examines the amount of honesty and guardedness in the text. This category assesses the narrative authenticity, where higher scores indicate "more honest, personal, and disclosing text" and lower scores signify "a more guarded, distanced form of communication" (Pennebaker et al., 2015, p. 22). With the scale ranging from zero to 100 , the news stories examined in this study were low in their use of authentic words $(M=24.40, S D=12.35)$.

The third measure of narrative was the use of tone. The tone category in LIWC examines the degree of positivity and optimism at the high end of the scale and the degree of anxiety, sadness, and hostility at the low end of the scale. Ranging from zero to 100, this scale's midpoint of 50 indicates "either a lack of emotionality or different levels of ambivalence" (Pennebaker et al., 2015, p. 22). The news stories considered here had, on average, a more negative and pessimistic tone $(M=31.73, S D=22.54)$.

Additionally, LIWC was used to count the mentions of several different countries to discover any patterns in how each network covered particular countries in their discussion of immigration. This variable simply counts the number of mentions of each country and/or its people. The countries included are those frequently discussed in reference to immigration in 2017. The mean values for these counts indicate the 
percentage of the time these countries were mentioned, ranging from zero (never mentioned) to 100 (that country is the only word used). The countries included in this analysis are: Syria $(M=0.03, S D=0.10$, mentioned in 14.3 percent of stories); Iraq $(M=0.05, S D=0.16$, mentioned in 15.7 percent of stories); Afghanistan $(M=0.01, S D=0.06$, mentioned in 2.8 percent of stories); $\operatorname{Iran}(M=0.04, S D=0.17$, mentioned in 12.9 percent of stories); Mexico $(M=0.09, S D=0.27$, mentioned in 24.0 percent of stories); Canada $(M=0.04, S D=0.20$, mentioned in 9.4 percent of stories); and the United States $(M=0.42, S D=0.41$, mentioned in 83.3 percent of stories).

\section{Results}

To begin the analyses, the focus of the networks' coverage of immigration in Trump's first 100 days in office was considered. Table 5.1 illustrates the distribution of coverage by network and country. Sorted from highest to lowest, this table shows that the United States was the most frequently covered country. Given this sample focused on U.S. news coverage of the U.S. presidency, this result is not surprising. However, it does illustrate a U.S.-centric focus, which may cater to the networks' U.S. audience or, conversely, provide an in-group reference used in comparison to some out-group (i.e., other countries) (e.g., Hoewe, Bowe, \& Makhadmeh, 2014). ABC, in particular, was likely to include a focus on the United States, where 94 different news stories (nearly 90 percent of its stories) mentioned the country. CBS, on the other hand, covered the United States the least of the three networks. Using a one-way analysis of variance (ANOVA), this difference of coverage was significant, $F(2,284)=4.28, p<.001, \eta_{\mathrm{p}}{ }^{2}=.18$. The pairwise comparisons in this model indicated that $\mathrm{ABC}$ broadcast significantly more stories about the United States than did NBC $(p<.001)$ or CBS $(p<.001)$.

Table 5.1 Countries mentioned in stories about immigration

\begin{tabular}{|c|c|c|c|c|c|c|c|c|}
\hline & \multicolumn{2}{|r|}{$N B C$} & \multicolumn{2}{|r|}{$C B S$} & \multicolumn{2}{|r|}{$A B C$} & \multicolumn{2}{|r|}{ Total } \\
\hline & $N$ & $\operatorname{Pct}^{1}(\%)$ & $N$ & Pct. (\%) & $N$ & Pct. (\%) & $N$ & Pct. $(\%)$ \\
\hline \multicolumn{9}{|l|}{ Countries $^{2}$} \\
\hline United States & 67 & 89.3 & 78 & 73.6 & 94 & 88.7 & 239 & 83.3 \\
\hline Mexico & 27 & 36.0 & 27 & 25.5 & 15 & 14.2 & 69 & 24.0 \\
\hline Iraq & 15 & 20.0 & 14 & 13.2 & 16 & 15.1 & 45 & 15.7 \\
\hline Syria & 12 & 16.0 & 15 & 14.2 & 14 & 13.2 & 41 & 14.3 \\
\hline Iran & 11 & 14.7 & 13 & 12.3 & 13 & 12.3 & 37 & 12.9 \\
\hline Canada & 10 & 13.3 & 10 & 9.4 & 7 & 6.6 & 27 & 9.4 \\
\hline Afghanistan & 2 & 2.7 & 3 & 2.8 & 3 & 2.8 & 8 & 2.8 \\
\hline
\end{tabular}

1 Percentages were calculated based on the respective news network.

2 Stories may have mentioned more than one country, so total percentage will not reflect 100 percent. 
The next most talked about country was Mexico. Much of Trump's immigration policy focused on lessening Mexican immigration, including promises of a wall built along the border between the United States and Mexico. This finding illustrates that Trump's rhetoric about these potential policies translated into broadcast news coverage of immigration in his first 100 days in office. NBC focused more of its coverage on Mexico, while ABC focused a lesser amount on Mexico. A one-way ANOVA showed that this difference in coverage was significant, $F(2,284)=4.36, p=.01, \eta_{\mathrm{p}}^{2}=.03$. The pairwise comparisons in this model indicated that $\mathrm{ABC}$ covered Mexico significantly less than NBC $(p=.02)$ or CBS $(p=.09)$.

The next three countries - Syria, Iran, and Iraq-are all nations included in Trump's executive order that restricted travel from these countries to the United States. This controversial "travel ban" included Muslimmajority nations, including Syria - a country currently experiencing a refugee crisis due to ongoing military conflict between government forces and several rival factions. These three broadcast networks covered each of these countries in relatively equal numbers, suggesting that these countries were on the radar in news about Trump's immigration policies, but they were not the primary focus.

A multivariate analysis of variance (MANOVA) was used to test any potential difference in coverage of these three countries by network, and the omnibus model was not significant, Wilks' $\Lambda=.99, F(6,564)=0.63$, $p=.71, \eta_{\mathrm{p}}{ }^{2}=.01$. It is important to note that the combined amount of coverage for these three nations exceeds that of the coverage of Mexico. That is, when considering three of the countries included in the so-called "Muslim ban," their combined coverage was substantial but equally distributed among the networks.

Finally, Canada - the U.S.'s northern neighbor - and Afghanistan were covered infrequently. Given the low number of news stories including these countries, further analyses of these two countries were not conducted.

The second research question addressed the similarities and differences in narrative coverage of Trump's immigration and deportation policies. To address this question, the narrative elements in these networks' coverage of immigration during the initial 100 days of Trump's presidency were examined. To begin, a one-way ANOVA was used to test the networks' use of analytic thinking, and significant differences emerged, $F(2,284)=$ $7.94, p<.001, \eta_{\mathrm{p}}{ }^{2}=.05$. Using the estimated marginal means and pairwise comparisons with the Sidak correction, this difference was in ABC's lacking use of analytical language. $\mathrm{ABC}(M=84.82)$ used significantly less language related to formal and logical processing than did NBC $(M=89.61, p=.001)$ or CBS $(M=88.57, p=.006)$. This result shows that $\mathrm{ABC}$ used more elements of narrative thinking in its coverage, while NBC and CBS focused more on analytical thinking. 
Considering the narrative use of authentic language in these news stories, an ANOVA revealed a significant difference, $F(2,284)=3.39$, $p=.04, \eta_{\mathrm{p}}{ }^{2}=.02$. The estimated marginal means showed that ABC $(M=26.60)$ was significantly more likely to use language related to honesty and disclosure than was NBC $(M=21.85, p=.03)-$ but this difference was not statistically significant for CBS $(M=24.00, p=.33)$. This finding illustrates that $\mathrm{ABC}$ was more likely to use language related to authenticity of the narrative, while NBC was more guarded in its coverage of immigration during the initial stages of Trump's presidency.

Finally, the use of emotional tone was considered as the final narrative element of this news coverage. A one-way ANOVA revealed a significant difference among the three networks, $F(2,284)=14.36, p<.001, \eta_{\mathrm{p}}{ }^{2}=.03$. As shown by the estimated marginal means with the Sidak correction, NBC $(M=12.17)$ used a significantly more negative tone than did $\mathrm{ABC}$ $(M=38.54, p<.001)$ and CBS $(M=32.38, p=.002)$. That is, ABC and CBS were more positive and optimistic in their coverage of immigration during Trump's first 100 days in office. NBC was significantly more negative, including more words related to sadness, anxiety, and hostility.

\section{Discussion}

In the first 100 days of the Trump administration, the president attempted to strongly assert his positions on immigration, in part because those issues played a large role in his campaign. This research examined the media response to these political stances, particularly the news stories aired on NBC, CBS, and ABC - the three major network news organizations in the United States.

The first point of focus was the countries considered in these news stories. When discussing Trump's policies and stances on immigration and deportation, which countries did the news media tell news consumers to think about? It is notable that almost all of the news stories mentioned the United States, and the bulk of them discussed either Mexico or three of the nations included in the travel ban on citizens of eight Muslim-majority countries - Syria, Iraq, and Iran. In this way, the coverage set up an ingroup, out-group dichotomy that frames the issues not in terms of their intrinsic characteristics, but in terms of how they affect the United States.

For example, stories were less concerned with why refugees were fleeing Syria and more with the impact of a large influx of refugees on the West. This portrayal is not uncommon, as much prior research has indicated the news media's inclination to show the United States as being at odds with other, non-American countries (e.g., Hoewe et al., 2014; Powell, 2011; Said, 1997), particularly those countries perceived as having a greater social distance culturally, geographically, and politically (e.g., Meirick, 2006). 


\section{Jennifer Hoewe et al.}

Given the rhetoric focused on building a wall between the United States and Mexico and the push to ban travel from several Muslim-majority countries, this news coverage illustrates the networks' willingness to follow the news agenda set by the president. As President Trump increased his focus on controlling access to the United States for both immigrants and refugees, the news media followed suit. In particular, the news focused its coverage on Mexico, Syria, Iraq, and Iran, which is similar to the claims laid by Trump and his early presidential policy moves.

Despite some similarities in coverage among the three networks examined here, there were some noteworthy differences. As Reese and Shoemakers' (2016) hierarchical model explains, news workers are embedded within a system whose constraints and routines have consequences on the ways stories are told. As such, the differences among the networks merit scrutiny. Specifically focused on the countries covered in news about immigrants, $\mathrm{ABC}$ broadcast more news stories than both NBC and CBS that focused coverage on the United States and fewer stories focused on Mexico. This finding shows the more ethnocentric focus in $A B C$ 's coverage, possibly indicating a stronger U.S. orientation than NBC or CBS. This worldview subtly suggests the world is divided into two camps - the United States (i.e., "us") and everybody else ("them"). The granular geopolitical intricacies behind global migration are then pushed into the background in favor of an analysis that foregrounds the (real or imagined) impacts on Main Street, USA.

When considering the narrative components of this news coverage, this study specifically addressed the use of language related to analytical/ narrative thinking, authenticity, and valence of tone. Here again, $A B C$ differed in its coverage when compared to CBS and NBC. ABC used more narrative (as opposed to analytical) elements in its coverage of immigration in Trump's first 100 days in office, guiding viewers using less formal and more personal forms of storytelling. For example, ABC's morning coverage on January 30 included a statement from its legal analyst stating, "There are gonna be all sorts of challenges, but keep in mind, the President has enormous discretion when it comes to immigration, so these cases are not going to be easy.”

Conversely, NBC and CBS used more analytical language, encouraging their viewers to think more critically and rationally about the story. A January 30 story on CBS discussed protests regarding Trump's travel ban, with the anchor leading off the story saying, "[Protesters] want an end to President Trump's travel ban while Mister Trump continues to defend his executive order." A story broadcast two days earlier on NBC led with the anchor explaining the controversy surrounding Trump's early decision: "As the new immigration policy plays out, the Trump administration was also dealing with the repercussions today and much more." These examples illustrate the tendency of ABC's coverage to take a less formal tone, becoming more personal and involving more elements 
of narrative thinking, while CBS and NBC used more formal language focused particularly on LIWC's counting of words related to "logical and hierarchical thinking" (Pennebaker et al., 2015, p. 21).

A second point of comparison was the use of authentic language in these news stories. Again, ABC differentiated itself by being more likely to use authentic language to describe issues of immigration and deportation in the initial days of Trump's presidency. For example, a story that ran on ABC on January 29 discussed the "wild scenes" happening in response to Trump's travel bans, indicating that the restrictions caused "not only confusion, but shock waves all across the country." Adding to the authenticity of the narrative, this story went on to present interviews from several families influenced by the travel restrictions. These narratively engaging stories that ran on ABC included elements that portrayed more honesty and more disclosing information to the audience. Comparatively, NBC was significantly less authentic in its storytelling. Instead, NBC utilized language that LIWC categorizes as "a more guarded, distanced form of communication" (Pennebaker et al., 2015, p. 22).

The final element of story construction that was considered in this study was the overall tone. NBC was considerably more negative in tone than were $\mathrm{ABC}$ and CBS. NBC focused much of its coverage on the drawbacks and negative effects of Trump's initial policies regarding immigration. For example, a story about Trump's policy regarding illegal immigration that aired on NBC on April 20 began with a lead in from the anchor:

Now to a legal twist of fate that has a lot of people talking. As the Trump administration moves aggressively to stop illegal immigration, it's caught up in a legal dispute over a so-called dreamer from California who was deported, his lawyers say, for no reason.

Another story broadcast on NBC Nightly News on February 4 began with "Immigration war: New protests nationwide over President Trump's order, now temporarily blocked by a federal judge."

In sum, these results illustrate the distinctions in coverage even among three U.S. broadcast network news outlets. In particular, the narrative elements in coverage differed, suggesting news consumers could experience a different frame - and possibly then form a different opinion - surrounding immigration and deportation issues when watching these networks. In its coverage of immigration issues during Trump's first 100 days in office, $\mathrm{ABC}$ used more narrative - less analytic storytelling elements, while also including more authentic language and a more positive tone. $\mathrm{ABC}$ also focused more on the United States and less on Mexico in its coverage. The distinctiveness of ABC's coverage found in this study may illustrate what ABC President Ben Sherwood described as the network's goal to "be adaptive and responsive" in its 


\section{Jennifer Hoewe et al.}

formation of news content while also believing "in relevance as a unifying idea in the choices we make" in order to make its content stand out to viewers (Stelter, 2012).

$\mathrm{NBC}$, on the other hand, used more formal and analytical language but a more guarded style of communication and more negative tone. Finally, CBS relied more heavily on analytical discourse in its news stories while maintaining a more positive overall tone. Since each network differed in its portrayal of issues related to immigration and deportation, it is important for news viewers to understand how the news is being framed and packaged for their consumption and how that might shape viewers' subsequent attitudes toward immigration policy.

This study's findings may have practical applications as well by helping journalists and journalism educators understand the biases that undermine ethical norms for "fair and balanced coverage" of social and political conflicts (e.g., NPR, 2012; Society of Professional Journalists, 2014; The New York Times, 2004). Research on network news coverage reveals an imbalance in coverage of political candidates and source usage especially during presidential campaigns, indicating certain networks have partisan bents (Diddi et al., 2014; Zeldes, Fico, Carpenter, \& Diddi, 2008; Zeldes, Fico, \& Diddi, 2012). This chapter adds to these studies, indicating that U.S. network news coverage portrays issues of immigration differently as well - either through its focus on particular countries or the narrative elements used in the telling of those news stories.

\section{References}

American Press Institute. (2017). People have more trust in the media. Retrieved at www.americanpressinstitute.org/publications/reports/survey-research/mymedia-more-trusted-than-the-media.

Barthel, M., \& Mitchell, A. (2017). American's attitudes about the news media deeply divided along partisan lines. Retrieved at www.journalism. org/2017/05/10/americans-attitudes-about-the-news-media-deeply-dividedalong-partisan-lines.

Chavez, L. (2001). Covering Immigration: Popular Images and the Politics of a Nation. Berkeley: University of California Press.

Chavez, M., Whiteford, S., \& Hoewe, J. (2010). Reporting on immigration: A content analysis of major U.S. newspapers' coverage of Mexican immigration. Norteamérica, 5(2), 111-125.

Cohn, M. A., Mehl, M. R., \& Pennebaker, J. W. (2004). Linguistic markers of psychological change surrounding September 11, 2001. Psychological Science, 15, 687-693.

Confessore, N. (2016, July 13). For Whites sensing decline, Donald Trump unleashes words of resistance. The New York Times. Retrieved at www.nytimes. com/2016/07/14/us/politics/donald-trump-white-identity.html.

Department of Homeland Security. (2017, June 29). Executive orders on protecting the homeland. Retrieved at www.dhs.gov/executive-orders-protectinghomeland. 
Diddi, A., Fico, F., \& Zeldes, G. A. (2014). Partisan balance and bias in TV network coverage of the 2000, 2004, and 2008 presidential elections. Journal of Broadcasting \& Electronic Media, 58(2), 161-178.

Enli, G. (2017). Twitter as arena for the authentic outsider: Exploring the social media campaigns of Trump and Clinton in the 2016 U.S. presidential election. European Journal of Communication, 32(1), 50-61.

Feinstein, A., \& Storm, H. (2017). The Emotional Toll on Journalists Covering the Refugee Crisis. Reuters Institute. Retrieved at http:// reutersinstitute.politics.ox.ac.uk/publication/emotional-toll-journalists-coveringrefugee-crisis.

Felter, C., \& Renwick, D. (2017, June 29). The U.S. immigration debate. Council on Foreign Relations. Retrieved at https://www.cfr.org/backgrounder/usimmigration-debate- 0 .

Gidda, M. (2017, April 18). Obama vs. Trump: Who has deported more immigrants? Newsweek. Retrieved at www.newsweek.com/illegal-immigrationundocumented-migrants-obama-trump-585726.

Gross, K., Porter, E., \& Wood, T. (2017). Presidential debates in the age of partisan media: A field experiment. SSRN. Retrieved at https://ssrn.com/ abstract $=2926553$.

Harper, J. (2017, June 29). Numbers don't lie: Media bias against Trump is entrenched, vicious, persistent. The Washington Times. Retrieved at www. washingtontimes.com/news/2017/jun/29/inside-the-beltway-media-biasagainst-trump-is-ent.

Harris, M. (2016, November). A media post-mortem on the 2016 presidential election. mediaQuant. Retrieved at www.mediaquant.net/2016/11/a-media-postmortem-on-the-2016-presidential-election.

Hoewe, J., \& Bowe, B. J. (2017). Magic words or talking point? The uses and effects of "radical Islam" and its function as a proxy term for terrorism. Presented at the International Communication Association's 67th annual conference, San Francisco.

Hoewe, J., Bowe, B. J., \& Makhadmeh, N. (2014). Broadcasting sharia: American TV news' illustration of social identity and the emergence of a threat. Journal of Media and Religion, 13(2), 67-81.

Hoffner, C., \& Rehkoff, R. A. (2011). Young voters' responses to the 2004 presidential election: Social identity, perceived media influence, and behavioral outcomes. Journal of Communication, 61(4), 732-757.

Huang, J., Jacoby, S., Strickland, M., \& Lai, K. K. R. (2016, November 8). Election 2016: Exit polls. The New York Times. Retrieved at www.nytimes. com/interactive/2016/11/08/us/politics/election-exit-polls.html.

Jacobs, L., Meeusen, C., \& d'Haenens, L. (2016). News coverage and attitudes on immigration: Public and commercial television news compared. European Journal of Communication, 31(6), 642-660.

Kaye, B. K., \& Johnson, T. J. (2016). Across the great divide: How partisanship and perceptions of media bias influence changes in time spent with media. Journal of Broadcasting \& Electronic Media, 60(4), 604-623.

Kulish, N., Yee, V., Dickerson, C., Robbins, L., Santos, F., \& Medina, J. (2017, February 21). Trump's immigration policies explained. The New York Times. Retrieved at www.nytimes.com/2017/02/21/us/trump-immigration-policiesdeportation.html. 


\section{Jennifer Hoewe et al.}

Leary, J. P. (2017). Decoding "build the wall”: What liberal critics miss. NACLA Report on the Americas, 49(2), 146-148.

Martin, G. J., \& Yurukoglu, A. (2017). Cable news: Persuasion and polarization. Retrieved at https://web.stanford.edu/ ayurukog/cable_news.pdf.

McCann, E., \& Bromwich, J. E. (2016, October 20). "Nasty woman"” and "'bad hombres"”: The real debate winners? The New York Times. Retrieved at www.nytimes.com/2016/10/21/us/politics/nasty-woman-and-bad-hombresthe-real-debate-winners.html.

Meirick, P. C. (2006). Media schemas, perceived effects, and person perceptions. Journalism \& Mass Communication Quarterly, 83(3), 632-649.

Network News Fact Sheet. (2017, June 16). Pew Research Center. Retrieved at www.journalism.org/fact-sheet/network-news.

Newman, M. L., Pennebaker, J. W., Berry, D. S., \& Richards, J. M. (2003). Lying words: Predicting deception from linguistic style. Personality and Social Psychology Bulletin, 29, 665-675.

Newport, F., \& Brands, R. (2016, October 27). “Gallup review: Americans, immigration, and the election." Retrieved at www.gallup.com/opinion/pollingmatters/196733/gallup-review-americans-immigration-election.aspx.

NPR. (2012). NPR ethics handbook. Retrieved at http://ethics.npr.org.

Oliver, J. E., \& Rahn, W. M. (2016). Rise of the Trumpenvolk. The Annals of the American Academy of Political and Social Science, 667(1), 189-206.

Parker, A., Nakamura, D., \& Rucker, P. (2017, July 19). Trump's wall: The inside story of how the president crafts immigration policy. The Washington Post. Retrieved at www.washingtonpost.com/politics/trumps-wall-the-inside-storyof-how-the-president-crafts-immigration-policy/2017/07/19/b11b8b9468da-11e7-8eb5-cbccc2e7bfbf_story.html.

Pennebaker, J. W., Booth, R. J., Boyd, R. L., \& Francis, M. E. (2015). Linguistic Inquiry and Word Count: LIWC2015. Austin, TX: Pennebaker Conglomerates (www.LIWC.net).

Pennebaker, J. W., Chung, C. K., Frazee, J., Lavergne, G. M., \& Beaver, D. I. (2014). When small words foretell academic success: The case of college admissions essays. PloS One, 9, 1-10.

Pew Research Center. (2016, July 7). Top voting issues in 2016 election. Retrieved at www.people-press.org/2016/07/07/4-top-voting-issues-in-2016-election.

Pew Research Center. (2017, June 1). Cable news fact sheet. Retrieved at www. journalism.org/fact-sheet/cable-news.

Powell, K. A. (2011). Framing Islam: An analysis of U.S. media coverage of terrorism since 9/11. Communication Studies, 62(1), 90-112.

Reese, S. D., \& Shoemaker, P. J. (2016). A media sociology for the networked public sphere: The hierarchy of influences model. Mass Communication and Society, 19(4), 389-410.

Rosenstiel, T. R., Mitchell, A., \& Jurkowitz, M. (2012). Winning the media campaign 2012: Both candidates received more negative than positive coverage in mainstream news, but social media was even harsher. Pew Research Center. Retrieved at www.journalism.org/files/legacy/Winningthemediacampaign 2012.pdf.

Said, E. W. (1997). Covering Islam: How the Media and the Experts Determine How We See the Rest of the World. New York, NY: Vintage Books. 
Santa Ana, O. (2016). The cowboy and the goddess: Television news mythmaking about immigrants. Discourse \& Society, 27(1), 95-117.

Sargent, G. (2017, January 31). Is this a "Muslim ban?" Look at the history and at Trump's words. The Washington Post. Retrieved atwww.washingtonpost. com/blogs/plum-line/wp/2017/01/31/is-this-a-muslim-ban-look-at-thehistory-and-at-trumps-own-words/?utm_term=.92751af2a261.

Schaefer, T., \& Fordan, R. (2014). Balance and bias in network evening news coverage of presidential state of the union addresses. Electronic News, 8(4), 274-289.

Schmidt, S. (2017, January 17). Why people keep comparing Donald Trump to P.T. Barnum, of circus fame. The Washington Post. Retrieved at www. washingtonpost.com/news/morning-mix/w p/2017/01/17/out-goes-p-tbarnums-circus-in-comes-donald-trump/?utm_term=.d023b2fe6b3b.

Schmidt, V. A. (2017). Britain-out and Trump-in: A discursive institutionalist analysis of the British referendum on the EU and the US presidential election. Review of International Political Economy, 24(2), 248-269.

Shane, S., Rosenberg, M., \& Lipton, E. (2017, February 1). Trump pushes dark view of Islam to center of U.S. policy-making. The New York Times. Retrieved at www.nytimes.com/2017/02/01/us/politics/donald-trump-islam.html.

Society of Professional Journalists. (2014). SPJ code of ethics. Retrieved at www.spj.org/ethicscode.asp.

Stelter, B. (2012, January 8). Big three newscasts are changing the state of play. The New York Times. Retrieved at www.nytimes.com/2012/01/09/business/ media/at-abc-cbs-and-nbc-news-accentuating-the-differences.html.

Swift, A. (2016). Americans' trust in mass media sinks to new low. Gallup. Retrieved at www.gallup.com/poll/195542/americans-trust-mass-mediasinks-new-low.aspx?g_source=Trust+in+Media\&g_medium=search\&g_ campaign=tiles.

The New York Times. (2004). Ethical Journalism: A Handbook of Values and Practices for the News and Editorial Departments. Retrieved at www.nytco. com/wp-content/uploads/NYT_Ethical_Journalism_0904-1.pdf.

Vasile, A. A. (2017). Positive and/or negative meaning as style traits and strategy throughout the 2016 American presidential campaign - Hillary Clinton and Donald Trump. Journal of Media Research, 10(1), 23-31.

Wells, C., Shah, D. V., Pevehouse, J. C., Yang, J., Pelled, A., Boehm, F., ... Schmidt, J. L. (2016). How Trump drove coverage to the nomination: Hybrid media campaigning. Political Communication, 33(4), 669-676.

Zapotosky, M. (2017, June 5). Trump's latest tweets will probably hurt effort to restore travel ban. The Washington Post. Retrieved at www.washingtonpost. com/world/national-security/trumps-latest-tweets-could-hurt-effort-to-restoretravel-ban/2017/06/05/c8eb5940-49e8-11e7-bc1b-fddbd8359dee_story.html.

Zeldes, G. A., Fico, F., Carpenter, S., \& Diddi, A. (2008). Partisan balance and bias in network coverage of the 2000 and 2004 presidential elections. Journal of Broadcasting \& Electronic Media, 52(4), 563-580.

Zeldes, G. A., Fico, F., \& Diddi, A. (2012). Differences in the way broadcast, cable and public TV reporters used women and non-White sources to cover the 2008 presidential race. Mass Communication and Society, 15(6), 831-851. 


\title{
6 By Any Other Name Media and White-Supremacist Terrorism in the Trump Era
}

\author{
Katherine M. Bell
}

It may be too soon in the early stages of Donald Trump's presidency to suggest that his election ushered in a new era of white-supremacist attacks in the United States, even in the face of violence that erupted in the summer of 2017. In truth, the country has an ongoing crisis with racebased violence, forged from its founding in slavery. Recent decades have seen far-right violence surge notably in the 1990s, defined by Timothy McVeigh's anti-government bombing of a federal building in Oklahoma City. It swelled again with the country's first African American president (Anti-Defamation League, 2017; Potok, 2015). But Trump's political rise is inseparable from his xenophobic rallying cries to loyal followers. In a July 2017 speech to rightist Polish officials and bussed-in supporters in Warsaw, he said:

The fundamental question of our time is whether the West has the will to survive. We are fighting hard against radical Islamic terrorism, and we will prevail. We cannot accept those who reject our values and who use hatred to justify violence against the innocent.

(CNN, 2017)

Trump's assertion of "our values" is a dog whistle for the far-right and its fear and hatred of non-white, non-Christian Americans, or immigrants. The phrase marks a boundary of inclusion and exclusion. Sometimes Trump couches his rhetoric as he did in Poland. At other times his racism is overt, as when he labeled white supremacists in Charlottesville, Virginia, as "very fine people" (Hayes, 2017), when he lied about Muslims cheering as the World Trade Center towers went down (Carroll, 2015), when he called for "a total and completed shutdown of Muslims entering the United States" (Johnson, 2015), or when he launched his presidential campaign in 2015 by suggesting that Mexican people in the United States are drug dealers and rapists (Washington Post, 2015). Trump's modus operandi has been not only to minimize the threat of racist white extremism but to actively foment it for personal gain and aggrandizement.

While racist violence is not new, Trump has emboldened extremists, as rallies such as Charlottesville demonstrate. In recent years, white 
nationalist Richard Spencer helped popularize the Orwellian term "altRight" as a benign-sounding moniker for white nationalists online, and the media quickly made the term mainstream (Harkinson, 2016). Spencer remained a frequent spokesperson in media coverage of extremist protests. Alt-Right darling Milo Yiannopoulos emerged from the Breitbart News machine that helped propel Trump into office and garnered extensive mainstream coverage (Fulwood, 2017). Former Klansman David Duke reemerged and ran for federal office in 2016 on an openly racist platform (Domonoske, 2016). He appeared as a spokesman at Charlottesville and directly linked the racist movement to Trump's political rise (Stolberg \& Rosenthal, 2017). Through such messengers, simmering race-based hatred reached a boil with Trump's nascent political career.

The mainstream media have covered racist rhetoric and violence in the Trump era, as they did in the past. Barack Obama's tenure saw white supremacist Dylann Roof murder nine African American parishioners in a church in Charleston, South Carolina, among other attacks. It also saw tragically regular instances of police violence against unarmed black men and women (e.g., Friedersdorf, 2015; Williams, 2016). Reporters struggled before Trump's rise with whether to call these acts "terrorism," with all of the media images of barbarism that attach to the term. Ultimately, news organizations remain wary of applying the same criteria to white-supremacist attacks that they have to so-called Islamist violence since 9/11. They have not come to terms with the reality of violence against racialized minorities in the United States as terrorism by another name.

This chapter calls on the mainstream media to reassess their role in covering white-supremacist terrorism. At this historic moment, they must name terrorism consistently and heed research that time and again cites right-wing extremism as the biggest terrorism threat in the United States. It is not that racist attacks in 2017 were markedly different than those during Obama's presidency, but that the conditions for race-based violence are at a new conjuncture. The Trump administration heralds an upswing in Jim Crow-style acts of racist intimidation and speech from an emboldened extremist right (e.g., Doubek, 2017; Strickland \& Gottbrath, 2017). Trump himself has been a reluctant critic of the attacks as he promises a "law-and-order" platform. This conjuncture thus brings mainstream political recognition of extremists and a White House set on banning visitors from Muslim countries that have not attacked U.S. soil. ${ }^{1}$

The media's inconsistency, I suggest, flows from institutional biases rooted in an ideology of whiteness. Racialized assumptions within the fabric of journalism are entwined with Orientalist views about Muslims since 9/11. Such assumptions by the media are shot through with the rhetoric of political leaders and government agencies that deal with racebased crime. Ultimately, the media must take seriously the evidence that 
places domestic right-wing extremism as a greater threat to the country than Islamic extremism. Through the establishment of consistent ethical standards in naming what counts as "terrorism," and through nuanced treatment of the plots, attacks, and ideologies that spawn them, the media can influence public perceptions of the threats Americans face. Thus, this chapter urges journalists to examine the institutional and ideological biases that impede them.

The discussion below begins with a snapshot of several racist attacks in early 2017, followed by a brief overview of the multiple definitions of terrorism, historically and currently. I connect media treatment of extremist violence to the political and institutional ideologies of whiteness and examine several research studies that serve as evidence for this connection in coverage of terrorism. The chapter ends with a discussion of the impediments to U.S. media in naming terrorism and how they relate to racial institutional bias more broadly.

\section{Terrorism in the Trump Era}

In March 2017, James Harris Jackson traveled from his home in Baltimore to Manhattan to quench his seething hatred of black men, particularly those "mixing" with white women (Southall, 2017). He stalked several men over three days before he set his sights on Timothy Caughman, 66, whom he stabbed with a sword. Caughman managed to stumble to a nearby police precinct but died of his wounds. Jackson chose New York for the publicity that his attacks would bring. The stabbing was meant to be practice for a violent rampage against black men, but Jackson threw his sword in a trash bin and turned himself in. Police charged him with murder as a hate crime and later with state charges of murder as an act of terror. Jackson expressed some remorse that his victim was "elderly." He wished that he had attacked a younger black man, perhaps someone who was with a white woman.

In May, avowed white supremacist Jeremy Christian boarded a lightrail train in Portland, Oregon, and approached two teenage girls, one African American and the other Muslim American and wearing a hijab. As he spewed a racist diatribe at them, several bystanders intervened and tried to calm him down. He drew a knife and stabbed three white men, two of whom died and one of whom he seriously wounded. Police arrested Christian after he left the train and charged him with two counts of aggravated murder, attempted aggravated murder, first-degree assault, two counts of intimidation, and three counts of unlawful use of a weapon. "Free speech or die, Portland," Christian yelled in his first court appearance. "You've got no safe place. This is America. Get out if you don't like free speech" (Bernstein, 2017a).

These were but two of numerous attacks in 2017. A member of a Facebook group called "Alt-Reich Nation" stabbed and killed an African 
American college student and Army lieutenant on the University of Maryland campus in May (Lerner, 2017). A white patron shot and killed two immigrants from India in a Kansas bar in February (Eligon, Blinder \& Najar, 2017). Many of the killings had several themes in common. They were so-called lone-wolf attacks carried out by a single person against one or two individuals. In each case, suspects were white and were soon characterized by authorities as having mental health or substance abuse problems. Through social media or personal connections, most suspects had expressed a confusing array of xenophobic political beliefs (e.g. Acker, 2017a, 2017b; Bromwich \& Blinder, 2017).

The summer of 2017 also saw white violence in the context of a media spectacle of right-wing hate. A white supremacist plowed his car into a crowd of anti-racist protesters in the streets of Charlottesville, killing a woman and injuring 19 . The protesters were countering a rally of whitesupremacist groups that had marched the night before carrying torches and chanting slogans reminiscent of Nazi Germany. At this writing, law enforcement officials had not determined whether the 20 -year-old driver, James Alex Fields, would face charges of domestic terrorism, though numerous politicians across the spectrum said it was terrorism (Thrush \& Haberman, 2017; Robinson, 2017). Media coverage in the week following emphasized Trump's erratic response to the tragedy. He was initially silent, then blamed "both sides." Two days later he read a statement condemning violence by white supremacists; a day later he again blamed the "alt-left" as equally culpable (Shear \& Haberman, 2017).

The 2017 cases each have their own characteristics in terms of the media coverage. Charlottesville notwithstanding, most white terrorist acts have been characterized by a single attack that does not take place with cameras rolling. Many bring a flurry of initial reporting, but do not attract widespread or sustained mainstream media treatment. Even the Jackson case, which did result in state terrorism charges, did not impel the major media into deeper investigation and analysis on the nature of white-supremacist terrorism. The media offered limited explanation of the ways in which such perpetrators become radicalized or context about the broader threat of white-supremacist violence.

In the Christian case, Portland's own paper, The Oregonian, produced relatively few stories beyond the spot coverage. In the weeks following, its coverage included comment from an FBI agent that it was too soon to call the attack terrorism (Oregonian, 2017). Stories included discussion of the fact that a hate-crime charge would be difficult given that the men killed were not those being targeted by the racist threat (Bernstein, 2017b). A reporter prepared a look at terminology and affiliations of farright extremists (Acker, 2017a) and an examination of Christian's beliefs based on his social media presence (Acker, 2017b).

The U.S. and international media did give blanket coverage to a white man's attack on Ramadan worshippers outside a London mosque in 


\section{Katherine M. Bell}

June. One person died at the scene and 11 were injured when Darren Osborn plowed his rented van into a group of people who had just left the mosque. National media in the United States had extensive reporting on the attack, both spot developments and wider analysis and opinion. The attack's location in a major world city and that fact that British officials did not waver at labeling it as terrorism, made the politics of this particular story somewhat different for U.S. media. The New York Times, for example, published two pieces decrying right-wing terrorism.

A news feature by columnist Max Fisher (2017) examined what acts of violence are deemed terrorism, hate crimes, or murder and suggested that the London attack fit scholarly and legal definitions of terrorism. He contemplated the sensitivity of naming an act terrorism and the discrimination that Muslim communities experience following such events. There are clear disparities between how acts of violence committed against them are treated compared with those by Islamic extremists. Fisher wrote:

Years of seeing terrorism as a foreign threat, and of arguments that Muslim communities must address the roots of extremism, has freighted the term with accusations that extend beyond the attacker to his or her community.

His point gets to the crux of how the terrorist label forces individual Muslims, and communities of color generally, to account for the deeds of their larger communities. The reverse is not true of acts of politically motivated violence by white citizens.

A Times op-ed by scholars Amarnath Amarasingam and Jacob Davey (2017) of the London-based Institute for Strategic Dialogue cited a 2017 report by the U.S. Government Accountability Office (GAO, 2017) to highlight the threat of right-wing violence. The report states that 73 percent of deadly terrorist attacks on American soil since 9/11 were committed by anti-government, white-supremacist, and neo-Nazi extremists from within the United States? They argued broadly for greater attention to such attacks and called for such violence to be treated similarly to that of jihadist terrorists. Significantly, they did not specify whether their call was directed at the media, law enforcement, prosecutors, or politicians. Neither did Fisher mention the news media's role in defining terrorism as an act perpetrated by Muslim suspects.

These examples all capture a number of themes that I take up below. For one, the media are wary of labeling terrorism in the absence of official sources doing so. As well, the legal system uses a confusing array of legal charges, which can inhibit journalists in formulating their own definitions of terrorism. These challenges stem in part from a pervasive ideological investment in whiteness that long predates Trump's racist rhetoric. The following section begins with an exploration of definitions 
of the word "terrorism" and makes the theoretical connection to the analytical concept of whiteness. It also examines research on the contradictory media treatment of acts of terrorism.

\section{What is Terrorism?: News Coverage, Whiteness, and Orientalism}

These examples demonstrate the inconsistencies that have challenged media in covering extremist violence since well before Trump. The media are not helped, as Fisher implies, with the varied and imprecise meanings of the word "terrorism." Not only are there conflicting academic and legal definitions, but different government and international agencies have their own criteria. Some definitions are overly broad: The Oxford English Dictionary begins with a broad definition: "[ $\mathrm{t}]$ he unlawful use of violence and intimidation, especially against civilians, in the pursuit of political aims" (Oxford, n.d.).

However, the National Institute of Justice, the research arm of the federal Department of Justice, uses a more precise definition from Title 22 of the U.S. Code of Laws in that terrorism is “...premeditated, politically motivated violence perpetrated against noncombatant targets by subnational groups or clandestine agents, usually intended to influence an audience" (National Institute of Justice, n.d.). Meanwhile, the Federal Bureau of Investigation (FBI) defines it as "the unlawful use of force or violence against persons or property to intimidate or coerce a government, the civilian population, or any segment thereof, in furtherance of political or social objectives" (National Institute of Justice, n.d.).

European terrorism scholar Alex P. Schmid (1983) provides language useful for journalists, describing it as an act of "an anxiety inspiring method of repeated violent action, employed by (semi-)clandestine individual, group or state actors, for idiosyncratic, criminal or political reasons" (p. 70). A key characteristic of terrorism is that victims are often random. Terrorists choose symbolic targets to send a message and publicize their political aims and grievances. This definition implies an obvious reality: media are an essential part of the equation for terrorism; they are the primary means by which terrorists' actions and ideological beliefs are publicized. Yet, the media connection is not always direct. And in recent decades, terrorists have not always claimed credit for violent acts, though the publicity remains a key characteristic of terrorist violence (Yin, 2013, pp. 37-38).

The meaning of terrorism has been remade over time in different places, and scholars debate the historical significance of various "waves" of terrorism (e.g., Hanhimäki \& Blumenau, 2013). The term carried a positive connotation in the late eighteenth century, used by the French revolutionary state as a tool for maintaining order and governance (Hoffman, 2006). Some scholars suggest the first wave 


\section{Katherine M. Bell}

of global terrorism took place in the decades before the First World War, coinciding with massive economic shifts (Jensen, 2013; Rapoport, 2013). It took on its more contemporary character internationally after the Second World War (Hoffman, 2006). The 1960s and 1970s brought debates about nationalist and separatist groups such as Yasser Arafat's Palestinian Liberation Organization and about distinctions between freedom fighters and terrorists in the post-colonial context. In the early 1980s, terrorism became associated with the destabilization of the West and by the mid-1980s, state-sponsored terrorism became a reality that enabled weaker states to challenge dominant powers (Hoffman, 2006; Riegler, 2013). In the wake of 9/11, the definition of terrorism shifted again as U.S. President George W. Bush deployed the phrase "war on terror." He invoked the term "evildoers" to define perpetrators and used the definition to take out Iraqi leader Saddam Hussein despite a lack of evidence connecting his regime to the attacks (Hoffman, 2006; Rapoport, 2013).

Many working definitions of terrorism combine political aims and unlawful use of force as being primary characteristics. The AntiDefamation League (2017) in the United States, for instance, identifies it as "a pre-planned act or attempted act of significant violence by one or more non-state actors in order to further an ideological, social or religious cause, or to harm perceived opponents of such causes" (p. 2). These criteria have been assigned to Islamic extremism since at least September 11, 2001, and in the early years subsequent, U.S. military, security officials, politicians, and law enforcement agencies focused heavily on Al-Qaeda, which claimed responsibility for the airplane attacks. More recently, U.S. political leaders and security officials have focused their efforts against terrorism on other organized groups such as ISIS and on solitary actors who self-radicalize on the internet.

News organizations have spent vast resources covering attacks and plots by radical Islamic groups and individuals. They have investigated the strategies, cultures, leadership, resources, and motivations of groups across the Middle East and beyond. Such a response would be expected given the enormity of the 2001 attacks; however, scholars and commentators have critiqued the broad assumptions and characterizations of Muslims and Arabs the news media used in the years following 9/11 (e.g., Akram, 2002; Ismael \& Measor, 2003; Kellner, 2016). News accounts have been filled with anxious stories of the Muslim "Other," and often offer little nuance about the varied cultures and beliefs of Muslim people.

These portrayals flow from a news culture steeped in Orientalist assumptions about a distant Other (Said, 1978, 1997), a news culture also rooted in whiteness as an ideology (Dolan, 2011). Extensive research reveals the pervasiveness of whiteness as part of the institutional structures of the United States and other Western countries. Assumptions 
about the normative nature of whiteness as a non-race permeate the law, judicial system, education, politics, and journalism (Omi \& Winant, 1986). Scholars have analyzed whiteness as an ideology, a discursive formation, a "process constituted by an ensemble of social and material practices" (Shome, 2000) and as structural racial formation (Omi \& Winant, 1986), among other conceptions. All approaches are committed to making whiteness visible as a social category.

As race is itself a social construction, whiteness is created, historically and currently, in the interests of maintaining power structures (Lipsitz, 1998; Nakayama \& Krizek, 1995; Omi \& Winant, 1986; Shome, 1996). It can be difficult to see the impact of white privilege because it is the norm in the United States. It is everywhere and nowhere at once. It is the unmarked category against which all other racial categories are valued. In fact, it flourishes in its invisibility. People equate racism to overt prejudice, but whiteness often operates on a much subtler level. As a form of racial bias, it serves to maintain institutions, norms, laws, and expectations in ways that privilege its dominance and obscure it as a racial category.

Both journalism's norms and its practitioners are suffused with normative assumptions about the dominance of whiteness. This accounts for an overrepresentation of white journalists in news organizations, but it goes much deeper. The norms that dictate news practices-from objectivity to selection of sources to decisions about what constitutes news-are forged from the invisibility of whiteness, which makes them seem wholly unconnected to racial dominance (e.g., Dolan, 2006; Heider, 2000; Wilson, 1995). Indeed, U.S. journalism pedagogy is a study in whiteness, where aspiring reporters are schooled in "diversity" from the perspective of white dominance (Alemán, 2014).

Journalism is institutionally structured to deploy practices that assume whiteness as a non-race. Journalists of color must also adopt these institutional norms and practices. People "learn" to be white, as Raka Shome notes $(2000$, p. 368). This is true for white people, but also in a sense for people of color in order to conform to dominant social norms. As such, performing within the rubric of whiteness can be a survival strategy for non-white journalists, a strategic decision in the name of success, or a less conscious assimilation.

From within this structural paradigm, where journalists marinate in an organizational culture that renders whiteness invisible, came the coverage of the Muslim and Arab Other after 9/11. Edward Said's (1978) classic book Orientalism describes the "Orient" as a colonial creation of the West. Orientalism is a strategic racialized process that has maintained European superiority over non-white cultures, particularly Middle Eastern and other Asian subjects. As Said describes, it allows the West to view itself as superior in juxtaposition to Arab cultures as backward, violent, hypersexualized, and irrational. Orientalist views that 


\section{Katherine M. Bell}

justified the treatment of Chinese immigrants in the nineteenth century, of Japanese-American citizens during the Second World War, and others percolated through news and popular culture (Ono \& Pham, 2009).

After the 9/11 attacks, political leaders and news media portrayed Muslim and Arab cultures, which they knew little about, as barbaric. Some researchers call this clash of civilizations narrative "new Orientalism." Politicians and pundits continue this rhetoric, as do the news media (e.g., Altwaiji, 2014; Amin-Khan, 2012). While this chapter does not take up all the nuances and impacts of Orientalism, from a journalistic perspective it is an ideological outlook that enables opinion leaders to mark Islam as the "antithesis of "Western civilization"” (Amin-Khan, 2012, p. 1596). Orientalism maintains the West, as represented by whiteness, as the natural order of things. At the same time, it inflects coverage that minimizes white-supremacist violence against all people of color.

\section{Media Research and the Bias of Whiteness}

Researchers have written volumes on the impact of whiteness across U.S. institutions. Content analyses and framing studies bear out that an Orientalist ideology permeates news coverage of Muslims. One framing analysis of six major organizations' coverage of 11 attacks on U.S. soil from 9/11 to December 2009 found news reports infused with fear of Muslim terrorism (Powell, 2011). Domestic terrorism, meanwhile, "is cast as a minor threat that occurs in isolated incidents by troubled individuals" (p. 91). The attacks included high-profile threats by domestic and international perpetrators, Muslim and non-Muslim, including an anthrax mail attack and the "shoe bomber" attempt of late 2001. Media made connections to al-Qaeda without evidence, associated suspects' names with Islam incorrectly (Powell, 2011, p. 97), and used the term "terrorism" with scant proof. The anthrax case, in which the main suspect was white, saw media de-emphasize terrorism in accordance with officials' insistence that the country focus on the threat of another al-Qaeda attack.

A legal case study of four separate attacks in the 2000s found similar inconsistencies. News reports described Muslim suspects as terrorists and white suspects as common criminals with a sorry past. Journalists labeled two as terrorism where suspects were identified as Muslim (Yin, 2013). Two of the cases, both in Oregon, involved bombers: Mohamed Mohamud and Joshua Turnidge. The other two involved shootings: the 2009 attack by Army psychologist Malik Hasan at Fort Hood and the 2011 mass shooting in Arizona by Jared Lee Loughner, who killed six people and wounded 13, including U.S. Congresswoman Gabrielle Giffords. In the two bombing cases, the local coverage of Mohamud garnered significant national media attention as an act of terrorism, while Turnidge's case did not (p. 47). 
Mohamud, the subject of an FBI sting, proposed making a car bomb to go off at a Portland Christmas-tree lighting ceremony. Agents helped him acquire materials and moved in for the arrest when he tried to detonate the device, which was inert. Turnidge, 32, called in bomb threats to two banks in December 2008. When police tried to detonate one device it exploded and killed two officers. The Oregonian described Turnidge and his father, who was also arrested, as conducting a murder plot, even as police cited anti-government sentiment as a motivation (Yin, 2013). Just 1.7 percent of stories about the Turnidges mentioned terrorism; 29.8 percent of the stories about Mohamud did so. And there were many more stories in total about Mohamud.

A recent analysis of two attacks in Canada found a similar proclivity among major news organizations to characterize non-Muslim perpetrators in a softer light. In two politically motivated attacks in 2014, Carver and Harrie (2017) found that the media labeled the one in which the suspect declared an allegiance to Islam as terrorism; the other was a "shooting spree." Michael Zehaf-Bibeau, a homeless man with a drugabuse problem who had converted to Islam, carried out one attack in Ottawa. The other, in Moncton, New Brunswick, was by Justin Bourque, a libertarian "gun enthusiast" with a hatred of government and police. Carver and Harrie (2017) write that a Muslim terrorist frame overrode the fact that Zehaf-Bibeau had mental health issues relating to substance abuse and homelessness. Reports did not portray Bourque as a terrorist, though he clearly had anti-government motives.

Many studies also demonstrate media bias against African American subjects (e.g., Entman \& Rojecki, 2000; Dixon \& Azocar, 2007). News coverage of crime involving African Americans tends to be framed in terms of already existing stereotypes about black citizens (Holt \& Major, 2010). While each case has unique circumstances, motivations, and treatment under the law, the research highlights a pervasive bias that makes violent and stereotyped assumptions about people of color, including Muslims. It is not possible to know what precise decisions lead organizations to their coverage of white-supremacist terrorism. However, the pattern is evident and it is borne out in research by antidiscrimination groups as well: mainstream media give significantly less coverage to violent acts that stem from right-wing extremism (AntiDefamation League, 2017). In many cases, news reports suggest the mental stability of the white perpetrators somehow precludes the possibility of terrorism. Police and attorneys frequently activate the specter of mental competence with white suspects. This detail clouds newsroom decisions about how to characterize white-supremacist attacks.

Dylann Roof, for example, refused to be declared unfit despite the insistence of his attorneys. He represented himself before a jury that later sentenced him to death. "There's nothing wrong with me psychologically," he told jurors (Blinder \& Sack, 2017). He planned his 


\section{Katherine M. Bell}

2015 killing of nine African Americans at the Emanuel AME Church in Charleston, South Carolina, for at least six months. He told police he wanted to start a race war, and he expressed no remorse. He believed that the "lower race" had forced him to take action. A court-appointed psychiatrist found him to suffer from a number of disorders, including social anxiety disorder and a schizoid personality disorder, both broad categories that have a range of symptoms.

The case prompted media discussion about whether Roof was motivated by extreme ideology and should be declared a terrorist. The shootings constituted the worst act of right-wing violence since McVeigh's 1995 bombing in Oklahoma City. In the aftermath, some media contemplated the disparity between the easy labeling of attackers who are Muslim or other people of color as terrorists. U.S. Attorney General Loretta Lynch's explanation did not clarify matters. She originally stated that federal officials were investigating Roof as a terrorist. He was charged with hate crimes. "Hate crimes are the original domestic terrorism and we feel that the behavior that is alleged to have occurred here is archetypal behavior that fits the federal hate crimes statutes and vindicates their purpose," Lynch told reporters (Craven, 2015).

The Roof case raises a number of issues that come into focus in the context of an overtly xenophobic White House. One is whether and how journalists can name an act of white-supremacist violence as terrorism when police, justice officials, or psychiatric experts might label the suspect mentally ill. The other is the confusing array of state and federal charges that suspects might face and how that creates impediments to media naming a white domestic perpetrator as a terrorist. The law offers limited options for terrorism-related charges against domestic suspects (Zakaria, 2016a), as I discuss further below. First, the following section examines research on the threat of right-wing violence, which provides a backdrop to the argument for news media to attend to institutionalized racial bias in the Trump era.

\section{The Threat of Right-Wing Violence}

If the news media are to erode the ideology of whiteness in journalism and employ ethical protocols that account for acts of extreme-right violence, they must take seriously a vast body of existing research. It includes:

- A study on the far right for the Combating Terrorism Center at West Point found that "contentious and conservative political environments as well as ... political empowerment" are associated with far-right violence, as well as "the sense of empowerment that emerges when the political system is perceived to be increasingly permissive to far right ideas" (Perliger, 2012, p. 5) 
- An analysis by Triangle Center on Terrorism and Homeland Security at Duke University stated that law enforcement agencies "consider anti-government violent extremists, not radicalized Muslims, to be the most severe threat of political violence that they face" in the United States (Kurzman \& Schanzer, 2015)

- A report prepared for the U.S. Department of Justice on "lone-wolf" terrorism found that the prominence of attacks by single perpetrators has been on the rise since $9 / 11$ and that military personnel and police have increasingly become targets of such attacks (Hamm \& Spaaj, 2015)

- A Southern Poverty Law Center study of both radical-right and jihadist terrorism from 2009 to 2015 found that an attack occurred on average every 34 days. Of the more than 60 incidents it examined, 74 percent were carried out by lone actors. It echoed other reports that find "more people have been killed in America by non-Islamic domestic terrorists than jihadists" (Potok, 2015, p. 4)

- An Anti-Defamation League study (2017) finds that right-wing extremism has been a major source of terrorism over 25 years and one under-represented by the media. The vast majority of incidents stem from white-supremacists and anti-government extremists. Most were by people acting on their own.

- A 2011 study by the New America Foundation, a Washington-based think tank, found that right-wing terrorists since 2001 had killed 48 people compared with 26 by jihadist attacks. It examined the motivations and attributes of the perpetrators. (Sterman \& Bergan, 2011)

This is not an exhaustive list, but such reports agree that right-wing violence, including white-supremacist violence, poses a serious national threat in the United States. As the 2017 Government Accountability Office report to Congress mentioned earlier states, since 2001, "fatalities resulting from attacks by far-right wing violent extremists have exceeded those caused by radical Islamist violent extremists in 10 of the 15 years," (GAO, p. 4). Of 85 extremist incidents that resulted in death since 9/11, "far right wing violent extremist groups were responsible for 62 (73 percent) while radical Islamist violent extremists were responsible for 23 (27 percent)" (p. 4). The Anti-Defamation League's inventory of 25 years of right-wing terrorism argues that the media have under reported the problem, which tamps down awareness among public officials and the public (2017, p. 1).

Several such studies classify right-wing extremism by type, which is a useful starting point for nuanced coverage. Perliger (2012), for example, delineates a typology of three major ideological strains. The first, white-supremacy groups, consists of the Ku Klux Klan, neo-Nazi groups, skinheads, and other organizations such as the National Alliance. These collectives aim to impose, or in their words to "preserve and restore," a 
racial hierarchy through establishing codified social and political control over non-whites. The second type of right-wing extremism includes sovereign citizen groups that aim to undermine the influence, legitimacy, and sovereignty of the federal government. It includes people such as McVeigh, although he also held white-supremacist beliefs. The third category fuses religious fundamentalism with white supremacy, Perliger suggests, as with groups such as the Aryan Nations.

These typologies are not discreet categories, as the McVeigh case points out. However, they do provide a framework for media to think about farright extremism. Equitable coverage on domestic terrorism in the Trump era begins with an understanding of whiteness as a pervasive ideology. It deploys consistent definitions and pays attention to a typology of extremism on the right where research identifies the greatest threat. The media cannot be limited by law-enforcement and justice system determinations of what counts as terrorism. They must develop and adapt a consistent colloquial understanding that captures the multiplicity of actors, many of whom are inspired by, but not members of, extremist groups.

The problem of deferring to official sources to classify news characterizations of terrorism is evident in a report for the Tow Center on Digital Journalism at the Columbia School of Journalism (Beckett, 2016). Editors reported a sense of discomfort with using the word "terrorism," sensing rightly that it was frequently misused. Some news organizations banned its use, while others grappled with the fact that the word can be a barrier to public understanding. One editor for $\mathrm{ABC}$ News told researchers that its journalists may only use the word when quoting someone else as having said it. "Our modus operandi is to do what it says on the tin. We would wait to see how someone [in authority] characterized it," said Jon Williams, international managing editor (Beckett, 2016, p. 18). Such a standard for naming terrorism means that the media cedes all power and moral authority to agencies that themselves are afflicted by institutional racial bias, as I discuss below.

The following section takes up the political pressures and influences that mainstream news organizations face as well as institutional biases that inflect journalism's response to white-supremacist violence. These responses include media uptake of institutional bias among law enforcement, justice, and legal representatives who downplay white violence as a form of terrorism. They also include structural impediments within the law. Both are linked, I argue, to the mental health frame so common in media coverage of white domestic perpetrators.

\section{Whiteness and Impediments to Media Coverage}

There's no doubt that matters of race come with vast political implications for the media. So strong is the pressure from elected and unelected officials that news organizations face a chill when they depart from the 
political rhetoric about terrorism as an act of an "evil" foreign aggressor (Beckett, 2016, p. 20). After the World Trade Center attacks, politicians chastised coverage that they believed did not toe the patriotic line. For example, Condoleezza Rice, U.S. Secretary of State under President George W. Bush, warned media against broadcasting material from Osama bin Laden (Thussu \& Freedman, 2003, p. 43). Some journalists lost their jobs for questioning the government's handling of the "war on terror" (pp. 163-164). Politicians declared criticism of the wars in Iraq and Afghanistan unpatriotic and disrespectful of the military personnel whom the Commander-in-Chief had ordered into battle. Since then, military, and political leaders, particularly Trump, continue to deploy the threat of foreign terrorism for political aims, even in the face of attacks by domestic actors.

Such institutionalized bias from the political sphere certainly beset the Obama administration as well. A Department of Homeland Security (DHS) report in 2009 warned that the economic downturn, coupled with the election of the first African American president "present unique drivers for rightwing radicalization and recruitment" (Office of Intelligence and Analysis, 2009, p. 2). It pointed out the willingness of a small number of disillusioned former military personnel to join extremist groups in the 1990s. Conservative politicians latched onto that point, saying it painted all veterans as right-wing extremists. In the ensuing storm of criticism, then Department of Homeland Security Secretary Janet Napolitano disavowed the entire report and issued an apology. The agency soon dismantled the DHS group that produced it.

Yet, Trump demonizes foreigners, and non-white citizens, with a torrent of invective too extensive to itemize. His vitriol linking terrorism to Islam has incited a moral panic that the White House used to justify discriminatory travel bans in 2017. In this toxic environment, which seeps outward to touch all people of color and gender minorities, the media face political pressure against attempts to define terrorism outside of hegemonic norms. The current political landscape valorizes the power of whiteness in journalism, and raises the stakes for media reliance on official sources that maintain racialized policies and language. American journalism norms, combined with pressures on corporate media to select saleable, clickable news content, stunt the media's resolve to risk backlash from powerful segments of the political and public spheres that rely on fear of difference.

Institutional bias within police and justice systems is one manifestation of the invisibility of whiteness that percolates through media coverage (c.f. Alexander, 2010). Federal terrorism laws are largely focused on international terrorism and on tracking and preventing terrorism by Muslims in particular. Only 33 states have laws to prosecute domestic terrorism not captured by federal statutes (Daniels, 2016). And U.S. federal law does not deal with the issue of material support 


\section{Katherine M. Bell}

for domestic terrorism (Zakaria, 2016a, 2016b). This means that hate speech by white-supremacists, on the internet or in public forums, is largely protected under the First Amendment. A Trump supporter can yell "Kill all Muslims," as happened during the campaign (Zakaria, 2016b), for instance, and white supremacists' spreading of hate online goes under the radar. Meanwhile authorities investigate and prosecute similar online activity by Muslims, such as retweeting or posting translations of jihadist material. Thus, news coverage that relies on an official definitions and confirmations of domestic terrorism will be deploying a race-based double standard.

As a report by the Tow Center for Digital Journalism at the Columbia School of Journalism argues, prosecution and reporting of hate crimes against Muslims remains low (Zakaria, 2016a, p. 6). If official sources do not telegraph the problem, the media are less likely to investigate it, despite consistent evidence of the threat of right-wing terrorism, including white-supremacist violence. Certainly, when new evidence comes out, such as the Anti-Defamation League's report (2017), the news media take notice. When a new attack takes place, media sometimes raise the question of terrorism, as with the Jackson and Christian cases in 2017, yet too often they pin this discussion to whether or not the accused will be charged with terrorism-related offences under the law or whether some official utters the word.

This tendency to defer has consequences, as scholars of critical race theory and others have argued (e.g., Crenshaw, 1995; Crenshaw, Ritchie, Anspach, \& Gilmer, 2015). Racial profiling has helped skew the public perception of terrorism and criminality toward people of color (Alexander, 2010; Yin, 2013, pp. 58-59). Police officers kill African Americans at traffic stops at a terrifying rate, and departments have spotty records, to say the least, at dealing with xenophobia from within (e.g., Department of Justice, 2016). Yet some notable media efforts to expose the roots of racial bias have had minimal impact. In January 2017, the news site The Intercept published an exclusive report from a classified FBI counterterrorism guide which states that white supremacists maintain an active presence in police departments and other domestic agencies (Speri, 2017). The FBI guide, dated 2015, discusses the agency's efforts to account for this infiltration. Likewise, an earlier well-publicized FBI intelligence assessment in 2006 also warned of white-supremacist groups' interest in infiltrating law enforcement (Speri, 2017).

Any infiltration by white supremacists in law enforcement agencies has to have an impact on the handling of white-supremacist crimes. At minimum, the expedient categorizing of white perpetrators as mentally ill is part of institutional bias that reinforces the invisibility of whiteness. The legal system poses the mental health question in opposition to terrorism. If the suspect is 'unhinged' it seems he-and most perpetrators are men-cannot be a terrorist. This is not true for non-white suspects. "Isn't it weird how we Muslims seem somehow immune to 'mental health 
issues?"” British journalist Mehdi Hasan noted in The Intercept (2017). Indeed, the question becomes whether mental health precludes the news media from reaching a different conclusion than what police, prosecutors, and defense attorneys publicly state. It is only through a willingness to examine the subtle pervasiveness of whiteness as an ideology that permeates institutions, including journalism, that members of the media can begin to unravel its hold.

\section{Whiteness as Official Policy}

This problem of bias is exacerbated in the current political moment. Trump is known to foment violence, including during campaign rallies of 2016 (e.g., Tiefenthaler, 2016) when he urged his crowd to "rough up" protesters and bemoaned the fact that security officers and police were not brutalizing those who protested or spoke against him from the crowd. In the summer of 2017, President Trump told an audience of law enforcement officers to not be too gentle with criminal suspects (Berman, 2017). "When you guys put somebody in the car and you're protecting their head, you know, the way you put their hand over?" Trump said. "I said, you can take the hand away, okay?" While some police departments and law enforcement organizations criticized the remark, some officers in the crowd clapped and smiled at the veiled reference to police brutality.

The Trump administration also reportedly planned to rename the Countering Violent Extremism program as "Countering Islamic Extremism" (Ainsley, Volz, \& Cooke, 2017), and it has held up funding for fighting right-wing terrorism (Pasha-Robinson, 2017). These moves highlight the administration's determination to stake its political ground on constructing a threat from outside the United States. If news organizations defer to official sources in deciding what counts as terrorism, and what constitutes a threat to U.S. citizens, it means that governments and agencies can deploy racially biased discourse and policies without a check on their power.

In the age of Trump, mainstream media must overcome their history of minimizing hate-based attacks from the right, a disposition rooted in an ideology of whiteness. News organizations cannot be governed by a legal and law enforcement fixation on the mental health of white suspects and indifference about the mental health of those who purport to act in the name of Islam. They must establish their own consistent standards for covering all political violence, including that by whitesupremacists and others on the extreme-right.

\section{Conclusion}

White-supremacy is a very uncomfortable subject in the United States, and the spectrum of news coverage about issues of race reflects that tension. In the Trump era, it is even more grievous for the media to gloss over the ideological biases that exist in political, religious, law enforcement 


\section{Katherine M. Bell}

and media circles. There is abundant evidence of racial bias, some overt and some percolating through the structures of whiteness that hold up our institutions, including within the Fourth Estate. Media will require an ideological shift to fully address the distinct Orientalist clash of civilization narrative that continues to drive coverage.

That narrative is inseparable from xenophobia that makes all people of color in the United States, particularly African Americans the research suggests, a target of violent extremism. Without a doubt, naming an act of terrorism is a complicated task. It asks a lot of editors that they formulate definitions that do not adhere to those in statutes or agency policy, or that are carried on the lips of official sources. Yet those official definitions are rooted in racial bias. Therefore, it is incumbent upon the credible mainstream media to employ ethically consistent criteria in naming terrorism.

The current media ecosystem includes many microclimates, not least of which is the right-wing news machine that has grown by leaps and bounds since Fox News made its debut in 1996. In the Trump era it includes Breitbart News, the rise of the propagandist Sinclair Broadcasting, the paranoid screeds of such characters as Alex Jones, and the more intellectual bigotry put forth by Richard Spencer. It includes an all-out assault by the right to change what counts as news and to defy the rigors of evidence and reason. This assault on fact-based journalism only adds to the stakes of reporting on hate from within the boundaries of the United States. This "post-truth" climate and the mainstreaming of organizations such as Breitbart in the White House press corps signals a media epoch that will not disappear when Trump leaves the Oval Office.

In the face of these challenges, the media cannot underestimate the current moment as a potential watershed for the normalizing of hate speech and for the end of even minimal civil discourse. Trump has brought a seismic shift in rhetoric and bigotry. And even in the era of social media his administration has been obsessed with how national news organizations cover the former reality TV star. With nearly every public address he brings injury to some individual or minoritized group. Trump's presidency heralds a kind of white identity politics and policy decisions that aim to roll back the gains made in the Civil Rights movement. The media's role in challenging racialized representations has never been more urgent, and that urgency calls for journalism to take stock of the racialized nature of its norms and practices and of the ideologies of whiteness that can be invisible to the eye.

\section{Note}

1 An original ban in January 2017 included Iraq, Syria, Iran, Sudan, Libya, Somalia, and Yemen. A later ban did not include Iraq. Both bans were challenged at the federal and/or Supreme Court levels. 


\section{References}

Acker, L. (2017a, June 2). Who is Jeremy Christian? Facebook shows a man with nebulous political affiliations who hated circumcision and Hillary Clinton. The Oregonian. Retrieved at www.oregonlive.com/portland/index. ssf/2017/05/who_is_jeremy_christian_facebo.html.

Acker, L. (2017b, June 11). Jeremy Christian's vocabulary and related ideas, explained. The Oregonian. Retrieved at www.oregonlive.com/portland/ index.ssf/2017/06/jeremy_christians_vocabulary_a.html.

Ainsley, J. E., Volz, D., \& Cooke, K. (2017, February 2). Exclusive: Trump to focus counter-extremism program solely on Islam - sources. Reuters. Retrieved at www.reuters.com/article/us-usa-trump-extremists-programexclusiv-idUSKBN15G5VO.

Akram, S. M. (2002). The aftermath of September 11, 2001: The targeting of Arabs and Muslims in America. Arab Studies Quarterly, 24(2/3), 61-118.

Alemán, S. M. (2014). Locating whiteness in journalism pedagogy. Critical Studies in Media Communication, 31(1), 72-88.

Alexander, M. (2010). The New Jim Crow: Mass Incarceration in the Age of Colorblindness. New York, NY: New Press.

Altwaiji, M. (2014). Neo-Orientalism and the neo-imperialism thesis: Post-9/11 US and Arab world relationship. Arab Studies Quarterly, 36(4), 313-323.

Amarasingam, A. \& Davey, J. (2017, June 21). What about terror by the far right? The New York Times. Retrieved at www.nytimes.com/2017/06/21/ opinion/finsbury-park-terrorist-attack-far-right.html.

Amin-Khan, T. (2012). New Orientalism, securitization, and the Western media's incendiary racism. Third World Quarterly, 33(9), 1595-1610.

Anti-Defamation League. (2017). A Dark and Constant Rage: 25 years of Rightwing Terrorism in the United States. New York, NY: Anti-Defamation League.

Beckett, C. (2016). Fanning the Flames: Reporting Terror in a Networked World. New York, NY: Tow Center for Digital Journalism.

Berman, M. (2017, July 28). Trump tells police not to worry about injuring suspects during arrests. The Washington Post. Retrieved at www.washingtonpost. com/news/post-nation/wp/2017/07/28/trump-tells-police-not-to-worryabout-injuring-suspects-during-arrests/?utm_term $=.25 \mathrm{a} 3 \mathrm{e} 49 \mathrm{~b} 85 \mathrm{e} 1$.

Bernstein, M. (2017a, June 2). Man accused in MAX attack confessed to stabbing, said, "I'm happy now. I'm happy now." The Oregonian. Retrieved at www.oregonlive.com/portland/index.ssf/2017/05/man_accused_in_max_ attack_cont.html\#incart_big-photo.

Bernstein, M. (2017b, June 4). Does hate crime law apply to MAX stabbing? Federal prosecutors still deciding. The Oregonian. Retrieved at www.oregonlive. com/portland/index.ssf/2017/06/does_hate_crime_law_apply_to_m.html.

Blinder, A. \& Sack, K. (2017, January 4). Dylann Roof, addressing court, offers no apology or explanation for massacre. The New York Times. Retrieved at www.nytimes.com/2017/01/04/us/dylann-roof-sentencing.html?mcubz=1.

Bromwich, J. E. \& Blinder, A. (2017, August 13). What we know about James Alex Fields, driver charged in Charlottesville killing. The New York Times. Retrieved at www.nytimes.com/2017/08/13/us/james-alex-fieldscharlottesville-driver-.html? mcubz $=0$.

Carroll, L. (2015, November 22). Fact-checking Trump's claim that thousands in New Jersey cheered when World Trade Center tumbled. PolitiFact. Retrieved 


\section{Katherine M. Bell}

at www.politifact.com/truth-o-meter/statements/2015/nov/22/donald-trump/ fact-checking-trumps-claim-thousands-new-jersey-ch/.

Carver, A. \& Harrie, C. (2017). Framing terrorists in Canada: A comparative analysis of two shootings. International Journal of Criminal Justice Sciences, 12(1), 98-110.

CNN. (2017). Trump's speech in Warsaw. CNN. Retrieved at www.cnn. com/2017/07/06/politics/trump-speech-poland-transcript/index.html.

Craven, J. (2015, July 24). Dylann Roof wasn't charged with terrorism because he's white. Huffington Post. Retrieved at www.huffingtonpost.com/entry/ dylann-roof-terrorism_us_55b107c9e4b07af29d57a5fc.

Crenshaw, K. (1995). Critical Race Theory: The Key Writings that Formed the Movement. New York, NY: New Press.

Crenshaw, K., Ritchie, A. J., Anspach, R., \& Gilmer, R. (2015). Say Her Name: Resisting Police Brutality Against Black Women. Center for Intersectionality and Social Policy Studies. New York, NY: Columbia University.

Daniels, L. (2016, October 26). Prosecuting terrorism in state court. Lawfare. Retrieved at www.lawfareblog.com/prosecuting-terrorism-state-court.

Department of Justice. (2016). Investigation of the Baltimore City Police Department. Civil Rights Division. Washington, D.C.: U.S. Department of Justice.

Dixon, T. L. \& Azocar, C. L. (2007). Priming crime and activating blackness: Understanding the psychological impact of the overrepresentation of blacks as lawbreakers on television news. Journal of Communication, 57(2), 229-253.

Dolan, K. (2011). Whiteness and News: The Interlocking Social Construction of "Realities." Urbana, IL: University of Illinois at Urbana-Champaign. Retrieved at www.ideals.illinois.edu/handle/2142/24404.

Domonoske, C. (2016, August 5). Former KKK leader David Duke says "Of course" Trump voters are his voters. NPR. Retrieved at www.npr.org/ sections/thetwo-way/2016/08/05/488802494/former-kkk-leader-davidduke-says-of-course-trump-voters-are-his-voters.

Doubek, J. (2017, February 2). Breitbart editor's event canceled as protests turn violent at UC Berkeley. NPR. Retrieved at www.npr.org/sections/ thetwo-way/2017/02/02/512992000/breitbart-editors-event-canceled-asprotests-turn-violent-at-uc-berkeley.

Eligon, J., Blinder, A., \& Najar, N. (2017, February 24). Hate crime is feared as 2 Indian engineers are shot in Kansas. The New York Times. Retrieved at www. nytimes.com/2017/02/24/world/asia/kansas-attack-possible-hate-crimesrinivas-kuchibhotla.html? $\mathrm{mcubz}=0$.

Entman, R. M. \& Rojecki, A. (2000). The Black Image in the White Mind: Media and Race in America. Chicago, IL: University of Chicago Press.

Fisher, M. (2017, June 20). Complex Politics of “Terrorism” Label, New York Times, p. A8.

Friedersdorf, C. (2015, April 24). When police brutality goes beyond "a bad apple" cop. The Atlantic. Retrieved at www.theatlantic.com/national/ archive/2015/04/when-police-brutality-goes-beyond-a-bad-apple/390303.

Fulwood, S. (2017, February 27). The rise and fall of an alt-Right Breitbart hero. Newsweek. Retrieved at www.newsweek.com/rise-fall-alt-right-breitbarthero-561735.

GAO. (2017, April). Countering Violent Extremism: Actions Needed to Define Strategy and Assess Progress of Federal Efforts. Washington, D.C.: U.S. Government Accountability Office. Retrieved at www.gao.gov/assets/690/683984.pdf. 
Hamm, M. \& Spaaj, R. (2015). Lone Wolf Terrorism in America: Using Knowledge of Radicalization Pathways to Forge Prevention Strategies. Terre Haute, IN: Indiana State University.

Hanhimäki, J. M. \& Blumenau, B. (2013). An International History of Terrorism: Western and Non-Western Experiences. Abingdon, Oxon \& New York, NY: Routledge.

Harkinson, J. (2016, Oct. 27). Meet the white nationalist trying to ride the Trump train to lasting power. Mother Jones. Retrieved at www.motherjones. com/politics/2016/10/richard-spencer-trump-alt-right-white-nationalist.

Hasan, M. H. (2017, May 31). The numbers don't lie: White far-right terrorists pose a clear danger to us all. The Intercept. Retrieved at https:// theintercept.com/2017/05/31/the-numbers-dont-lie-white-far-rightterrorists-pose-a-clear-danger-to-us-all.

Heider, D. (2000). White News: Why Local News Programs Don't Cover People of Color. Mahwah, NJ: Erlbaum.

Hayes, S. (2017, August 17). Hayes: Where are Trump's “very fine people?" The Weekly Standard. Retrieved at www.weeklystandard.com/hayeswhere-are-trumps-very-fine-people/article/2009330.

Hoffman, B. (2006). Inside Terrorism. New York, NY: Columbia University Press.

Ismael, T. \& Measor, J. (2003). Racism and the North American media following 11 September: The Canadian setting. Arab Studies Quarterly, 25(1/2), 101-136.

Jensen, R. B. (2013). The first global wave of terrorism and international counter-terrorism. In J. M. Hanhimäki \& B. Blumenau (Eds.), An International History of Terrorism: Western and Non-Western Experiences (pp. 16-33). Abingdon, Oxon \& New York, NY: Routledge.

Johnson, J. (2015, December 7). Trump calls for "total and complete shutdown of Muslims entering" the United States. The Washington Post. Retrieved at www. washingtonpost.com/news/post-politics/wp/2015/12/07/donald-trumpcalls-for-total-and-complete-shutdown-of-muslims-entering-the-unitedstates/?utm_term=.299adbf0ce02.

Kellner, D. (2016). Media Spectacle and the Crisis of Democracy: Terrorism, War and Election Battles. New York, NY: Routledge.

Kurzman, C. \& Schanzer, D. (2015). Law Enforcement Assessment of the Violent Extremism Threat. Triangle Center on Terrorism and Homeland Security. Durham, NC: Duke University.

Lerner, K. (2017, May 22). Member of “Alt Reich” Facebook group charged with stabbing black student to death. Think Progress. Retrieved at https:// thinkprogress.org/umd-stabbing-hate-6e62dfeb19e7.

Lipsitz, G. (1998). The Possessive Investment in Whiteness: How White People Profit From Identity Politics. Philadelphia: Temple University Press.

Nakayama, T. K. \& Krizek, R. L. (1995). Whiteness: A strategic rhetoric. Quarterly Journal of Speech, 81, 291-309.

National Institute of Justice. (n.d.). Research on Domestic Radicalization and Terrorism. Washington, D.C.: National Institute of Justice. Retrieved at https://nij.gov/topics/crime/terrorism/Pages/welcomeOLD.aspx.

Office of Intelligence and Analysis. (2009). Rightwing Extremism: Current Economic and Political Climate Fueling Resurgence in Radicalization and Recruitment. Washington, D.C.: U.S. Department of Homeland Security.

Omi, M. \& Winant, H. (1986). Racial Formation in the United States: From the 1960s to the 1980s. New York, NY: Routledge \& Kegan Paul. 


\section{Katherine M. Bell}

Ono, K. A. \& Pham, V. N. (2009). Asian Americans and the Media. Cambridge, UK \& Malden, MA: Polity.

Oregonian. (2017, May 30). "Too early" to call MAX attacks a federal hate crime or terrorism. The Oregonian. Retrieved at www.oregonlive.com/ portland/index.ssf/2017/05/too_early_to_call_max_attacks.html.

Oxford English Dictionary. (n.d.). "terrorism, n.”. Retrieved from http://www. oed.com/view/Entry/199608? redirectedFrom=terrorism\&.

Pasha-Robinson, L. (2017, May 3). Donald Trump freezes funding to groups fighting right-wing terror and white supremacism. The Independent. Retrieved at www.independent.co.uk/news/world/americas/us-politics/donald-trumpcounter-violent-domestic-extremism-white-supremacism-cve-funding-freeze10-million-a7715101.html.

Perliger, A. (2012). Challengers from the Sidelines: Understanding America's Violent Far-right. West Point, NY: Combating Terrorism Center, U.S. Military Academy.

Potok, M. (2015). A Study of the Rise of Lone Wolf and Leaderless Resistance. Montgomery, AL: Southern Poverty Law Center.

Powell, K. (2011). Framing Islam: An analysis of U.S. media coverage of terrorism since 9/11. Communication Studies, 62(1), 90-112.

Rapoport, D. C. (2013). The four waves of modern terror. In J. M. Hanhimäki \& B. Blumenau (Eds.), An International History of Terrorism: Western and non-Western Experiences (pp. 282-310). Abingdon, Oxon \& New York, NY: Routledge.

Riegler, T. (2013). Quid pro quo: State sponsorship of terrorism in the Cold War. In J. M. Hanhimäki \& B. Blumenau (Eds.), An International History of Terrorism: Western and Non-Western Experiences (pp. 115-132). Abingdon, Oxon; New York, NY: Routledge.

Robinson, E. (2017, August 14). Trump's response to Charlottesville should surprise no one. The Washington Post. Retrieved at www.washingtonpost. com/opinions/trumps-response-to-charlottesville-should-surprise-noone/2017/08/14/f5cd59c6-8125-11e7-ab27-1a21a8e006ab_story.html?utm_ term $=. c 512 \mathrm{~d} 3 \mathrm{dbd} 062$.

Said, E. W. (1978). Orientalism. New York, NY: Pantheon Books.

Said, E. W. (1997). Covering Islam: How the Media and the Experts Determine How We See the Rest of the World. New York, NY: Vintage Books.

Schmid, A. P. (1983). Political Terrorism: A Research Guide to Concepts, Theories, Data Bases and Literature. New Brunswick, NJ: Transaction.

Shear, M. \& Haberman, M. (2017, August 15). Trump defends initial remarks on Charlottesville; again blames "both sides." The New York Times. Retrieved at www.nytimes.com/2017/08/15/us/politics/trump-press-conference-charlott esville.html? mcubz=0.

Shome, R. (2000). Outing whiteness. Critical Studies in Media Communication, 17(3), 366-371.

Shome, R. (1996). Race and popular cinema: The rhetorical strategies of whiteness in city of joy. Communication Quarterly, 44(4), 502-518.

Southall, A. (2017, March 22). Suspect in Manhattan killing hated black men, police say. The New York Times. Retrieved at www.nytimes.com/2017/03/22/ nyregion/manhattan-nyc-james-harris-jackson-hate-crime.html? mcubz=0.

Speri, A. S. (2017, January 31). The FBI has quietly investigated white supremacist infiltration of law enforcement. The Intercept. Retrieved at 
https://theintercept.com/2017/01/31/the-fbi-has-quietly-investigated-whitesupremacist-infiltration-of-law-enforcement.

Sterman, D. \& Bergan, P. (2011). Terrorism in America After 9/11. New America Foundation. Retrieved at www.newamerica.org/in-depth/terrorismin-america/.

Strickland, P. \& Gottbrath, L.W. (2017, July 10). Threats and attacks: White supremacists target campuses. Al Jazeera. Retrieved at www.aljazeera. com/indepth/features/2017/07/threats-attacks-white-supremacists-targetcampuses-170708055258069.html.

Stolberg, S. G. \& Rosenthal, B. M. (2017, August 12). Man charged after white nationalist rally in Charlottesville ends in deadly violence. The New York Times. Retrieved at www.nytimes.com/2017/08/12/us/charlottesvilleprotest-white-nationalist.html? mcubz=0.

Thrush, G. \& Haberman, M. (2017, August 15). Trump gives white supremacists an unequivocal boost. The New York Times. Retrieved at www.nytimes. com/2017/08/15/us/politics/trump-charlottesville-white-nationalists. html?mcubz=0\&_r=0.

Thussu, D. K. \& Freedman, D. (2003). War and the Media: Reporting Conflict 24/7. London, UK: Sage.

Tiefenthaler, A. (2016). Trump's history of encouraging violence. The New York Times. Retrieved at www.nytimes.com/video/us/100000004269364/ trump-and-violence.html? mcubz=1.

Washington Post. (2015, June 16). Full text: Donald Trump announces a presidential bid. The Washington Post. Retrieved at www.washingtonpost. com/news/post-politics/wp/2015/06/16/full-text-donald-trump-announcesa-presidential-bid/?utm_term=.97875bb98924.

Williams, J. P. (2016, July 13). Why aren't police prosecuted? U.S. News \& World Report. Retrieved at www.usnews.com/news/articles/2016-07-13/ why-arent-police-held-accountable-for-shooting-black-men.

Wilson, C. C. (1995). Race, Multiculturalism, and the Media: From Mass to Class Communication. Thousand Oaks, CA: Sage.

Yin, T. (2013). Were Timothy McVeigh and the Unabomber the only white terrorists?: Race, religion, and the perception of terrorism. Alabama Civil Rights and Civil Liberties Law Review, 4, 33-87.

Zakaria, R. (2016a). Hate \& Incriminate: The U.S. Election, Social Media, and American Muslims. New York, NY: Tow Center for Digital Journalism. Retrieved at www.cjr.org/tow_center_reports/hate_terrorism_trump_election_ social_media_american_muslims.php.

Zakaria, R. (2016b). How Media Coverage of Terrorism Endorses a Legal Double Standard. New York, NY: Tow Center for Digital Journalism. Retrieved at www.cjr.org/special_report/media_terrorism_muslim_law_trump.php. 


\section{The Hell that Black People Live Trump's Reports to Journalists on Urban Conditions}

\section{Carolyn Guniss}

It's February 16, 2017.

Donald J. Trump has been in the White House as Commander-in-Chief for just about a month.

Trump holds a press conference to announce that he had nominated Alexander Acosta, a Hispanic man, as the U.S. Secretary of Labor. He uses the moment to update Americans about the "mess at home and abroad" that he inherited. He also took questions from journalists at his first press conference as president.

Trump takes a question from April Ryan, a veteran White House correspondent for American Urban Radio Networks. She has been in that role since 1997, is in the process of covering her fourth U.S. president, and serves as the radio network's Washington, D.C. bureau chief.

Standing about midpoint, to the left of the room for the viewers, she signals to Trump that she wants to ask a question.

Trump does what he does best when dealing with people of color: He finds a way to offend Ryan.

"Yes, oh, this is going to be a bad question, but that's OK," he said.

It is unclear what Trump meant by the statement, but whatever he meant, it wasn't positive. Is it that he expected a badly phrased question, or that she was going to ask a question that was going to make him uncomfortable? The reporters who had asked questions before Ryan asked about his ties to the Russian controversy and Michael Flynn, Trump's fired national security adviser. Those were "bad questions" for Trump.

Ryan pivots to the question that the 41 million or so Black people in America wanted to know the answer to: When was Trump going to implement his plan for the nation's “inner cities" - Trump's code word for Black neighborhoods, but by no means an accurate description.

To contextualize Ryan's question, we must enumerate Trump's colossally flawed agenda for Black Americans - if one can use such a positive word as "agenda" to describe Trump's antagonistic, ignorant attitude toward this group.

Even the way Trump treated the seasoned White House correspondent who no doubt had spent more time in the White House than Trump had at 
that point - was demeaning. Trump didn't even let Ryan finished her question before he started to answer it.

He first says that her question was good and professional. Everyone should have known from that moment the exchange was going to deteriorate. He basically told Ryan with that statement, "I didn't expect very much from you."

Hard to know if it was her gender that made Trump feel she would be less than professional or if it was a combination of being Black and a woman that gave Trump a reason to have low expectations.

Ryan follows up with a question as to whether the president planned to meet with the "CBC." Trump, the political neophyte, doesn't know the popular acronym, so Ryan is accommodating and rephrases her question, replacing "CBC" with "Congressional Black Caucus."

Trump again acts less than appropriate. He asks Ryan to set up the meeting between himself and the Black Caucus.

Ryan respectfully declines to set up Trump's meeting.

Ryan raised the question because the Caucus had written to Trump, as well as had used Trump's preferred way of communicating - Twitter to request a meeting. The Caucus had pointed out on social media that Trump had not responded to its letter.

Trump goes on to ask Ryan if she knew any of the Caucus members and if they were her friends. Here again, Trump is being disrespectful and condescending. He is also intimating that neither he nor his staff would know anyone in the Caucus, but since Ryan is a Black person, certainly she should.

The Ryan volley with Trump underscores the way Trump thinks of and refers to Black people. When he speaks of them it is as if they are forgeiners, aliens. He refers to the entire Black population as "they," "them," and "those."

The exchange overshadowed the press conference as most media outlets latched onto the story.

It would only be about six weeks later when then-Press Secretary Sean Spicer had a testy exchange with Ryan during a press conference.

On March 28, 2017, Ryan asks Spicer how the White House was going to fix its image since in less than three months it had managed to draw so many negative stories.

By now, the Trump administration was facing an investigation into its ties to Russia and had alleged that the Obama administration had wiretapped Trump Tower, which turned out to be false. Spicer, during the very combative interview, twice tells Ryan to stop shaking her head, which she doing in response to his empty answers (Henderson, 2017).

Another round of headlines and broadcasts ensued. For Ryan, Trump's and Spicer's gaffs raised her profile and seemingly created opportunity, both for media outlets and for Ryan. CNN announced on April 3, 2017, 
that Ryan was hired as a political contributor and that; the National Association of Black Journalists had named her Journalist of the Year.

Let's take a look at some interactions that Trump has had with African Americans, especially in context of the "hell" in which they live, an observation Trump himself made. This essay will explore not only the results of the negative influence Trump's dealing with Black people produces, it will also explore his and his family's documented history of racism and questionable behavior.

Quietly, in tandem with Trump's ascent, violence against African Americans across the nation had ticked up. Reported in isolation to each location, the story about the salacious trend and its impact was flying under the radar. But the national disruption became evident when violent clashes started appearing on college campuses.

In June 2017, The New York Times reported that there were 900 incidents of hate within 10 days after the 2016 presidential election, as collected by the Southern Poverty Law Center. By March, the center had enumerated more than 1,800 (North, 2017).

"White supremacist charged with terrorism over murder of black man," is the headline on a March 28, 2017, article by NPR about the added charge of terrorism to a White supremacist who had traveled from Baltimore to New York to kill a Black man, which he did on March 22, 2017 (Domonoske, 2017).

A Slate article on June 1, 2017, "What we have unleashed," held the premise that the spate of hate crimes happening in 2017 were connected to Trump's ideologies and popularity. The article pieces together killing after killing of people of color across the nation - all in the name of race and during the ascension of Trump (Bouie, 2017).

"Hate crimes up in California, fueled by hate-filled trump era," is the headline of a July 15, 2017, article in The Los Angeles Blade. The Blade's piece cited statistics from the California Department of Justice's annual report released July 3, 2017, showing hate crimes were up 10 percent against Muslims and Latinos, the groups Trump berated the most (Ocamb, 2017).

Welcome to the era of Trump.

\section{Trump, Self-Proclaimed Answer for Black America}

In courting the African American vote, which Trump seemingly grudgingly did, he addressed them directly, ironically however, before a crowd of mostly White people at an August 19, 2016, rally in Michigan.

There, Trump said Black people were living in "hell" and that he had a plan to change all that.

"What the hell do you have to lose?" Trump asked. "No group in America has been more harmed by Hillary Clinton's policies than African Americans - no group." 
He continued:

The inner cities of our country have been run by the Democratic Party for more than 50 years. ... it is time to hold them accountable for what they have done to these communities. Look how much African American communities have suffered under Democratic control. To those I say the following: 'What the hell do you have to lose by trying something different, like Trump?'

Trump was making the appeal just about three months before the 2016 presidential election. By then, Trump was already damaged goods to many African Americans, mostly because how he tortured President Barack Obama with his made-up lies about where Obama was born. The media dubbed it the Obama birther issue.

So, it seemed hypocritical if not downright foolhardy for Trump to believe all of the people would soon forget and throw him their support.

A subtle pattern had emerged during Trump's campaign: He planned to dismantle everything that he could that Barack Obama had put into place while he was president.

Underlying that argument is that Trump was going to be a better president than the Black president.

Trump would spend the first few months of his presidency rolling back Obama's policies, including those done by executive orders. Then there would be the failed attempts to dismantle the Affordable Care Act, better known as Obamacare.

To better understand Trump's contempt for Black citizens, and the outgoing president in particular, however, we must flashback to Obama's first term in office.

Trump, and people who think like him, were very angry that a Black man was leading America. He and others were also concerned that Obama was not acting forceful enough toward radical Islam.

So, it wasn't a surprise that a prominent white person would attack President Obama. It was probably more surprising that it was Donald Trump, the somewhat eccentric real estate mogul who had made several attempts before at the Oval Office, starting in 1987 (TV Guide, 2015).

Still, Trump's try again made sense.

Trump was now an international household name. He had created the wildly popular The Apprentice reality show, which ended weekly with Trump or his children saying the catch phrase, "You're fired." The public had met him over the years, mostly through the Trump brand and his frequent and well-publicized bankruptcies.

In the 2000 presidential primaries, for example, Trump received 15,000 votes as a Reform Party candidate in the party's California primary (TV Guide, 2015). 
But Trump had seared himself into the consciousness of Black Americans, especially New Yorkers, in the Central Park Jogger case - 20 years prior.

In 1989, police arrested four Black and one Latino boys and charged them with raping a white woman in Central Park, a case that positioned Trump as an advocate for racist and harsh law and order policies (Ross, 2016).

The next month, in May 1989, Trump took out full-page ads that cost $\$ 85,000$ in four New York dailies, condemning the act, calling for a return of the death penalty, and even suggesting civil liberties end when safety is at stake (Sorkin, 2014).

Known as the Central Park Five, the boys, who ranged in ages 14 to 16, were given sentences ranging from 5 to 15 years, but they were all released in 2002 after DNA exonerated them and another man confessed to the crime (Weiser, 2014). The boys had served between 6 and 13 years for a crime that they had not committed but to which they made coerced confessions.

During the 2016 campaign, Trump still maintained that the Central Park Five were guilty (Burns, 2016). The nation would soon come to find out that Trump's racist stereotyping was a part of a pattern established by his father and inherited by the son.

Consider the following, for instance. Between 1969 and 1982, the U.S. Justice Department and other individuals sued Trump or his family, mostly concerning housing discrimination (Corn, 2016; NPR, 2016).

Though never convicted or forced to pay a fine, the frequent challenges do seem to speak to a culture in which the Trump business did not try to implement best practices and industry standards to avoid actions that conflicted with federal housing laws.

And while Trump didn't pay a housing fine - for those claims, anyway The Trump Plaza Hotel and Casino was once forced to pay $\$ 200,000$ to the Casino Control Commission, a fine for race discrimination in the workplace (UPI, 1992). It was alleged that Blacks and female dealers had to be moved to other tables to accommodate a favored racehorse broker.

Anger toward Trump within Black communities only increased as he took on the country's first Black president - Barack Obama.

\section{Where Were You Born?: Trump on (His) Birther Issue}

Birther (informal) - A person who doubts the legitimacy of Barack Obama's presidency because of a conspiracy theory that Obama is not a natural-born US citizen.

Google Dictionary, 2017

Despite all the racial baggage and gauche statements, Trump would save his most provocative, deceptive, and divisive statements for his most-recent forage his into politics. 
If we, and I mean those of us in the media, were paying attention, we would have noticed that in March 2011, Trump made a soft launch of his 2016 presidential campaign. He did so picking the biggest dog in the pen with whom to pick a fight: Barack Obama.

Trump understood that if he even sneezed within distance of Obama, he would be guaranteed a headline or a sound bite.

Trump had a foe, and that foe was the leader of the free world at the time, Obama.

Trump couldn't have chosen a better protagonist for what would become a carefully (or not) orchestrated campaign issue. By floating the birther issue, consider the elements that could be investigated, if even briefly, at least according to Trump and his supporters:

- Did Americans elect a non-America to lead the nation?

- Did that create a Constitutional problem?

- How did Obama make it this far, if he wasn't a citizen?

- Did Obama have people perpetuate a fraud?

- If Obama's father is African, that mean's his father is from another country, and doesn't that strengthen concerns about Obama's own nationality?

Yes, the birther lie had enough known dimensions that surely the story would last way into the campaign.

Trump was right - the birther lie was a lie that could not be buried.

In 2016, The New York Times chronicled how Trump started the incredulous lie (Parker \& Eder, 2016). According to the Times:

In the birther movement, Mr. Trump recognized an opportunity to connect with the electorate over an issue many considered taboo: the discomfort, in some quarters of American society, with the election of the nation's first Black president. He harnessed it for political gain, beginning his connection with the largely white Republican base that, in his 2016 campaign, helped clinch his party's nomination.

"The appeal of the birther issue was, 'I'm going to take this guy on, and I'm going to beat him," said Sam Nunberg, who was one of Mr. Trump's advisers during that period but was fired from his current campaign. "It was a great niche and wedge issue."

The Times said Trump taunted the president for six weeks straight and abruptly stopped, but it wasn't before he publicly asked Obama to show his birth certificate, raised doubt Obama's American citizenship, and caused uneasiness for the nation's first Black president.

Trumps rant lived on, too. 
On August 6, 2012, Trump wrote on Twitter: "An 'extremely credible source' has called my office and told me that @BarackObama's birth certificate is a fraud."

The note was retweeted 23,773, and as late as August 2017, the birther story was still getting headlines, the latest being about how the Republican Party should have stopped Trump from advancing the birther lie.

Sounds like a veiled apology to me, and now that the Republicans are deep in buyers' remorse of their support and election of the Tweeter-inChief, they are claiming mea culpa.

The birther lie should have died a quick death. It should have been fact-checked and laid to rest.

But the media was complicit because Trump generated sound bites, hits, and headlines.

In a time that traditional media were under extreme pressure from bloggers, vloggers, and podcasters, Trump was a saving grace.

Not much has changed.

\section{Starting a Race War}

During his campaign, Trump seemed to be baiting a race war, though his moves were either lost on society or not taken seriously by Americans and their media.

Trump tested the idea that Americans live in a post-racial utopia and would beat back the hateful diatribe he spewed. But within months of even discussing his run for president, he proved that a post-racial America was a farce, a figment of hopeful imaginations.

Trump opened his campaign June 16, 2015, with the infamous inflammatory speech about Mexican immigrants:

When Mexico sends its people, they're not sending their best. They're not sending you. They're not sending you. They're sending people that have lots of problems, and they're bringing those problems with us. They're bringing drugs. They're bringing crime. They're rapists. And some, I assume, are good people.

(Washington Post, 2015)

Trump would continue to dig a hole of disdain and display his lack of intelligence about African Americans, Latinos, Jewish Americans, Chinese Americans, and well, pretty much everyone.

At the first presidential debate on September 26, 2016, at Hofstra University in Hempstead, New York, baseless Trumpism was once again uttered about Blacks.

When NBC broadcast journalist Lester Holt asked the candidates what it was that they planned to do to fix race relations in the United 
States following widening fissures amplified by shootings of AfricanAmericans by police, Trump delivered this response:

We have a situation where we have our inner cities, AfricanAmericans, Hispanics are living in hell because it's so dangerous. You walk down the street, you get shot. In Chicago, they've had thousands of shootings, thousands, since January 1st. Thousands of shootings. And I say, where is this? Is this a war-torn country? What are we doing? And we have to stop the violence, we have to bring back law and order, in a place like Chicago, where thousands of people have been killed. Thousands, over the last number of years.

(Blake, 2016)

That night may have been the beginning of journalists and journalism organizations like PolitiFact fact-checking Trump, almost in real time, and articles appeared about the rising African American middle class and the declining crime rates in key Black communities.

An NBC News analysis of Trump's speech called Trump's answer about Black communities antiquated. In his September 28, 2016, article "In 2016 Debate, Donald Trump Spoke of a Black America That No Longer Exists," author Perry Bacon Jr. pointed out that Trump seemed "like a man who had stopped reading the news about Black Americans in 1987" (Bacon, 2016).

Former President of the National Association for the Advancement of Colored People Cornell Brooks was quoted in The Los Angeles Times article "Trump says African Americans are living in hell (Kaleem \& Simmons, 2016). That depends on what you mean by hell" said Trump's statement was too board and was without context.

"To say African Americans are living in hell, that has the descriptive specificity of a bumper sticker," Brooks said. "There are communities where there are hellish conditions, but there are also communities where you find people who are gainfully employed, who attend houses of faith. There are vibrant cultural and artistic communities."

An op-ed in The New York Times stated that data from whitepapers and government agencies shows that, despite Trump's claims of massive, Black economic decline, "the black upper middle class is ascending the economic ladder at a faster rate than its white counterpart" (Edsall, 2017).

But Trump was not wrong about his assessment of Chicago, specifically, PolitiFact found (Valverde, 2016). PolitiFact rated the comment that Trump made about the thousands of shootings in Chicago as being true.

Still, Trump's stumbling in the dark continued, and he rolled out his urban renewal plan for rebuilding America's inner cities. 
Trump dubbed it a New Deal for Black America, which included "safe communities, great education, and high-paying jobs" (Funk \& Morrill, 2016).

Originally released to MediaTakeOut.com, Trump's transition team in November 2016 released a 10-point plan for Black America. Trump said his administration would provide:

- Great Education Through School Choice

- Safe Communities

- Equal Justice Under the Law

- Tax Reforms to Create Jobs and Lift up People and Communities

- Financial Reforms to Expand Credit to Support New Job Creation

- Trade That Works for American Workers

- Protection from Illegal Immigration

- New Infrastructure Investment

- Protect the African-American Church

- America First Foreign Policy

The lack of attention given to this list will be discussed later, but it needed to be mentioned here because it underscores why April Ryan was asking Trump about his plans for the inner city in the first place.

The 10-point plan wasn't the only reason why Ryan had good reason to question Trump that day.

Since his official swearing in, Trump had stumbled over his own feet when it came to his interaction with African Americans.

He countered all of his arguments of uniting the country and being the best president for Black people through his cabinet appointments.

The nation watched in horror as Trump picked known racists such as far-right nationalist and Breitbart News editor Steve Bannon as his chief strategist and Jeff Sessions, a known anti-Civil Rights lawyer, as the nation's attorney general.

The inner sanctum of Trump included Press Secretary Sean Spicer and Reince Priebus, the former a previous chair of the Republican $\mathrm{Na}$ tional Committee turned Trump's chief of staff. Priebus, as chairman, had pushed fellow Republicans to fall in behind the controversial and extremely damaged presidential candidate.

Even after a series of indefensible discoveries about Trump's character, including that he groped women, Priebus stood behind Trump when a 2005 tape surfaced of Trump saying near an open microphone while speaking with Access Hollywood host Billy Bush on a tour bus that he "can't help myself" when he grabs women by the pussy (his words) (Fahrenthold, 2016).

Trump's appointment of Betsy DeVos as Secretary of Education set off a firestorm of complaints so much so that it took Vice President Mike Pence's vote to push through her confirmation. 
The whole nation scratched its collective head when Trump selected a renown Black brain surgeon to be, not the Surgeon General, but the head of the federal housing department better known as HUD.

The appointment of Ben Carson to lead HUD smacked of some stereotyping - give the Black man the department that oversees public housing and the nation's low-income housing efforts, since the perception is that mostly poor, Black people live in government-subsidized housing.

But maybe Trump picked Carson because when Carson was a presidential candidate, he said publicly that he didn't believe government assistance is a fix for those in need.

When Trump was done with his first cabinet, a March 10, 2017, New York Times article dubbed it the Whitest, most-male cabinet in more than half a century (Lee, 2017). "Donald Trump is rolling back the clock on diversity in the cabinet," professor Paul Light of New York University's Wagner Graduate School of Public Service told the Times.

Declaring war, as Trump did, on racial inclusiveness, would lead to questions of his legitimacy to serve in the Oval Office.

\section{Questioning Trump, Hoping for Solutions}

Shortly before Trump was inaugurated, U.S. Rep. John Lewis questioned the president-elect's legitimacy to hold the office on national television. Lewis told "Meet the Press" moderator Chuck Todd that he believed there was a conspiracy with Russia to help Trump win the election and, conversely, to position Hilary Clinton to lose (NBC News, 2017).

Questions of Trump's legitimacy centered mostly on reports from at least four U.S. intelligence agencies that Russia interfered with the election - through connections to Trump. Lewis also said he would not attend Trump's inauguration ceremony Democratic Congresswoman Maxine Waters and others would join the chorus.

But let the hypocrites line up. Lewis only did to Trump what Trump did to Obama with the birther issue: He questioned the legitimacy of the Trump's right to be the president.

And while Trump had no evidence that Obama's birth certificate was fake, he floated the outright lie for several years without any consequences. So why not question Trump?

If anyone has the right to question any president's legitimacy, it's Lewis.

Besides serving his Congressional district in Georgia for more than 30 years, he is a living symbol of those who fought with blood and sweat for the Voting Rights Act of 1965 and other equalities for African Americans. Lewis is a Freedom Rider, a group of activists who pushed for the Interstate Commerce Commission (ICC), which banned segregation on buses and facilities under their jurisdiction. 
The Riders were met with violence, though they gain national attention and caused change.

Lewis is a former chair of the Student Nonviolent Coordinating Committee, founded by four Black college students in Greensboro, North Carolina, who wanted to eat at a Woolworth lunch counter - and did.

Indeed, some would liken the modern-day Black Lives Matter movement to SNCC.

On "Bloody Sunday," Lewis was beaten as he and others tried to cross the Edmund Pettus Bridge to Selma, Alabama to register to vote.

But Trump, probably not even knowing Lewis' history, felt the need to lash out at Lewis, questioning his leadership. And, so, Trump did - on Twitter:

Congressman John Lewis should spend more time on fixing and helping his district, which is in horrible shape and falling apart not to mention crime infested rather than falsely complaining about the election results. All talk, talk, talk - no action or results. Sad!

Trump again made a sweeping inference that Lewis' district is made up of Black, poor criminals and, in turn, drew bipartisan backlash on Twitter and from more than 67 Democrats who decided to sit out the inauguration on January 20, 2017.

The Twitter responses included:

- From NAACP President Cornell Brooks, "By disrespecting @repjohnlewis, @realDonaldTrump dishonored Lewis' sacrifice \& demeaned the Americans \& rights, he nearly died 4. Apologize."

- From U.S. House Minority Leader Nancy Pelosi, "Let us remember that many have tried to silence @repjohnlewis over the years. All have failed.”

- From Representative David Cicilline, directed at Trump, "John Lewis is an American hero. You're a fake billionaire who won't release his taxes. Put down Twitter and get serious about governing."

Despite the attention, mainstream media did not handle Lewis' statement very well.

While it was important to highlight the accomplishments of Lewis, which are unimpeachable, the press should have more vigorously tested whether his statement that the president was not legitimate had merit.

The press at the time ignored other areas needing further attention, as well, such as allegations that Russia interfered in the U.S. presidential election. Such allegations should have sparked more outrage than it had among the press, if media serve its watchdog function effectively. 
In fact, if U.S. House Speaker Paul Ryan said Trump is an "illegitimate president" it would be treated differently than if someone (read, Black) like Lewis did. For the press, the claims related to Trump's legitimacy and involvement in foreign manipulation of domestic affairs, may have been the case of good message, but not the right messenger.

Diving into Trump's 10-point plan and how policy decisions he had made by August 2017 impact lifting Black people out of the hell in which they have been trapped, or so says Trump, reveals another layer to how Trump views Black America.

Trump would address his plans for "the inner city" during the question-and-answer segment of an August 15, 2017, speech at Trump Tower in New York City when he announced an executive order to shore up the American infrastructure and promised permitting reform for urban areas.

Apart from the fact that he was using an executive order to tell several federal agencies to slacken their rules, Trump made the announcement in the days after an incendiary and deadly racial incident in Charlottesville, Virginia. Related to that case, Trump was under fire for not condemning the violence by Ku Klux Klan and Nazi sympathizers.

The debate about officials in Charlottesville removing a Confederate general's statue from a public park started almost two years before Trump's talk.

But since Trump didn't condemn former Ku Klux Klan grand wizard David Duke's support during his campaign (Jackson, 2016), White supremacists have become more vocal, and web sites and news organizations have given them platforms for their ideals.

It is that emboldened behavior of hate groups that would erupt into chaos and death in Charlottesville, and would place Trump at the very center of American racial hate speech.

Demonstrations about the removal of the statue and the renaming of the park to something other than related to the Civil War (and Southern remembrance of it) had started in August 2017 when white nationalists took their protest onto the University of Virginia campus.

On the second day, the Unite the Right protest appeared in city streets where police tried to keep White supremacists away from the multicultural counter-protestors.

But the protest turned deadly.

James Alex Fields Jr., a 20-year-old White man, drove his car into a crowd at the intersection of Forth and Water Streets, killing 32-year-old Heather Heyer and injuring about 20 people (Rankin, 2017).

And while Trump wanted to change the narrative with the press, since he had been accused of first not condemning the White nationalists then condemning them but later changing his statement to say both sides were to blame for the violence and death, reporters only focused on the weekend's altercation alone. And rightly so. The nation was hurting. 


\section{Carolyn Guniss}

Older Americans watched as familiar images of the Civil Rights movement played out on their modern TV sets - this time in full color and high definition.

Younger Americans and immigrants were getting a glimpse of bits and pieces of history they had gathered over the years from Martin Luther King, Jr. Day celebrations or when an icon of the Civil Rights movement gave a speech or died.

Trump, once again, displayed a lack of empathy and understanding of race relations in this country. So, as reporters tried to steer the questions to Charlottesville and Trump's position on racial hatred, Trump demanded questions focus on his other announcements.

Yet, when an unnamed reporter asked Trump about his thoughts on race relations, he had to take on the question:

REPORTER: How concerned are you about race relations in America and do you think things have gotten worse or better since you took office?

TRUMP: I think they have gotten better - or the same. They've been frayed for a long time, and you can ask President Obama about that because he'd make speeches about it. But, I believe that the fact that I brought in, it will be soon, millions of jobs - you see where companies are moving back into our country - I think that's going to have a tremendous positive impact on race relations ... You know why? It's jobs. What people want now, they want jobs. They want great jobs with good pay and, when they have that, you watch how race relations will be. I'll tell you, we're spending a lot of money on the inner cities. We're fixing the inner cities. We're doing far more than anybody's done with respect to the inner cities. It's a priority for me. And it's very important.

One has to wonder whether fixing poorer, urban neighborhoods is a priority for the Trump administration. Not according to budget priorities. PolitiFact found that $\$ 225$ million could fund a backlog of fixes and investments needed for the nation's public housing and related education and job training programs. Yet Trump's proposed budget for 2018 kills the Community Development Block Grants program, which is funded through HUD and granted to communities for economic development.

How ironic that Trump pledged to lift Black people out of the "hell" they lived in but he himself was proposing budget cuts to programs that encourage prosperity.

To be sure, though, Trump has a supporter of a leaner HUD budget in Carson who has launched a "listening tour" to find out more about America's affordable housing. Rather than telling him about their 
housing needs, people have had to listen to Carson tell them about his love of public-private partnerships, because government alone cannot solve the housing crisis.

During a listening tour stop in Miami in April 2017, for example, Carson visited the southeastern U.S.'s oldest housing project, Liberty Square.

The run-down housing project is undergoing demolition only to be rebuilt as a mixed-income community of public housing, market-rate rentals and units for homeownership, commercial spaces, and a grocery store. Miami-Dade County and the developer, the Related Group, partnered to tackle the $\$ 300$ million project, and Carson praised the effort.

"Liberty City's new construction is a holistic approach to housing that we at HUD believe is essential for creating strong communities that allow residents to succeed," Carson told The Miami Times (Guniss, 2017). "As I have been on my listening tour, I have seen firsthand the benefits that come from developments that foster community like this one."

But what if more developers do not want to go into the public housing business?

For those who do, it is not clear how and who will control the pricing of the units once built, and we can already see in new developments that current residents will not be able to afford to live in the new units.

So much for Trump doing more for Black people than any other president, and so much for the media in calling him out on his lies.

If anything, Trump has created a new "hell" for people of color in America, and the press has continued to ignore it.

As a result, our Commander-in-Chief has rolled back the progress Americans made in learning to live with each other.

Enter, Trump, the Destroyer-in-Chief.

\section{References}

Bacon, P. (2016, September 28). Analysis: In 2016 debate, Donald Trump spoke of a black America that no longer exists. NBC News. Retrieved at www. nbcnews.com/storyline/2016-presidential-debates/analysis-debate-donaldtrump-spoke-black-america-no-longer-exists-n655581.

Blake, A. (2016, September 26). The first Trump-Clinton presidential debate transcript, annotated. The Washington Post. Retrieved at www.washingtonpost.com/news/the-fix/wp/2016/09/26/the-first-trump-clinton-presidentialdebate-transcript-annotated/?utm_term=.cd3f829b8419.

Bouie, J. (2017, June 1). What we have unleashed. Slate. Retrieved at www.slate. com/articles/news_and_politics/politics/2017/06/this_year_s_string_of_ brutal_hate_crimes_is_intrinsically_connected_to_the.html.

Burns, S. (2016, October 17). Why Trump doubled down on the Central Park Five. The New York Times. Retrieved at www.nytimes.com/2016/10/18/opinion/ why-trump-doubled-down-on-the-central-park-five.html? mcubz=1.

Corn, D. (2016, October 25). Here's another time a Trump company was sued for discriminating against black people. Mother Jones. Retrieved at 


\section{Carolyn Guniss}

www.motherjones.com/politics/2016/10/another-housing-discriminationlawsuit-donald-trump.

Domonoske, C. (2017, March 28). White supremacist charged with terrorism over murder of black man. NPR. Retrieved at www.npr.org/sections/thetwoway/2017/03/28/521805165/white-supremacist-charged-with-terrorismover-murder-of-black-man.

Edsall, T. B. (2017, April 27). Black people are not all "living in hell." The New York Times. Retrieved at www.nytimes.com/2017/04/27/opinion/blackpeople-are-not-all-living-in-hell.html? $m c u b z=1$.

Fahrenthold, D. A. (2016, October 8). Trump recorded having extremely lewd conversation about women in 2005. The Washington Post. Retrieved at www.washingtonpost.com/politics/trump-recorded-having-extremely-lewdconversation-about-women-in-2005/2016/10/07/3b9ce776-8cb4-11e6-bf8a3d26847eeed4_story.html?utm_term=.0c4f71a71e59.

Funk, T. \& Morrill, J. (2016, October 26). Donald Trump promises "a new deal for black America” at Spirit Square. Charlotte Observer. Retrieved at www.charlotte observer.com/news/politics-government/election/article110546817.html.

Guniss, C. (2017, April 11). HUD Secretary will stop at the public housing project as part of his national listening tour. The Miami Times. Retrieved at www.miamitimesonline.com/news/ben-carson-to-visit-liberty-square-wednesday/article_ 93935524-1ee4-11e7-82eb-ebc348430837.html.

Henderson, M. (2017, March 30). April Ryan asked the most important question of the Trump presidency. CNN. Retrieved at www.cnn.com/2017/03/29/ politics/april-ryan-sean-spicer-trump-presidency/index.html.

Jackson, D. M. (2016, February 28). Trump blames faulty earpiece for KKK comments. USA Today. Retrieved at www.usatoday.com/story/news/politics/ onpolitics/2016/02/28/donald-trump-david-duke-ku-klux-klan-cnn-state-ofthe-union/81073572.

Kaleem, J. \& Simmons, A. M. (2016, November 5). Trump says African Americans are living in hell. That depends on what you mean by hell. The Los Angeles Times. Retrieved at www.latimes.com/nation/la-na-global-blackamerica-snap-20161103-story.html.

Lee, J. C. (2017, March 10). Trump's cabinet so far is more white and male than any first cabinet since Reagan's. The New York Times. Retrieved at www.nytimes.com/interactive/2017/01/13/us/politics/trump-cabinet-womenminorities.html $\mathrm{mcubz}=1 \& \mathrm{mtr}$ ref=www.google.com \&gwh=BAA8BBC30 F6928F71A4E274896682D08\&gwt=pay.

NBC News. (2017, January 13). John Lewis: “I don't see Trump as a legitimate president." NBC News. Retrieved at www.nbcnews.com/meet-the-press/ video/rep-john-lewis-trump-won-t-be-legitimate-854384195610.

North, A. (2017, June 1). The scope of hate in 2017. The New York Times. Retrieved at www.nytimes.com/2017/06/01/opinion/hate-crime-lebron-jamescollege-park-murder.html? $\mathrm{mcubz}=1 \& \_r=0$.

NPR. (2016, September 29). Decades-old housing discrimination case plagues Donald Trump. NPR. Retrieved at www.npr.org/2016/09/29/495955920/ donald-trump-plagued-by-decades-old-housing-discrimination-case.

Ocamb, K. (2017, July 5). Hate crimes up in California, fueled by hate-filled Trump era. Los Angeles Blade. Retrieved at www.losangelesblade.com/2017/ 07/05/hate-crimes-california-fueled-hate-filled-trump-era. 
Parker, A. \& Eder, S. (2016, July 2). Inside the six weeks Donald Trump was a nonstop "birther." The New York Times. Retrieved at www.nytimes. com/2016/07/03/us/politics/donald-trump-birther-obama.html?mcubz=1.

Rankin, S. (2017, August 16). Inside a day of violence, terror in Charlottesville. US News \& World Report. Retrieved at www.usnews.com/news/best-states/ virginia/articles/2017-08-15/inside-a-day-of-violence-terror-in-charlottesville.

Ross, J. (2016, October 8). Donald Trump's doubling down on the Central Park Five reflects a bigger problem. The Washington Post. Retrieved at www. washingtonpost.com/news/the-fix/wp/2016/10/08/donald-trumps-doublingdown-on-the-central-park-five-reflects-a-bigger-problem/? utm_term=. $368 \mathrm{e} 6 \mathrm{cc} 2 \mathrm{f} 1 \mathrm{c} 0$.

Sorkin, A. D. (2014, June 23). Donald Trump and the Central Park Five. The New Yorker. Retrieved at www.newyorker.com/news/amy-davidson/ donald-trump-and-the-central-park-five.

TV Guide. (2015, July 28). Here's a timeline of every time Donald Trump ran for president. TV Guide. Retrieved at www.tvguide.com/news/donaldtrump-presidential-campaign-timeline.

UPI. (1992, October 19). Trump Plaza loses appeal of discrimination penalty. UPI. Retrieved at www.upi.com/Archives/1992/10/19/Trump-Plaza-loses-appealof-discrimination-penalty/1911719467200.

Valverde, M. (2016, September 27). Donald Trump says Chicago has experienced thousands of shootings this year. PolitiFact. Retrieved at www. politifact.com/truth-o-meter/statements/2016/sep/27/donald-trump/ donald-trump-says-chicago-has-experienced-thousand.

Washington Post. (2015, June 16). Full text: Donald Trump announces a presidential bid. The Washington Post. Retrieved at www.washingtonpost.com/ news/post-politics/wp/2015/06/16/full-text-donald-trump-announces-apresidential-bid/?utm_term $=.79 \mathrm{~b} 80 \mathrm{db} 20 \mathrm{a} 79$.

Weiser, B. (2014, June 19). 5 exonerated in Central Park jogger case agree to settle suit for $\$ 40$ million. The New York Times. Retrieved at www.nytimes. com/2014/06/20/nyregion/5-exonerated-in-central-park-jogger-case-are-tosettle-suit-for-40-million.html? $\mathrm{mcubz}=1$. 


\section{Media Narratives of Gender in the Contentious Conservative Age of Trump \\ Pam Creedon}

Trump's (s)election ${ }^{1}$ has reinvigorated feminism around the globe. He has ignited the fourth wave of feminism - a "rebirth" of the movement for equality, gender equity, and the abolishment of discrimination. ${ }^{2}$ Jodi Enda, assistant managing editor for special projects at CNN Politics, described Trump's election as both the best and worst time for the future of feminism:

The election of a president whom detractors view as misogynistic and backward-thinking has done nothing less than spark a wholesale resurgence of feminism. His defeat of the first woman who might have been president - coupled with his incendiary comments about women and his divisive policies on reproductive rights and other issues - lit a fire under a movement that had failed to excite younger generations of women who benefited from the battles of the last century and saw no need to keep fighting.

(Enda, 2017)

This chapter is a critical feminist scholarship analysis of media narratives in the Contentious Conservative Age of Trump. It examines how the media have covered Trump's patriarchal values and reviews the gendered narratives of his media messages.

\section{Media Narratives and Gender Equity}

Media narratives of gender equity reveal the feminism fire lit by Trump's (s)election. Inclusive, interconnected, and intersectional, feminism seeks social justice and equality, which discourse analysis shows is contrary to Trump's rhetoric. Its rebirth manifested itself in the Women's March when more than 500,000 marched in Washington, D.C., and an estimated 3.3 to 4.6 million people marched in more than 500 cities across United States and in more than 100 rallies in 60 countries on all seven continents (Waddell, 2017). From marchers carrying a poster with a Muslim woman wearing a red, white, and blue hijab to marchers wearing pink 
"pussy" hats to reclaim female genitalia from Trump, the march showcased the global resurgence of feminism.

Today, we also are in a social media ecosystem that is connecting and intertwining people of similar interests and values. The campaign and election coverage documented the interconnectedness of individuals in social media. Everyone can be social media critics, collectors, joiners, or spectators, but it is the creators who are developing their own social media ecosystem (Hanna, Rohm, \& Crittenden, 2011).

Feminist scholars thought that the internet represented hope for a democratic communicative space for questioning the government and corporate elite, which could "mobilize political action for change across temporal, spatial, and other boundaries" (Byerly, 2005, p. 281). Nearly a decade later, the communicative space is being seen as a media conglomeration that excludes women and consolidates men's economic and political power (Byerly, 2014).

The global outcomes of media conglomeration have influenced critical scholars, who now "are the most likely to break with the notions of maintaining distance to achieve 'objective' inquiry" (Byerly-a, forthcoming). The new focus of many critical feminist scholars is acknowledging that they incorporate their values and experiences into their scholarship (Byerly-b, forthcoming).

The interconnectedness of like-minded individuals has created a plethora of individually "reconceived" news. In the communication conglomeration network, Trump is the "daily news creator" and in January 2017, his social media ecosystem had 30 million followers (Bort, 2017). ${ }^{3}$

\section{The Trump Bump: Social Media and "Fake” News}

Trump is saving newspapers. Described as the "greatest source of lead generation," his "media-bashing... has accidentally engineered what newspaper analysts are calling the Trump bump" (Media Landscape, 2017). As some media reports state:

One of the most widely reported examples of this "Trump bump" is the New York Times, which added more than 250,000 new digital subscribers in the final three months of 2016. That was its best quarterly performance since it launched its online paywall in 2011.

(Ingram, 2017)

The report continues:

The Washington Post has also seen a wave of subscriptions, with a record number of new sign-ups in January, and is said to have passed the 300,000 digital-subscriber mark for the first time. 


\section{Pam Creedon}

Media election coverage studies indicated that controversies rather than policies were the news focus, with Clinton's emails and Trump's taxes accounting for 17 percent of the coverage, or one in every six news reports (Patterson, 2016). Media narratives used gender stereotypes to tell their stories. Nearly 2,000 tweets and memes during the campaign were examined by researchers who found that traditional gender stereotypes predominated media coverage:

Clinton was seldom pictured showing traditional female characteristics of warmth and friendliness, despite her campaign slogan of "Stronger Together." The most viral images contradicted that stereotype, depicting her as corrupt and untrustworthy. By comparison, the most viral photos of Trump were consistent with agentic male characteristics of assertiveness and independence.

(Nee \& De Maio, 2017)

One study of media coverage of Trump and Clinton's campaigns by Harvard's Kennedy School found coverage of the 2016 presidential campaign revealed the media's sexism. Clinton's alleged scandals received four times the coverage of Trump's treatment of women. The study found:

Criticism dogged Hillary Clinton at every step of the general election. Her "bad press" outpaced her "good press" by 64 percent to 36 percent. She was criticized for everything from her speaking style to her use of emails.

(Patterson, 2016) $)^{4}$

Ten of these Clinton "scandals" reported by WikiLeaks ranged from "cozy and improper relationship with mainstream media" to steering "the media's attention from the email scandal to the House Benghazi investigation" (Riddell, 2016). Simply put, mainstream media found these so-called "scandals" to be headline news.

In contrast, the narratives provided rationales to justify Trump's communication during the campaign. If Trump insulted people, the narrative reported that he was being honest by saying what he thinks. ${ }^{5}$ If he bragged, he was only doing what a corporate executive would do. If he seemed ignorant of how government worked, it was because he has been a boss and his employees always knew how to implement his decisions. Honesty was the most disparate trait these media reports assigned to Trump (Gabler, 2016).

Since his election, Trump's tweets are the front page news and continuously promoted by CNN as "Breaking News." The Columbia Journalism Review has argued that the media coverage of Trump's tweets is allowing the definition of news to be reconceived: 
What would happen if, instead of screaming every time Trump hit "Tweet," we let some of the most inane messages die? What if we took a breath and thought through what they mean? ...What is important is that he's a serial liar, obsessed with his media mentions to the point of hysteria, and continues to judge women largely by their appearance.

(Pope, 2017)

If increasing the number of subscriptions, subscribers, and viewers are today's news values, Trump is the news "creator." As the data shows, in the media conglomeration network, the "Trump bump" has become the branding umbrella.

\section{Twitter Trump, Sexual Harassment and Sexist Remarks}

Trump loves Twitter and describes it as his "Modern Day Presidential" communication. Trump's Twitter texting from @realDonald Trump garnered "front page" media headlines before and during the campaign and election. In one study before the election, The New York Times did an analysis of 95,000 words that Trump had spoken publicly in rallies, speeches, interviews, and news conferences during one week. The study found that divisive phrases, harsh words, and violent imagery were predominant (Healy \& Haberman, 2015).

To monitor Trump's twitter feed in real time, a Twitter archive was created on January 27, 2017, at www.trumptwitterarchive.com. As of August 8, 2017, Trump had accused the media of spreading fake news 96 times in his tweets, according to the Trump Tweet archive.

Criticizing women journalists has been on Trump's tweeting agenda since 2014 and also is archived in the Trump Twitter Archive. The female journalist who received the most attention from Trump's tweet during the campaign and debates was Megyn Kelly, who was at the time at Fox News. She won with 16 Trump tweets directed to her and using her name to better target his attack. Kelly's Republican debate question on August 6, 2015, let her cross the finish line to win the Trump Tweet Award when she asked him the following:

Mr. Trump, one of the things people love about you is you speak your mind and you don't use a politician's filter. However, that is not without its downsides, in particular, when it comes to women. You've called women you don't like "fat pigs," "dogs," "slobs" and "disgusting animals.”...

Your Twitter account has several disparaging comments about women's looks. You once told a contestant on "Celebrity Apprentice” it would be a pretty picture to see her on her knees. 
Does that sound to you like the temperament of a man we should elect as president, and how will you answer the charge from Hillary Clinton, who was [sic] likely to be the Democratic nominee, that you are part of the war on women?

(Blake 2016)

Trump denied ever using those "descriptors" during the debate, but FactCheck.org, a project of The Annenberg Public Policy Center, found evidence of Trump's "amnesia" and reported that he had used all of the terms multiple times (Farley, 2015).

Trump's Megyn tweets included:

- Re Megyn Kelly quote: "you could see there was blood coming out of her eyes, blood coming out of her wherever" (NOSE). Just got on w/thought (7:46 a.m., August 8, 2015)

- Everybody should boycott the @megynkelly show. Never worth watching. Always a hit on Trump! She is sick, $\&$ the most overrated person on tv. (2:55 p.m., March 18, 2016)

- If crazy@megynkelly didn’t cover me so much on her terrible show, her ratings would totally tank. She is so average in so many ways! (10:16 a.m., March 19, 2016)

Trump also had an issue with Katie Couric:

- Katie Couric, the third rate reporter, who has been largely forgotten, should be ashamed of herself for the fraudulent editing of her doc. (4:14 p.m., May 31, 2016)

He didn't like the way that CNN's Alisyn Camerota interviewed him:

- CNN's Alisyn Camerota "treats me very badly...a disaster" (12:36 p.m., January 21, 2016)

He doesn't like female newspaper journalists at The New York Times, The Washington Post or Huffington Post either:

- @RuthMarcus of the @washingtonpost was terrible today on Face The Nation. No focus, poor level of concentration-but correct on Hillary lying. (11:03 a.m., January 3, 2016)

- Highly untalented Wash Post blogger, Jennifer Rubin, a real dummy, never writes fairly about me. Why does Wash Post have low IQ people? (12:46 p.m., December 1, 2015)

- Frumpy and very dumb Gail Collins, an editorial writer at The New York Times, is so lucky to even have a job. Check her out incompetent! (4:31 p.m., March 15, 2014) 
- Huffington Post is just upset that I said its purchase by AOL has been a disaster and that Arianna Huffington is ugly both inside and out! (6:57 p.m., April 20, 2014)

Women do not need to be journalists to be tweeted by Trump:

- I just realized that if you listen to Carly Fiorina for more than ten minutes straight, you develop a massive headache. She has zero chance! (2:06 p.m., August 9, 2015)

- Sarah Jessica Parker voted "unsexiest woman alive" - I agree. She said "it's beneath me to comment on the potential Obama charitable gift." What's really beneath her? (3:05 p.m., October 26, 2013)

- How does @michellemalkin get a conservative platform? She is a dummy - just look at her past. (9:17 a.m., October 25, 2012)

- 26,000 unreported sexual assults (sic) in the military-only 238 convictions. What did these geniuses expect when they put men $\&$ women together? (6:04 p.m., May 7, 2013)

Yet, despite his goal of having the most Twitter followers in the world, Trump blocked followers whose criticism hit home too directly. He blocked Holly O'Reilly (@AynRandPaulRyan), who programmed her phone after the election to alert her every time Trump tweeted:

If his tweet was particularly inane, I would reply with my own equally dumb remarks and memes. Since I started doing this, I've accumulated a very vocal group of Twitter followers who cheer me on when I troll the president. It takes about five minutes out of my day, and it makes me feel better knowing that this narcissistic, egomaniacal, misogynistic, xenophobic POTUS can read how I feel about him.

(O’Reilly, 2017)

After the Twitter block, O'Reilly contacted lawyers from Columbia University's Knight First Amendment Institute to get unblocked. Her attorney argued that Trump's Twitter account is a "designated public form" and blocking users "suppresses speech in a number of ways" (Hoffman, 2017). ${ }^{6}$

Trump's "locker room banter" in 2005 that bragged about groping women without consent and his other sexist comments were reported in The Washington Post two days before the second presidential debate in 2015 (Fahrenhold, 2016). The article in the Post reported (Allen \& Schouten, 2016):

In the video posted Friday, Trump and Billy Bush, the former Access Hollywood host now with NBC's Today show, engage in graphic 
discussions en route to the Days of Our Lives set, where Trump is set to record a piece about an upcoming appearance on the soap opera.

"I did try and f--- her," Trump tells Bush in reference to a married woman, while acknowledging he was unsuccessful. "I moved on her like a b---- but I couldn't get there," Trump says.

Later in the video, as Trump and Bush spot Arianne Zucker - who The Post says was there to escort them to the set for the segment the real estate mogul says: "I better use some Tic Tacs just in case I start kissing her," adding that he immediately starts kissing "beautiful" women when he encounters them.

After Trump's groping history was revealed, he apologized; but when 12 women accused him of other sexual misconduct, he tweeted that he had evidence and would sue the media for reporting the accusations. Trump's attorney sent a letter to The New York Times for a retraction of the article and wrote:

(It was) reckless, defamatory and constitutes libel per se. ...We hereby demand that you immediately cease any further publication of this article, remove it from your website and issue a full and immediate retraction and apology. Failure to do so will leave my client with no option but to purse [sic] all available actions and remedies.

(Byers \& Stelter, 2016)

New York Times general counsel David McwCraw informed Trump's counsel that the paper would not retract and wrote:

The essence of a libel claim, of course, is the protection of one's reputation. Mr. Trump has bragged about his non-consensual sexual touching of women. He has bragged about intruding on beauty pageant contestants in their dressing rooms. He acquiesced to a radio host's request to discuss Mr. Trump's own daughter as a “piece of ass." Multiple women not mentioned in our article have publicly come forward to report on Mr. Trump's unwanted advances.

(Mullin, 2016)

As of this writing, Trump had not filed a lawsuit and there was no follow up by the media on Trump's promise (Parker \& Rucker, 2017).

It has been argued that voters took Trump's tweets and public speeches seriously, but not literally, but the media took them literally, not seriously (Zito, 2016). More concerning is finding that the media coverage of Trump's tweets were and are narratives that ignore news values (Harrington, 2016). 


\section{Women's March and Gender Equity}

Women voters supported Clinton over Trump by 54 percent to 42 percent (Tyson \& Maniam, 2016). Clinton received nearly 3,000,000 - three million - more votes than Trump (Krieg, 2016). ${ }^{7}$ However, the 'winner takes all' Electoral College policy 8 elected Trump (www.archives.gov/ federal-register/electoral-college/about.html). ${ }^{9}$

Despite the current counselor to the president Kellyanne Conway's dissing of the women's movement as "pro-abortion and anti-male" (Wagner, 2017), the women-led Women's March post-inauguration was an inclusive global event. Men and women; gay and straights; black, brown, white, red, and multicolored; Medicare and Medicaid-ers; pre-schoolers and PhDs; Jews and Muslims; and any other color, religion, age, sex, ability marched.

The world's largest coordinated protest march held on all seven continents, the Women's March brought together generations with myriad concerns about the future of the country. In Washington, D.C., it was the second-busiest day in the subway system's history, with 1,001,613 passengers, compared with the 570,557 recorded on Trump's Inauguration Day (Stein, Hendrix, \& Hauslohner, 2017).

Media narratives of what has been called the "resistance revival" were the headline news on January 23. On their website, womensmarch.com, described why the march was the largest coordinated protest in U.S. history at www.womensmarch.com/march/:

...(people marched to) "call for a world that is equitable, just and safe for all, where the human rights and dignity of each person is protected and our planet is safe from destruction"

Following the inauguration, 10 Women's March actions were held in the first 100 days attempting to sustain the movement, including the following:

- \#NoBan Rallies were held in January and February 2017 in more than 30 cities around the country to protest Trump's executive order ban on immigration (Bacon \& Gomez, 2017). Protestors chanted multiple messages: "Sanctuary for all," "No ban, no wall," "No hate, no fear." "Refugees are welcome here" (Siddiqui, Laris, \& Chandler, 2017).

- Health Care Demonstrations. The Women's March coordinated phone calls, letters, marches, sit-ins, and die-ins ${ }^{10}$ to protest the Senate vote on repealing the Affordable Health Care Act. The organization of die-ins included an online payback planning guide at: www. paybackproject.org/diein-toolkit.

- A Day Without a Woman. The Women's March promoted March 8th as A Day Without a Woman and suggested that women take the 
day off from paid and unpaid labor, to avoid shopping for one day, and to wear red to showcase solidarity (see, www.womensmarch. com/womensday).

- The Women's March announced a search for an Executive Director in July 2017 (see www.womensmarch.com/ed-search). Its goal is to dismantle "systems of oppression through nonviolent resistance, direct lobbying, policy advocacy and building inclusive structures guided by self-determination, dignity and respect.”

- Women's March has published specific goals that include, saving federal funding of Planned Parenthood, retaining and enhancing LGBTQ ${ }^{11}$ rights, and ensuring that Title IX, the Equal Rights Amendment, and Roe vs. Wade are not overturned (Enda, 2017).

- A Women's Convention (see, www.womensconvention.com), organized by the Women's March, was scheduled to be held in Detroit, Michigan, from October 27 to 29, 2017, with the goal to involve members of 5,000 local groups or "huddles" from the 50 states. One focus at the conference was to develop congressional campaign plans in states with the most active local chapters including: Ohio, Florida, South Carolina, and Georgia. "Building power is not just about power in the streets. It's about political power," said Bob Bland, co-president of the Women's March (Przybyla, 2017).

Today, the Women's March organization remains active. It has 491,000 Twitter followers (@womensmarch) and 783,000 followers on Facebook at www.facebook.com/womensmarchonwash. The Women's March has a collective agenda on empowering gender equity and eliminating sexism in the Trump administration.

\section{Women Who Work: \#GrabYourWallet}

Starting with Eleanor Roosevelt, First Ladies advised their Presidential husbands in government. Many were influential and set their own agendas: Barbara Bush's literacy campaign, Nancy Reagan's antidrug campaign, Rosalynn Carter serving as honorary chair of the Presidential Commission on Mental Health.

In 1993, Hillary Clinton became the first First Lady given a West Wing office to head a committee to work on overhauling the nation's health-care system. Media questioned her appointment as nepotism. Opposition to the "Hillarycare" plan by the health insurance industry and members of Congress resulted in it never making it on the floor for a vote.

However, there was no corporate or Congressional nepotism controversy made when Trump added his first daughter, Ivanka, in March 2017 and her husband, Jared Kushner, in January 2017, as unpaid senior 
advisors to the president. The appointments were investigated by Department of Justice that found:

...the anti-nepotism law covers only appointments in an "executive" agency and that the White House Office is not an executive agency within the law. (They also) cited a separate law that gives the President broad powers to hire his staff.

(Merica, Borger, Acosta, \& Klein, 2017)

Ivanka says that her life's goal is to improve the lives of working women. After her appointment, she was in the Oval Office during the signing of a bill to encourage women in STEM (science, technology, engineering, and mathematics) careers and spoke at a Smithsonian Air and Space Museum to encourage women in STEM (Merica et al., 2017).

Her second book, Women Who Work: Rewriting the Rules for Success was published in May 2016, during the presidential campaign. ${ }^{12}$ Not all working women who read her book found their success in her rewritten rules:

This is the sort of feminism that drives some women bananas, having less to do with structural change than individual fulfillment and accessorizing properly; perhaps it can even be achieved by wearing her fine jewelry or apparel, which she repeatedly mentions throughout the book (as well as her family's tremendous hotels).

(Senior, 2017)

Macy's, which sells Ivanka Trump's clothing, handbags, and shoes (see https://ivankatrump.com), dropped the line during the primaries after her father called Mexican immigrants "killers" and "rapists" (Abrams, 2017). In January 2017, before the inauguration, Maine's L.L. Bean brand was affected by boycotts and protests about the brand due to a news of an illegal campaign contribution (Chandler, 2017). Nordstrom and Neiman Marcus also dropped Ivanka's clothing lines in February 2017, citing "brand performance" as the rationale (Phelps \& Caplan, 2017).

The drop led to a Trump tweet crusade against Nordstrom, which had a feminist outcome. It promoted the \#GrabYourWallet hashtag, which documents companies with ties to Trump and his family and suggests boycotts of the merchandise.

At its site (https://grabyourwallet.org/), ${ }^{13}$ a list of companies that sell Trump brands and have relationships to Trump, is documented. The list includes companies advertising on Celebrity Apprentice, CEO's who raised funds and endorsed Trump, retailers that sell Trump family brand products, and Trump-owned, -branded, or -operated businesses. The Top 10 companies the website recommends boycotting are: Macy's, Bed 
Bath \& Beyond, L.L. Bean, Bloomingdales, Zappos.com, Amazon.com, Hudson's Bay, T.J. Maxx, Lord \& Taylor, and Dillard's (Wafi.com/). Also, aside from Trump-owned properties, the site lists other companies to boycott that include: Overstock.com, Wal-Mart, Century 21, Trident, MillerCoors, New Balance, and Hobby Lobby.

Media coverage of \#GrabYourWallet is recorded at https://grabyourwallet.org. On July 25, 2017, it had more than 100 media stories documenting coverage, ranging from USA Today to Twitter Moments, from The Sydney Morning Herald to the San Francisco Chronicle, from Nightline on ABC to NBC, and from Vanity Fair to The New York Times. The site also had more than a billion views of its hashtag on social media by August 2017.

What about Mrs. Trump? ${ }^{14}$ During the presidential campaign, his wife, Melania, demanded a retraction and apology from People magazine for an October 2016 article (Borchers, 2016). The article stated that in 2005 Mr. Trump had pushed a magazine reporter against a wall and kissed her at the Trump home in Mar-a-Lago, Florida, while Melania was upstairs. However, Melania's lawsuit only focused on false statements in the article regarding the author's encounter with her and son Barron, as they walked into Trump Tower on Fifth Avenue in New York several months after the alleged assault (Borchers, 2016). ${ }^{15}$

The media coverage of Melania's acceptance speech at the Republican convention in Cleveland, Ohio, revealed that it "mirrored" former First Lady Michelle Obama's speech, aka plagiarism (Bump, 2016). Melania's speechwriter, Meredith McIver, took responsibility for using the "mirror" when she wrote the speech (Chan, 2016).

In February 2017, Melania filed a $\$ 150$ million lawsuit against the Daily Mail newspaper, for publishing "damaging and unfounded allegations that she once worked as an 'elite escort' in the 'sex business"' (Wamsley, 2017). She won the libel suit and was paid over $\$ 3,000,000$ in damages and legal costs in April 2017. The retraction read:

The Daily Mail newspaper and the Mail Online/DailyMail.com website published an article on 20th August 2016 about Melania Trump which questioned the nature of her work as a professional model, and republished allegations that she provided services beyond simply modelling. The article included statements that Mrs Trump denied the allegations and Paolo Zampolli, who ran the modelling agency, also denied the allegations, and the article also stated that there was no evidence to support the allegations. The article also claimed that $\mathrm{Mr}$ and Mrs Trump may have met three years before they actually met, and 'staged' their actual meeting as a 'ruse'.

We accept that these allegations about Mrs Trump are not true and we retract and withdraw them. We apologise to Mrs Trump for any 
distress that our publication caused her. To settle Mrs Trump's two lawsuits against us, we have agreed to pay her damages and costs.

(Bowcott \& Watt, 2017)

The popularity of First Lady Melania souvenirs was investigated and found a bestseller - "Free Melania" T-shirts (Cochrane, 2017). Many other items are also available, but those that are "X-rated" are not accepted at many stores. In April 2017, Melania posted her airbrushed First Lady photo, showcasing her 10th anniversary 25-carat diamond ring from her husband, which resulted in much media Twitter banter (Puente, 2017). Ivanka and Melania were weathering the media coverage storm at the time of this writing and making fewer headlines and breaking news.

\section{Trump's Brand and Gender Equity}

Gender equity provides equal access and fairness for men and women. For women, the idea isn't evidenced in the White House. Or in Trump Towers and International Hotels located in New York City, Chicago, Honolulu, Las Vegas, New York City, Sunny Isles Beach, Florida, Washington, D.C., White Plains, New York, or Panama, Vancouver, Canada, and Istanbul, Turkey. Or in his golf courses located in Florida, New Jersey, New York, North Carolina, California, Pennsylvania, Washington, D.C., and in the United Arab Emirates, Ireland, and Scotland.

Reports show that Trump's corporate brand is being affected by his sexist, misogynistic, racist, and homophobic comments and tweets. At his golf courses and hotels, female employees are filing lawsuits. USA Today reviewed more than 4,000 lawsuits filed by and against Trump and found at least 20 gender discrimination lawsuits filed by female employees who were fired when pregnant or not young or pretty enough (Kelly, Penzenstadler, \& Reilly, 2016). In one lawsuit, Trump National Golf Club employee Sue Kwiatkowski's sworn statement documented what Trump said when he pulled her aside:

I want you to get some good looking hostesses here. ...People like to see good looking people when they come in.

(Kelly, Penzenstadler \& Reilly, 2016)

Kwiatkowski added that the club's managers acted on Trump's directive to hire younger and "prettier" staff and to make sure other female workers were not seen whenever he visited.

\section{Is There Gender Equity in the Trump Brand White House?}

Daughter Ivanka is a woman of high level influence in the Oval Office. Although a formal title has not been revealed, it is not a ceremonial 
position, she is an (the) assistant to the president. Critics suggested that the position was a marketing coup for her product lines by promoting her brand hashtag, \#womenwhowork.

Despite her support for women entrepreneurs, the White House gender pay gap is wider than the national gender pay gap in 1980 (Ingraham, 2017). Since it became the "Trump's House," the gender pay gap of staff has tripled and the White House Council on Women and Girls has been disbanded (Miller, 2017). Trump's White House gender pay gap is more than double the national pay gap, i.e., 37 percent to 17 percent, according a Pew Research Center study (Brown \& Patten, 2017).

The median female White House employee is drawing a salary of $\$ 72,650$ in 2017 , compared to the median male salary of $\$ 115,000$. The typical female staffer in Trump's White House earns 63.2 cents per $\$ 1$ earned by a typical male staffer.

(Perry, 2017)

One of Ivanka's first duties was joining her dad on his trip to Saudi Arabia in May 2017 where she received a $\$ 100$ million donation from Saudi Arabia and the United Arab Emirates for a Women's Entrepreneur Fund (Palmeri, 2017). In July 2017, she went with her dad to the G-20 Summit in Hamburg, Germany, to represent the United States in the Women Entrepreneurs Finance Fund sessions. She took her dad's seat between British Prime Minister Theresa May and Chinese President Xi Jinping when Trump left a session on Africa partnership, which raised appropriateness questions when reported in the media (Moran, 2017).

And, her meetings with international leaders have taken her clothing line off her homepage:

Photos of Ms. Trump posing next to the Canadian prime minister, Justin Trudeau, or sitting in on meetings with business leaders have replaced pictures of her shoes and handbags in her Instagram feed.

(Haberman \& Abrams, 2017)

\section{Is There Gender Equity in the Trump Brand U.S. Education Department?}

Title IX, which was passed 1972, prohibits gender discrimination in any school that receives federal funding, is under Trump "investmentgation.” Trump-appointed Education Secretary Betsy DeVos is reviewing the guidelines from the Obama administration regarding the relationship of gender discrimination and sexual assault cases on campuses that were incorporated into Title IX compliance evaluations in 2011 (Shapiro, 2017; Trautwein, 2017; Izadi, 2015). 
She is being criticized by the ACLU and other Civil Rights organizations for rescinding the Obama administration's instructions that schools should allow transgender students to use bathrooms of their choice. She also has been sued by attorney generals in 18 states and the District of Columbia over her decision to suspend rules meant to protect college students from abuses (Garvey, 2017).

\section{Is There Gender Equity in the Trump Brand Office of Gender Equality and Women's Employment?}

Trump named an anti-transgender activist as a senior adviser in the office of Gender Equality and Women's Empowerment, Bethany Kozma. She held positions in the White House and Homeland Security under George W. Bush and opposes President Obama's guidelines to allow transgender students use their preferred names and pronouns - male or female - and use school restrooms and locker rooms based on their gender identity preferences (Gilchrist, 2017). ${ }^{16}$

Through the Freedom of Information Act, the National Women's Law Center (NWLC) is actively investigating the Trump administration acts to dismantle gender equity:

Nearly 30 years ago, the Supreme Court confirmed that discrimination based on stereotypical ideas about an individual's-or sex stereotyping-constitutes illegal sex discrimination. For example, it is discriminatory for an employer to pass over a woman for a promotion because she acts or dresses in a 'masculine' way. Since then, courts have repeatedly held that discrimination against people because of their sexual orientation (or perceived sexual orientation) and discrimination against people because of their gender identity are types of discrimination that fall under the umbrella of unlawful sex discrimination.

(Hanson, 2017)

In June 2017, the NWLC filed a discrimination lawsuit against the U.S. Department of Education regarding Title IX (Brodsky, 2017). The outcome will provide legal insight into the future of the Trump administration's right to define gender equity.

\section{The Contentious Conservative Age of Trump}

In the Contentious Conservative Age of Trump his discourse is unrestrained. His public performances are delivery over content and his interactions are celebrity over presidential. It has become a media marketing bonanza. Tweets are news. Memes are news. Fake news is news. News has evolved into branding for market value to increase advertising revenue. 
Today's Age of Media Conglomeration continues to provide a daily menu of media narratives that disengage news values. While Trump rants about "fake news" coverage, the morning media regurgitate his tweets and allow social media influencer Trump to set the news agenda each day. His 140-character tweeting starts when the sun comes up and results in daily Trump Twitter headlines.

His public events and speeches focus on whatever controversy he chooses to start or outrageous opinion he chooses to share. The coverage frenzy is extremely disconcerting as journalists perform as talk show conversationalists, making Trump's tweets the headline news. CNN has made Trump's tweets its Breaking News "talk show." The New York Times has made his tweets their online news of the day.

Trump's victory had myriad commentary and editorials attempting to assess how the polls got the voter projections wrong. Maybe it was Clinton's lack of connectivity in her messaging. Maybe it was Trump's ability to connect emotionally with those who felt they were not valued. Whatever the cause, the news media has failed to analyze how its coverage played a role in the Trump triumph.

Media narratives have returned to the Hearst and Pulitzer days of yellow journalism. For those devouring news about the administration, the choice of narratives is choosing those that reflect individual and group desires. Readers and viewers follow the narrative of their choice, which ignores the core values of equality and equity. In contrast, I would argue that today's media is full of critics, spectators, and collectors, but today's media has no "creators" who know the principles and practice of journalism.

The White House is a Congressional and media flashpoint filled with internet intrigue, overspeak, and tweets. Congressional conversations with citizens have impeachment in its hashtags and followers.

One of the things that distinguishes rule-of-law democracies from personalized dictatorships is their reliance on procedures, not individual whims, and on officials - experienced people, subject to public scrutiny and ethics laws - not the unsackable relatives of the leader. That distinction is now fading.

(Applebaum, 2017)

We are looking over and overlooking the world's deepest precipice. Social media has given the Trump family (p)residency in the White House an interpersonal and international communication empire. Trump's unconventional egotistical eccentricity is divorcing him from Congress and us from the rest of the world.

He has invested in strengthening masculinity in his policies and military support, while closing and abolishing "feminized state institutions that are associated with the care, well-being, and education of the population and the soft power of diplomacy" (Gokariksel \& Smith, 2017). 
I want to conclude with an impartiality disclaimer. I am a World War II baby boomer. I am a feminist. I sought gender equity in college and felt vindicated when Congress passed Title IX to the Higher Education Amendments Act. I voted for Hillary. I did the Women's March on January 23, 2017, in Washington, D.C. - the day after Trump's inauguration as the 45th President of the United States. Gender equity doesn't live in the Trump fiefdom. From my perspective, it is a time of overwhelming concern and angst.

"You're fired" were Trump's last words when he eliminated contestants on his NBC business skills television game show, The Apprentice. His catchphrase appears to have an aura of prediction for a live US Congress online show judging the governing skills of the 45th US president, "You're Impeached."

\section{Notes}

1 I chose to use the term (s)election as Trump was not elected by popular vote. He was selected by the Electoral College.

2 Historians argue that feminism is rooted in Greece with Sappho around 500 BC, but the first U.S. wave was at the Seneca Falls Convention in 1848 when 300 men and women drafted a resolution of temperance and abolition. The second wave began in the 1960 s with protests of the Miss America pageant. The third wave began in the mid-1990s with empowerment of choice. The fourth wave has eliminated gender as a binary and focuses on inclusion. The 2017 Women's March is emblematic of the wave's forward march. A legal history timeline of U.S. feminism compiled by the National Women's History Project can be found at www.nwhp.org/resources/womens-rights-movement/ detailed-timeline.

3 When audited in January 2017, the report found that of Trump's 30 million followers, only 51 percent are humans.

4 The data was collected from the print editions of the Los Angeles Times, The New York Times, The Wall Street Journal, The Washington Post, and USA Today, and the newscasts of ABC World News Tonight, CBS Evening News, CNN's The Situation Room, Fox's Special Report, and NBC Nightly News.

5 Narratives have been undergoing some evolution most recently and Trump's party's allegiance is waning. His compatriots tried to smooth over his narratives for his first 30 weeks, but the high profile firings and his failure to decry white supremacists after the violence and deaths in Charlottesville, Virginia on August 12 was causing disclaimers and distancing daily (Thrush \& Haberman, 2017).

6 As of this writing, no outcome has been reported.

7 Forty-eight of the 50 states give all of their electoral votes to the candidate who received the most votes in the state -51 percent to 49 percent and the +1 percent wins them all. Individual votes don't count. The Electoral College has 538 electors - essentially one elector for each member of the House of Representatives and one for each Senator - and requires 270 electoral votes to elect the president. Only Maine and Nebraska are not a "winner takes all" and divide their electors based on individual vote counts at: www. archives.gov/federal-register/electoral-college/faq.html\#.

8 One person, one vote. Women got the right to vote in the United States 97 years ago, but each vote still doesn't count. The Electoral College, established in 1804, is 213 years old, and it archaically elects the president. 


\section{Pam Creedon}

Polls have shown that lawyers, political scientists and voters have favored abolishing it.

9 Maine since 1972 and Nebraska since 1996 use a Congressional District Method of allocating electoral votes (www.fairvote.org/maine_nebraska).

10 A die-in is a nonviolent protest to draw attention and media coverage. Protestors lie down and pretend to be dead with signs and posters. It is recommended to be done near an event, office, or home of an elected member of Congress.

11 The evolution of LGBT acronym: Lesbian, gay, bisexual, and transgender/ transsexual movements have their roots in the 1950s. The addition of "Q" in the acronym stands for queer or questioning (LGBTQ). Other versions of the acronym have added "I" that stands for intersexed (LGBTI), those who are born with unique male/female biological characteristics. Cisgender also is now used as a term for those whose gender identify matches the sex they were assigned at birth. As of this writing, it appears that Trump is only concerned about the " $\mathrm{T}$ " (transgender/transsexual) individuals in the military using toilets of choice.

12 The Ivanka M. Trump Charitable Fund will accept the income from sales of the book and will "donate" the profit - and any remaining book advance to the Boys \& Girls Club and The National Urban League. Of course, Charitable Fund has overhead (salaries) that must be paid and deducted from the sales before they can make the donations.

13 It is interesting to note that \#GrabYourWallet website is ".org," which generally refers to non-profit organizations. It will be interesting to see if the Trump administration decides to require it to be a ".com."

14 Melania is a U.S. citizen since 2007. Cleveland, Ohio, is home to the largest U.S. Slovenian population, which is Melania's country of birth, but no attempt to meet or mention her heritage was made the convention.

15 The suit had not been settled at the time of this writing.

16 When transgender Trump supporter Caitlyn Jenner met with him during the campaign, Trump said she would be welcome to use the restroom of her choice. She has publicly denounced Trump's transgender military ban (Gleeson, 2017).

\section{References}

Abrams, R. (2017, February 4). Early signs suggest Trump's actions are taking a toll on Trump brand. The New York Times. Retrieved at www.nytimes. com/2017/02/04/business/the-trump-brand.html.

Allen, C. \& Schouten, F. (2016, October 7). Trump apologizes for video bragging about groping women. USA Today. Retrieved at www.usatoday.com/ story/news/politics/onpolitics/2016/10/07/trump-washington-postwomen-billy-bush-video/91743992.

Applebaum, A. (2017, April 27). Ivanka Trump's White House role is a symbol of democratic decline. The Washington Post. Retrieved at www. washingtonpost.com/opinions/global-opinions/ivanka-trumps-white-houserole-is-a-sy mbol-of-democratic-decline/2017/04/27/a060980c-2b64-11e7a616-d7c8a68c1a66_story.html?utm_term=.eaf9f5f9d09e.

Bacon, J. \& Gomez, A. (2017, January 28). Protests against Trump's immigration plan rolling in more than 30 cities. Retrieved at www.usatoday.com/ story/news/nation/2017/01/29/homeland-security-judges-stay-haslittle-impact-travel-ban/97211720. 
Blake, A. (2016, January 16). Here are the Megyn Kelly questions that Donald Trump is still sore about. The Washington Post. Retrieved at www.washingtonpost. com/news/the-fix/wp/2016/01/26/here-are-the-megyn-kelly-questions-thatdonald-trump-is-still-sore-about/?utm_term $=.3 \mathrm{~b} 22 \mathrm{a} 65 \mathrm{bcffc}$.

Borchers, C. (2016, October 14). Melania Trump's demand for a retraction by People magazine is simply amazing. Retrieved at https://www.washingtonpost. com/news/the-fix/wp/2016/10/14/melania-trumps-demand-for-a-retractionby-people-magazine-is-simply-amazing/?utm_term=.67bbbabb49ac

Bort, R. (2017, May 30). Nearly half of Donald Trump's Twitter followers are fake accounts and bots. Newsweek. Retrieved at www.newsweek.com/ donald-trump-twitter-followers-fake-617873.

Bowcott, O. \& Watt, H. (2017, April 12). Melania Trump accepts Daily Mail damages and apology in libel case. The Guardian. Retrieved at www.theguardian.com/us-news/2017/apr/12/melania-trump-acceptsdamages-and-apology-from-daily-mail.

Brodsky, A. (2017, June 12). We just sued the Department of Education. Here's why. National Women's Law Center. Retrieved at https://nwlc.org/blog/ we-just-sued-the-department-of-education-heres-why.

Brown, A. \& Patten, E. (2017, April 3). The narrowing, but persistent gender gap in pay. Pew Research Center. Retrieved at www.pewresearch.org/ fact-tank/2017/04/03/gender-pay-gap-facts.

Bump, P. (2016, July 19). Melania Trump's speech appears to have been cribbed from Michelle Obama's in 2008. The Washington Post. Retrieved at www.washingtonpost.com/news/the-fix/wp/2016/07/19/melania-trumps-speech-appearsto-have-cribbed-from-michelle-obamas-in-2008/?utm_term=.31abc8999a79.

Byerly, C. (2005). The formation of an oppositional discourse. Feminist Media Studies, 5(3), 281-296.

Byerly, C. (2014). Media conglomeration and women's interests: A global concern. Feminist Media Studies, 14(2), 322-326.

Byerly, C. (a-forthcoming). Feminist intersectionality research in communications: Origins, contributions and tensions. Ex Aequo.

Byerly, C. (b-forthcoming) Feminism, theory and communication: Progress, debates and challenges ahead. In D. Harp, J. Loke, \& I. Bachmann (Eds.), Feminist Approaches to Media Research and Theory. Palgrave Macmillan.

Byers, D. \& Stelter, B. (2016, October 13). New York Times to Donald Trump: We won't retract. CNN. Retrieved at http://money.cnn.com/2016/10/12/media/ new-york-times-donald-trump-lawsuit-threat/index.html.

Chan, M. (2016, July 20). Who is Melania Trump's speech writer Meredith McIver? Time. Retrieved athttp://time.com/4415378/meredith-mciver-donaldtrump-speech.

Chandler, A. (2017, February 8). Tale of the tweet: Donald Trump vs. Nordstrom. The Atlantic. Retrieved at www.theatlantic.com/business/archive/2017/02/ donald-trump-versus-nordstrom-twitter/516027.

Cochrane, E. (2017, August 20). The red cap aside, Trump souvenirs are a hard sell. The New York Times. Retrieved at www.nytimes.com/2017/08/20/us/ politics/trump-hats-merchandise.html? mcubz $=3$.

Enda, K. (2017, July). State: Donald Trump is the best - and worst - thing that's happened to modern American feminism. CNN. Retrieved at www.cnn.com/ interactive/2017/politics/state/womens-movement-donald-trump. 


\section{Pam Creedon}

Fahrenthold, D. A. (2016, October 8). Trump recorded having extremely lewd conversation about women in 2005. Retrieved at https://www.washingtonpost. $\mathrm{com} /$ politics/trump-recorded-having-extremely-lewd-conversation-aboutwomen-in 2005/2016/10/07/3b9ce776-8cb4-11e6-bf8a-3d26847eeed4_story. html?utm_term=.05a5eb808f0e.

Farley, R. (2015, August 11). Trump's amnesia. FactCheck.org. Retrieved at www.factcheck.org/2015/08/trumps-amnesia

Gabler, N. (2016, September 14). Media narratives imprison Clinton, Trump - and voters. Retrieved at http://billmoyers.com/story/hillary-clinton-donald-trumpmedia-narratives.

Garvey, M. (2017, August 4). Betsy DeVos refuses to take a stand against discrimination, again. ACLU. Retrieved at www.aclu.org/blog/speak-freely/ betsy-devos-refuses-take-stand-against-discrimination-again.

Gilchrist, T. E. (2017, June 30). Trump's appointment to gender equality office has hateful anti-trans record. The Advocate. Retrieved at www. advocate.com/politics/2017/6/30/trumps-appointment-gender-equalityoffice-has-hateful-anti-trans-record.

Gleeson, S. (2017, June 12). Caitlyn Jenner and Donald Trump's on again, off again relationship. USA Today. Retrieved at www.usatoday.com/story/ sports/olympics/2017/06/12/caitlyn-jenner-donald-trump-republican-partytransgender-rights $/ 102633186$.

Gokariksel, B. \& Smith, S. (2017). Intersectional feminism beyond U.S. flag hijab and pussy hats in Trump's America. Gender, Place \& Culture, 24(5), 628-644.

Haberman, A. \& Abrams, R. (2017, March 29). Ivanka Trump, shifting plans, will become a federal employee. The New York Times. Retrieved at www. nytimes.com/2017/03/29/us/politics/ivanka-trump-federal-employee-whitehouse.html? mcubz=3.

Hanna, R., Rohm, A., \& Crittenden, V. (2011). We're all connected: The power of the social media ecosystem. Business Horizons, 54(3), 265-273.

Hanson, E. (2017, August 7). Is the Trump administration quietly trying to dismantle sex discrimination protections? National Women's Law Center. Retrieved at https://nwlc.org/blog/is-the-trump-administrationquietly-trying-to-dismantle-sex-discrimination-protections-were-using-thefreedom-of-information-act-to-find-out.

Harrington, J. (2016, September 5). New influencers: Changing the face of PR and marketing. PR Week. Retrieved at www.prweek.com/article/1406138/ new-influencers-changing-face-pr-marketing.

Healy, P. \& Haberman, M. (2015, December 5). 95,000 words, many of them ominous, from Donald Trump's tongue. The New York Times. Retrieved at www.nytimes.com/2015/12/06/us/politics/95000-words-many-of-themominous-from-donald-trumps-tongue.html.

Hoffman, A. (2017, June 8). Meet the woman President Trump blocked on Twitter. Time. Retrieved at http://time.com/4809002/donald-trump-twitterblock-james-comey.

Ingraham, C. (2017, July 5.) White House gender pay gap more than triples under Trump. The Washington Post. Retrieved at www.washingtonpost.com/ news/wonk/wp/2017/07/05/white-house-gender-pay-gap-more-than-triplesunder-trump/?utm_term=.1210485ce648. 
Ingram, M. (2017, March 7). Trump's victory has people signing up for news like it's going out of style. Fortune. Retrieved at http://fortune.com/2017/03/07/ the-trump-effect.

Izadi, E. (2015, May 20). Columbia student protesting rape carries a mattress during commencement. The Washington Post. Retrieved at www. washingtonpost.com/news/grade-point/wp/2015/05/19/columbia-studentprotesting-campus-rape-carries-mattress-during-commencement/?utm_ter$\mathrm{m}=.9 \mathrm{~d} 54662920 \mathrm{ac}$.

Kelly, J., Penzenstadler, N., \& Reilly, S. (2016, October 9). Trump, companies accused of mistreating women in at least 20 lawsuits. USA Today. Retrieved at www. usatoday.com/story/news/politics/elections/2016/10/09/trumps-lawsuits-include20-involving-allegations-mistreating-women-president-republican/91832012.

Krieg, G. (2016, December 22). It's official: Clinton swamps Trump in popular vote. CNN. Retrieved at www.cnn.com/2016/12/21/politics/donald-trumphillary-clinton-popular-vote-final-count/index.html.

Media Landscape. (2017). Boon, bane or both? Brunswick Review, 12, 66. Retrieved at www.brunswickgroup.com/boon-bane-or-both-i5393.

Merica, D., Borger, G., Acosta, J., \& Klein, B. (2017, March 30). Ivanka Trump is making her White House job official. CNN. Retrieved at http://edition.cnn. com/2017/03/29/politics/ivanka-trump-white-house-job/index.html.

Miller, K. (2017, July 13). It's Not a Women's White House. Retrieved at http:// billmoyers.com/story/its-not-a-womens-white-house/.

Moran, L. (2017, July 8). Ivanka Trump stepped in for her dad at the G-20 Summit, and folks weren't happy. Huffington Post. Retrieved at www.huffingtonpost. com/entry/ivanka-trump-donald-trump-g20_us_5960dab0e4b0615b9e91c8dc.

Mullin, B. (2016, October 17). The New York Times legal department is still waiting for a reply from Donald Trump. Poynter. Retrieved at www.poynter. org/2016/the-new-york-times-legal-department-is-still-waiting-for-a-replyfrom-donald-trump/434996.

Nee, R. C. \& De Maio, M. (2017, August 11). The bitch is back: Gender stereotypes of Hillary Clinton in 2016 Twitter images and memes. Paper presented at the Association for Education in Journalism and Mass Communication, Commission on the Status of Women, Chicago, IL.

O'Reilly, H. (2017, June 7). President Trump is violating constitutional rights by blocking me on Twitter. The Washington Post. Retrieved at www.washingtonpost.com/posteverything/wp/2017/06/07/president-trump-is-violating-myconstitutional-rights-by-blocking-me-on-twitter/?tid=ss_tw\&utm_term=. ba79ada8e 510 .

Palmeri, T. (2017, June 30). White House council for women and girls goes dark under Trump. Politico. Retrieved at www.politico.com/story/2017/06/30/ donald-trump-white-house-council-for-women-and-girls-239979.

Parker, A. \& Rucker, P. (2017, July 25). Trump famously said, "You're fired!” But he tends to demean rather than dismiss. The Washington Post. Retrieved at www.washingtonpost.com/politics/trump-famously-said-youre-fired-but-hetends-to-demean-rather-than-dismiss/2017/07/25/056a12a4-7152-11e7-8839ec48ec4cae25_story.html?utm_term=.f4ead1651787.

Patterson, T. E. (2016, December 7). News coverage of the 2016 general election: How the press failed the voters. Shorenstein Center. Retrieved at https://shorensteincenter.org/news-coverage-2016-general-election/?platform=hootsuite. 


\section{Pam Creedon}

Perry, M. (2017, July 3). Based on median salaries, gender pay gap at Trump White House is almost $2 \mathrm{X}(37 \%)$ what the media are reporting $(20 \%)$. AEI. Retrieved at www.aei.org/publication/based-on-median-salaries-gender-paygap-at-trump-white-house-is-almost-2x-37-what-the-media-are-reporting-20.

Phelps, J. \& Caplan, D. (2017, February 4). Nordstrom, Neiman Marcus drop Ivanka Trump fashion collection, citing brand's performance. ABC News. Retrieved at http://abcnews.go.com/Politics/nordstrom-drops-ivanka-trumpsclothing-collection-citing-brands/story? id=45241255.

Pope, K. (2017, July 5). What we miss when we obsess over Trump's tweets. Columbia Journalism Review. Retrieved at www.cjr.org/covering_trump/ trump_tweets_press_journalists.php?newsletter.

Przybyla, H. M. (2017, August 14). Women's March to reconvene around 2018 after Charlottesville. USA Today. Retrieved at www.usatoday.com/ story/news/politics/2017/08/14/womens-march-reconvene-around-2018after-charlottesville/564963001.

Puente, M. (2017, April 4). Melania Trump's first official White House portrait photo is out. USA Today. Retrieved at www.usatoday.com/story/ life/2017/04/03/melania-trumps-first-official-white-house-portrait-photoout/99983518/7.

Riddell, K. (2016, Oct. 12). Top 10 Clinton scandals exposed by WikiLeaks. The Washington Times. Retrieved at www.washingtontimes.com/news/2016/ oct/12/top-10-hillary-clinton-scandals-exposed-wikileaks.

Shapiro, T. R. (2017, April 28). Expelled for sex assault, young me are filing more lawsuit to clear their names. Retrieved at https://www.washingtonpost.com/ local/education/expelled-for-sex-assault-young-men-are-filing-more-lawsuitsto-clear-their-names/2017/04/27/c2cfb1d2-0d89-11e7-9b0d-d27c98455440_ story.html?utm_term=.3998e3780553Senior, J. (2017, May 2). Having trouble having it all? Ivanka alone can fix it. The New York Times. Retrieved at www. nytimes.com/2017/05/02/books/review-ivanka-trump-women-who-work. html.

Siddiqui, F., Laris, M., \& Chandler, M. A. (2017, January 29). City, airport rallies across U.S. urge Trump: "Let them in." The Washington Post. Retrieved at www.pressreader.com/usa/the-washington-post/20170130/281711 204373017.

Stein, P, Hendrix, S., \& Hauslohner, A. (2017, January 22). Women's marches on DC: More than one million marchers protest Trump. The Washington Post. Retrieved at www.washingtonpost.com/local/womens-march-on-washingtona-sea-of-pink-hatted-protesters-vow-to-resist-donald-trump/2017/01/21/ae4def62-dfdf-11e6-acdf-14da832ae861_story.html?utm_term=.cf0318ce10c7.

Thrush, G. \& Haberman, M. (2017, August 12). Trump is criticized for not calling out white supremacists. The New York Times. Retrieved at www. nytimes.com/2017/08/12/us/trump-charlottesville-protest-nationalist-riot. html?mcubz=3.

Trautwein, C. (2017, July 14). Columbia settles lawsuit brought by former student accused of sexual assault by "mattress girl." Time. Retrieved at http:// time.com/4858979/columbia-university-paul-nungesser-mattress-girl-emmasulkowicz.

Tyson, A. \& Maniam, S. (2016, November 9). Behind Trump's victory: Divisions by race, gender, education. Pew. Retrieved at www.pewresearch.org/ 
fact-tank/2016/11/09/behind-trumps-victory-divisions-by-race-gendereducation.

Waddell, K. (2017, January 23). The exhausting work of tallying America's largest protest. The Atlantic. Retrieved at www.theatlantic.com/technology/ archive/2017/01/womens-march-protest-count/514166.

Wagner, J. (2017, February 23). Kellyanne Conway: Feminism associated with being anti-male and pro-abortion. The Washington Post. Retrieved at www. washingtonpost.com/news/post-politics/wp/2017/02/23/kellyanne-conwayfeminism-associated-with-being-anti-male-and-pro-abortion/?utm_ter$\mathrm{m}=.408814 \mathrm{c} 3200 \mathrm{e}$.

Wamsley, L. (2017, February 7). Melania Trump lawsuit argues "Once in the Lifetime" chance to make millions lost. NPR. Retrieved at www.npr. org/2017/02/07/513970871/melania-trump-lawsuit-argues-once-in-alifetime-chance-to-make-millions-is-lost.

Zito, S. (2016, September 23). Taking Trump seriously, not literally. The Atlantic. Retrieved at www.theatlantic.com/politics/archive/2016/09/trump-makeshis-case-in-pittsburgh/501335. 


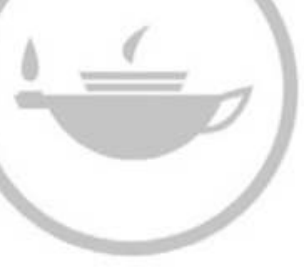

Taylor \& Francis Taylor \& Francis Group

http://taylorandfrancis.com 


\section{Part III}

\section{Trump, Rhetoric, and Understanding Amid Media Fragmentation}




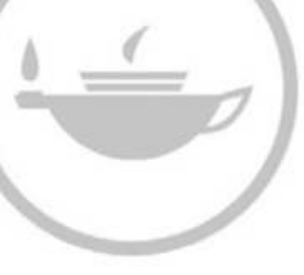

Taylor \& Francis Taylor \& Francis Group

http://taylorandfrancis.com 


\section{The Origins of Trump's "Alternative Reality" \\ A Brief History of the Breitbart Effect}

\section{Frank Durham}

"Fake news," "alternative facts," and American conservatives' hostility to the mainstream media have a long history, one that dates to the rejection of science by the Right at the end of the First World War in favor of its own, traditional beliefs. By focusing on the uses of historically non-mainstream media by the Right in their reaction against science-based professional journalism at the time, this essay assesses the lasting effects of that monumental fight for the control of American culture. In brief, the denial of science by Biblical fundamentalists and, more generally, by cultural conservatives a hundred years ago established a practice of belief-driven counter-factuality that prefigured Andrew Breitbart's attacks on the straight press in the early 2000s, as well as setting the stage for the "alternative reality" claimed by the Trump regime.

In the national chaos in 1919 following the war, the contest for and against science was exemplified by two principals, each of whom was dedicated to establishing separate and competing systems of social meaning to instill order for a nation in distress: William Bell Riley, the conservative Baptist minister from Minneapolis founded the World's Christian Fundamentals Association (WCFA) in 1918 (Marsden, 1980), and Walter Lippmann, whose work just before and after the First World War shows him to be the first media theorist and an original proponent of science-based approaches to journalism (Jansen, 2012).

In the post-war period, Riley's Biblical literalism and Lippmann's science-based approach to journalism as the basis of democracy were symptoms of the tenuous nature of the first culture war. In outlining the origins of their indirect, but apparent, cultural contest here, it is possible to see that even ahead of the alt-Right phenomenon of the Trump era, Andrew Breitbart's twenty-first-century war on progressivism owed directly to the Right's original challenge to the perceived hegemony of "science" and with it, modern journalism.

In those terms, the science-based society that Lippmann called for in Drift and Mastery (1914) and that he would apply to journalism after the war in Liberty and the News (1920) and in "A Test of the News" (an essay that appeared in the New Republic) amounted to heresy for 


\section{Frank Durham}

fundamentalists who ardently resisted challenges to their religious worldview and for conservatives' intent on preserving traditional norms. As a result, their general response to the mainstream press was to avoid it in favor of creating their own media in order to conserve their worldviews.

\section{9: The Right Influences the Reform of Journalism}

In its objection to progressivism, the early conservative movement, including fundamentalists, served as a catalyst for the professionalization of journalism. But without reference to the broader cultural context of the turbulent post-World War I period, the naïve reader might fairly assume that the definition of "objectivity" offered by the American Society of Newspaper Editors (ASNE) in 1923 had sprung from the Progressive movement in reaction to prior journalistic practice, alone.

By coding new "canons" of professionalism, the newly founded organization held that objective news should "be free from opinion or bias of any kind," that journalism should be "freedom from all obligations except that of the public interest." Further, the ASNE warned that "promotion of any private interest...is not compatible with honest journalism" and that "partisanship that knowingly departs from the truth does violence to the best spirit of American journalism" (quoted in West, 2001, p. 51).

Given that the ASNE was reacting against the partisanship and commercialism of the nineteenth-century press, that series of developments offers a premise for understanding the broader development of twentieth-century journalism and its place in American democracy. Certainly, the ability to counter the early "fake news" of yellow journalism produced by Randolph Hearst and Joseph Pulitzer that led to the Spanish-American War, for example, marked a significant step in refining the ability of the press to report the facts. But as the recent literature on the Right and its use of their own media to counter-progressivism shows (Hemmer, 2016; Lichtman, 2008; McPherson, 2008), the forces that shaped the professionalization of the postwar mainstream press were more diverse than that.

By broadening the scope of the history of journalism to consider the place of journalism within the culture war in this period, it becomes necessary to consider the profound cultural animus against progressivism that was held by conservatives and the cultural dynamic they created around the changing practice of journalism. That traditionalist counter-current meant avoiding modern science-based journalism in favor of a different way of knowing, one that would privilege the world as it had been before the war.

In this first culture war, unlike today, conservatives were disadvantaged, but determined. According to Lichtman (2008), "To achieve their ambitious aims, conservatives have had to stay disciplined, mobilize 
their resources, and wage total war against liberals, with unconditional surrender as the only acceptable result" (p. 6). Even so, in that moment and for most of the rest of the twentieth century, the terms by which American social reality would be defined remained in favor of journalistic objectivity and the kind of science-based reporting that Walter Lippmann (1920) had advocated just after the war. In making the case for a reformed practice of journalism, Lippmann pointedly used ecclesiastical language to describe the way that science-based journalism was already displacing religion as the engine of American democracy. $\mathrm{He}$ wrote:

The news of the day as it reaches the newspaper office is an incredible medley of fact, propaganda, rumor, suspicion, hopes, and fears, and the task of selecting and ordering that news is one of the truly sacred and priestly offices in a democracy. For the newspaper is in all literalness the bible of democracy, the book out of which a people determines its conduct. It is the only serious book most people read. It is the only book they read every day. Now the power to determine each day what will seem important and what shall be neglected is a power unlike any that has been exercised since the Pope lost his hold on the secular mind.

Even as Lippmann, the culture warrior, was cataloging the inadequacies of the press to produce truth here, he was claiming victory in the culture war over the false mysticism of religion.

Significantly, upon the United States' entry into the war in 1917, Riley had warned against the kind of modernized - science-based - democracy Lippmann favored. While Riley said that President Wilson's pledge to “make the world safe for democracy" posed him no problem, the minister asked:

Who will make democracy safe for the world?" Only "the blood of the Son of God" could change human nature sufficiently for that. Preachers should not allow for "modern voices to substitute democracy for a divinely appointed plan of REDEMPTION....

(quoted in Marsden, 1982, p. 152)

Although Lippmann and Riley never engaged each other directly - Bryan and Darrow would act that controversy out in the Scopes trial in 1925 each saw opportunity in the nation's distress to seize the day.

\section{Science, Conservatism, and the Struggle to Define Truth}

The line between science and conservatism was drawn in lasting terms before the First World War. In 1914 in Drift and Mastery, his first widely read book, Walter Lippmann (1914 [1917]) described a "sense 


\section{Frank Durham}

of epochal change" in the Western world where "scientific invention and blind social currents have made the old authority impossible in fact" (p. xviii). Influenced by the Einsteinian revolution in the physical sciences and by his deep reading of Freud in the emerging social sciences (Steel, 1980), Lippmann (1914) saw a break with past ways of knowing.

Instead, he described his "attempt to diagnose the current unrest and to arrive at some sense of what democracy implies. It begins with the obvious drift of our time and gropes for the terms of its mastery" (p. xxiv). Calling for political liberals to rally against the dominance of traditional beliefs, Lippmann (1914) declared, "The American conservative, it seems to me, fills a vacuum, where democratic purpose should be." In the martial language of the moment, he inveighed, "The rebel program is stated. Scientific invention and blind social currents have made the old authority impossible in fact, the artillery fire of the iconoclasts has shattered its prestige. We inherit a rebel tradition" (p. xviii, emphasis in original).

In Lippmann's view, the fate of the postwar world could not depend not on faith, but on science. In Drift \& Mastery (1914), he explained, "This is what mastery means: the substitution of conscious intention for unconscious striving” (p. 269). In his view, science and democracy offered a way to organize a world where mere religious faith would no longer suffice. Lippmann explained:

Rightly understood science is the culture under which people can live forward in the midst of complexity, and treat life not as something given but as something to be shaped. Custom and authority will work in a simple and unchanging civilization, but in our world only those will conquer who can understand.

There is nothing accidental then in the fact that democracy in politics is the twin-brother of scientific thinking. They had to come together. As absolutism falls, science arises. It is self-government.

(pp. 275-276)

In these terms, Lippmann effectively declared a new moment for the Enlightenment in America.

\section{Fundamentalism, 1919}

After a frenzied campaign to win public support for the war, its abrupt end brought, as Marsden writes, "an overwhelming atmosphere of crisis” for fundamentalists like Riley, evangelist Billy Sunday, and anti-evolutionist William Jennings Bryan, as well as for the rest of the loosely organized movement. Marsden (1980) described a "directionless belligerence which sought a new outlet” (p. 153). So, when in 1919 
Riley organized the WCFA's first meeting of 6,000 devotees in Philadelphia to stem the tide of modernist science against Biblical truth, the challenge reflected change in a moment of war. Marsden reports that:

[A]s in conservative-evangelical anti-German war-time rhetoric, evolution and modernism were tied together and seen as a cultural, as well as a specifically religious threat. Out of these concerns to which anti-Communism was soon added, fundamentalist superpatriotism began to grow.

(pp. 152-153)

Conservatives had plenty to be concerned about. By 1919, Darwin's theory of evolution was 60 years old. The Red Scare of 1919-1920 translated the fearful nativism of nineteenth-century White, Anglo-Saxon Americans into a new fear of Communism (Lichtman, 2008). The collectivism of the labor movement, a sore spot for nineteenth-century industrialists, also fueled the Red Scare as massive labor strikes stopped the national economy and threatened its government. In those crises, returning white, "American" veterans faced competition from the foreign-born workers who had replaced them in the nation's factories and foundries during the war. And all the while, the god-less Russian Revolution threatened Europe (Brecher, 1997).

Apart from the organized movement, a survey of the media developed by conservatives at the time shows the anti-pluralist beliefs defended by contemporary conservatives. In a defense of Christian doctrine, "[T]he national Baptist newspaper, the Watchman-Examiner, coined the more specific use of the term, 'fundamentalist,' in 1920 for Christians who still cling to the great fundamentals who mean to do great battle royal for them" (Lichtman, 2008, p. 26).

Lichtman (2008) explained:

For fundamentalists, the Bible provided the only unified theory of material and spiritual life, fully compatible with the "facts" of God's natural world. Evolution, in their view, contradicted the Book of Genesis, conflated men with beasts, substituted theory for fact, and robbed human life of divine meaning and purpose.

From 1919 when the WCFA was founded until the Reagan administration repealed the Fairness Doctrine in 1987 (Hemmer, 2016; McPherson, 2008), conservative polemicists and Progressive journalists competed for political primacy though a tacitly dualistic media system. Having their own media gave the otherwise outnumbered and out-published conservatives the space to nurture their beliefs without having to argue the differences in the mainstream press. Until the mid-1990s with the advent 


\section{6}

of the internet, conservatives used books, magazines, pamphlets, brochures, and, later, radio, television, and movies, as ideological redoubts against the hegemony of the modern MSM. In that way, they continued to create media as ideologically discrete spaces for preserving the values they cherished. Perhaps most importantly, these media perpetuated the themes of conservatism and their remarkably stable issue agenda, which is again in evidence today in the resurgence of the Ku Klux Klan, white nationalism, and neo-Nazism.

Perhaps the most significant movement-related publication was The Fundamentals, a series of twelve books published between 1910 and 1915, which were "meant to be a great 'Testimony to the Truth.'” The series, which was underwritten by Lyman Stewart, a Southern California oil millionaire, represented the work of the best Biblical scholars of the day. Some three million copies were distributed to "every pastor, missionary, theological student, YMCA and YWCA secretary, college professor, Sunday school superintendent, and religious editor in the English-speaking world." Although the books did not generate a strong reaction, the title became a common reference point for referring to the "fundamentalist" movement (Marsden, 1980, pp. 118-119).

In the 1920s, the variety of traditional beliefs represented in conservative publications shows how much broader the conservative movement agenda was than Riley's fundamentalist WCFA. Albert J. Nock's libertarian magazine, The Freeman, which was "often judged to have been the finest magazine in the country in the early years of the decade" (Lora $\&$ Longton, 1999, p. 5), endorsed a kind of laissez-faire economics bordering on anarchy in its run from 1920 to 1924.

In 1921, Outlook magazine warned against the "Red Terror" and, notably, the risk of overreaction to it (Lichtman, 2008, p. 19). From 1920 to 1922, Henry Ford published a magazine, The Dearborn Independent, which he had purchased as a vehicle for reprinting the fictitious antiSemitic tracts of The Protocols of the Elders of Zion, as well as The International Jew: The World's Foremost Problem. Those anti-Semitic tracts would combine with existing nativist ideology in ways that extended the Right's reaction in extreme directions of fascism and Nazism. Later, Gerald B. Winrod would publish the Defender, a fundamentalist Christian magazine, which "loathed modernism and published opinions common to fundamentalism." After Winrod visited Hitler's Germany, he endorsed the Third Reich, often blaming the New Deal on a "Jewish-Communist" scheme (Lora \& Longton, 1999, p. 379) in the same vein as Father Coughlin, the "Radio Priest," whose demagogic and, ultimately, pro-Nazi ministry, reached millions from 1926 to 1936.

During the Ku Klux Klan's resurgence from 1920 to 1925, the Klan's magazine, Fiery Cross, offered anti-Semitic, anti-papist values in defense of "white Protestant values" (Lichtman, 2008, p. 31). In the name of White racial purity, Madison Grant published his anti-miscegenation 
work in 1916, The Passing of the Great Race, and Harry Laughlin published Eugenical Sterilization in the United States in 1922 (Lichtman, 2008; Lora \& Longton, 1999). Across these texts, the constant theme of anti-pluralism depended on a common rejection of other cultures in favor of a singular, theologically based belief in WASP supremacy.

The urban-rural culture war of the Twenties that gave place to these publications came to a head in 1925 in the Scopes trial in Dayton, Tennessee, showing how much rural Americans "distrusted human capacity and relied on divine intervention” (Leuchtenberg, 1958, p. 222). Featuring the clash between celebrity attorneys William Jennings Bryan and Clarence Darrow over the legal truth of evolution and science, the small town assumed a carnival-like atmosphere during the 11-day "monkey trial." Vendors hawked festival food and drinks, and carnies offered chimpanzees to pose for paid photos with the tourists who had flocked to the hamlet.

In anticipation of school teacher John T. Scopes' trial for having violated an obscure and little-enforced state law, the Butler anti-evolution bill that banned teaching lessons other than creationism in public schools, the small town's hotels overflowed, and the national media produced what some have called the "first media spectacle." WGN radio of Chicago broadcast much of the ongoing trial from the court room to a growing radio audience, giving northern urbanites a sense of the peculiar quality of southern Protestantism. Striking the tone of the culture war, H.L. Mencken lampooned the region as a "cesspool of Baptists, a miasma of Methodists, phony real estate operators, and syphilitic evangelists" (quoted in Israel, 2004, p. 3).

From his vantage point in New York, Lippmann (1928) saw that anti-evolutionist William Jennings Bryan and his fundamentalists had won the trial, but at the cost of their dignity and broader appeal. Still, Lippmann (1928) described the Scopes trial as "a new phase in the ancient conflict between freedom and authority." Noting that Clarence Darrow's cross-examination had humiliated Bryan, causing the courtroom to erupt in derision, Lippmann wrote, "The world has laughed at them, but has not yet laughed them off" (p. 6). He was right: The disbelief in science remains central to partisan politics today.

\section{Breitbart's Use of "Narrative" Against the Science-based Press}

Andrew Breitbart was perhaps the most prominent modern heir to the conservative media tradition of the Twenties. The media may have changed, but the motivation to stop science-based journalism remained the same. Breitbart emerged in 2005 as a co-creator of the thenconservative Huffington Post before becoming a protégé of conservative 
blogger Matt Drudge. Founder of a series of political Web sites, including Breitbart.com, he is best described as a conservative "media insurgent" (Coté, 2011). His attacks on journalism and liberal politicians earned him the reputation of a kind of Right-wing jihadist whose genius lay in his implicit understanding of the facility of the fragmented internet as a weapon. In that sense, it is possible to see the characteristics of Breitbart's conservative legacy that informs the Trump era and the fecklessness of "fake news" and the alt-Right.

In his autobiography, Righteous Indignation: Excuse Me While I Save the World, which appeared the year before his death at 43, Breitbart (2011) defined his goal of "circumventing Old Media by using new media, forcing them to cover the story and to shape, control, and even change narratives (as) a once-in-a lifetime experience" (p. 9). As a dedicated, latter day culture warrior, he described a "winnable New Media war against the Progressive movement and its standard bearer, President Obama." Never shy about the big picture, Breitbart saw himself "on the front lines with an army of New Media warriors following me into the fray" (p. 5).

In all of his bombast, the most telling statement Breitbart made to tie his moment to his ideological forebears came in the form of a complaint that conservatives have made since 1919.

He wrote:

The left does not win its battles in debate. It doesn't have to. In the twenty-first century, media is everything. The left wins, because it controls the narrative. The narrative is controlled by the media. The left is the media. Narrative is everything.

(p. 4, emphasis in original)

In his quest for conservative dominance, Breitbart sabotaged professional journalism in the name of truth. In traditionally conservative fashion, he created a media space that he could control. But unlike conservatives of the Twenties for whom husbanding and diffusing their ideas was the point, Breitbart worked outwardly to destroy mainstream journalists by feeding them intentionally false "narratives." He worked to poison the news system.

Between 2008 and 2011, James O'Keefe and Breitbart produced and distributed deceptively edited videos attacking a range of liberal organizations by using inexpensive video equipment, cheap costumes, and deceptive editing (Dreier \& Martin, 2010). Their most prominent targets included Planned Parenthood in 2008, ACORN (Association of Community Organizations for Reform Now) in the Fall of 2009, the New Orleans offices of U.S. Sen. Mary Landrieu in early 2010, and National Public Radio (NPR) in Spring 2011. 
The traditionally hostile dynamic between the power of the national news media and the counter-power of the Breitbart-O'Keefe insurgency was observable when these videos became media events that were recirculated from the internet and put into heavy on-air rotation by the Fox News Network. When the videos became the subject of the news, they were also often re-reported by the national news, broadening their impact as fake news.

Although I am not sure what William B. Riley would have made of the professionally profane personality that was Andrew Breitbart, it is clear that Breitbart understood the conservative movement's past. He reveled in the polarized dynamic framed by Riley for conservatives in the first culture war and embraced the advantages of conservatives' owning their media. Yet, unlike Riley, who had a formal, religious premise for his crusade, Breitbart was a kind of nihilist. By conservative tradition, his willingness to say and do anything to win resonated with the spirit of "total war" that characterized the struggle not just to define American social reality after the First World War, but to eliminate progressive narratives and progressivism with them in favor of a White, Protestant hegemony. The populism of Trump's America has been well served by this media legacy.

\section{Conclusions}

The durability of today's conservative ideology owes much to the movement's historical ability to sequester itself from the eyes of mainstream journalism within its own media system from the beginning. By conserving their White Protestant values from the start, conservatives were able to preserve their position that belief in science represents a counterideology that competes with their own beliefs. Indeed, a constant complaint from those precincts has been that the conservative media were, themselves, the authentic "mainstream media" (Hemmer, 2016).

In this discussion, Lippmann's science-based journalism is not a straw man, but reflects an important political theory that has developed in an epic century-long competition with conservatism to define the ideological basis of post-war American society to date. In that sense, Lippmann did not think and write in a historical vacuum. Rather, he saw conservatives as a cultural enemy. In turn, where Lippmann saw religion as a source of dysfunctionalizing myth, fundamentalists regarded the development of a scientific journalism to be heretical, as were all progressives. Here is the beginning of contemporary, media-based polarization.

In a broader view, the WCFA was not the only major Protestant organization to see that the world was changing too fast after the war to be safe. Against the WCFA's conservatism, the short-lived Interchurch World Movement (IWM) engaged a progressive social agenda, including the use of progressive investigative reporting to investigate labor 
conditions of the Great Steel Strike of 1919 (Wisehart, 1921). To the extent that Lippmann was aware of the IWM's science-driven programs, he approved (Lippmann, 1920, 1922).

If for much of the past century, the American political system maintained a kind of countervailing balance between the religiosity and anti-Communism of the Republican Party and the post-New Deal progressivism of the Democratic Party, that ideological equilibrium is nowhere to be found today. Instead, Breitbart's animosity to journalism reflects the primordial themes of American conservatism confronted today with a science-based worldview that it cannot (or will not) admit. However one accounts for the violent cycle of populism that we are in today, both here and abroad, the American fundamentalist rejection of science has become dominant. Anti-Communism has morphed into anti-Islamism. Laissez-faire capitalism appears as neoliberalism and Trumpian corruption. Anti-Semitism and Nazism are now tacitly endorsed by a U.S. president. The Ku Klux Klan fought alongside White nationalists at Charlottesville with the president's approval. And White nationalism has a foothold in the political arena.

Within the brief historical comparison made here, the media insurgency led by Breitbart with O'Keefe and supported by Fox News at the start of the twenty-first century reflects the stakes that the original fundamentalist movement established, stakes that have suddenly become paramount for journalism and for democracy. From Breitbart and O'Keefe's video fictions, it becomes clear that the willingness to create "fake news" in the service of controlling the "narrative" informs the authoritarianism of the Trump administration and its sinister grip on "reality" versus real journalism today.

\section{References}

Brecher, J. (1997). Strike! Cambridge, MA: South End Press.

Breitbart, A. (2011). Righteous Indignation: Excuse Me While I Save the World. New York, NY: Grand Central Publishing.

Coté, (2011). What is a media dispositive? Compositions with Bifo. Journal of Communication Inquiry, 35(4), 378-386.

Dreier, P. \& Martin, C. R. (2010). How ACORN was framed: Political controversy and media agenda setting. Perspectives on Politics, 8(3), 761-792.

Hemmer, N. (2016). Messengers of the Right: Conservative media and the transformation of American politics. Philadelphia, PA: University of Pennsylvania Press.

Israel, C. A. (2004). Before Scopes: Evangelism, Education, and Evolution in Tennessee, 1870-1925. Athens, GA \& London, UK: University of Georgia Press.

Jansen, S. C. (2102). Walter Lippmann: A Critical Introduction to Media and Communication. New York, NY: Peter Lang. 
Leuchtenberg, W. E. (1958). The Perils of Prosperity, 1914-32. Chicago, IL: University of Chicago Press.

Lichtman, A. J. (2008). White Protestant Nation: The Rise of the American Conservative Movement. New York, NY: Atlantic Monthly Press.

Lippmann, W. (1914 [1917]). Drift and Mastery: An Attempt to Diagnose the Current Unrest. New York, NY: Henry Holt \& Co.

Lippmann, W. (1920). Liberty and the News. Mineola, NY: Dover Publications. Lippmann, W. (1922 [1949]). Public Opinion. New York, NY: The Free Press.

Lippmann, W. (1928). American Inquisitors: A Commentary on Dayton and Chicago. Barbour-Page Lectures, University of Virginia. New York, NY: Macmillan Co.

Lora, R. \& Longton, W. H. (1999). The Conservative Press in Twentiethcentury America. Westport, CT: Greenwood Press.

Marsden, G. M. (1980). Fundamentalism and American Culture: The Shaping of Twentieth-century Evangelism: 1870-1925. Oxford, UK: Oxford University Press.

McPherson, J. B. (2008). The Conservative Resurgence and the Press: The Media's Role in the Rise of the Right. Evanston, IL: Northwestern University Press.

Steel, R. (1980). Walter Lippmann and the American Century. Boston, MA: Little Brown.

West, D. M. (2001). The Rise and Fall of the Media Establishment. Belmont, CA: Thomson Wadsworth.

Wisehart, M. K. (1921). The Pittsburgh Newspapers and the Steel Strike. In Commission of Inquiry, Interchurch World Movement (Eds.), Public Opinion and the Steel Strike: Supplementary Reports to the Investigators to the Commission of Inquiry (pp. 87-162). New York, NY: Harcourt, Brace and Howe. 


\section{Advertisements in the Age of Hyper-Partisan Media Breitbart's \#DumpKelloggs Campaign}

\section{Prashanth Bhat}

The 2016 U.S. presidential elections were perhaps the most divisive and polarized political contests in modern American history. The election of a rabble-rouser like Donald Trump to the White House not only brought to light deep-rooted racial fault lines that continue to persist in the American society but also highlighted the economic resentment that has been simmering in many parts of suburban America (Gest, Reny, \& Mayer, 2017). Trump ran a campaign that was filled with xenophobic rhetoric, which will most likely have far-reaching consequences on the larger public discourse in the United States (Kellner, 2016). At the receiving end of his hate-filled rhetoric were not only immigrants and religious minorities but also news reporters from the mainstream news media (Flood, 2016).

Trump's frequent branding of journalists as "dishonest," "rigged," and "enemies of the American people" cemented the idea of "liberal media bias" among Republican voters and created an opportunity for the mainstreaming of far-right media outlets that were hitherto considered fringe (Erickson, 2017). Popular among such outlets is Breitbart News Network, a self-proclaimed platform for the "alt-Right," which is a loosely defined group comprising of white supremacists and neo-Nazis. The network's chairman, Stephen Bannon, who was selected by Trump to be the CEO of his presidential campaign and was later appointed the White House chief strategist, has risen to become one of the most influential political personalities in the country. ${ }^{1}$

The normalization of ultra-conservative news outlet like Breitbart is ironic given that for years the United States had prided itself as the global champion for free press and positioned itself as the harbinger of professional values in journalism. The core element of such professional values is a strong boundary between editorial and business functions of the news organization. The boundary, which is simply known as "the wall," is one of the foremost professional markers of journalism that has been reinforced strongly in important sites such as journalism text books, media schools and newsrooms.

That hyper-partisan media outlets like Breitbart, publish falsehoods and conspiracy theories, and disregard values of professional journalism 
such as truth, fairness, objectivity, transparency, and autonomy, is now well-established (Ballard, 2017; McNair, 2017). However, Breitbart's violation of an important occupational value - the boundary between editorial and advertising functions of a news organization has received far less scholarly examination.

In this chapter, I examine Breitbart's \#DumpKelloggs campaign against multinational food manufacturing company Kellogg's to evaluate the far-right media outlet's approach towards journalism's core principle - separation of editorial from the business-oriented functions of a news organization. First, I examine the origins and development of professional values of journalism. Next, I outline the rise of Breitbart and its relationship with Donald Trump, particularly the role played by the far-right media group during the 2016 presidential elections. Then, I analyze Breitbart's campaign against Kellogg's following the cereal maker's decision to withdraw advertisements from its news site. Finally, I highlight two contemporary issues - programmatic advertising and the return of hyper-partisan media -that might be perceived as a threat to news-advertising boundary. The most important finding of this examination is that Breitbart is resorting its advertisers to blackmail and extortion for refusing to advertise on their news site - a trait that is commonly visible in media systems where civil society groups and democratic institutions are still nascent. The implications of such blackmail tactics for journalism, and editorial-business functions of news organization are discussed.

\section{Partisanship and Professionalization of American Journalism}

For most of American history, news media were partisan. The period between the 1780 s and 1830 s is known as "party press era" because newspapers then received patronage from political parties. During this time, editors shaped news for partisan purposes and even worked for legislators and U.S. congressmen. Journalists openly took partisan viewpoints and newspapers were filled with literary hoaxes, vindictive stories, and propaganda in order to influence public opinion in favor of the political party they were associated with (Levendusky, 2013).

Drastic changes in lifestyle, technology, and communication systems witnessed during the first half of the nineteenth century in the United States led to increased political participation among the working and middle class, in addition to enhanced literacy rates, and rapid urbanization. These socioeconomic changes contributed to the rise in demand for newspapers, which in turn led to the production of "Penny Press," or cheap newspapers that not only served the political world but also reported news on the wider world (Roggenkamp, 2005). Increasing newspaper circulation enabled the Penny Press to operate 


\section{Prashanth Bhat}

independently instead of depending on political parties for revenue. Popular newspapers such as the New York Sun and New York Herald sought advertising and circulation instead of relying on political parties for financial support.

Newspapers realized that independence from party domination was good for their business (Risley, 2002). As news publications turned big businesses and increased their readership in the growing market place, advertising revenue surpassed subscription fee as their primary source of income. Over the years, advertisers completely replaced politicians as the sustaining economic force behind news publications. Over a period of time, advertisers provided newspapers with 70-80 percent of their revenue (Altschull, 1997). To further increase their circulation and reach to new readers, newsrooms practiced fact-centered and news-centered journalism rather than devoting their pages primarily to political commentary.

The shift from political patronage to advertising-based financial model coincided with journalists' attempt to make their profession more respectable (Banning, 1998). As a result, they developed professional practices, ethics, and normative values that have come to be recognized as the universal yard stick by which journalism should be practiced. Development of such values also helped identify journalists as a distinct occupational group (Schudson, 2001). Traditional news media began to operate on the philosophy that reality ought to be reflected objectively with all sides having their say. In the early twentieth century, journalistic professionalization was institutionalized with the establishment of journalism schools across the United States where future reporters were trained in professional values in addition to the skills required to perform their jobs.

Also known as "Anglo-American model of journalism," or a "professional model" of journalism, "value systems" associated with these models have set normative standards for news gathering and reporting across the world. They provide reporters an understanding of their role in the society and how they should do their job as journalists (Williams, 2006). In fact, scholars have argued that in an increasingly interconnected world, the ideas associated with the "professional model" such as a belief in journalistic autonomy, objectivity, public service, and the importance of ethics are widely espoused by journalists on a global scale (Deuze, 2005; Elliott, 2009). The professional model assumes that journalists serve the public, strive for fairness and balance in their news products, and seek to act as a "Fourth Estate" in democracy.

\section{Boundary between News and Advertising}

Of all the values within professional model, one that is fundamental to the understanding of professional journalism is the boundary between 
journalistic and business-oriented functions of a news organization. Along with the principle of independence from political parties, the news-business wall is the cornerstone that upholds American journalism's sense of autonomy (Carlson, 2015; Coddington, 2015). This boundary was deemed necessary for journalism to function as a profession and to safeguard its autonomy.

Such boundaries enabled journalists to exercise judgement and control their work process without commercial influences. They feared that if advertisers influence the news, it will hurt newspapers' credibility. This professional value of independence from business are encoded at the professional level in codes of ethics. For instance, the Society of Professional Journalists, in its code of ethics, asserts that journalists should "distinguish news from advertising and shun hybrids that blur the lines between the two" (SPJ, 2014). Similarly, other prestigious journalism associations and think-tanks have established principles for publications on the separation of advertising and editorial content.

This separation is often expressed in news-business boundary discourse through a metaphor called a "Chinese wall" or "church-state division," or simply the "wall". Although autonomy from the advertiser is often not realized owing to market pressures and the economics governing the news industry, segregation between editorial and advertising remained sacrosanct and a normative ideal for journalists across the world. In fact, as early as 1869 , literary critics such as Richard White have called for the formation of "news-advertising wall." According to White, the most insidious threat to journalistic ideals was advertising. He said: "absolute and without exception, that nothing in the interests of an advertiser, no matter what his importance, shall be admitted into the editorial columns for any consideration" (Delorme \& Fedler, 2005).

Journalists took the church-state connotations of the "wall" seriously so much so that the separation itself was often referred to as "sacred" and the newsroom territory was considered "hallowed." News reporters and editorial staff often set their public service and commercial goals in opposition to each other. But despite their best efforts, the boundary has been susceptible to encroachment by advertisers. Yet, the resistance of journalists to the interference of advertisers in editorial functions is an important part of the story of modern American journalism for the role it played in shaping journalists' professional identity.

In recent years, numerous scholars have documented violations of the boundary in a variety of contexts (Baerug \& Harro-Loit, 2012; Williams, 1998). The advent of online journalism has increased the potential for blurring between news and commercial content. Lack of institutionalized ethical norms and lowered barriers to entry have magnified the tensions between advertising and journalism. Further, the return of partisanship in American journalism has adversely affected the professional norms of journalism with the wall between news and advertising being no exception. 


\section{Prashanth Bhat}

\section{Return of Partisanship in American Journalism}

Even as American newsroom conventions were shaping global news reporting practices, leaders and philanthropists affiliated to the Republican party were making investment in think tanks and journalistic institutions in the United States as a means of moving the public debate to the right (Gonzales \& Delgado, 2015; Meagher, 2012). In the late 1940s and early 1950s, conservative magazines such as the National Review and Human Events were launched, which became the lifeblood of modern conservatism in the post-war period (Major, 2012). These publications relied on millions of dollars contributed by conservative foundations rather than on advertising to sustain their magazines.

At the same time, mainstream media's negative coverage of politicians such as Barry Goldwater and President Richard Nixon increased the right-wing critique of news media (Horwitz, 2013; Nye, 1990). During the presidency of Ronald Reagan, the Federal Communications Commission (FCC) repealed the "Fairness Doctrine," which required radio stations to provide equal response time to political opponents to make their statements. This repeal gave rise to conservative talk radio, which helped conservatives entrench their ideas and spread the notion of "liberal bias" to millions of listeners.

In recent years, popular conservative media personalities such as Rush Limbaugh, Glenn Beck, Peggy Noonan, Michelle Malkin, and Sean Hannity have accused the press of "liberal bias," which seems to have struck a chord with their core constituents (Jamieson \& Cappella, 2008). Conservative activist Paul Weyrich formed the National Empowerment Television (NET) network in 1993 to counter the so-called liberal bias. Although it failed to make a major impact, it laid a solid foundation for the launch of Fox News Channel by Rupert Murdoch in 1996. This right-leaning channel cemented the notion of liberal bias among Republican voters leading to a steady decline of their trust in news media (DellaVigna \& Kaplan, 2007; Morris, 2005). According to a 2016 Gallup poll, Americans' confidence in news media has eroded from 55 percent in 1998 to 32 percent in 2016. More importantly, only 14 percent of Republicans surveyed said they trust U.S. media as opposed to 51 percent of Democrats (Swift, 2016).

\section{The Age of Donald Trump and Breitbart}

Declining public trust in established media - particularly among conservative voters - and the rise of new media technologies provided a fertile ground for the spread of far-right media portals. Prominent among them include Drudge Report, VDare, Townhall, Daily Caller, Infowars, and Breitbart News Network. While each of them play a key role in promoting the ideas on the extreme-right, Breitbart is associated 
with white ethno-nationalist groups that were until recently considered fringe elements. With access to President Trump's inner circle, Breitbart has grown from being an outlier to a powerful political player in a short span of time. It rose to fame with its extensive coverage on the 2009 hidden-camera videos that led to the closure of Association of Community Organizations for Reform Now (ACORN) and the 2011 Anthony Weiner "sexting" scandal.

Established by Andrew Breitbart in 2007, this web-portal is now closely aligned with the members of the "alternative-right," or "altRight," who believe in race-based nationalism and white superiority. The Southern Poverty Law Center (SPLC), which monitors hate groups in the United States, found the members of the alt-Right to be frequently advocating for racial separatism, anti-Semitism, and acts of violence against minority groups (SPLC, 2016).

In an interview with Mother Jones in July 2016, Stephen Bannon admitted that the website provided a "platform for the alt-Right" (Posner, 2016). The site often features stories that attack Republican elites, foster anti-immigrant sentiment, and promote political conspiracy theories. Even so, its hateful rhetoric struck a powerful chord with Donald Trump who appointed its chairman as the chief strategist in the White House. After a short stint at the White House, Bannon returned to Breitbart as its executive Chairman.

In addition to Bannon, former Breitbart staffers Julia Hahn and Sebastian Gorka were hired to shape Trump administration's policies. Trump's contribution to Breitbart's rise is evidenced by its growing popularity in the web-world. ComScore, an audience measurement platform ranked Breitbart 27th in the general news category with about 8 million monthly visitors as of October 2014. That same month, Pew Research Center released a survey report according to which 3 percent of respondents received their news from Breitbart (Pew Research Center, 2014). However, in June 2015 when Trump announced that he would run for president, the site was read by 5.7 percent of the general news audience and by the end of the campaign cycle in October 2016, Breitbart's traffic was at 9 percent of the market, with an estimated 18 million visitors (Malone, 2016).

Breitbart is funded by Long Island-based hedge fund manager Robert Mercer, who is reported to have invested at least $\$ 10$ million on the news site in 2011. The other owners include Andrew Breitbart's widow Susie Breitbart and the site's CEO Larry Solov (Gold, 2017).

Enthused by Trump's victory in the elections, Breitbart plans to launch its sites soon in Germany, Italy, and France. The site already has its operations in the United Kingdom where it supports right-wing populist leader Nigel Farage (Sullivan \& McAuley, 2017). The move to expand to Western Europe is seen as an attempt to foment anger and anti-immigrant sentiment in that region (Flitter, 2016). 


\section{Prashanth Bhat}

\section{Breitbart's \#DumpKelloggs Campaign}

Since Donald Trump won the U.S. presidential election, Breitbart has received much attention, particularly from Civil Rights groups and activists fighting racism and bigotry. In December 2016, a social media campaign was organized by a group called "Sleeping Giants," which aims to resist racist and sexist media by stopping Breitbart's ad dollars. This group encourages social media users, particularly on Twitter, to call out large multinational companies that place their ads on Breitbart and demand them to stop doing business with the media outlet. In addition, marketing specialist Shannon Coulter created a \#GrabYourWallet campaign by preparing a boycott list of brands that advertise on Breitbart (Picchi, 2016). These attempts seem to have yielded desired results as more than 2,500 advertisers have blocked Breitbart from their media-buying programs. According to data from MediaRadar, a New York firm that tracks online advertising, the number of advertisers on Breitbart has dropped 90 percent between March and May 2017 (Bhattarai, 2017).

Major digital ad suppliers like AppNexus, The Trade Desk, and Rocket Fuel have dropped Breitbart from most of their ad buys. According to a trade report, during the first two months of 2016, these digital ad agencies were collectively responsible for purchasing about 15 percent of Breitbart's inventory. By March 2017, they have collectively purchased less than 0.5 percent of Breitbart's inventory. These agencies have listed Breitbart to their list of brand-unsafe websites because the far-right site violated their hate speech policies (Benes, 2017).

Significant among brands that withdrew ads from Breitbart is food maker Kellogg Company. In an email statement released November 29, 2016, the firm's representative, Kris Charles, told a news outlet, "We regularly work with our media buying partners to ensure our ads do not appear on sites that aren't aligned with our values as a company" (Wabha, 2016). Soon after Kellogg's made this announcement, other brands including Allstate, Nest, EarthLink, Warby Parker, and SoFi withdrew their ads from Breitbart. In reaction, the media outlet launched a \#DumpKelloggs campaign on social media encouraging its 45 million monthly readers to boycott Kellogg's products.

Breitbart news editor-in-chief Alexander Marlow described Kellogg's action as "bigoted and anti-American." Urging readers to boycott Kellogg's products, Marlow said, "If you serve Kellogg's products to your family, you are serving up bigotry at your breakfast table" (Breitbart. com, 2016). Within hours, Breitbart dedicated its entire front page to the \#DumpKelloggs campaign, with one story linking to a boycott petition that received more than 100,000 signatures. On social media, many white nationalists and alt-Right extremists used hashtag \#DumpKelloggs and \#BoycottKelloggs to support Breitbart. 
The far-right publisher followed up this online campaign with a series of negative articles against Kellogg's on its own site. Prominent among them was an article titled, "Shock: Amnesty International Blasts Kellogg's for Using Child Labor-Produced Ingredients" (Pollak, 2016). Another article titled, "\#DumpKelloggs: Minority Employees Accuse Kellogg's of Racism" (Huston, 2016), was published soon after. To proclaim its victory against Kellogg's, Breitbart also appropriated the drop in the firm's share value. An article titled, "Kellogg's Stock Drops Another 1.44\% at End of Thursday Trading" (Breitbart News, 2016) appeared on the site. Breitbart conducted a sustained campaign against the cereal maker for several months. Between November 29, 2016, ${ }^{2}$ and August 1, 2017, the website published 80 articles portraying Kellogg's in a poor light.

In addition to the anti-Kellogg's posts, Breitbart shared submitted photos and videos of its readers and supporters throwing boxes of Kellogg's products in the trash. In its anti-Kellogg's campaign, the far-right media outlet adopted what some scholars have called "confrontational boycott" strategy, which is often used by left-liberal groups to evoke progressive responses from corporate giants (Hallward \& Berg, 2014). For instance, in 2009, the supporters of Obama administration's proposed health-care reforms organized "boycott Whole Foods" campaign after its CEO openly opposed the health-care reforms (Kang, 2012). More recently, activists took up \#BoycottUber to protest Uber CEO Travis Kalanick's decision to work with Trump administration (Fuster, 2017). Several non-governmental organizations and activists have employed this strategy to levy pressure on multinational companies and governments. However, in this case, Breitbart is a news-media outlet and has taken up this campaign to target a brand for refusing to place advertisements on its site. In doing so, the news site played victim by claiming that it was being targeted by multinational firms for holding a certain ideological and political view point.

\section{New Challenges to News-Advertising Boundary}

In addition, the decline of legacy media and the advent of digital advertising driven by algorithms has further complicated the advertisingeditorial relationship. As evident from Kelloggs' controversy, the food giant wasn't even aware that its ads were being placed on the far-right media outlet. In an automated advertising environment where website traffic has become the criteria for ad placements, advertisers run the risk of bankrolling media outlets that relay extremist views. In an era of programmatic advertising where a software automatically places ads in media outlets, brands run the risk of being associated with media outlets that may not align with their company's values. Besides, many of these media outlets don't even comply with the values of professional journalism. Some of these media sites, as evidenced by Breitbart, disregard 
normative journalistic practices and even attack brands that withdraw ads from their site.

Advertising has changed along with media technologies. As is the case with news, advertising also has become more fragmented and better targeted to individual buyers (Nesamoney, 2015). A small part of the digital advertising is placed in a traditional fashion where a brand manager makes a choice to place it in a particular online publication. Another method of ad placement involves digital platforms auctioning off ad space across online properties, from little-known websites to popular sites like Breitbart.

Google's ad sense is one of the most well-known platforms for this type of online advertising. This type of digital advertising delivers access to a specific audience rather than to particular online publications. Ads are placed based on advanced targeting technologies and data crunching rather than using subjective measures that are context driven. As a result, advertisements of many leading brands appear in online environments they would otherwise avoid including websites that publish fake news and hyper-partisan and extremist media outlets. Case in point is recent controversy where ads of car markers Mercedez-Benz and Jaguar appeared on YouTube next to pro-ISIS videos raising concerns over extremists' earning thousands of dollars from automated advertising. In the case of Breitbart, brands such as Kellogg's withdrew ads because they didn't want to be associated with a media outlet that produces racist and xenophobic content.

Breitbart's response to Kellogg's decision to withdraw ads clearly violates the fundamental value of professional journalism, i.e., the boundary between editorial and business functions of news organizations. The far-right media group's \#DumpKelloggs campaign also highlights the twin challenges faced by news-advertising boundary in the form of resurgent hyper-partisan media and algorithm-based advertising. While hyper-partisan tone of reporting allows Breitbart to mobilize its ideologically driven readers to target brands that refuse to place ads, the automated online advertising environment curtails brands from making considered choices when it comes to ad placements.

In addition to undermining traditional journalistic values such as objectivity, public service, ethics, and autonomy and independence, partisan outlets like Breitbart also depart from professional journalism's normative commitment to the separation of editorial functions from advertising. Journalistic professionalism requires unambiguous marking of what is editorial and what is advertising. Although, several scholars lament the fact that brand placements in the mass media in non-advertising formats (Avery \& Ferraro, 2000; Lewis, Williams, \& Franklin, 2008; Schauster, Ferrucci, \& Neill, 2016) are ubiquitous and have given rise to hybrid discourses and new genres such as advertorials, infotainment, and edutainment, Breitbart has reverted to pre-professionalization 
practices of American journalism by launching a vicious campaign against a commercial organization for refusing to advertise with them.

Such blackmail and coercion are commonplace in nascent democracies where media systems and journalistic ethics are still evolving (Mancini, 2005). That a U.S.-based media outlet would organize a campaign against a cereal brand for pulling advertisements is a serious setback to one of the most fundamental values espoused in the professional model of journalism. The erosion of this boundary is likely to have practical consequences for the public image and professional identity of journalists at large. The boundary had long served journalists in maintaining a professional practice that primarily served democratic aims rather than commercial ones. As episodes like \#DumpKelloggs begin to crumble the "wall," between editorial and advertising, the credibility of news media is likely to decline further in the days to come.

The other challenge faced by news-advertising boundary is in the form of programmatic ad placements. In this ad environment, it is difficult to keep track of media outlets where ads might be placed. Brands are required to continuously monitor their ad placements and take necessary steps to avoid platforms that publish blatant lies and exaggerations. With partisan media outlets targeting brands for refusing to place ads on their sites, commercial organizations are likely to be more cautious in making their ad placement choices. In professional model of journalism, news outlets didn't target brands based on their ideological affiliations and therefore, commercial organizations could deem it safe to make their ad placement choices without fear of repercussions or damage to their brand image. Following campaigns like \#DumpKelloggs, advertisers would most likely demand more transparency about ad placements and seek digital ad networks to blacklist sites for publishing hateful-content. Such cautionary tactics will also help brands avoid being caught in the midst of partisan-media run ideological warfare.

\section{Conclusion}

After 'Penny-Press' era, U.S news rooms laid the foundations for good news reporting practices, which became guiding principles for ideal journalism across the world. The professional model or the Anglo-American model of journalism, whose values provided defense against attempts at influence by either the state or economic interests became the professional marker of journalism in democratic countries. The latest developments in U.S. media, which include the return of hyper-partisanship as evidenced by the rise of Breitbart and deviation from the newsadvertising boundary as witnessed by \#DumpKelloggs campaign, endanger and invalidate the professional model promoted and popularized by American journalistic institutions. 


\section{Prashanth Bhat}

The spread of internet and exponential growth of online media add new dimensions and challenges to advertising based financial models of news media. These new developments such as programmatic ads and the challenges they pose to professional norms requires urgent scholarly attention and deliberation. As a way forward, it is necessary to study the trajectory of American journalism and its news practices. Scholars and journalistic institutions must deliberate on some of the most fundamental questions such the definition of what constitutes news and whether hyper-partisan outlets such as Breitbart should be considered news outlets or propaganda sites and whether then the professional norms of journalism apply to the content produced by their sites at all. Regardless, the resurgence of partisan media, requires professional news organizations and journalistic institutions to reassert boundaries between editorial and business functions of news outlets. At a time when scholars have begun to question whether professional values such as objectivity are an impediment in countering hateful rhetoric spread by demagogues like Donald Trump, it is also important to include the scenario of ever-changing news-advertising boundary in the conversation.

\section{Notes}

1 Steve Bannon resigned from his post at the White House on August 18, 2017, and returned to Breitbart as its executive chairman.

2 The day Kellogg's Co. announced the withdrawal of its ads from Breitbart.

\section{References}

Altschull, J. H. (1997). Boundaries of journalistic autonomy. In D. Berkowitz (Ed.), Social Meanings of News (pp. 259-268). Thousand Oaks, CA: Sage.

Avery, R. J., \& Ferraro, R. (2000). Verisimilitude or advertising? Brand appearances on prime-time television. Journal of Consumer Affairs, 34(2), 217-244.

Baerug, J. R., \& Harro-Loit, H. (2012). Journalism embracing advertising as traditional journalism discourse becomes marginal: A comparative study of European MICE (Meetings, Incentives, Conferences and Events) magazines. Journalism Practice, 6(2), 172-186.

Ballard, M. S. (2017). Indoctrination over objectivity? Examining Breitbart's framing of candidates and social issues in the 2016 election. Retrieved at http:// digitalcommons.salve.edu/cgi/viewcontent.cgi?article=1113\&context=pell_ theses.

Banning, S. A. (1998). The professionalization of journalism: A nineteenthcentury beginning. Journalism History, 24(4), 157.

Benes, R. (2017, March 16). More programmatic buyers are shunning Breitbart. Digiday. Retrieved at https://digiday.com/media/programmatic-platformsbreitbart.

Bhattarai, A. (2017, June 8). Breitbart lost 90 percent of its advertisers in two months. Who's still there? The Washington Post. Retrieved at www. washingtonpost.com/news/business/w p/2017/06/08/breitbart-lost-90- 
percent-of-its-advertisers-in-two-months-whos-still-there/?utm_ter$\mathrm{m}=.958 \mathrm{a} 7 \mathrm{cf} 9 \mathrm{fa} 15$.

Breitbart.com. (2016, November 30). \#DumpKelloggs: Breakfast brand blacklists Breitbart, declares hate for 45,000,000 readers. Retrieved at www. breitbart.com/big-government/2016/11/30/dumpkelloggs-kelloggs-declareshate-45-million-americans-blacklisting-breitbart.

Breitbart News. (2016, December 1). Kellogg's stock drops another $1.44 \%$ at end of Thursday trading. Breitbart. Retrieved at www.breitbart.com/ big-journalism/2016/12/01/kelloggs-stock-drops-another-1-44-endthursday-trading.

Carlson, M. (2015). When news sites go native: Redefining the advertisingeditorial divide in response to native advertising. Journalism, 16(7), 849-865.

Coddington, M. (2015). The wall becomes a curtain. In M. Carlson \& S. C. Lewis (Eds.), Boundaries of Journalism (pp. 67-82). London \& New York, NY: Routledge.

DellaVigna, S., \& Kaplan, E. (2007). The Fox News effect: Media bias and voting. The Quarterly Journal of Economics, 122(3), 1187-1234.

DeLorme, D. E., \& Fedler, F. (2005). An historical analysis of journalists' attitudes toward advertisers and advertising's influence. American Journalism, 22(2), 7-40.

Deuze, M. (2005). What is journalism? Professional identity and ideology of journalists reconsidered. Journalism, 6(4), 442-464.

Elliott, D. (2009). Essential shared values and 21st century journalism. In L. Wilkens \& C. G. Christians (Eds.), The Handbook of Mass Media Ethics, Routledge Handbooks Online. Abingdon: Routledge.

Erickson, A. (2017, February 18). Trump called the news media an 'enemy of the American people.' Here's the history of the term. The Washington Post. Retrieved at www.washingtonpost.com/news/worldviews/wp/2017/02/18/ trump-called-the-news-media-an-enemy-of-the-american-people-heres-ahistory-of-the-term/?utm_term=.a6f3ed6965b3.

Flitter, E. (2016, November 9). Riding Trump wave, Breitbart News plans U.S., European expansion. Reuters. Retrieved at www.reuters.com/article/ us-usa-election-trump-strategy-idUSKBN1342TP.

Flood, B. (2016, August 15). Donald Trump goes on Twitter rampage against 'corrupt, dishonest' media. The Wrap. Retrieved at www.thewrap.com/ donald-trump-hillary-clinton-dishonest-media-new-york-times-twitterrampage.

Fuster, J. (2017, January 27). \#BoycottUber: Why Uber is Twitter's boycott of the day. The Wrap. Retrieved at www.thewrap.com/boycottuberuber-twitter-boycott.

Gest, J., Reny, T., \& Mayer, J. (2017). Roots of the radical right: Nostalgic deprivation in the United States and Britain. Comparative Political Studies. doi:10.1177/0010414017720705.

Gold, H. (2017, February 25). Breitbart reveals owners: CEO Larry Solov, Mercer Family and Susie Breitbart. Politico. Retrieved at www.politico. eu/blogs/on-media/2017/02/breitbart-reveals-owners-ceo-larry-solov-themercer-family-and-susie-breitbart-donald-trump-media.

Gonzales, M. G., \& Delgado, R. (2015). Politics of Fear: How Republicans Use Money, Race and the Media to Win. London \& New York, NY: Routledge. 


\section{Prashanth Bhat}

Hallward, M. C., \& Berg, J. P. (2014). The Olympia Food Co-op boycott: Nonviolent struggle versus conflict resolution process. Conflict Resolution Quarterly, 32(1), 33-54.

Horwitz, R. B. (2013). America's Right: Anti-establishment Conservatism from Goldwater to the Tea Party. Cambridge \& Malden, MA: John Wiley \& Sons.

Huston, W. (2016, December 1). \#DumpKelloggs: Minority employees accuse Kellogg's of racism, subjecting them to N-word, photo of a baboon. Breitbart. Retrieved at www.breitbart.com/video/2016/12/01/dumpkelloggs-minorityemployees-accuse-kelloggs-of-racism-subjecting-them-to-n-word-photo-of-ababoon.

Jamieson, K. H., \& Cappella, J. N. (2008). Echo Chamber: Rush Limbaugh and the Conservative Media Establishment. Oxford: Oxford University Press.

Kang, J. (2012). A volatile public: The 2009 whole foods boycott on Facebook. Journal of Broadcasting \& Electronic Media, 56(4), 562-577.

Kellner, D. (2016). American Nightmare: Donald Trump, Media Spectacle, and Authoritarian Populism. Rotterdam: Sense Publishers.

Levendusky, M. (2013). How Partisan Media Polarize America. Chicago, IL: University of Chicago Press.

Lewis, J., Williams, A., \& Franklin, B. (2008). A compromised fourth estate? UK news journalism, public relations and news sources. Journalism Studies, 9(1), 1-20.

Major, M. (2012). Objective but not impartial: Human events, Barry Goldwater, and the development of the "liberal media" in the conservative counter-sphere. New Political Science, 34(4), 455-468.

Malone, C. (2016). Trump Made Breitbart Great Again. Five Thirty Eight. Retrieved at https://fivethirtyeight.com/features/trump-made-breitbart-great-again.

Mancini, P. (2005). Is there a European model of journalism? In H. de Burgh (Ed.), Making Journalists: Diverse Models, Global Issues (pp. 77-93). London \& New York, NY: Routledge.

McNair, B. (2017). After objectivity? Schudson's sociology of journalism in the era of post-factuality. Journalism Studies. doi:10.1080/14616 70X.2017.1347893.

Meagher, R. (2012). The "vast right-wing conspiracy": Media and conservative networks. New Political Science, 34(4), 469-484.

Morris, J. S. (2005). The Fox News factor. Harvard International Journal of Press/Politics, 10(3), 56-79.

Nesamoney, D. (2015). Personalized Digital Advertising: How Data and Technology Are Transforming How We Market. Old Tappan, NJ: Pearson Education.

Nye, J. S. (1990). What Liberal Media?: The Truth About Bias and the News. New York, NY: Basic Books.

Pew Research Center. (2014). Where News Audience Fit on the Political Spectrum. Pew Research Center. Retrieved at www.journalism.org/ interactives/media-polarization.

Picchi, A. (2016, December 2). As Breitbart wages 'war' on Kellogg's, advertisers flee. CBSNews. Retrieved at www.cbsnews.com/news/as-breitbart-wages-waron-kelloggs-advertisers-flee.

Pollak, J. (2016, November 30). Shock: Amnesty International blasts Kellogg's for using child labor-produced ingredients. Breitbart. Retrieved at 
www.breitbart.com/big-government/2016/11/30/kelloggs-child-laboramnesty-international-wilmar-indonesia.

Posner, S. (2016, August 22). How Donald Trump's new campaign chief created an online haven for white nationalists. Mother Jones. Retrieved at www. motherjones.com/politics/2016/08/stephen-bannon-donald-trump-alt-rightbreitbart-news.

Risley, F. (2002). Politics and partisanship. In W. D. Sloan \& L. M. Parcell (Eds.), American Journalism: History, Principles, Practices (pp. 14-22). Jefferson, NC: McFarland.

Roggenkamp, K. (2005). Narrating the News: New Journalism and Literary Genre in Late Nineteenth-Century American Newspapers and Fiction. Kent, $\mathrm{OH} \&$ London: Kent State University Press.

Schauster, E. E., Ferrucci, P., \& Neill, M. S. (2016). Native advertising is the new journalism: How deception affects social responsibility. American Behavioral Scientist, 60(12), 1408-1424.

Schudson, M. (2001). The objectivity norm in American journalism. Journalism, 2(2), 149-170.

SPJ. (2014). SPJ code of ethics. Retrieved at www.spj.org/ethicscode.asp.

SPLC. (2016). Is Breitbart.com becoming the media arm of the alt-Right? Retrieved at www.splcenter.org/hatewatch/2016/04/28/breitbartcom-becoming-mediaarm-alt-right.

Sullivan, K., \& McAuley, J. (2017, April 27). Breitbart sees potential to expand in Europe amid French, German elections. The Washington Post. Retrieved at www.washingtonpost.com/national/breitbart-sees-potential-to-expand-ineurope-amid-french-german-elections/2017/04/27/b7535d88-26dc-11e7-a1b3faff0034e2de_story.html?utm_term=.9efc5972096e.

Swift, A. (2016, September 14). Americans' trust in mass media sinks to new low. Gallup. Retrieved at www.gallup.com/poll/195542/americans-trustmass-media-sinks-new-low.aspx.

Wabha, P. (2016, November 29). Kellogg to stop advertising on Breitbart over values difference. Fortune. Retrieved at http://fortune.com/2016/11/29/ kellogg-breitbart-trump.

Williams, K. (2006). Competing models of journalism? Anglo-American and European reporting in the information age. Journalistica-Tidsskrift for forskning $i$ journalistik, 1(2), 43-65.

Williams, W. S. (1998). The blurring of the line between advertising and journalism in the on-line environment. In D. L. Borden \& K. Harvey (Eds.), The Electronic Grapevine: Rumor, Reputation, and Reporting in the New OnLine Environment (pp. 31-42). London: Lawrence Erlbaum Associates. 


\title{
11 Scapegoater-in-Chief \\ Racist Undertones of Donald \\ Trump's Rhetorical Repertoire
}

\author{
Stephen J. Heidt
}

One of the keys to Donald Trump's unlikely rise to the presidency was his reliance on tropes of scapegoating to distinguish himself and his policies. Scapegoating, a trope that externalizes blame for one's own failures on another, has long held a central place in Trump's rhetorical repertoire. But during the 2016 campaign, Trump took the tactic to new levels, scapegoating immigrants, Muslims, foreign nations, and the political elite as a means to identify national failures and justify his candidacy. These rhetorical choices raised the profile of his campaign, garnered significant media attention, and distinguished Trump from the other Republican contenders. While initially slow to call out scapegoating, naming Donald Trump a scapegoater has now become ubiquitous in the political press. The American Conservative called him the "scapegoat supreme of our time" (Gornoski, 2016).

Roll Call noted how Trump's scapegoating rhetoric "cloaked" the absence of real policy proposals (Allen, 2016). The Washington Post argued his inaugural address established potential "scapegoats for his presidency" (Downie, 2017). The Atlantic identified how the president "scapegoats unauthorized immigrants for crime" (Beinart, 2017). Noam Chomsky (2017) pointed to the "obvious technique" of scapegoating as a mechanism for Trump to "maintain control." Yet others have pointed to the commonalities between Trump's rhetoric and Philippine President Duterte, who has scapegoated drug users to incite the police to seek out and arrest or kill them (Sanchez-Moreno, 2017), and the "rise of the politics of scapegoating" around the world, mostly by far-right candidates obsessed with immigration, refugees, and the shifting demographics of ostensibly "white" states (Blakely, 2017).

While scapegoating is common in political rhetoric, Trump's enactment of this form, particularly as targeted at immigrants and Muslims, entails an underlying racialist narrative as the basis of his campaign for the presidency. This scapegoating rhetoric challenged American political culture generally and the political press specifically for three reasons. First, the rhetoric implied racist themes that resonated with a sizable portion of the electorate. Second, it led to absurd policy proposals that were either infeasible or outright unconstitutional. Third, as Trump's 
fortunes grew and mainstream critiques of his discourse populated internetworked media, the candidate lashed out by scapegoating the press. While it would be unfair to criticize the political press for failing to stop Trump's rise, the aggregate impact of Trump's scapegoating rhetoric reveals a fundamental incapacity of the media to contest overtly racist tropes.

This chapter argues that Trump's scapegoating rhetoric has produced a pernicious political culture that enabled his rise to the presidency. Toward that end, I first discuss the nature of scapegoating in American public culture. Then, by analyzing Trump's rhetoric scapegoating of immigrants and Muslims, I demonstrate the depth and consistency of Trump's scapegoating rhetoric. I argue this rhetoric enabled Trump to gain recognition, to cobble together an electoral coalition, to stand in for policy, and to rationalize policy failure. I then conduct a limited analysis of reporting on Trump's scapegoating rhetoric, marking how the political press transitioned from treating Trump as novelty to dangerous. Finally, I conclude with some thoughts on the press's role in reporting on and contesting xenophobic rhetoric.

\section{Scapegoating in American Political Life}

For Carl Schmitt (2007), politics itself is defined by the "distinction" that lies "between friend and enemy" (p. 26). This ontology of the political isolated the enemy as discursively constituted in relation to the construction of the people. Constitutive acts to distinguish between friends and enemies emphasize the oppositional qualities in each and, as such, clarify both the character of the enemy and the people. As Shapiro (1999) has said, nationalist discourse defines the self through acts of "negation" (p. 42). The stronger the act of negation - in this situation via acts of scapegoating - the stronger the sense of identity becomes. This Hegelian thesis inscribes the state in an irrevocable process in which individuals are compelled to "engender an opposite and create an enemy" (Shapiro, 1999, p. 43). The downside of this conception of the political, of course, is that as Bruce Lawrence and Aisha Karim (2007) have observed, "violence [may be] constitutive of human nature" (p. 4). In other words, constituting national identity via negation brings into sharp relief the distinctions between us and them, but also inscribes politics into a cycle of violence from which there is no escape.

As a rhetorical device, scapegoating is perhaps one of the most powerful and integral to the construction of national identity. Most obviously deployed in the build up to war, scapegoating involves identifying an enemy, separating "us" from "them," and, in the process, commits the nation to war. As Bradley Klein (1988) has argued, the entire question of "threat" is ultimately a function of dramatic action where those external to a political community are coded in terms of 


\section{Stephen J. Heidt}

an us/them dichotomy or within an orientalist framework (p. 296). This process, what Kenneth Burke (1964) has called the scapegoating ritual, generates animosity toward an enemy while cleansing the nation of responsibility or guilt for political violence. While the scapegoated Other can absorb diverse characterizations, the transference of guilt and sin is a one-way movement in which a stable community deposits collective sin, guilt, and blame on a "sacrificial vessel" capable of embodying the evil faulted for the community's collective struggle (Foy, 2012, p. 95).

Part of the rhetorical power conferred by scapegoating is found in the ritual's ability to generate cathartic sentiments. These sentiments are rhetorically derived from the realization that another is responsible for the failings of their communities. In contemporary American political life, immigrants are popularly scapegoated for the dearth of low-skilled jobs, among other community "maladies" (Cisneros, 2008). Burke (1969) termed the purifying component of the process "catharsis by scapegoat" and explained it could be achieved via the identification and punishment of the scapegoat (p. 406).

The teleological character of the ritual, with its identification of purification as the ultimate destination, manifests first with a defense of the "inborn dignity" of the righteous, the location of a "projection device" for depositing "one's ills ... thereby getting purification by dissociation" and "symbolic rebirth" for the community in which members are offered "a 'positive' view of life" which they can achieve by "moving forward" in the direction implied by the scapegoating ritual (Burke, 2005, pp. 193-194).

Moreover, the purifying feature of the scapegoat ritual is found in what Foy (2012) called "a transformation process" experienced by the scapegoated entity (p. 95). This transformation accrues not merely by the casting out or exclusion of the scapegoated entity, or by dissociation, but by the ritual of sacrifice. As Burke (1969) put it, the "new principle of merger" emerges via the "dialectical opposition to the sacrificial offering," in which, via sacrifice, the community cleanses itself of the sins attributed to the scapegoated entity (p. 406). The completion of the scapegoat ritual depends on contextual and rhetorical factors in relation to the construction of the scapegoat and the remedy proposed.

Domestically, purification may be achievable via the casting out of particular populations or via the mere fact of division that distinguishes between one population and another, because, as Tom Douglas (1995) pointed out, "death is not the reason for scapegoating - it's an outcome" (pp. 8-9). While not all instances of scapegoating demand violence, Burke argued the ritual can only produce the "feeling of relief" that accompanies catharsis if the sins of the enemy are cleansed in some capacity (Burke, 1964, p. 16). For Burke, this pressure for relief compels political actors to take the ritual to its logical conclusion. 


\section{The Banality of Scapegoating}

A “ubiquitous discursive strategy," as James Jasinski (2001, p. 507) put it, scapegoating is constantly repeated in all aspects of human relations. Rene Girard (1979) found the ritual so dominant that he claimed scapegoating is inextricably linked to and the "source of all rituals and religions" (p. 302). Burke (1968) took things even further - describing scapegoating as ontologically written into language itself and manifest in all aspects of human social relations (pp. 19-24). Countless studies demonstrate this transformational process, identifying as scapegoated communities: Muslims, Immigrants, baseball players, foreign enemies, drug dealers, philandering presidents, political parties, and a diverse set of public actors across differentially located communities.

While all scapegoated communities or individuals are capable of absorbing multiple and sometimes conflicting depictions, they remain organized under a master term that restricts significant variation in how those communities are classified. The term "drug dealers," for example, is flexible enough to include people of every race, domestic and foreign, but designates a particular character premised on the actions of the individuals fitting the term. But, by scapegoating "drugs" and "dealers," public discourse produces "common enemies" by "(mis)placing blame" from societal or economic factors to the individual users and those who supply illicit intoxicants (Mackey-Kallis \& Hahn, 1994, pp. 2-3). In the first instance, the user is mortified, a process that demands admission of guilt. In the second, what Burke called victimage, the dealer is singled out as a unique cause of drug abuse. This differential aspect of scapegoating - between mortification and victimage - means that even while public advocates blames users for drug abuse, the dealer and producer receive unique rhetorical and material attention. Most notably, the discourse of the "War on Drugs" targets dealer and producer with police and military tactics organized by the discursive strategy.

Moreover, the scapegoating process implicates public deliberation by propagating mythic elements about a particular group and circulating that myth in the press. Press circulation of scapegoats often preserves the status quo, either by externalizing responsibility for a public problem or by undermining those seeking to address it. Jack Lule (2001), for example, has shown how the news scapegoated the Black Panthers as a means for "delegitimizing dissent" and sabotaged Huey Newton's activism in particular (pp. 62, 64-80). Jeremy Engels (2010) has contended scapegoating "manufactures consent by manipulating the vitriolic emotions" generated by figuring the public as victim of a "name[d] the enemy" (pp. 304, 308). Emily Weiser (2008), too, has noted the emphasis on division and naming with her modern readings of Burke's landmark essay "The Rhetoric of Hitler's Battle” (pp. 61-64). 
These critics have contended "unification by scapegoat" extends the dialectical relationship between the division of "us" and "them," a division that Burke (1968) has argued carries a "terministic compulsion" that drives individuals to "carry out the implications of one's terminology" (p. 19). Thus, just as the Romans needed to crucify Jesus to achieve the catharsis invoked by sacrifice and the Nazis had to commit genocide to complete the scapegoating of the Jews, so too do nations act out the scapegoating ritual in foreign and domestic policymaking (Burke, 1973, pp. 45-48). In this way, scapegoating drives a pseudo-deliberation in which scapegoating a political enemy serves as the basis for political consent.

\section{Trump's Scapegoating Rhetoric}

Cobbling together a narrow coalition that barely eked out an Electoral College victory, Trump's scapegoating rhetoric propelled his candidacy while revealing deeply rooted racism in American political culture, if not the Fourth Estate (Grusin, 2017, pp. S87-S88). This rhetoric is distinctive in that Trump wove it into arguments for impossible policy plans - the southern border wall Mexico would pay for and his pledge to ban Muslims from entering the country, shut down mosques, and otherwise suppress Islam in the United States. These proposals - one practically unfeasible, the other likely unconstitutional - comprised the policy core of his campaign and reflected Trump's ignorance and braggadocio.

Atypically, however, Trump's scapegoating rhetoric produced division and opposition rather than unity. The rise of "resistance" groups, his declining popularity, and his inability to manufacture consent for virulently racist policies speak to the divisive components of his rhetoric. By analyzing Trump's scapegoating of immigrants and Muslims - his most consistent targets - this section highlights the overtly racist components of his rhetoric and provides insight into his failure to generate unity.

\section{Scapegoating (Mexican) Immigrants as Criminals}

Scapegoating immigrants for American failures retains a central position in Trump's rhetorical arsenal. From his speech announcing his candidacy to the present, he has consistently spoken about the dangers posed by immigrants, identified immigrants as the source of national problems, and blamed Democrats for failing to stop immigrants from illegally entering the country. In his presidential announcement address on June 16, 2015, Trump laid the foundation for this discourse by focusing on Mexicans by stating:

When Mexico sends its people, they're not sending their best... They're sending people that have lots of problems, and they're bringing those problems with us. They're bringing drugs. They're bringing crime. They're rapists. And some, I assume, are good people. But I speak to 
border guards and they tell us what we're getting... They're sending us not the right people. It's coming from all over South and Latin America, and it's coming probably - probably - from the Middle East.

(Trump, 2016a)

This rhetoric figures immigration as something sent by foreign governments, implying those governments select their worst citizens and deliver them to the U.S. border. In doing so, Trump expands archetypal forms of scapegoating from the actual immigrants to include national governments. While Trump's scapegoating of immigrants blossomed into a fullthroated charge that Muslims are responsible for international terrorism as his campaign progressed, this speech focused attention on "the border." Implying immigrants only transit from south to north - thus there is only one border that matters - he pledged to build a wall between the United States and Mexico that they will "pay for" (Trump, 2016a).

Trump's scapegoat, distinctly brown and foreign, appeared as the source of drug abuse, crime, rape, and terrorism. The rhetoric turned a blind eye to America's collective appetite for illegal drugs and to how national policies contribute to the rise of terrorism in the world and instead outsourced responsibility to those most vulnerable. The rambling remarks moved from blaming individuals, however, to also scapegoat nations like Mexico and China as simultaneously weak and vindictive and marvels of technological advancement. Appearing contradictory, Trump's argument implied that America was "losing" because other nations had figured out how to take advantage of us to their own benefit (Trump, 2015a).

This rhetoric blamed American economic and social weakness on the strategies enacted by foreign presidents. It implied that Mexican leaders, in particular, had sought to undermine America's greatness by flooding the country with poorly skilled, criminal elements. Simultaneously, the rhetoric called for a strong, capable leader up to the task of returning America to its former glory, someone who could out-strategize the opposition. In short, it heralded the need for a master negotiator, a deal maker.

Perhaps responding to media pushback, Trump doubled down on his claims about Mexico, tweeting on June 30, 2015, "I love the Mexican people, but Mexico is not our friend. They're killing us at the border and they're killing us on jobs and trade. FIGHT!” (Trump, 2015b). While this rhetoric mimics how presidents refer to foreign enemies (Flanagan, 2009), Trump's identification of Mexico as an enemy was shocking in and of itself. The United States and Mexico have long enjoyed close relations. During the Cold War, Mexico supported American anti-Communism policies in the region. After the Cold War, in addition to Canada, the nations negotiated and acceded to a free trade agreement. President George W. Bush's first international trip was to Mexico. And the nations have an ongoing partnership to combat drug trafficking. 


\section{Stephen J. Heidt}

In short, since 1945, Mexico has been one of the United States' strongest and most reliable allies. Trump's narrowing of scapegoating to specifically identify Mexico as an enemy of the nation disrupted this longstanding relationship. In Trump's world, Mexico appeared as dangerous and hostile to American interests. As he put it at a campaign rally in New Hampshire on June 30, 2016, "that could be a Mexican plane up there. They're getting ready to attack" (Gass, 2016). Picked up by the press as a jest, Trump's audience appeared to enjoy the remark and, in the broader context of a rhetoric blaming Mexico for stealing American jobs, the claim extended Trump's scapegoating thesis. Mexico, in cooperation with the Clintons and NAFTA, orchestrated American malaise.

In one of the strangest twists of the campaign, Trump's scapegoating rhetoric entangled the Pope after the religious leader made comments opposing the candidate, his anti-Mexican rhetoric, and his proposed border wall. Trump's statement warned that "when the Vatican is attacked by ISIS ... the Pope would have only wished and prayed that Donald Trump would have been president" (Trump, 2016e). Raising the other primary target of Trump's scapegoating rhetoric - Muslims - the statement also extended his claims about Mexico. This time, Trump figured Mexico as a rude bully having "made many disparaging remarks about me." They also were suspicious and secretive, but Trump was "wise to them" and knew they "want[ed] to rip off the United States."

Indicting all Mexicans, not just the president or the country's leadership, Trump's scapegoat appeared as an entire nation, collectively responsible for America's decline. Their policies cause, Trump stated, "crime, the drug trafficking and the negative economic impact" (Trump, 2016e). All of these remarks figured Mexico as the responsible party for American economic and cultural suffering, depicting the southern neighbor as having both the intent and means to ruin the nation. At the same time, they figured Trump as the only candidate to truly know the shape of Mexican character and as being up to the task of defeating their nefarious designs.

Trump's anti-immigrant rhetoric reached an apex in his address accepting the nomination for president. In this speech he claimed "nearly 180,000 illegal immigrants with criminal records ... are tonight roaming free to threaten peaceful citizens" (Trump, 2016d). He punctuated the claim with an anecdote about an innocent (white) child killed by an undocumented immigrant (non-white) before shifting to claims about immigrants stealing American jobs. Once again, the rhetoric piled the blame for national ills on a foreign body. Crime, poverty, crumbling infrastructure, and budget deficits all resulted from massive waves of illegal immigration. Identifying the immigrant body - coded as a contaminant to the national body politic - as the cause of the nation's problems also pointed to the solution. Only by empowering Trump to run the nation could the immigrant body be banished from the country and prevented from returning. 
While Trump's scapegoating of Mexicans remained consistent across his campaign, his vainglorious trip to meet with the president of Mexico Enrique Peña Nieto - in August 2016, temporarily moderated the explicitness of his rhetoric. He followed up the visit with what he called a "detailed policy address" on "illegal immigration" in Phoenix, Arizona, on August 31, 2016. After praising Peña Nieto as someone "who truly loves his country," Trump claimed he would rework the relationship between the two nations on the basis of "fairness" (Trump, 2016f). The comment implied, of course, that the current relationship was unfair, balanced in favor of Mexico. The rest of the address mimicked the basic pattern by pointing out the harm caused by immigrants and by blaming President Barack Obama and presidential candidate Hillary Clinton.

In each instance, the scapegoated Other appeared as "illegal immigrants," rather than Mexico. Trump characterized immigrants as unable to "assimilate," as dangerous and violent, and as job stealers who are "hurting a lot of our people that cannot get jobs under any circumstances" (Trump, 2016f). This rhetoric justified Trump's policy proposals, most notably his claim that he would build a "beautiful southern border wall" that "Mexico will pay for" (Trump, 2016f). By singling out the southern border, the rhetoric again inferred the danger posed by darker, non-white bodies moving from South to North.

Conferring responsibility on Mexico for not controlling those bodies thus their responsibility to pay for the wall - Trump escalated the depiction by pointing to the technological sophistication necessary to keep immigrants out of the national body politic. "We will use the best technology," he claimed, listing off measures to detect and detain migrants from going under or above the wall (Trump, 2016f). The rest of his policy proposals related to amplifying the means to capture and banish immigrants from the country, which he summed up by saying, "otherwise we don't have a country" (Trump, 2016f). Again, the rhetoric implied the contamination of the national body by foreign, non-white Others. Immigrants didn't just represent danger or loss of jobs; they reflected a loss of identity.

\section{Scapegoating Mexicans from the Campaign to the Presidency}

In the first presidential debate on September 26, 2016, Trump continued to identify "illegal immigrants" as the source of rising crime rates. Claiming the residents of "our inner cities ... are living in hell because it's so dangerous," Trump blamed "gangs roaming the street. And in many cases, they're illegally here, illegal immigrants. And they have guns. And they shoot people" (Trump, 2016a). At the second debate on October 9, 2016, he continued the theme, insisting that:

children have been killed, brutally killed by people that came into our country illegally. You have thousands of mothers and fathers 


\section{Stephen J. Heidt}

and relatives all over the country. They're coming illegally. Drugs are pouring in through the border. We have no country if we have no border.

(Trump, 2016b)

And in the final debate on October 19, 2016, Trump reiterated all of the previous themes about drugs, criminality, loss of jobs, and a loss of national identity. Emphasizing his differences with Clinton, he finished his remarks by declaring that "we have some bad hombres here, and we're going to get them out" (Trump, 2016g). The picture evoked by this rhetoric entails a nation with the best intentions, hamstrung by a wave of brown, criminal bodies engaged in trafficking drugs, resorting to violence to pursue their goals, and unchecked by national authorities. Prototypical for racialized depictions of Latino immigrants (Santa Ana, 2002), Trump's rhetoric blamed both the immigrant and the Democrats for allowing the undocumented to corrupt the national fabric. As a rationale for his candidacy, this discourse distinguished his outlook from Clinton's while pushing his plan to "build a wall."

Atypical for presidents, Trump has held several campaign style rallies since his inauguration. In those rallies, he has again resorted to scapegoating immigrants for perceived national problems. In one such rally, he repeated his campaign tale of meeting "American families whose loved ones - sons and daughters, husbands and wives - were viciously killed by illegal immigrants" (Trump, 2017a). Simultaneously emphasizing American victimhood while blaming the previous administration and "the media" for enabling immigrant violence, Trump's scapegoating rhetoric expanded the number of parties responsible beyond just the immigrant. It also wielded presidential ethos to fill out a more complete picture of the scapegoated other.

Implying his vantage point provided a clearer picture of the problem, Trump stated that "we are finding that drug dealers, robbers, thieves, gang members, predators, killers and criminals of all types preying on our citizens ... one by one, they are being tracked down and thrown the hell out of our country, and we will not let them back in" (Trump, 2017a). This rhetoric placed criminality in a binary relation - criminals were foreign and illegal, the victim citizens, innocent and law abiding. The rhetoric implied immigrants had an animalistic character. They "preyed" on the innocent and had to be "tracked down" and evicted from the nation. He continued these themes a subsequent rally (Trump, 2017b), a White House event in which he brought in family members of persons killed by undocumented immigrants (Trump, 2017c), a statement on legislation to further criminalize undocumented border crossings (Trump, 2017d), and in a weekly address (Trump, 2017e).

But it wasn't until a rally held in Ohio on July 25, 2017, that the president explicitly called immigrants "animals," conferring subhuman 
status upon them (Roberts, 2017). Claiming immigrants were "predator and criminal aliens who poison our communities with drugs and prey on innocent young people," he then described how they kidnapped "a young, beautiful girl" and tortured her to death "because they want them to go through excruciating pain before they die" (Roberts, 2017). Embodying the most racist form of scapegoating, Trump's rhetoric dehumanized the foreign body, marking it as the source of domestic problems and signaling the likelihood that his policies would increasingly target the scapegoated population. It also collapsed distinctions between the undocumented and the documented, the criminal and the lawful.

\section{Scapegoating Muslims as Terrorists}

The scapegoating of Muslims by Trump appeared as a secondary target during the campaign. Having endorsed some of the worst conspiracy theories about Barack Obama's nationality and religious affiliation, Trump had a well-documented public record of expressing concern about Muslims. In his pre-campaign discourse, Muslims were suspicious by their very nature. His campaign rhetoric gradually embraced and expanded on the thesis that Muslims are inherently dangerous. At a rally in New Hampshire on September 30, 2015, he warned attendees that Syrian refugees "could be ISIS... This could be one of the greatest tactical ploys of all time. A 200,000-man army, maybe." Filling out the portrait, he asserted, "they're all men, and they're all strong-looking guys” (Johnson, 2015a).

Simultaneously casting Europe and the United States as potential victims of terrorist attack, the rhetoric depicted refugees as purposefully secretive, masculine, and potentially dangerous. Implicitly figuring the United States and Europe as white states - victims of Middle Easterners Trump's supposition extended his prior concerns about non-white bodies posing a danger to national identity and justified the a priori exclusion of refugees.

A month later, Trump implied that the problem was Islam itself, not merely Syrian refugees. In an interview with Fox Business, he expressed interest in shutting down mosques in the United States as something to "look at" (Bailey, 2015). He continued the theme in an interview on MSNBC on November 15. This time he was even more explicit, stating how closing mosques is "something that you're going to have to strongly consider because some of the ideas and some of the hatred - the absolute hatred - is coming from these areas." He elaborated: "The hatred is incredible; it's embedded. It's embedded. The hatred is beyond belief." Even while noting he knows some "Muslims, who are such unbelievably great people," the valence of his remarks left little doubt about the source of American insecurity and how to counteract it (Johnson, 2015b). 


\section{Stephen J. Heidt}

\section{The Episodic Scapegoating of Muslims}

Throughout the rest of 2015, Trump continued to insist that Muslims of all stripes were anti-American, different from the rest of "us" and in need of monitoring, if not exclusion. In Alabama, he claimed "thousands and thousands of people were cheering" the fall of the World Trade Center, and on $A B C$ News he clarified that those cheering were "a heavy Arab population" (Delawala, 2015). On MSNBC, Trump stated, "we are not loved by many Muslims" (Morning Joe, 2015). Each of these iterations distinguished between us - non-Muslim Americans - and them Muslims of many nationalities - implying that Muslims could never truly be part of the nation. The call reached its apex with Trump's response to the San Bernardino massacre on December 13, 2015. "You have to take out their families," Trump declared on Fox News. Later, he claimed "we have people out there that want to do great destruction to our country." He ended the year claiming that Islam is a "sickness" and Muslims are "sick people" (Friedman, 2015).

By March 2016, the scapegoating of Muslims resurged in Trump's speeches. He contended on CNN that "Islam hates us ... there's unbelievable hatred of us" (Schleifer, 2016). After three suicide bombings in Brussels, he expanded on the theme telling Fox Business that "we're having a problem with the Muslims ... these attacks aren't coming out of - they're not done by Swedish people" (Saul, 2016). The phrasing of "the Muslims" again distinguished between us and them by separating Muslims as a separate class. On NBC's TODAY, he added "there's no assimilation ... they want Sharia Law. They don't want the laws that we have" (Stump, 2016). The rhetoric replicated tropes of the national body contaminated by a foreign Other, warning that no Muslim immigrant could ever truly become American (or Western) because the very nature of their religion precluded it.

After the Pulse Nightclub massacre in Orlando, Florida, in June 2016, Trump extended his scapegoating of Muslims to renew his call for an immigration ban. Claiming the massacre was an "attack on the right of every single American to live in peace and safety," Trump's speech sought to produce unity via the identification of a common enemy (Trump, 2016c). Dodging the nature of the victims - LGBTQ people - Trump identified the enemy as Muslim and foreign, never truly "homegrown" and instead "imports from overseas." The rhetoric distinguished between us and them while urging unity across "the whole civilized world in the fight against Islamic terrorism, just like we did against Communism in the Cold War." Replicating orientalist tropes about Muslims and implying suspicion toward all Muslims, the narrative built a justification for his Muslim ban by scapegoating Barack Obama, Hillary Clinton, and the "dysfunctional immigration system" that left the nation vulnerable to attack (Trump, 2016c). This discourse distinguished Trump from Obama and Bush. 
While both of his predecessors embraced orientalist policies, Obama attempted to justify those policies without articulating stereotypical tropes about Islam (Goldberg, 2017). And Bush, even in calling for a Global War on Terror - a crusade of West versus East - attempted to articulate respect for Islam and dissociate the "terrorists" from the wider Muslim diaspora (Lee, 2017, 6). For Trump, nuanced distinctions were part of the problem.

Trump's speech accepting the Republican nomination for president leaned heavily on the scapegoating of Muslims to justify his candidacy. Framing his candidacy as the remedy to "a moment of crisis for our nation," Trump claimed:

...to make life in America safe, we must also address the growing threats we face from outside the country: we are going to defeat the barbarians of ISIS, and we're going to defeat them fast....The damage and devastation that can be inflicted by Islamic radicals has been proven over and over.

(Trump, 2016d)

Here, Trump's rhetoric simultaneously represented the nation as at risk and identified the cause of the danger as an external, non-white, non-Christian population.

The principle of division manifest in scapegoating discourse separating Americans from Muslims - marked the boundary that constituted a specific type of American identity. Rather than signify the sovereign border between the United States and the world, Trump's discourse marked that boundary as the division between (predominantly) white Christians and Muslims. Making "Islam" the dividing line introduced doubt in the Americanness of any American Muslim, a possibility he pointed to by naming the events of 9/11, the San Bernardino attack, the Boston Marathon bombing in 2013, the recruiting center attack in Tennessee in 2015, and the Orlando massacre. With the exception of 9/11, each of the named attacks involved American citizens who also claimed to worship Islam.

As the campaign wound down, Trump continued to blame the immigration system for permitting terrorists to infiltrate the national body. In a rally on September 19, 2016, Trump claimed that "Islamic terrorist attacks ... were made possible because our extremely open immigration system" (Nuzzi, 2016). Again, Trump's rhetoric highlights the "Islamic" component of the attacks. The move scapegoated Muslims for American vulnerability to terrorism while turning a blind eye to other forms of domestic terrorism like abortion clinic bombings or mass shootings that did not involve "Muslims."

Doing so facilitated the identification of a problem - immigration that Trump could solve. Redemption, in Trump's oration, appeared as 


\section{Stephen J. Heidt}

first endorsing his mandate for the presidency and then as empowering him to fix the problems created by Obama and Clinton. For his base, identifying Muslims, immigrants, and Democrats as the source of American ills proved cathartic. A week after his inauguration, Trump signed the first executive order barring Syrian refugees and citizens of seven other nations from entering the country for 90 days. After a series of court challenges, Trump reissued the ban in a way designed to withstand legal scrutiny (Liptak, 2017).

\section{Analysis of Media Response to Trump's Scapegoating Rhetoric}

The scope of this chapter does not permit a full analysis of the bulk of media coverage over the course of the campaign. Instead, the following focuses on three significant moments in the campaign: Trump's announcement address, his response to the Orlando massacre, and his address accepting the nomination for president. Analyzing press accounts of these four events provides insight into the shape and tone of coverage over the first year of his campaign and points to the ways the political press failed to take his campaign seriously. It also highlights enduring questions about the role of political journalism in political campaigns in challenging candidates.

\section{Announcement Address}

In an already crowded field of Republican challengers, the political press did not appear to take Trump's announcement of his candidacy entirely seriously. An analysis of press coverage revealed Trump's announcement address generated three primary responses from the political press: comments about the oddness of his speech, comments about his celebrity status, and observations about his chances. Commentary about the oddness of Trump's speech typically described the setting (Trump Tower in New York City), the length of the speech, and the rambling form of delivery. When discussing the content of the speech, typical accounts referred to it as odd, as "dramatic and eccentric," and filled with "the strangest quotes" (Clark, 2015). Politico referred to the speech and to Trump's campaign as "quixotic" and "pugnacious," but went on to list the "ten best lines" from the speech, with the "best" being a quip about Mexicans (Lerner, 2015).

The Guardian (2015) also called the speech "eccentric," noted the ways Trump scapegoated Mexicans, and then shifted to discuss the horserace component of a crowded field of Republican challengers. The Financial Times called his address a "bizarre tirade" and noted the "string of xenophobic comments - particularly about Mexican immigrants whom he said included 'rapists"' (Sevastopulo, 2015). National Public Radio 
(NPR) classified the speech "unconventional" but produced a list of its "best moments" (Kelly, 2015). Notably, the list did not mention the "rapists" comment. Matt Tiabbi (2015) wrote a column in Rolling Stone listing "the 47 funniest things about Donald Trump" and referred to his comments about Mexicans as a "crude swipe." These examples point to the ways the political press covered Trump's entry into the race as a form of comic relief. Very few mainstream news sources directly challenged Trump's scapegoating rhetoric, instead noting its atypical form for presidential aspirants.

A secondary strain of commentary highlighted Trump's celebrity status. ABC News recounted the candidate's descent on the escalator prior to his actual address, referring to him as "The Donald" (Santucci \& Stracqualursi, 2015). CNN emphasized Trump's celebrity status, noting he "flaunted his wealth and success in business" to prove his qualifications for the job (Diamond, 2015). Entertainment press coverage raised Trump and his candidacy as a spectacle and as a source of comedy (Scheck, 2015). Most accounts discussed Trump's candidacy as a "gift from the comedy gods" (Bauder, 2015). One account mentioned Trump had referred to Mexicans as "rapists," as well as attacking "U.S. politicians as 'stupid,' 'morally corrupt' losers" (Mcaffe, 2015). In none of these accounts did the press report on or challenge Trump's scapegoating of Mexicans. Instead, each of these accounts highlighted some capacity of Trump's celebrity status and the potential comic relief made possible by his candidacy.

The final major strand of commentary focused on Trump's chances to win the nomination. Most discounted the possibility of Trump winning the nomination. The Financial Times, again, claimed that "practically no one thinks the billionaire has a chance of becoming president," quoting academics and political analysts to demonstrate the consensus (Sevastopulo, 2015). One conservative commenter wrote a column titled "Anticipating Donald Trump's exit speech" and called the announcement speech "crazy," "incoherent," and a "joke" (Domke, 2015). In short, a significant strand of coverage did not take Trump's candidacy seriously.

\section{Responses to Trump's comments on Orlando Massacre, June 2016}

The analysis of press coverage of Trump's speech after the Orlando massacre demonstrates the significant shift in coverage from June 2015 to June 2016. Multiple reports specifically named and challenged his scapegoating of Muslims, noting that his rhetoric did not align with core American values. The New York Times, for example, emphasized Trump's claim that "all Muslim immigrants posed potential threats to America's security and called for a ban on migrants from any part of 
the world with 'a proven history of terrorism' against the United States or its allies" (Martin \& Burns, 2016). The reporting went on to explain how Trump had implicitly connected terrorism to all Muslims, coding Muslim bodies as inherently dangerous and incapable of becoming truly American.

Another account noted that Trump blamed "Muslim immigrants" for terrorism, even though the Orlando shooter had been born in the United States, rather than directly call out the candidate, this article reported that Clinton had stressed the need to work with Muslim communities rather than "scapegoating" them writ large (Cadei, 2016). Another commenter lamented the scapegoating of Muslims after the massacre, noting that for "Donald Trump ... basically all Muslims" are to blame (Gobry, 2016). And U.S. News called Trump's speech "one of the most demagogic anti-immigration speeches by a candidate in modern times" (Hemmer, 2016).

An additional line of media commentary emphasized the politicized nature of the event and pointed to differences between Clinton and Trump, as revealed in their speeches about the Orlando massacre. In what would become increasingly common after the conventions, these accounts depicted Clinton as a "thoughtful, cautious leader" and Trump as someone who "shoots from the hip and trusts his gut" (Elliot, 2016). These accounts identified scapegoating rhetoric in both candidates discourse - guns vs. immigration - but withheld judgment about the candidates themselves. Instead, they presented the candidates' remarks as indicative of leadership style, leaving it up to the voter to determine which style they preferred. A secondary component of this media coverage emphasized that the candidate's speeches "defied, as usual, political convention" (Biermann \& Halper, 2016). Much of this reporting appeared in a he said-she said format, in which both candidates' views were presented without much guidance offered to delineate or judge the two.

\section{Responses to Republican National Convention Address, July 2016}

Previous scholarship indicates that news media coverage of convention addresses tends to highlight the positive components of the speakers and the vision they offer the world (Benoit et. al., 2007, p. 147). Because of the potential "bump" in support media coverage of conventions can produce, candidates typically coordinate the speeches at the convention to ensure the nominee receives favorable coverage (Vigil, 2015, p. 130). In the current, digitized media ecosystem, convention addresses are now live blogged, immediately dissected, memed and otherwise cut into sound bites that political commentators employed by the major television and cable networks can easily circulate (Foley, 2012, pp. 613-614). 
While the TV news has, to some extent, participated in these practices for decades, the increasingly fragmented media landscape has undermined candidates' attempts to frame news coverage of convention addresses (Scacco \& Coe, 2016, p. 2017). That said, several strands of media coverage emerged in the aftermath of Trump's acceptance address. One strand emphasized the length of the speech and its significance to the Republican Party (Date, 2016). These accounts, while noting Trump was never a Republican and only became one to win the nomination, highlighted the policy components of Trump's address and his claim to leadership. In doing so, these reports detailed ideological and policy differences between Trump and the Republican Party.

The major media frame of Trump's address, however, emphasized the "darkness" of his speech. CNN, for example, noted that "Trump conjured a dire picture ... of an America sliding deeper into poverty, violence and corruption" (Collinson, 2016). Without using the words, the report identified Trump's reliance on scapegoating, particularly immigrants. Reuters, too, adopted a similar frame, claiming "Trump presented a bleak view of America under siege from illegal immigrants, threatened by Islamic State militants, hindered by crumbling infrastructure and weakened by unfair trade deals and race-related violence" (Holland, 2016).

Trump's scapegoating of immigrants for insecurity and economic malaise appeared as the dominant frame in these reports, although some outlets opted to fact-check the candidate and point to the lack of "policy agendas" designed to address the challenges he identified (Flores, 2016). And, in perhaps its most explicit move against Trump, The New York Times editorial page referred to the speech as a "campaign of fear," and warned that the candidate "intends to terrify voters into supporting him” (Editorial Board, 2016).

\section{Conclusion}

While it is tempting to write Trump off as an exception to the rule, as David Campbell $(1998)$ has said, "the ability to represent things as alien, subversive, dirty, and sick has been pivotal to the articulation of danger in the American experience" (p. 3). Historically constant, those representations have driven the nation to war, underwritten racist policies at home and abroad, and bonded American culture around notions of exceptional ideals. Trump rise to power, then, reflects synchronicity with a particular kind of identity politics that typifies American political culture.

Principally orchestrated via the discourse of scapegoating, this form of politics identifies others as the source of American malaise, offering up an image of America as held back by the nefarious designs of others. Trump's embodiment of the most racist scapegoating form, while 


\section{Stephen J. Heidt}

disconcerting, suggests that politicians can continue to exploit American commitments to the belief in their own exceptional qualities.

Trump's candidacy raises important questions for how the news media should report on populist leaders who directly challenge American democracy. As a profession organized to objectively report both sides, Trump's rise suggests limitations in the role the press can play in countering dangerous populist impulses. Rather than directly calling out Trump, his rhetoric, and his candidacy for underlying xenophobic and racist elements, initial accounts treated the Trump campaign as another act of political theater.

Moving from frames of novelty to frames of danger, the coverage indexed in this chapter demonstrates that Trump's rise corresponded with press concerns about his rhetoric, his policies, and his anti-democratic impulses. Rarely engaging explicit condemnation, the press's emphasis on identifying and condemning Trump's scapegoating of immigrants and Muslims suggests a shift in the coverage of the insurgent presidential candidate.

Still, Trump's rise generated significant and sustained opposition. A Black Lives Matter founder, for example, responded to Trump's nomination address by calling out the candidate's racist undertones. As she put it, "the terrorist on our televisions tonight was Donald Trump," he is "a charlatan who will embolden racists and destroy communities of color," and "White people of conscious must forcefully reject this hatred" (Edwards, 2016).

Defining Trump as a terrorist shifted the focus away from the elements of political theater and spectacle to emphasize the core essence of Trump and his campaign. This reframing shows how oppositional voices can wield a new rhetoric of the enemy to political gain, not as a technique of persuasion, but rather as an embodied position of opposition. Ultimately, these forms of embodied oppositions are likely to become increasingly important as Trump shows no sign of abandoning virulently racist forms of scapegoating.

\section{References}

Allen, J. (2016, September 8). Trump's immigration plan: Scapegoating cloaked as policy. Roll Call. Retrieved at www.rollcall.com/news/opinion/ trumps-immigration-plan-scapegoating-masquerading-policymaking.

Bailey, S. P. (2015, October 21). Donald Trump says he would consider closing down some mosques in the U.S. The Washington Post. Retrieved at www. washingtonpost.com/news/acts-of-faith/wp/2015/10/21/donald-trump-sayshe-would-consider-closing-down-some-mosques-in-the-u-s/?utm_term=. 59feaba78f28.

Bauder, D. (2015, June 17). Trump announcement a boon to late-night comics. San Diego Union Tribune. Retrieved at www.sandiegouniontribune.com/ 
sdut-trump-announcement-a-boon-to-late-night-comics-2015jun17-story. html.

Beinart, P. (2017, March 1). Trump scapegoats unauthorized immigrants for crime. The Atlantic. Retrieved at www.theatlantic.com/politics/archive/2017/03/ trump-scapegoats-unauthorized-immigrants-for-crime/518238.

Benoit, W. L., Stein, K. A., McHale, J. P., Chattopadhyay, S., Verser, R., \& Price, S. (2007). Bush Versus Kerry: A Functional Analysis of Campaign 2004. New York, NY: Peter Lang.

Biermann, N., \& Halper, E. (2016, June 13). The Trump and Clinton responses to the Orlando shooting just reset the political norm. Los Angeles Times. Retrieved at www.latimes.com/politics/la-na-pol-clinton-trump-orlando-20160613-snap-story.html.

Blakely, J. (2017, January 19). Trump and the international rise of the politics of scapegoating. Georgetown Journal of International Affairs. Retrieved at http://journal.georgetown.edu/trump-and-the-international-rise-of-the-politicsof-scapegoating.

Burke, K. (1964). Permanence and Change: An Anatomy of Purpose. Berkeley: University of California Press.

Burke, K. (1968). Language as Symbolic Action: Essays on Life, Literature, and Method. Berkeley: University of California Press.

Burke, K. (1969). The Grammar of Motives. Berkeley: University of California Press.

Burke, K. (1973). The Philosophy of Literary Form: Studies in Symbolic Action. Berkeley: University of California Press.

Burke, K. (2005). The Rhetoric of Hitler's “Battle.” In C. R. Burgchardt (Ed.), Readings in Rhetorical Criticism (pp. 191-220). State College, PA: Strata Publishing.

Cadei, E. (2016, June 13). Politics don't stop after Orlando, despite calls for unity. Newsweek. Retrieved at www.newsweek.com/politics-dont-stop-afterorlando-despite-calls-unity-469919.

Campbell, D. (1998). Writing Security: United States Foreign Policy and the Politics of Identity. Minneapolis, MN: University of Minnesota Press.

Chomsky, N. (2017, April 4). When scapegoating immigrants no longer works, would Trump stage an attack to maintain power? Democracy Now. Retrieved at www.democracynow.org/2017/4/4/when_scapegoating_ immigrants_no_longer_works.

Cisneros, D. (2008). Contaminated communities: The metaphor of "immigrant as pollutant" in media representations of immigration. Rhetoric \& Public Affairs, 11(4), 569-602.

Clark, T. (2015, June 16). 11 bonkers quotes from Donald Trump's campaign announcement. Vox. Retrieved at www.vox.com/2015/6/16/8789885/donaldtrump-president-shocking.

Collinson, S. (2016, July 22). Donald Trump accepts presidential nomination. CNN. Retrieved at www.cnn.com/2016/07/21/politics/republicanconvention-highlights-day-four/index.html.

Date, S. V. (2016, July 21). It's Donald Trump's party now. Huffington Post. Retrieved at www.huffingtonpost.com/entry/trump-republican-nominee_us_ 579167e1e4b0bdddc4d3f03c. 


\section{Stephen J. Heidt}

Delawala, I. (2015, December 4). What ABC News footage shows of 9/11 celebrations. ABC News. Retrieved at http://abcnews.go.com/Politics/abc-newsfootage-shows-911-celebrations/story?id=35534125.

Diamond, J. (2015, June 17). Donald Trump jumps in: The Donald's latest White House run is officially on. CNN. Retrieved at www.cnn.com/2015/06/16/ politics/donald-trump-2016-announcement-elections/index.html.

Domke, T. (2015, June 16). Commentary: Anticipating Donald Trump's exit speech. WBUR News. Retrieved at www.wbur.org/news/2015/06/16/donaldtrump-exit-speech.

Douglas, T. (1995). Scapegoats: Transferring Blame. London: Routledge.

Downie, J. (2017, January 20). Trump sets up scapegoats for his presidency. The Washington Post. Retrieved www.washingtonpost.com/blogs/post-partisan/ w p/2017/01/20/tr...-sets-up-the-scapegoats-for-his-presidency/?utm_ term $=.1 \mathrm{c} 393 \mathrm{~b} 5 \mathrm{dc} 6 \mathrm{a} 1$.

Editorial Board. (2016, July 22). Donald Trump's campaign of fear. The New York Times. Retrieved at www.nytimes.com/2016/07/22/opinion/donald-trumpscampaign-of-fear.html?_r=1\&mtrref=undefined\&assetType=opinion.

Edwards, B. (2016, July 22). Black Lives Matter responds to Trump's acceptance speech at RNC. The Root. Retrieved at www.theroot.com/blacklives-matter-responds-to-trump-s-acceptance-speec-1790856130.

Elliot, P. (2016, June 13). What caused Orlando? Hillary Clinton blames guns. Donald Trump blames immigration. Time. Retrieved at http://time. com/4367193/orlando-shooting-hillary-clinton-donald-trump-speeches.

Engels, J. (2010). The politics of resentment and the tyranny of the minority: Rethinking victimage for resentful times. Rhetoric Society Quarterly, 40(4), 303-325.

Flanagan, J. (2009). Imagining the Enemy: American Presidential War Rhetoric from Woodrow Wilson to George W. Bush. Claremont, CA: Regina Books.

Flores, R. (2016, July 22). Donald Trump offers dark vision of America in GOP convention speech. CBS News. Retrieved at www.cbsnews.com/news/ donald-trump-gop-convention-speech.

Foley, M. (2012). Sound Bites: Rethinking the Circulation of Speech from Fragment to Fetish. Rhetoric \& Public Affairs, 15(4), 613-622.

Foy, M. M. (2012). Disrupting the scapegoat mechanism: Steve Barbar versus University of Virginia's college at wise. Southern Communication Journal, 77(2), 94-110.

Friedman, D. (2015, December 13). Trump cites 'sickness' in defense of Muslim immigration ban proposal. Fox News. Retrieved at www.foxnews.com/ politics/2015/12/13/trump-cites-sickness-in-defense-muslim-immigrationban-proposal.html.

Gass, N. (2016, June 30). Trump's plane joke: It's Mexico 'getting ready to attack.' Politico. Retrieved at www.politico.com/story/2016/06/trump-jokesabout-plane-its-mexico-getting-ready-to-attack-224995.

Girard, R. (1979). Violence and the Sacred. Baltimore, MD: Johns Hopkins University Press.

Gobry,P.(2016, June 15). The shamefulscapegoating after Orlando. The Week.Retrieved at http://theweek.com/articles/629751/shameful-scapegoating-afterorlando. 
Goldberg, J. (2017, August 13). Why won't Trump call out radical white terrorism? The Atlantic. Retrieved at www.theatlantic.com/politics/archive/2017/08/ what-obama-could-teach-trump-about-charlottesville/536703.

Gornoski, D. (2016, September 1). Trump and the scapegoat effect. The American Conservative. Retrieved at www.theamericanconservative.com/ articles/trump-and-the-scapegoat-effect.

Grusin, R. A. (2017). Donald Trump's evil mediation. Theory \& Event, 20(1), 86-99.

The Guardian. (2015, June 16). Donald Trump announces US presidential run with eccentric speech. The Guardian. Retrieved at www.theguardian.com/ us-news/2015/jun/16/donald-trump-announces-run-president.

Hemmer, N. (2016, June 14). Trump's New Low. US News. Retrieved at www. usnews.com/opinion/articles/2016-06-14/trumps-orlando-immigrationspeech-was-a-new-low.

Holland, S. (2016, July 21). Trump accepts Republican nomination, vows to put 'America first.' Reuters. Retrieved at www.reuters.com/article/us-usaelection-idUSKCN10114A.

Jasinski, J. (2001). Sourcebook on Rhetoric: Key Concepts in Contemporary Rhetorical Studies. Thousand Oaks, CA: Sage Publications.

Johnson, J. (2015a, September 30). Donald Trump: Syrian refugees might be a terrorist army in disguise. The Washington Post. Retrieved at www.washingtonpost.com/news/post-politics/wp/2015/09/30/donald-trump-syrianrefugees-might-be-a-terrorist-army-in-disguise/?utm_term=.74b79a81ccf2.

Johnson, J. (2015b, November 16). Donald Trump would 'strongly consider' closing some mosques in the United States. The Washington Post. Retrieved at www.washingtonpost.com/news/post-politics/wp/2015/11/16/donald-trumpwould-strongly-consider-closing-some-mosques-in-the-united-states/?utm _ term $=.736464118 \mathrm{~b} 03$.

Kelly, A. (2015, June 16). The best moments From Donald Trump's announcement speech. NPR. Retrieved at www.npr.org/sections/itsallpolitics/2015/ 06/16/414914628/the-best-moments-from-donald-trumps-announcementspeech.

Klein, B. S. (1988). After strategy: The search for a post-modern politics of peace. Alternatives, 13(3), 293-318.

Lawrence, B., \& Karim, A. (2007). On Violence. Durham, NC: Duke University Press.

Lee, M. J. (2017). Us, them, and the war on terror: Reassessing George W. Bush's rhetorical legacy. Communication and Critical/Cultural Studies, 14(1), 3-30.

Lerner, A. B. (2015, June 16). The 10 best lines from Donald Trump's announcement speech. Politico. Retrieved at www.politico.com/story/2015/06/ donald-trump-2016-announcement-10-best-lines-119066.

Liptak, A. (2017, July 19). Trump refugee restrictions allowed for now; ban on grandparents is rejected. The New York Times. Retrieved at www.nytimes. com/2017/07/19/us/politics/trump-travel-ban-supreme-court.html.

Lule, J. (2001). Daily News, Eternal Stories: The Mythological Role of Journalism. New York: The Guilford Press.

Mackey-Kallis, S., \& Hahn, D. (1994). Who's to blame for America's drug problem?: The search for scapegoats in the "War on Drugs." Communication Quarterly, 42(1), 1-20. 


\section{Stephen J. Heidt}

Martin, J., \& Burns, A. (2016, June 13). Blaming Muslims after attack, Donald Trump tosses pluralism aside. The New York Times. Retrieved at www.nytimes. com/2016/06/14/us/politics/donald-trump-hillary-clinton-speeches.html.

Mcaffe, T. (2015, June 16). The 5 most over-the-top things Donald Trump said during his presidential announcement. People. Retrieved at http://people. com/celebrity/donald-trumps-presidential-announcement-speech-5-mostover-the-top-quotes.

Morning Joe. (2015, November 30). Donald Trump: 'We are not loved by many Muslims' (Full). Retrieved at www.youtube.com/watch?v=NMYeVasogH4.

Nuzzi, O. (2016, September 19). Trump: Make America scared again. The Daily Beast. Retrieved at www.thedailybeast.com/trump-make-americascared-again.

Roberts, A. (2017, July 26). Trump at Ohio rally: Many immigrants are 'animals' who 'slice and dice...young, beautiful girls. Uproxx. Retrieved at http:// uproxx.com/news/trump-immigrants-animals-ohio-rally.

Sanchez-Moreno, M. M. (2017, May 2). Scapegoating in the name of fighting drugs: What Trump and Duterte have in common. The Hill. Retrieved at http://thehill.com/blogs/pundits-blog/crime/331563-scapegoating-in-thename-of-fighting-drugs-what-trump-and-duterte.

Santa Ana, A. (2002). Brown Tide Rising: Metaphors of Latinos in Contemporary American Public Discourse. Austin: University of Texas Press.

Santucci, J., \& Stracqualursi, V. (2015, June 16). Donald Trump announces 2016 presidential campaign: 'We Are Going Make our Country Great Again.' ABC News. Retrieved at http://abcnews.go.com/Politics/donaldtrump-announces-2016-presidential-campaign-make-country/story?id= 31799741.

Saul, H. (2016, March 22). Donald Trump claims 'we're having problems with Muslims' after Brussels and calls for mosques to be studied. The Independent. Retrieved at www.independent.co.uk/news/people/brussels-attack-explosiondonald-trump-muslims-a6945891.html.

Scacco, J. M., \& Coe, K. (2016). The ubiquitous presidency: Toward a new paradigm for studying presidential communication. International Journal of Communication, 10, 2014-2037.

Scheck, F. (2015, June 16). Hollywood mocks Donald Trump's announcement that he'srunningforpresident. HollywoodReporter.Retrieved atwww.hollywoodreporter.com/news/donald-trump-running-president-hollywood-802762.

Schleifer, T. (2016, March 10). Donald Trump: 'I think Islam hates us.' CNN. Retrieved at www.cnn.com/2016/03/09/politics/donald-trump-islam-hates-us.

Schmitt, C. (2007). The Concept of the Political. Chicago, IL: The University of Chicago Press.

Sevastopulo, D. (2015, June 16). Donald Trump launches own job audition for White House. Financial Times. Retrieved at www.ft.com/content/ abadb0dc-1446-11e5-ad6e-00144feabdc0?mhq5j=el.

Shapiro, M. J. (1997). Violent Cartographies: Mapping Cultures of War. Minneapolis, MN: University of Minnesota Press.

Stump,S.(2016, March 22). Donald Trump: Brussels is 'catastrophic,'waterboarding Paris suspect 'would be fine.' TODAY. Retrieved at www.today.com/news/ donald-trump-responds-brussels-attacks-it-s-very-dangerous-city-t 81716. 
Tiabbi, M. (2015, June 17). The 47 funniest things about Donald Trump. Rolling Stone. Retrieved at www.rollingstone.com/politics/news/the-47-funniestthings-about-donald-trump-20150617.

Trump, D. (2015a, June 16). Presidential announcement speech. Time. Retrieved at http://time.com/3923128/donald-trump-announcement-speech.

Trump, D. (2015b, June 30). Twitter statement. https://twitter.com/ realdonaldtrump/status/615866741994954752?lang=en.

Trump, D. (2016a, September 26). Presidential debate at Hofstra University in Hempstead, New York. Presidential Candidates Debates. Online by Gerhard Peters and John T. Woolley, The American Presidency Project. Retrieved at www.presidency.ucsb.edu/ws/?pid=118971.

Trump, D. (2016b, October 19, 2016). Presidential debate at the University of Nevada in Las Vegas. Presidential Candidates Debates. Online by Gerhard Peters and John T. Woolley, The American Presidency Project. Retrieved at www.presidency.ucsb.edu/ws/? pid=119039.

Trump, D. (2016c, June 13). Remarks at Saint Anselm College in Manchester, New Hampshire. Online by Gerhard Peters and John T. Woolley, The American Presidency Project. Retrieved at www.presidency.ucsb.edu/ws/?pid= 117775.

Trump, D. (2016d, July 21). Address accepting the presidential nomination at the Republican National Convention in Cleveland, Ohio. Online by Gerhard Peters and John T. Woolley, The American Presidency Project. Retrieved at www.presidency.ucsb.edu/ws/?pid=117935.

Trump, D. (2016e, February 18). In response to the Pope. Retrieved at www. facebook.com/DonaldTrump/posts/10156658168535725.

Trump, D. (2016f, August 31). Remarks on immigration at the Phoenix Convention Center in Phoenix, Arizona. Online by Gerhard Peters and John T. Woolley, The American Presidency Project. Retrieved at www.presidency. ucsb.edu/ws/?pid=119805.

Trump, D. (2016g, October 21). Presidential debate at the University of Nevada in Las Vegas. Online by Gerhard Peters and John T. Woolley, The American Presidency Project. Retrieved at www.presidency.ucsb.edu/ ws/?pid=119039.

Trump, D. (2017a, March 20). Remarks at a 'Make America Great Again Rally' in Louisville, Kentucky. Online by Gerhard Peters and John T. Woolley, The American Presidency Project. Retrieved at www.presidency.ucsb.edu/ ws/?pid=123589.

Trump, D. (2017b, April 29). Remarks at a 'Make America Great Again Rally' in Harrisburg, Pennsylvania. Online by Gerhard Peters and John T. Woolley, The American Presidency Project. Retrieved at www.presidency.ucsb.edu/ ws/?pid=123899.

Trump, D. (2017c, June 28). Remarks during a meeting with immigration crime victims. Online by Gerhard Peters and John T. Woolley, The American Presidency Project. Retrieved at www.presidency.ucsb.edu/ws/?pid=126578.

Trump, D. (2017d, June 29). Statement on House passage of Kate's Law and No Sanctuary for Criminals Act. Online by Gerhard Peters and John T. Woolley, The American Presidency Project. Retrieved at www.presidency.ucsb.edu/ ws/?pid=126568. 


\section{Stephen J. Heidt}

Trump, D. (2017e, June 30). The president's weekly address. Online by Gerhard Peters and John T. Woolley, The American Presidency Project. Retrieved at www.presidency.ucsb.edu/ws/? pid=126616.

Vigil, T. R. (2015). Connecting with Constituents: Identification Building and Blocking in Contemporary National Convention Addresses. Lanham, MD: Lexington Books.

Weiser, M. E. (2008). Burke, War, Words: Rhetoricizing Dramatism. Columbia: The University of South Carolina Press. 


\section{Part IV}

\section{Journalistic Recovery \\ Post-Trump}

Lessons Learned 


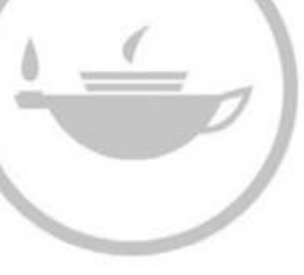

Taylor \& Francis Taylor \& Francis Group

http://taylorandfrancis.com 


\section{2 “Stop Overlooking Us!” Missed Intersections of Trump, Media, and Rural America}

\section{Al Cross}

As the election maps grew redder on the night of November 8, 2016, reflecting the rural landslide for Donald Trump, Chuck Todd of NBC News summed them up: "Rural America is basically screaming at us, 'Stop overlooking us!'” The network's gray eminence, Tom Brokaw, a son of rural South Dakota, chimed in: "What we underestimated was the depth of the anger." Todd's exclamation helped explain the result: There was a sense in rural America, borne out by statistics, of being left behind. Brokaw acknowledged that the presumed "enthusiasm gap" between supporters of Trump and Hillary Clinton in polls was bigger than the news media had reckoned - perhaps because relatively few reporters spent much time in rural areas, missing the depth of resentment against urban elites.

Looking at a map of Florida, Todd said Clinton had racked up the sort of margin in Tampa and Hillsborough County - usually the state's bellwether - that usually wins the state, but she lost the exurban and rural counties to the north and south by margins no one had expected. "That's the story of what's happening in rural America," Todd told audiences. The trend was replicated in other battleground states Trump carried (Scher, 2016). Other news outlets quickly deemed Trump's victory a rural one. The Wall Street Journal attributed Trump's win to "running up wide margins in rural and blue-collar parts of the country, while Clinton showed a weakened hold on the major, urban areas" (Zitner \& Overberg, 2016).

Nationally, one news media exit poll found that the smaller a place's population - grouped in nine types from the largest cities to thoroughly rural areas - the stronger its vote for Trump, with one very small exception that was within the margin of error (Kurtzleben, 2016). Dividing the exit-poll results three ways - urban, suburban, and rural or nonmetropolitan (for more, see Figure 12.1) - Trump won 62 percent of the rural vote and Clinton got only 34 percent (Huang, Jacoby, Strickland, \& Lai, 2016). That continued a rural trend for Republican presidential candidates, but was a smaller increase from 2012 than from 2008 to 2012. Between those elections, there was a 6-percentage-point Republican shift in the rural vote, giving Mitt Romney 59 percent. Rural turnout was down significantly in 2012, especially among Democrats, 


\section{Al Cross}

so that boosted Romney's percentage (Bishop \& Gallardo, 2012), but the shift in turnout and choice of candidate suggest there was a rural disaffection in 2012, and there is evidence to show it continued in 2016, providing fertile ground for Trump.

Each year from 2012 through 2016, fewer people lived in rural America than the year before. Each year, that set a record, because rural population had never declined before 2012 - except, of course, as a percentage of the total population (Marema \& Bishop, 2017). Rural America is losing population partly because it lost, during the Great Recession, jobs and businesses that have not come back. In mid-2016, employment in metropolitan areas was 4.8 percent higher than in the first quarter of 2008, the official start of the recession, but non-metro employment was 2.4 percent less (Hertz, 2017).

That decline that can be seen all over rural America, in closed factories, vacant storefronts, and streams of workers commuting to more urbanized places. In many places, there is also a social and cultural decline, indicated by above-average drug use and divorces, poor health, increasing mortality rates among middle-aged whites, and a workforce that shrinks as disability payments expand. Also in rural America, there is a documented resentment of urban elites, including the news media, reflecting a feeling that rural areas aren't getting a fair shake from government and its trade deals, and that they are looked down upon.

Onto this landscape strode a brash billionaire whose TV reality show and business career had made him a household name, offering few specifics but promising to "make America great again" and acting as a tribune for disaffected people who were hungry for a politician who

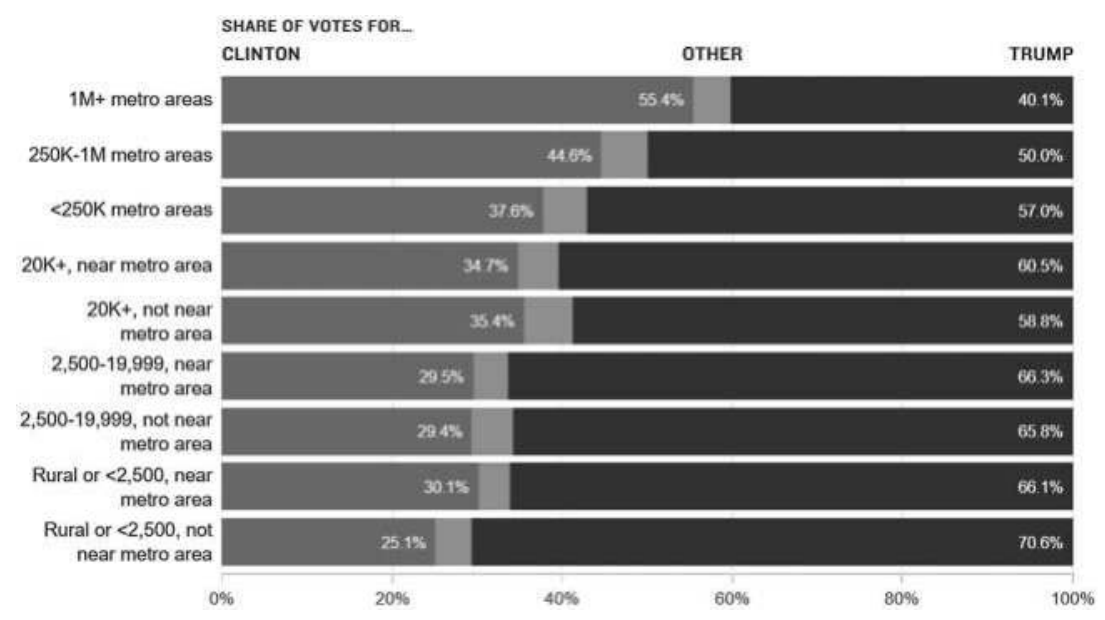

Figure 12.1 The 2016 vote by population area.

Source: NPR Analysis of AP data, using Rural-Urban Continuum Codes from the U.S. Department of Agriculture. Tyler Fisher and Alyson Hurt/NPR. Image edited by Carina Vo. 
would improve their daily lives. In 40 years of covering politics, I have never seen a candidate who generated the reaction, depth of support, and enthusiasm as Donald Trump, especially in rural areas. This chapter suggests and explores some of the reasons he was able to do that, with special attention to the role of journalism in creating Trump's rise.

\section{Meanings of Rural-Urban Divides}

"Rural" is a fuzzy term. Its easiest definition is "non-metropolitan," meaning a census tract outside a standard metropolitan statistical area (SMSA), which requires a core city of at least 50,000 people. But SMSAs are defined by commuting patterns, so many metro areas include census tracts that are defined as rural; about half the rural population of the United States is in metro areas. There are many other ways to define "rural," and federal agencies have more than two dozen, which range so widely that "The share of the U.S. population considered rural ranges from 17 to 49 percent depending on the definition used," the U.S. Department of Agriculture (USDA) explains (Cromartie \& Bucholz, 2008). "Rural and urban are multidimensional concepts, making clear-cut distinctions between the two difficult. Is population density the defining concern, or is it geographic isolation?" The USDA has a rural-urban continuum with nine categories for counties (Figure 12.2).

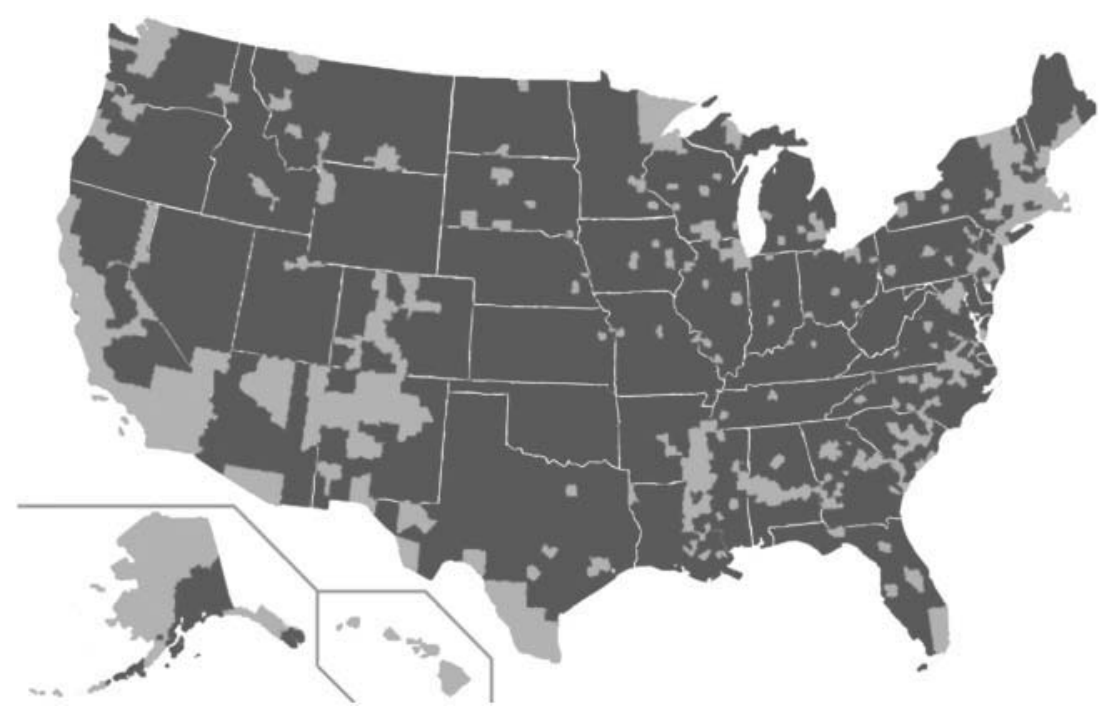

Figure 12.2 Darker shading of this map indicates counties that voted predominantly for Donald Trump in the 2016 U.S. presidential election. Lighter shading represents counties that voted predominantly for Hillary Clinton.

Source: Image by Carina Vo. Adapted from https://commons.wikimedia.org/wiki/File: United_States_presidential_election_results_by_county,_2016.svg. 


\section{Al Cross}

When The Washington Post and the Kaiser Family Foundation went looking for factors that drove Trump's victory, they used the CDCNCHS designations (National Center for Health Statistics, 2017) and classified as "rural" the three least urban categories: "small metropolitan," SMSAs of less than 250,000; "micropolitan," labor market areas centered on an urban cluster with 10,000 to 50,000 people; and "noncore," counties outside the metros or micros (Hamel, Wu \& Brodie, 2017). The three categories "are home to nearly one-quarter of the U.S. population," the Post explained (DelReal \& Clement, 2017). The non-metropolitan population was 16 percent in the 2010 Census, which classifies as "rural" any area outside an urbanized area of 50,000 or more, or outside an urban cluster of 2,500 or more (Ratcliffe, Burd, Holder, \& Fields, 2016).

The Post-Kaiser poll appears to be the most comprehensive, current public survey of the rural United States, broadly defined. Taken from April 13 to May 1, 2017, it surveyed 1,070 adults in counties it defined as rural, 303 in counties it defined as urban, and 307 in counties it defined as suburban. In exploring rural-urban differences, it helps to remember that some small metro areas are inherently rural in cultural terms, and rural disaffection is seen in areas that are classified as metropolitan. For example, Grand Junction, Colorado, population 58,000 , is surrounded by much uninhabited land on the Western Slope of the Rocky Mountains, and the place has a rural feel, culturally and economically.

\section{Examining the Rural Vote}

Donald Trump's margin among white voters without college degrees typically called "working class" and broadly representative of the rural vote - was 39 percentage points, 13 points better than Mitt Romey's in 2012 (Zitner \& Overberg, 2016). Hillary Clinton led in almost all polls until the election, but pollsters cautioned there was an "enthusiasm gap" that favored Trump, and that enthusiasm was on clear display in rural areas, and not so much in cities. A post-election study found that if Democratic turnout had been the same as in 2012, Clinton would have carried Pennsylvania, Michigan, and Wisconsin, and would have won the presidency (Fraga, McElwee, Rhodes, \& Schaffner, 2017).

In Wisconsin, the biggest Republican swings from 2012 to 2016 came in communities of 1,000 or less, and Trump won more than 500 towns and villages with a median population of 800 that had voted for Barack Obama (Gilbert, 2016). Nationally, rural turnout exceeded even the Trump campaign's expectations, and Clinton's urban turnout didn't meet her expectations. Rural areas, as defined by the American Communities Project (ACP), produced about half a million more votes than in 2012, even though some of the ACP's four rural categories had 


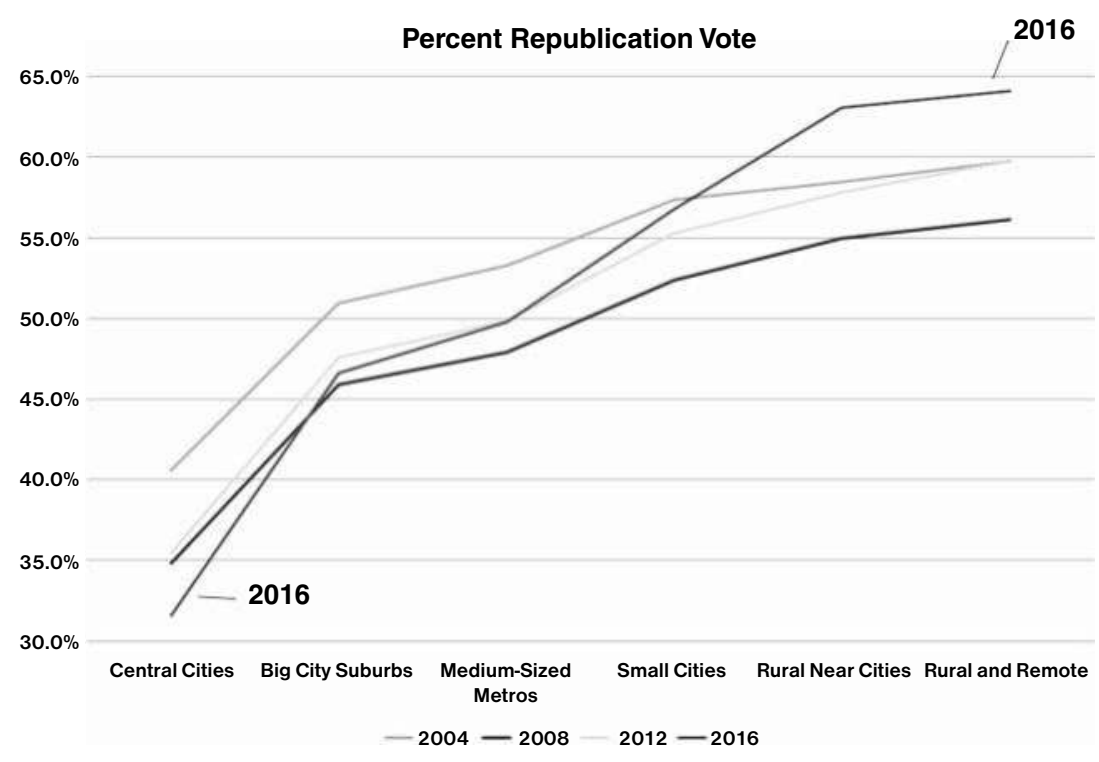

Figure 12.3 Percent Republican Vote. Source: Daily Yonder, The Center for Rural Strategies. Data by Bill Bishop. Imaged edited by Carina Vo.

lost population. Meanwhile, urban votes were down about 2.5 million (Todd, Murray, \& Dann, 2016).

Among counties with populations of 25,000 or less, 90 percent voted more Republican in 2016 than in 2004 when relatively rural President George W. Bush defeated urbanite Sen. John Kerry of Massachusetts (Gamio, 2016; for more, see Figure 12.3). In the key states of Michigan and Pennsylvania, Trump received, respectively, 67 and 77 percent of the rural vote (Marema \& Bishop, 2016c). ACP's broader definition of the rural vote said Trump got 57 percent of it in Michigan, 71 percent in Pennsylvania, and 63 percent in Wisconsin (Todd et al., 2016).

The 2016 election confirmed a strong rural-urban divide. It continued a trend, seen since 1976, of more "landslide counties," defined as those won by 20 percentage points or more. "It's more evidence that we are sorting ourselves into communities of like-minded Americans," wrote Bill Bishop, who first defined the trend in the 2008 book The Big Sort. The phenomenon showed a marked increase in 2016, most markedly in rural areas. University of Maryland political scientist James Gimpel told Bishop, who wrote about the phenomenon in 2016: "Some view this urban-rural split as a racial division, and there is an element of that present. But it also reflects other big cultural differences by occupation, affluence and religiously rooted values" (Bishop, 2016). 


\section{Al Cross}

\section{Recent Rural Economics: Setting the Stage for Trump}

In the Post-Kaiser poll mentioned earlier, 21 percent of rural respondents said a lack of employment was the biggest problem facing their communities. Only 6 and 7 percent of urban and suburban residents said that, respectively. Asked if they would "encourage young people in your community to stay in the area or leave for more opportunity elsewhere," 59 percent of rural residents said they would advise the latter and 32 percent said they would advise the former (Hamel et al., 2017). Such results mark a major change in rural parts of the United States. Rural America's workforce has been shrinking, partly because it had the fastest increase in disability rates from 2005 to 2015, accounting for 100 of the 102 counties where more than one in six working-age adults are on federal disability programs. The Washington Post reported:

The rise in disability has emerged as yet another indicator of a widening political, cultural and economic chasm between urban and rural America.... Majority-white counties voted overwhelmingly for Donald Trump, whose rhetoric of a rotting nation with vast joblessness often reflects lived experiences in these communities.

(McCoy, 2017)

Economic ills were also reflected in a reduced number of businesses. During the recovery, 59 percent of U.S. counties had a net loss of business establishments, far above the 37 percent and 17 percent recorded in the recoveries of 2002 to 2006 and 1992 to 1996, respectively. Counties of less than 100,000 population accounted for only 19 percent of net establishment creation and only 9 percent of net job creation. In the previous recoveries, they accounted for 20 and 27 percent of new jobs. And their net establishment growth rate from 2010 to 2014 was negative 1 percent (Economic Innovation Group, 2016). Simply put, the loss of business establishments eats away at the civic capital in small towns where local business people provide leadership and innovation. The shortage of civic capital is a problem in rural areas like south central Kentucky, where one lawyer and civic leader told me:

Now, if you want to go to college but want to live in Albany, or Greensburg, or Campbellsville to a lesser extent, you must teach (the last resort for many), go into medical or government service, or be one of a handful of professionals, and I tend to think that people who work for someone else can lose their motivation to be active and aggressive in local affairs and projects.... In other words, they work, collect a paycheck, and go home. The biggest drain is the loss of the local merchant/family business, thanks to Walmart, Dollar General, Lowe's, Home Depot, RiteAid, and Detroit's philosophy of bigger regional car dealers.

(D. Cross, email, May 27, 2017) 
Meanwhile, many traditional industries of rural America have been hurting. Mark Muro, a senior fellow at the Brookings Institution, told a New York Times contributing columnist in April 2017, "Rural America has been hammered by the end of the post-crisis commodity boom, and now there is precious little relief there: Agricultural prices are low, coal prices and automation are hammering coal country, natural-gas prices are suffering from glut conditions" (Edsall, 2017).

So, as rural Americans went to the polls in 2016, many of them saw their communities as economically stagnant and needing a boost. But their problems went deeper than economics.

\section{A New “Inner City,” Discovered Post-election}

What writer Thomas Edsall calls "the rural crisis" has been compounded, the Brookings Institution's Moro told him, by rising mortality rates among non-college-educated, middle-aged white people, often from opioid overdoses, alcohol, and suicide (Case \& Deaton, 2017). Broad problems of rural America were largely missed by national news media before the election. They were starkly documented by The Wall Street Journal in a May 2017 article titled "Rural America is the new 'inner city.'” According to the newspaper:

By many key measures of socioeconomic well-being, those charts have flipped. In terms of poverty, college attainment, teenage births, divorce, death rates from heart disease and cancer, reliance on federal disability insurance and male labor-force participation, rural counties now rank the worst among the four major U.S. population groupings (the others are big cities, suburbs and medium or small metro areas).

(Adamy \& Overberg, 2017)

As rural areas and small towns have fallen farther behind larger cities in wages as well as employment, the Journal wrote, "[m]any of the most ambitious young residents packed up and left, too.” It continued:

In 1980, the median age of people in small towns and big cities almost matched. Today, the median age in small towns is about 41 years - five years above the median in big cities.... Lawmakers from both parties concede they overlooked escalating small-town problems for years.

(Adamy \& Overberg, 2017)

Issues of health were also indicators of Trump support. The Economist, using the County Health Rankings developed at the University of Wisconsin, found a strong correlation between a county's heath and its vote for Trump: "The data suggest that the ill may have 


\section{Al Cross}

been particularly susceptible to Mr. Trump's message" (The Economist, 2016). Rural America's relatively poor health status has been exacerbated by the recent epidemic of opioid abuse and overdoses, a phenomenon that for years was disproportionately rural. In a spring 2016 series, building on academic research showing rising mortality rates among whites, especially the lesser educated (Case \& Deaton, 2015), The Washington Post explored how drugs and other problems had created "an urban-rural mortality gap" (Achenbach \& Keating, 2016).

Mortality rates from what the Post called "risky behaviors" seemed to be another factor that fueled Trump's rural vote. Compared with the vote for Mitt Romney in 2012, he did better "in counties with the highest drug, alcohol and suicide mortality rates," wrote Shannon Monnat of Penn State. She elaborated:

Much of this relationship is accounted for by economic distress and the proportion of working-class residents. Trump performed best in counties with high economic distress and a large working class. Drug, alcohol and suicide mortality rates are higher in counties with more economic distress and a larger working class. Many of the counties with high mortality rates where Trump did the best have experienced significant employment losses in manufacturing over the past several decades.

Political reporter James Hohmann (2016) of The Washington Post emphasized the drug angle, writing that Monnat's study "suggests a relationship between the opioid epidemic and support for Donald Trump." Citing counties in Ohio, West Virginia, and New Hampshire as examples in the study. Hohmann wrote:

Alcoholism, overdoses and suicide are symptoms of the deeper social decay that was caused by deindustrialization. This decay led to the fears and anxieties which Trump so effectively capitalized on... I saw this firsthand on the campaign trail all year, in countless interviews with folks who were down in the dumps and struggling to get ahead (or, quite frankly, just get by). Many supported Barack Obama eight years ago because they were desperate for hope and change. They're still desperate, and now they're hopeful Trump can bring the change they're looking for.

(Hohmann, 2016)

\section{Trump's Win with Race, Immigration, and Trade}

Feelings about economics, race, immigration, and trade were related among Trump voters. Analysis of data from the American National 
Election Studies found Trump voters were much more likely to agree that "Whites can't find jobs because employers are hiring people of color." About 10 percent of Trump voters said it was extremely likely, 17 percent said it was very likely, and more than 30 percent each said it was moderately or slightly likely. Among Trump voters who voted for Obama in 2012, the feeling was strong: 27 percent said it was very likely (McElwee, 2017). "While rural and urban Americans share some economic challenges, they frequently diverge on questions of culture and values," two Washington Post reporters wrote after analyzing the Post-Kaiser poll. "On few issues are they more at odds than immigration” (DelReal \& Clement, 2017).

Immigration was perhaps the most central plank in Trump's platform: a wall on the Mexican border, disparagement of Mexicans ("They're rapists"), and his call for a "total and complete shutdown of Muslims entering the United States until our country's representatives can figure out what is going on" (Johnson \& Weigel, 2015). Trump critics accused him of appealing to racial animus, noting that in the years just before his candidacy he was the most prominent supporter of the notion that Obama was born in Kenya. Whatever his motives, strategy or tactics, Trump clearly benefited from anti-immigration feelings and probably racial animus, research and election results indicate.

In Republican primaries and caucuses, rural Midwestern towns that have attracted many more immigrants - particularly Latinos - were Trump strongholds. A Wall Street Journal study used the diversity index, which measures the likelihood that any two people chosen at random in a county will have a different race or ethnicity. The researchers found that:

[i]n 88 percent of the rapidly diversifying counties, Latino population growth was the main driver. [Trump] took 73 percent of those where diversity at least doubled since 2000 , and 80 percent of those where the diversity index rose at least 150 percent.

(Adamy \& Overberg, 2016)

Research issued just before the election showed Trump polling well in racially isolated white communities, as defined by factoring the difference between the percentages of white population in their ZIP code and their commuting zone with the diversity index of the commuting zone divided by the diversity index of the ZIP code. This research, by members of The Gallup Organization, found that Trump voters appeared to be less motivated by economic concerns than by issues of race, ethnicity, and immigration. As the researchers wrote:

The results show mixed evidence that economic distress has motivated Trump support. His supporters are less educated and more 
likely to work in blue-collar occupations, but they earn relatively high household incomes and are no less likely to be unemployed or exposed to competition through trade or immigration. On the other hand, living in racially isolated communities with worse health outcomes, lower social mobility, less social capital, greater reliance on Social Security income and less reliance on capital income, predicts higher levels of Trump support.

(Rothwell \& Diego-Rosell, 2016, p. 1)

Indeed, research before and after the election concluded that aside from identification with the Republican Party, "fears about immigrants and cultural displacement were more powerful factors than economic concerns in predicting support for Trump among white working-class voters" (Cox, Lienesch, \& Jones, 2017). While this research did not break out rural counties, those are disproportionately populated by the white working class (51 percent compared to 22 percent in urban areas), and other research provides strong evidence of the importance of race and immigration in Trump's election. From Cox et al. (2017):

White working-class voters who say they often feel like a stranger in their own land and who believe the U.S. needs protecting against foreign influence were 3.5 times more likely to favor Trump than those who did not share these concerns... White working-class voters who favored deporting immigrants living in the country illegally were 3.3 times more likely to express a preference for Trump than those who did not... The effects of economic concerns were complex, with economic fatalism predicting support for Trump, but economic hardship predicting support for Clinton.

The researchers' 2012 poll found that 42 percent of rural voters said immigrants are a burden on the United States, while only 31 percent of suburbanites and 16 percent of urbanites said that. Majorities of the latter groups agreed with the statement that "[i]mmigrants today strengthen our country because of their hard work and talents," but only 48 percent of rural voters agreed with that statement. And when asked if "whites losing out due to preferences for blacks and Hispanics is a bigger problem" than the opposite, rural voters were evenly divided at 34 percent each, while only 25 percent of other voters agreed with the statement (Cox et al., 2017).

The same researchers also identified Trump's position on trade as a significant factor in his election:

One issue where white working-class Americans stand out from other Americans is free trade. Six in ten (60 percent) white working-class people say free-trade agreements with other countries are mostly 
harmful because they send jobs overseas and drive down wages, while one-third (33 percent) say they are mostly helpful because they open markets for U.S. companies and allow Americans to buy goods more cheaply.

(Cox et al., 2017)

Furthermore, in a post-election survey of four focus groups in Cincinnati, the researchers also found that "White working-class voters who said discrimination against whites is a serious problem were much more likely to favor Trump than those who did not (74 percent vs. 40 percent, respectively)" (Cox et al., 2017). Chris Clayton, who covers farm policy for DTN/The Progressive Farmer, though, said in a post-election television interview that race wasn't an issue with rural voters in the Midwest - he noted that Obama carried Iowa twice - but immigration was a huge issue: "People are concerned that they're losing their culture, somewhat" (NBC News Transcript, 2016).

\section{Cultural Differences, Religion, and Authoritarianism}

There is a sense in rural America that its culture is not only eroding, but is under attack by urbanites. Analyzing the Post-Kaiser poll, Post reporters wrote:

The political divide between rural and urban America is more cultural than it is economic, rooted in rural residents' deep misgivings about the nation's rapidly changing demographics, their sense that Christianity is under siege and their perception that the federal government caters most to the needs of people in big cities.

(DelReal \& Clement, 2017, p. 1)

The poll found that 68 percent of Americans it defined as rural said they have different values than people in big cities, and 41 percent said those values are very different. Among those the poll defined as urban, 48 percent said their values are different from those in rural areas and small towns, and only 18 percent said they were very different. To illustrate the difference, Post reporters chose this quote from a man who grew up in northern Wisconsin: "Being from a rural area, everyone looks out for each other. People, in my experience, in cities are not as compassionate toward their neighbor as people in rural parts." Overall, the poll reflected that 72 percent of rural respondents said their community was excellent or good "as a place where people look out for each other." Suburban and urban figures were 69 percent and 56 percent, respectively (DelReal \& Clement, 2017).

While rural Americans in the poll expressed "far more concern about jobs in their communities" than those in more populated areas, the poll 


\section{Al Cross}

found "that those concerns have little connection to support for Trump, a frequent theory to explain his rise in 2016," the reporters wrote (DelReal \& Clement, 2017). Adherents of the two parties view the world differently, and many Republicans do it through a religious lens, wrote the news director of a radio station in rural Knoxville, Iowa. Robert Leonard, a self-described liberal, said he had long struggled to understand how his conservative friends and neighbors in Marion County which gave more than 60 percent of its vote to Trump - "could think so differently from me." Then Leonard said he met J. C. Watts, a Baptist minister and former Republican congressman from rural Oklahoma. Leonard (2017) recalled Watts telling him in 2015:

The difference between Republicans and Democrats is that Republicans believe people are fundamentally bad, while Democrats see people as fundamentally good. We are born bad. We teach them how to be good. We become good by being reborn - born again. Democrats believe that we are born good, that we create God, not that he created us. If we are our own God, as the Democrats say, then we need to look at something else to blame when things go wrong, not us.

Leonard, writing on the op-ed page of The New York Times, continued:

Hearing Watts was an epiphany for me. No wonder Republicans and Democrats can't agree on things like gun control, regulations or the value of social programs. We live in different philosophical worlds, with different foundational principles.

Leonard also cited an increasing number of young conservatives in rural areas like his:

They are part of a growing movement in rural America that immerses many young people in a culture - not just conservative news outlets but also home and church environments - that emphasizes contemporary conservative values. It views liberals as loathsome, misinformed and weak, even dangerous... Rural conservatives feel that their world is under siege, and that Democrats are an enemy to be feared and loathed.

Trump won 81 percent of the votes of white Evangelical Christians despite being "an insulting, profane, thrice-married, megalomaniacal billionaire from New York City who can't even pronounce 2 Corinthians correctly," a Pentecostal pastor and former religion reporter in Kentucky wrote in his regular newspaper column (Prather, 2016). The pastor deduced a reason from an article by a Ph.D. candidate in political science 
at the University of Massachusetts-Amherst, who conducted a multistate poll among likely Republican primary voters and found that the strongest predictor of a vote for Trump was "authoritarian inclinations" (MacWilliams, 2016). The pastor-columnist wrote that Christianity has long been divided "between disciples who focus on authority and those who focus on freedom, between those driven and riven by fear, and those propelled by hope and joy." Identifying himself with the latter, the pastor continued:

In the Christian vernacular, it's a spiritual contest between "the Law" and "Grace." Christians who lean toward the Law are all about God's authority, the Bible's authority, church leaders' authority, men's authority, civil authority. They're the church's cops and prosecuting attorneys. They serve a stern God who lectures dryly from above, brooks no dissent and expects them to flog the daylights out of the dense and disobedient. They thrive on order... In a world overrun by brigands and terrorists, authoritarian Christians prefer a ban-bar-and-bomb president, even if he's a self-promoting heathen, over some milquetoast pseudo-Christian who embraces strangers and prefers negotiation to warfare.

(Prather, 2016)

Authoritarianism goes beyond religion to social class. White workingclass Americans are much more likely than those with a college degree to express a preference for authoritarian traits (Cox \& Jones, 2012). Using an authoritarian scale based on four questions about preferred childhood traits, a follow-up study found a similar gap: 64 percent of white working-class Americans have an authoritarian orientation, including 37 percent who were "high authoritarian." But only 39 percent of the white and college-educated had an authoritarian profile (Cox et al., 2017).

\section{Trump's Manna: The Rural Resentment of Elites}

When cultural differences get political, there is often resentment. Trump ran an anti-elites campaign that appealed to "all the places and voters that feel left behind in an increasingly diverse, post-industrial, and urbanized America," Ron Brownstein wrote for The Atlantic soon after the 2016 election. Relatedly, reporters on the Post-Kaiser poll wrote:

Disagreements between rural and urban America ultimately center on fairness: Who wins and loses in the new American economy, who deserves the most help in society and whether the federal government 
shows preferential treatment to certain types of people. President Trump's contentious, anti-immigrant rhetoric, for example, touched on many of the frustrations felt most acutely by rural Americans.

(DelReal \& Clement, 2017)

The poll also found that 56 percent of rural voters agreed with the statement that " $[t]$ he federal government does more to help people living in and around large cities," while 37 percent agreed with the statement that it treats "both urban and rural areas equally." While the federal government has many programs aimed at rural areas, the poll found rural voters are evenly split, three ways, on whether "[f]ederal government programs aimed at improving people's standard of living generally make things worse, make things better, or don't have much impact one way or the other."

Feelings that government is biased in favor of urban elites has been most comprehensively described in Wisconsin, a state that University of Wisconsin political scientist Katherine Cramer studied closely in her 2016 book, The Politics of Resentment: Rural Consciousness in Wisconsin and the Rise of Scott Walker. Walker is a conservative Republican governor who survived a recall election and ran briefly for president, himself, in the 2016 election.

In her book, Cramer (2016a) writes that she found puzzling the following phenomenon: "As income inequality has risen in the United States, low-income voters' preference for redistribution of income has moved ... in the same direction as that of high-income voters" (p. 4). Cramer writes that conversations with people in $27 \mathrm{Wisconsin} \mathrm{commu-}$ nities "enabled me to examine what it looks like when people who might benefit from more government instead prefer far less of it." Cramer then discovered "a significant rural-versus-urban divide and the powerful role of resentment" and that "...many rural residents exhibit an intense resentment against their urban counterparts" (p 5).

Through her work, Cramer discerned what she calls "rural consciousness," a rural identity that goes beyond place, to "a sense that decision-makers routinely ignore rural places and fail to give rural communities their fair share of resources, as well as a sense that rural folks are fundamentally different from urbanites in terms of lifestyles, value and work ethic," (p. 6) and that rural residents identify rural public employees as effectively urbanite. Cramer also noticed from her conversations that the Great Recession was a defining period for this rural-urban divide, and that it differed from the one Thomas Frank defined in his 2004 book, What's the Matter with Kansas?, which showed how social issues drove social conservatives (who are disproportionately rural) to vote against their economic interests.

Cramer's book presaged the identity politics that defined the 2016 election, with identity groups playing a stronger role than ever in the 
Clinton campaign, and the Trump vote being driven in large measure by a resentment of elites. "Perhaps issues are secondary to identities," Cramer writes (p. 7), stating a truth long known to professional politicians, pollsters, and other campaign consultants, but perhaps not so much to political scientists or even journalists. In an interview with The Guardian, Cramer said rural people believe they have less stressful, more meaningful lives with higher value on family and neighbor relationships than urbanites, but that they have become pop-culture caricatures, and their voices have been ignored in political debate (Quart, 2017). Cramer (2016b) wrote for the Post's "Monkey Cage" platform that rural Wisconsinites:

...resented that they were not getting respect. They perceived that city folks called people like them ignorant racists who could not figure out their own interests. To them, urban types just did not get small-town life - what people in those places value, the way they live, and the challenges they face. Onto this terrain trod Trump. And he found firm footing, just as Scott Walker did in his rise to the governorship. His message was basically this: "You are right. You are not getting your fair share. And you should be angry about it. You work hard, you are deserving, and yet you are not getting what you should. Instead, the people currently in charge are giving some people way more than they deserve. Elect me and I'll make American great again. I'll give you back what you deserve and a way of life you are sorely missing." For people who were feeling ignored, disrespected and overlooked by the urban elite, the Trump campaign had a strong appeal.

(Cramer, 2016b)

Wisconsin, especially its hilly southwest quadrant, had many counties that voted for Obama in 2012 and Trump in 2016. In Wisconsin, Iowa, and northwest Illinois, 64 counties, most of them rural, flipped that way. A typical county that flipped was Crawford County, Wisconsin, one of the state's poorest, which gave 53 percent of its vote to Obama in 2012 but 59 percent to Trump - the first time it had voted Republican since 1984. There, the owner of a struggling small-engine repair shop told The Associated Press:

If you ask anybody here, we'll all tell you the same thing: We're tired of living like this. I just hope we get the jobs back and the economy on its feet, so everybody can get a decent job and make a decent living, and have that chance at the American dream that's gone away over the past eight or ten years. I'm still optimistic. I hope I'm not wrong.

(Galofaro, 2017) 
In Kentucky, which went heavily for Trump after he won its caucuses by four points over Senator Ted Cruz, there was a sense that Trump might not be the best tribune, but that he at least is one. Sharon Burton, editor and publisher of the statewide farm newspaper and a local weekly, wrote after the election that Trump wasn't among her top three choices for the Republican Party nomination, but that:

I think Americans are saying that our nation is spending too much of its resources caring for others and not enough resources taking care of its own. We have approved trade agreements at the expense of jobs... I hope we can survive Trump. I hope we can thrive with Trump. Mostly, I think our elected officials have been awakened to the frustration Americans feel toward their inability to address the nation's problems. Frankly, I think the Trump vote was a message to the political elite, and the message is, clean up your act, or "You're fired."

(Burton, 2016)

Another anti-elite part of Trump's campaign was about the Second Amendment. Trump was "the most pro-gun-rights nominee in modern GOP history," a New Yorker who grew up shooting guns in Kentucky wrote for The New York Times in August (Hayes, 2016). Trump's alliance with the National Rifle Association (NRA), which spent more than $\$ 30$ million to elect him, helped make up for his two-to-one spending deficit with Clinton. The NRA's chief executive, Wayne LaPierre, told its convention: "It's up to us to speak up against the three most dangerous voices in America: academic elites, political elites and media elites. These are America's greatest domestic threats." In turn, The Nation reported, "LaPierre understands the gun-rights movement as a culture war first and a battle over gun laws second" (Zornick, 2017).

The NRA-stoked fears that the Second Amendment was at risk, and the resentment that rural people increasingly feel toward urban elites, were fuel for Trump's anti-elite campaign that appealed to many rural residents' sense that their ways of life were in jeopardy.

\section{Trump's Rural Campaign That Clinton Missed}

While the Republican share of the rural vote has increased steadily in recent years, the rural share of the electorate was decreasing, as metropolitan areas grew and rural population stagnated. So, when Trump put more emphasis in rural areas than Romney did, holding rallies in small towns that had never seen a live presidential candidate, traditional Republican strategists thought that was a mistake (Zitner \& Overberg, 2016). However, polls had failed to predict that a significant difference in turnout between rural and urban voters would help Trump. After 
the election, the Trump campaign revealed that it was pressing its rural turnout advantage. A campaign contractor told Politico that his analysis of early absentee voting in swing states showed signs of an "extremely high" rural turnout, which exceeded even those expectations (Evich, 2016).

Clinton's campaign, on the other hand, ignored Agriculture Secretary Tom Vilsack's advice to pay more attention to rural voters, Politico reported, adding, "One source said a staffer in Brooklyn was dedicated to rural outreach, but the assignment came just weeks before the election." Such a move was clearly too little, too late. "Rural communities are, almost by definition, not densely populated, so it requires much more time and effort to do outreach," Politico noted, quoting a young Democrat who exchanged candor for anonymity:

It's a tough slog. It's hard to speak to rural America. It's very regionally specific. It feels daunting. You have these wings of the party, progressives, and it's hard to talk to those people and people in rural America, and not seem like you're talking out of both sides of your mouth.

(Evich, 2016)

Unlike Trump, Clinton issued a relatively detailed rural-policy platform. Trump didn't need to. Instead, he tossed out a few issues with rural appeal, such as Environmental Protection Agency regulation of farms, but in the end, experienced rural observers said he won the day with his anti-elite pitch and capitalized on Clinton's clumsy comments about "deplorables" and shutting down coal mines. "What Trump did in rural areas was try to appeal to folks culturally," said Dee Davis of the Center for Rural Strategies. "Our ears are tuned to intonation. We think people are talking down to us. What ends up happening is that we don't focus on the policy - we focus on the tones, the references, the culture" (Evich, 2016).

Trump bet on rural audiences. In the last two weeks of the race, for instance, his campaign spent $\$ 150,000$ to buy every available spot on RFD-TV, a digital and satellite channel that reaches more than 46 million homes, largely in rural America. Clinton spent nothing with the Nashville-based channel, and its founder and president, Patrick Gottsch, blamed Clinton's loss on a lack of outreach in rural areas - in addition to economic malaise and resentment of elites among rural voters. As Gottsch told Variety, "You could really see it turning in the last couple of weeks. I couldn't find a woman in rural America who was going to vote for Secretary Clinton, and I found that odd" (Littleton, 2017).

Relatedly, the Trump campaign also made an unusual deal with Sinclair Broadcast Group, which at the time owned 173 TV stations, mostly in smaller markets and often requires affiliates to run news and 
commentary it sends them. In exchange for more access to Trump and his campaign, including extended interviews of Trump by local anchors, Sinclair sent the interviews to other stations to run without commentary. Sinclair reported that the Clinton campaign declined the same deal (Dawsey \& Gold, 2016).

\section{Trump's Rural Factor and News Coverage of It}

Trump's rural trend got noticed after March 1, "Super Tuesday," when he displayed major rural strength in winning 7 of 11 contests (Marema \& Bishop, 2016a). Clinton also did well in rural areas that day, but low turnout in rural areas signaled trouble ahead (Marema \& Bishop, 2016b). On March 14, with plenty of primary and caucus results in hand to match with 10 demographic variables, The New York Times identified the trend, but only on a blog:

The places where Trump has done well cut across many of the usual fault lines of American politics - North and South, liberal and conservative, rural and suburban. What they have in common is that they have largely missed the generation-long transition of the U.S. away from manufacturing and into a diverse, information-driven economy deeply intertwined with the rest of the world.

(Irwin \& Katz, 2016)

In early summer, writers for The Washington Post saw the rural-driven United Kingdom vote to leave the European Union as a signal that some of the same forces were at work in both nation (Balz, 2016). Other news coverage around that time made clear that rural America was Trump's most solid base (Cross, 2016). By and large, however, major news media seemed to think it wouldn't make a difference. They were out of touch. Journalist Neal Gabler (2016) wrote on the Bill Moyers website, for example, that "pontificating political reporters and pundits ... got it all wrong about Donald Trump and Bernie Sanders." Gabler issued a near-indictment:

It is very possible that reporters - especially the Big Feet - dismissed Trump and Sanders because journalists couldn't possibly fathom the deep, seething, often unspoken economic discontent that afflicts so many Americans and that has helped fuel both the Trump and Sanders movements. They couldn't fathom it, perhaps, because they haven't experienced it.

Campaign reporters are generally in the air, on buses, and at events, not driving on the roads, where they would have noticed the prevalence of Trump yard signs and the dearth of support for Clinton, and where 
they could have interviewed voters as the Post's James Hohmann did. While there were occasional reports of Trump's rural potential, they were often limited to niche publications, such as the newsletter AgriPulse, in which Pennsylvania's Democratic agriculture secretary said the state was up for grabs and rural voters would decide it (Brasher, 2016).

Nearer to the election, a few journalists reported on rural unhappiness and suggested it could make a difference in states such as Iowa and Wisconsin, where more than 30 percent of the population is rural. The USA Today Network had reporters from its regional newspapers do stories from eight key states, and one reporter from The Des Moines Register did a story on rural Iowa that said Trump's "picture of a limping nation in need of more radical change" was "a message that seems tailor-made for rural America." The report carried a prescient headline: "If people in any place yearn to be made great again, it's in rural America" (Hardy, 2016). Aside from agriculture, though, the article offered no data showing broad, bad, rural trends.

Two days before the election, Nate Cohn (2016) of The New York Times was quite prescient, but again, only on one of the paper's blogs, where he wrote:

Trump's strength among the white working class gives him a real chance at victory. He could win enough Electoral College votes without winning the popular vote, through narrow victories in Midwestern and Northeastern battlegrounds like Wisconsin and New Hampshire, where Democrats depend on support among white working-class voters. Mr. Trump's strength with that group could even be enough for him to win Florida.

At a local level, campaign coverage by rural news media was driven by largely by local events, and the most rural places, served by weekly newspapers, got relatively little coverage from them, as usual, for weeklies. A small handful of rural dailies (reportedly, six) endorsed Trump, including the Hillsboro (Ohio) Times-Gazette, whose editor-publisher, Gary Abernathy, now does two columns a month for The Washington Post, which wanted a "Trump country" voice in its op-ed section. Asked in an interview if people in Highland County have a sense that rural America isn't getting a fair shake, he told me:

I just think rural America feels very much looked down on from the east and west coast elitists, including the media ... so when Trump picks on the media and talks about fake news - the media's not popular, especially in rural America - there's a natural anti-big-media feeling in this part of the country.

(G. Abernathy, telephone interview, July 28, 2017) 
Dissatisfaction with the news media is common, but is more pronounced in rural areas. The Post-Kaiser poll asked, "How much do you think the news media respects people like you?" and found that only 37 percent of rural people responded with "a lot" or "some," while 47 percent of other Americans said so (Hamel et al., 2017). Repeated news-media references to Trump polling well among both rural and lesser-educated voters may have stirred anti-media feelings, said Clayton of The Progressive Farmer. "I think they took some of these things that were said over and over throughout the last four, five months of the campaign, also very personally themselves," Chuck Todd said Clayton's remark stung him, because " $[w]$ hen we would say these things, it was an academic exercise. But the minute he said it, I was, like, 'Oh, my, my late father would've kicked me in the rear for that." New York Times columnist David Brooks said he had a mea culpa watching Clayton, because:

people with college degrees voted very differently than people with, with high school degrees, but.... when you actually don't have a college degree, you hear, 'Oh, they think I'm stupid.' I'm guilty of that because I use that shorthand too. And you saw so much sense of moral injury when you went around the Trump world.

(NBC News, 2016)

Trump's media criticism has filtered down to community journalism, rural and small-town, editors have reported (Cross, 2017).

\section{News Media's Post-Election Response}

After the election, some major news organizations realized they had missed what was going on in rural and small-town America. They didn't pay enough attention to rural areas, NBC's Chuck Todd said, creating "a trust problem in rural America" (Mullin, 2017). Todd also said major news outlets downplayed Clinton's rural unpopularity to avoid appearing sexist:

What we all knew as reporters, and didn't fully deliver, was how hated the Clintons were in the heartland.... If we sort of were straight-up honest and blunt about, "Hey, do we understand the level of hatred that's out there?," and you know, all the "Hillary for Prison" signs that are out there, we certainly would have at least made the viewer know, "Hey, you know, she's not well-liked in some places in this country in ways that's times 10 when it comes to Trump."

In reaction to the election result and feelings that they had missed something, some major news outlets responded. The New York Times, for instance, moved some national reporters around the country to better 
grasp the people and factors that elected Trump. The Reuters wire service named Los Angeles correspondent Tim Reid a political correspondent covering the Midwest and Southeast. The Washington Post started "About US," news and commentary about the nation's changing demographics. And, the Post and NPR each named beat reporters to explore the rural-urban divide.

But what of rural news media? Soon after Trump took office, Civitas Media, which owns dozens of weeklies and small dailies, placed a button on its papers' sites to display his tweets and news about him. "It wasn't an endorsement of Trump; it's just that Trump communicates so much by tweet," said Gary Abernathy, whose Ohio paper was owned by Civitas at the time. Abernathy said the idea came from an information-technology professional at company headquarters (Interview, July 28, 2017).

It has been unusual to find such a national political link on the websites of rural newspapers, but Trump has changed many things. Just as he has driven up ratings of national news channels, now he is a traffic builder for rural papers.

\section{Conclusion: Rural Under Trump}

When it comes to issues, as president, Trump has not always played to his rural base. Two central positions of Trump's campaign, favoring more restrictions on immigration and repeal of the North American Free Trade Agreement, were averse to American agriculture, but he moderated those positions (Clayton, 2017). On several other issues, however, the Trump administration had made moves not to the advantage of rural Americans, such as supporting bills that experts said would lead to less access to health care in rural areas, including hospital closures (Bynum, Santana, \& Foody, 2017), withdrawing regulations to limit predation by for-profit colleges, which is more prevalent in rural areas (Strauss, 2017), and proposing a budget that rural interests called "a slap in the face" (Wise \& Lowry, 2017) that included cuts in such programs as Amtrak, the Appalachian Regional Commission, public broadcasting, and farm programs. Trump's new Federal Communications Commission chair has talked much about extending high-speed internet to rural areas, but the president proposed cutting air-route subsidies that help rural airports stay open, and those interests also criticized his plan to privatize air-traffic control.

Beyond issues, though, what impact does having Donald Trump as president have on rural America's daily life? In Grand Junction, Colorado, "[h]is tone has a deeper influence than his policies," making life more contentious, the New Yorker said in a subhead on a story titled, "How Trump is Transforming Rural America" (Hessler, 2017). And what of rural journalism? The focus on Trump, driven by social media, has hurt smaller daily newspapers that focus on local and state news, 


\section{Al Cross}

said Tom Rosenstiel, a Brookings Institution fellow who founded and ran for 16 years the Project for Excellence in Journalism. Quoted in The Guardian, Rosenstiel says:

The real crisis in American journalism is not technological, it's geographic. The crisis is that local journalism is shrinking. I wouldn't say it's dying but it's the most threatened. There is so much more national and international news available to people, it has changed what people are interested in. [During the election] I saw clear and distinct evidence that people were consuming more national news and less local.

(McLaughlin, 2017)

As president, Trump keeps the focus on himself, leaving less room in our news diet for detailed examination of issues. His election made urban-oriented media pay more attention to the rural problems that helped elect him, but the issues of rural America rarely get sustained attention from national news outlets. Trump's policies toward that major segment of his base should be fodder for accountability journalism, both urban and rural.

\section{References}

Achenbach, J., \& Keating, J. (2016, April 10). A new divide in American death. The Washington Post. Retrieved at www.washingtonpost.com/sf/ national/2016/04/10/a-new-divide-in-american-death.

Adamy, J., \& Overberg, P. (2016, November 1). Places most unsettled by rapid demographic change are drawn to Donald Trump. The Wall Street Journal. Retrieved at www.wsj.com/articles/places-most-unsettled-by-rapid-demographicchange-go-for-donald-trump-1478010940.

Adamy, J., \& Overberg, P. (2017, May 28). Rural America is the new 'inner city.' The Wall Street Journal. Retrieved at www.wsj.com/articles/rural-americais-the-new-inner-city-1495817008.

Balz, D. (2016, June 24). As Britain decided its future, striking parallels with U.S. political debates emerged. The Washington Post. Retrieved at www. washingtonpost.com/world/as-britain-decides-its-future-striking-parallelswith-us-political-debates-emerge/2016/06/23/8cca4dd2-38e5-11e6-af021df55f0c77ff_story.html.

Bishop, B. (2016, November 21). Caught in a landslide - county-level voting shows increased sorting. Daily Yonder. www.dailyyonder.com/caught-in-alandslide-county-level-voting-shows-increased-sorting/2016/11/21/16361.

Bishop, B., \& Gallardo, R. (2012, November 29). Rural voter turnout drops $12 \%$ in 2012. Daily Yonder. Retrieved at www.dailyyonder.com/ rural-voter-turnout-drops-18-2012/2012/11/29/5514.

Brasher, P. (2016, July 28). Which presidential candidate can capture Pennsylvania's rural vote. Agri-Pulse. www.agri-pulse.com/Which-presidentialcandidate-can-capture-Pennsylvanias-rural-vote-07272016.asp. 
Brownstein, R. (2016, November). How the election revealed the divide between city and country. The Atlantic. www.theatlantic.com/politics/archive/ 2016/11/clinton-trump-city-country-divide/507902.

Burton, S. (2016, November 10). Surviving Trump. Adair County Community Voice, p. 4.

Bynum, R., Santana, R., \& Foody, K. (2017, March 20). Already in peril, rural hospitals unsure on health-care bill. The Associated Press. Retrieved at www. apnews.com/4b31ebe4a64e4b06aeced0589f28081c.

Case, A., \& Deaton, A. (2015, September 17). Rising morbidity and mortality in midlife among white non-Hispanic Americans in the 21st Century. Proceedings of the National Academy of Sciences, 112(49), 15078-15083.

Case, A., \& Deaton, A. (2017, March 17). Mortality and morbidity in the 21st Century. Brookings Papers on Economic Activity. Retrieved at www.brookings. edu/wp-content/uploads/2017/03/6_casedeaton.pdf.

Clayton, C. (2017, May 19). 'Do no harm' urged in trade talks. The Progressive Farmer. Retrieved at www.dtnpf.com/agriculture/web/ag/news/article/ 2017/05/19/ag-groups-stress-need-keep-current.

Cohn, N. (2016, November 6). Why the election is close, and what Trump and Obama have in common. The New York Times. Retrieved at www.nytimes. com/2016/11/07/upshot/why-the-election-is-close-and-what-trump-andobama-have-in-common.html.

Cox, D., \& Jones, R. (2012, September 20). Beyond guns and god: Understanding the complexities of the white working class in America. Public Religion Research Institute. Retrieved at www.prri.org/research/race-class-culturesurvey-2012.

Cox, D., Lienesch, R., \& Jones, R. (2017, May 9). Fears of cultural displacement pushed the white working class to Trump. Public Religion Research Institute and The Atlantic. Retrieved at www.prri.org/research/white-working-classattitudes-economy-trade-immigration-election-donald-trump.

Cramer, K. (2016a). The Politics of Resentment. Chicago, IL: University of Chicago Press.

Cramer, K. (2016b, November 13). How rural resentment helps explain the surprising victory of Donald Trump. The Washington Post. Retrieved at www.washingtonpost.com/news/monkey-cage/wp/2016/11/13/how-ruralresentment-helps-explain-the-surprising-victory-of-donald-trump.

Cromartie, J., \& Bucholz, S. (2008, June 1). Defining the 'rural' in rural America. Economic Research Service, U.S. Department of Agriculture. Retrieved atwww. ers.usda.gov/amber-waves/2008/june/defining-the-rural-in-rural-america.

Cross, A. (2016, July 5). Economic and cultural issues, and Donald Trump, make rural America 'redder' than ever. The Rural Blog. Retrieved at http:// irjci.blogspot.com/2016/07/economic-and-cultural-issues-and-donald.html.

Cross, A. (2017, July 6). President Trump's criticism of the news media affects local journalists, some of them say. The Rural Blog. Retrieved at http://irjci. blogspot.com/2017/07/president-trumps-criticism-of-news.html.

Dawsey, J., \& Gold, H. (2016, December 16). Kushner: We struck a deal with Sinclair for straighter coverage. Politico. Retrieved at www.politico.com/ story/2016/12/trump-campaign-sinclair-broadcasting-jared-kushner-232764.

DelReal, J., \& Clement, S. (2017, June 17). Rural divide. The Washington Post. Retrieved at www.washingtonpost.com/graphics/2017/national/rural-america/? utm_term=.fb345b16f003. 


\section{Al Cross}

Economic Innovation Group. (2016, May). The new map of economic growth and recovery. Retrieved at http://eig.org/wp-content/uploads/2016/05/recoverygrowthreport.pdf.

The Economist. (2016, November 19). Illness as indicator. The Economist. Retrieved at www.economist.com/blogs/graphicdetail/2016/11/daily-chart-13.

Edsall, T. (2017, April 13). Reaching out to the voters the left behind. The New York Times. Retrieved at www.nytimes.com/2017/04/13/opinion/reachingout-to-the-voters-the-left-left-behind.html.

Evich, H. (2016, November 13). Revenge of the rural voter. Politico. Retrieved at www.politico.com/story/2016/11/hillary-clinton-rural-voters-trump-231266.

Fraga, B., McElwee, S., Rhodes, J., \& Schaffner, B. (2017, May 8). Why did Trump win? More whites - and fewer blacks - actually voted. The Washington Post. Retrieved at www.washingtonpost.com/news/monkey-cage/wp/2017/05/08/whydid-trump-win-more-whites-and-fewer-blacks-than-normal-actually-voted.

Gabler, N. (2016, April 23). The mainstream media's big disconnect: Why they don't get middle America. Moyers \& Co. Retrieved at http://billmoyers.com/story/the-mainstream-medias-big-disconnect-why-they-dont-getmiddle-america.

Galofaro, C. (2017, February 7). Voters await economic revival in a part of pro-Trump America. The Associated Press. Retrieved at https://apnews. com/9b6824edd567411db1c4853c5ad0778f.

Gamio, L. (2016, November 17). Urban and rural America are becoming increasingly polarized. The Washington Post. Retrieved at www.washingtonpost. com/graphics/politics/2016-election/urban-rural-vote-swing.

Gilbert, C., (2016, December 4). As dust settled, parts of political map scrambled. Milwaukee Journal Sentinel. Retrieved at www.jsonline.com/ story/news/blogs/wisconsin-voter/2016/12/04/dust-settles-partspolitical-map-scrambled/94834650.

Hamel, L., Wu, B., \& Brodie, M. (2017, July 16). The health care views and experiences of rural Americans. Kaiser Family Foundation. Retrieved at http:// files.kff.org/attachment/Report-The-Health-Care-Views-and-Experiencesof-Rural-Americans.

Hardy, K. (2016, October 2). Yearning to be great again, rural Iowa turns to Trump. Des Moines Register. Retrieved at www.desmoinesregister.com/story/ news/politics/2016/10/02/people-place-yearn-made-great-rural-america/ 91328484.

Hayes, D. (2016, August 20). Donald Trump takes aim. The New York Times. Retrieved at www.nytimes.com/2016/08/21/opinion/campaign-stops/donaldtrump-takes-aim.html.

Hertz, T. (2017, July 6). Rural employment and unemployment. Economic Research Service, U.S. Department of Agriculture. Retrieved at www. ers.usda.gov/topics/rural-economy-population/employment-education/ rural-employment-and-unemployment.

Hessler, P. (2017, July 24). How Trump is transforming rural America. The New Yorker. Retrieved at www.newyorker.com/magazine/2017/07/24/how-trumpis-transforming-rural-america.

Hohmann, J. (2016, December 9). Trump over-performed the most in counties with the highest drug, alcohol and suicide mortality rates. The Washington Post. https://www.washingtonpost.com/news/powerpost/paloma/ daily-202/2016/12/09/daily-202-trump-over-performed-the-most-in-counties- 
with-the-highest-drug-alcohol-and-suicide-mortality-rates/584a2a59e9b69b7e $58 \mathrm{e} 45 \mathrm{f} 2 \mathrm{e} /$ ?utm_term $=.7 \mathrm{f} 65 \mathrm{e} 6 \mathrm{c} 47 \mathrm{cc} 3$.

Huang, J., Jacoby, S., Strickland, M., \& Lai, K. (2016, November 8). Election 2016: Exit polls. The New York Times. Retrieved at www.nytimes.com/interactive/2016/11/08/us/politics/election-exit-polls.html.

Irwin, N., \& Katz, J. (2016, March 12). The geography of Trumpism. The New York Times. Retrieved at https://mobile.nytimes.com/2016/03/13/upshot/thegeography-of-trumpism.html.

Johnson, J., \& Weigel, D. (2015, December 8). Trump calls for 'total' ban on Muslims entering United States. The Washington Post. Retrieved at www. washingtonpost.com/politics/2015/12/07/e56266f6-9d2b-11e5-87281af6af208198_story.html.

Kurtzleben, D. (2016, November 14). Rural voters played a big part in helping TrumpdefeatClinton.NPR.Retrievedatwww.npr.org/2016/11/14/501737150/ rural-voters-played-a-big-part-in-helping-trump-defeat-clinton.

Leonard, R. (2017, January 5). Why rural America voted for Trump. The New York Times. Retrieved at www.nytimes.com/2017/01/05/opinion/why-ruralamerica-voted-for-trump.html.

Littleton, C. (2017, January 19). Network aimed at rural America speaks for population that feels underserved by the media. Variety. Retrieved at http:// variety.com/2017/tv/news/rfd-tv-rural-america-1201963217.

MacWilliams, M. (2016, January 17). The one weird trait that predicts whether you're a Trump supporter. Politico. Retrieved at www.politico.com/magazine/ story/2016/01/donald-trump-2016-authoritarian-213533.

Marema, T., \& Bishop, B. (2016a, March 2). Trump gets help from a fragmented field and rural voters. Daily Yonder. Retrieved at www.dailyyonder.com/ trump-gets-help-from-a-fragmented-field-and-rural-voters/2016/03/02/11806.

Marema, T., \& Bishop, B. (2016b, March 2). Rural South breaks strongly for Clinton.Daily Yonder.Retrieved atwww.dailyyonder.com/rural-south-breaksstrongly-for-clinton/2016/03/02/11788.

Marema, T., \& Bishop, B. (2016c, November 9). In three key states, both rural and urban voters part of Trump's victory. Daily Yonder. Retrieved at www. dailyyonder.com/in-three-key-states-both-rural-and-urban-voters-part-oftrumps-victory/2016/11/09/16158.

Marema, T., \& Bishop, B. (2017, April 14). Rural population drops for fifth straight year, but other patterns are changing. Daily Yonder. Retrieved at www.dailyyonder.com/rural-population-drops-fifth-straight-year/2017/04/14/18850.

McCoy, T. (2017, March 30). Disabled, or just desperate? The Washington Post. Retrieved at www.washingtonpost.com/sf/local/2017/03/30/disabledor-just-desperate.

McElwee, S. (2017, April 13). How racism helped Trump and halts progressive policy. Demos. Retrieved at www.demos.org/blog/4/13/17/how-racismhelped-trump-halts-progressive-policy.

McLaughlin, K. (2017, January 30). The big journalism void: 'The real crisis is not technological, it's geographic.' The Guardian. Retrieved at www.theguardian.com/media/2017/jan/30/the-big-journalism-void-thereal-crisis-is-not-technological-its-geographic.

Monnat, S. (2016, December 4). Depths of despair and support for Trump in the 2016 presidential election. The Pennsylvania State University. Retrieved at http://aese.psu.edu/directory/smm67/Election16.pdf. 


\section{Al Cross}

Mullin, B. (2017, January 19). NBC's Chuck Todd: 'I don't like being a political prop.' Poynter. www.poynter.org/2017/nbcs-chuck-todd-i-dont-like-beinga-political-prop/445896.

National Center for Health Statistics. (2017, June 1). NCHS Urban-Rural classification scheme for counties. Centers for Disease Control and Prevention, National Center for Health Statistics. Retrieved at www.cdc.gov/nchs/data access/urban_rural.htm.

NBC News. (2016, November 13). Meet The Press. Retrieved at www.nbcnews. com/meet-the-press/meet-press-november-13-2016-n683211.

Prather, P. (2016, January 30). The mystery of Christians' support for Donald Trump is solved. Lexington Herald-Leader. Retrieved at www.kentucky. com/living/religion/paul-prather/article57553638.html.

Quart, A. (2017, June 22). Why a lot of Americans resent the cultured 'New York City elite.' The Guardian. Retrieved at www.theguardian.com/us-news/2017/ jun/22/new-york-city-elite-american-resentment.

Ratcliffe, M., Burd, C., Holder, K., \& Fields, A. (2016, December). Defining Rural at the U.S. Bureau. U.S. Department of Commerce. Retrieved at www2.census.gov/geo/pdfs/reference/ua/Defining_Rural.pdf.

Rothwell, J., \& Diego-Rosell, P. (2016, November 2). Explaining nationalist political views: The case of Donald Trump. Social Science Research Network. Retrieved at https://papers.ssrn.com/sol3/papers.cfm?abstract_id=2822059.

Scher, B. (2016, December 16). Doing the math on election 2016. Our Future. Retrieved at https://ourfuture.org/20161216/what-happened-doing-the-mathon-election-2016.

Strauss, V. (2017, June 14). Betsy DeVos delays 2 Obama-era rules designed to protect students from predatory for-profit colleges. The Washington Post. Retrieved at www.washingtonpost.com/news/answer-sheet/wp/2017/06/14/ betsy-devos-delays-2-obama-era-rules-designed-to-protect-students-frompredatory-for-profit-colleges.

Todd, C., Murray, M., \& Dann, C. (2016, November 16). Trump's rough transition start. NBC News. Retrieved at www.nbcnews.com/politics/first-read/ trump-s-rough-transition-start-n684651.

Wise, L., \& Lowry, B. (2017, May 23). Trump's budget seen as 'slap in the face' to rural voters who elected him. McClatchy Washington Bureau. Retrieved at www.mcclatchydc.com/news/politics-government/congress/article 152224902.html.

Zitner, A., \& Overberg, P. (2016, November 9). Rural vote fuels Trump; Clinton loses urban grip. The Wall Street Journal. Retrieved at www.wsj.com/articles/ rural-vote-helps-donald-trump-as-hillary-clinton-holds-cities-1478664251.

Zornick, G. (2017, July 17). Trump and the NRA. The Nation, p. 13. 


\title{
13 Reeducation or Rejuvenation? Trump's Influence on News Interest and Literacy
}

\author{
Fred Blevens
}

If John Locke, John Stuart Mill, Matthew Arnold, and Alexis de Tocqueville could reassess the philosophical and cultural constructs of our mature version of America, their narratives certainly would echo longago debates about religion, secularism, journalism, politics, and our advance from "transatlantic" connections to a global society.

From hand presses to Twitter handles, the communication platforms have changed dramatically over 240 years, but the debates over moral conduct, democracy, and journalism have changed very little. Even so, our apparent capitulation to political, cultural, and social incivility during the nascent era of Donald J. Trump deserves some retracing of the paths that took us from highbrow gentility to the depths of lowbrow discourse. The devolution, in fact, has brought us full circle to the original era of cultural chaos that ensued after the nation's founding.

We begin with early America, a period when journalism and democracy both were on a new frontier. Like the rest of the awkwardly evolving culture of the New World, both struggled with transatlantic influences of foreign observers and philosophers as well as the privileged aristocrats who were seeking the same oppressive form of Victorianism that gripped the mother country. Once rampaging literacy set journalism free, the evolving culture stumbled through 200 years of battles over control, from those who saw citizens as subservient to state and industry and those who propounded individual and natural rights. Through all the echoes, there's been a successful search for a middle ground, a place of coexistence, until Trump as journalism and democracy enter one of the most stressed and tested periods in history.

\section{The Power of High Art, Journalism, and Politics in Early America}

In that earlier world, American culture was rooted in birthright, wealth, preferred positions in social and political roles, and "distinct ideological traditions.” Joan Shelley Rubin (1992) writes: 


\section{Fred Blevens}

At its base was a model of cultivation forged by the gentry, who, in the eighteenth century, populated the "great houses" of the Eastern seaboard. The ideal combined the British legacy of insistence on fine manners, proper speech, and elegance with the demand, in the American setting, for moral substance.

(pp. 1-2)

The male-only cultivators of culture were the same elite who led colonies and maintained expensive lifestyles fueled by commercial success. Even so, within that backdrop was a developing press that could only be described as a new cultural and social frontier. Journalists of the day were autonomous, often worked alone, and required a primitive hand press to communicate news of the day to the few who could read. Colonial printers, in fact, operated much like modern-day bloggers, untethered by the yoke of professionalism or the need for formal journalism education. Particularly in the run-up to the Revolution, journalists were partisan and often incendiary.

By the late 1700s, coincidentally, the values of the market began to disengage from high art and culture. Artists, artisans, and journalists critiqued industrialization and, after the turn of the nineteenth century, "genuine cultivation" became inextricably tied to inward virtue:

The democratization of property ownership and the rise of republicanism enhanced the prospect that Americans of more modest means could attain the respectability formerly limited to the aristocracy. Although the relationship between money and "the best people" remained ambiguous, many writers of popular advice manuals stressed that genteel conduct did not depend on financial resources.

(Rubin, 1992, pp. 2-3)

By the middle of the nineteenth century, the sphere of gentility belonged to those who were well educated and who were leaders in politics and culture. The journalists of the day seldom populated those ranks, though their partisanship paved the way for power partnerships in both arenas. The journalists, instead, were marching toward conventions that eschewed the disruption so critical to the colonial press and embraced the origins of structured corporate media.

Fueling this evolving gentility was American Victorianism, which differed from the British version but still had roots in Matthew Arnold and John Stuart Mill. Described by David D. Hall (1975) as "a transatlantic network or 'connection'” (p. 561), the bond had profound influences on politics, culture, journalism, and antebellum reform. As America struggled feverishly to build its own literary canon, the European Enlightenment and its intelligentsia provided the fodder for an emerging group of American intellectuals who shaped "a new cultural system in which 
the university replaced the church and the serious writer found means of reaching a wide audience" (p. 562). As Hall writes: "Innovative in their thinking, the members of the Victorian connection formed a bridge between the world of the past and the world of the modern" (p. 563).

Hall (1975) writes that Mill went modern by turning to Unitarianism, "a halfway house on the road away from orthodoxy. For others, Unitarianism provided an example of how to survive as an avant-garde surrounded by a hostile culture" (p. 563). Under this Unitarian cover, Mill and his fellow Philosophical Radicals found a free religion, one that offered them a formidable position from which they could launch social reform and mount opposition to the ruling aristocracy. Mill's philosophy, in turn, became the rallying cry for the connection, a safe harbor of liberalism that "was tempered by awareness of the dangers inherent in democracy, and by a preference for experience over any doctrinaire scheme" (p. 566). Rubin (1992) writes: "One's obligation, they preached, was to engage in character development - which they also called 'a progressive purification of the personality' - in order to do honor to divine creation" (p. 5).

Such thinking had its roots in the Age of Reason and John Locke's "natural rights" for the rational person. Locke, like Mill and the Philosophical Radicals, took a minimalist position on religion. Mill and his cohorts often said the Church of England's interpretations of the Bible were far more strident in doctrine than in truth and that the evangelical revival, in concert with the aristocracy, was obstructing social reform (Hall, 1975). There were similarities, too, in their thoughts on the differences between the rights and correlative power of the corporate body (state or industry) and the individual. Locke Scholar John Yolton (1985) writes:

Society takes many forms: family, tribe, club, religious and civic groups. Locke's individual is always in a social context. Indeed, without the context of a nurturing society to care for and treat children as persons, an essential condition for making those transitions from man to moral man and then to person would be lacking.

In Locke's mind, as well as in Enlightenment philosophy, moral rules at most were synonymous with laws of nature or at least with "derivations from those laws." In other words, "to be moral is to be rational" (Yolton, 1985, p. 35). It is a safe leap in faith, then, to Locke's basic premise that liberty was a natural right, that individuals created governments and granted certain rights to those corporate structures. Rousseau, and to some extent Hobbes, contended that individuals were subservient to the state, that they surrendered power to the corporate structure. Locke's postulates stressed reason in the conduct of all affairs, personal and 


\section{Fred Blevens}

civil. In that context, the person is socialized by what Yolton (1985) describes as a two-stage process: from childhood to personhood and from the community of mankind to the community of political society.

In the first, the child is brought by tutors and parents into the world of virtuous habits (i.e., reading the Bible) and, thereby, the stages of reason and personhood. This is an important difference in Locke's thinking as opposed to Rousseau or Hobbes. Locke posited that persons develop into society with reason as the compass; Hobbes thought development was directed by something (or, perhaps, someone) other than the reason associated with the laws of nature. Thus, Yolton writes:

The move into a civil society is a move from individualism to corporatism. Even those persons who perform official duties in the civil society do so as public persons, not as private individuals. This corporation of the body politic, of the will of the community, of the living organism which is the total society, is Locke's way of protecting that aspect of individualism which is most important for him: the person and the extension of the person, all his property (life, health, labor, estates, and possessions).

(pp. 52-53)

In other words, the laws of nature are not allowed to clash with the laws of a specific community: individual first, corporate individual second. Above all, the natural rights for the individual extend only to the limit of harm to others. Virtues, Locke said, bring morality to the behavior of persons, and it is the development into moral person that allows for rationality to dictate what is right and wrong in the all-important personal deliberations of ethical decision-making. Liberty, even as important as Locke considered it to the individual, carried responsibility and accountability. It was concern for those Lockean precepts that was occupying the minds of the American Victorians in the mid-1800s as they went about constructing their culture. The battle, Hall (1975) tells us, was lonely:

The very reason for being of the Victorian connection was to afford relief to an avant-garde isolated in the midst of Anglo-American culture. These secular intellectuals despised demagogues, hotgospelers, aristocrats, and entrepreneurs. Those groups hated them in return, and since cultural power lay predominantly with the evangelicals and the entrepreneurs, making a living and being heard were not always easy matters for many in the Victorian connection.

Even so, the cohorts from both sides of the Atlantic bonded frequently on American shores as English visitors came abroad to witness the 
democratic experiment. It was Mill, however, who read of Alexis de Tocqueville's visit in 1831 and was "startled" by the evil possibilities lurking behind majority rule. Mill was turning his distrust toward public opinion, adopting a comparatively elitist remedy for the "mediocrity" of the masses by prescribing a "political system in which power rested with the 'few' who were trained to use their minds and had the courage to stand apart from the masses" (Hall, 1975, pp. 568-569).

\section{Tocqueville, Journalism, and the Emerging American Mass}

Tocqueville, who journeyed to America at the age of 26, published his first volume of social and political observations in 1835, the second in 1840. Tocqueville's view of America, which predated the growth of the rail network and the industrial revolution, was one of French aristocracy, one that caught glimpses of the overachieving frontiersmen but ignored the issue of slavery. He was viewing the American press in the early throes of the Penny Press, an era that recognized growing literacy among the masses and removed the press from its dependence on funding from political factions. His was a look primarily at the northern half of America, a position that allowed him to foretell America's love of mass production, the coming age of mechanization, and the dulling effects of horizontal integration on the American working class. He even predicted the future population of the country and its Cold War relationship with Russia.

Like Locke, Tocqueville believed that liberty was a natural right, but its preservation was in working with, not against, modernity. Although he points to its scars and blemishes, America's version of democracy was seen as evidence that the form can be tamed and directed toward social equality. He, too, found comfort in the protection afforded by the Founding Fathers and in individual citizenship tempered by the restraints of religion as social cement. Tocqueville was impressed by the separation of church and state, a Lockean influence on the Founding Fathers; in fact, he said, the division tended to strengthen religion because there was, in theory, a free marketplace of spiritual ideas competing for members and strength. In many ways, his ideas of education and political liberty in America ran parallel to Locke's socialization theory (Tocqueville, 1964, pp. 136-140). He writes:

Political associations may therefore be considered as large free schools, where all members of the community go to learn the general theory of association.... Thus it is by the enjoyment of a dangerous freedom that the Americans learn the art of rendering the dangers of freedom less formidable. 


\section{Fred Blevens}

The essential tool to this organizational life, Tocqueville said, was a free press. Through the press, people found others of like mind, providing the nation with a network of associations - some private, some public making use of public communication for recruitment and action. Specifically, he saw the press as a primary construct of the organization of churches, hospitals, and colleges as well as social crusades such as the one for temperance. It was a social tool, long before sociologists proved it quantitatively so a hundred years later (pp. 67-71): "A newspaper," Tocqueville writes, "is an adviser who does not require to be sought, but who comes to his own accord, and talks to you briefly every day of the common weal, without distracting you from your private affairs" (p. 69).

That passage also goes to the heart of Tocqueville's endorsement of the Lockean separation of what was public and private for the individual:

The Americans, who mingle so readily in their political assemblies and courts of justice, are wont on the contrary to carefully separate into small distinct circles, in order to indulge by themselves in the enjoyments of private life.

So it was that political liberty subsumed much of Tocqueville's thought. He was concerned, however, that America was risking a passing into egocentricity as individuals withdrew into "virtuous materialism," and he feared there would be attempts to establish an aristocracy that would doom the democratic enterprise. If there were to be a saving grace, he thought, it would be the "small distinct circles" forming in society. Tocqueville thought these groups embodied the freedom of association that he found attractive to his countrymen, whom he was trying to convince that societies were best when they were made, not born (Tocqueville, 1964, pp. 251-253). What is most interesting, however, to considerations of the press and other democratic institutions, is Tocqueville's paradox of freedom and equality. Democracies, he posited, have a "natural taste" for freedom and will go to relative extremes to protect it. But, he wrote:

...for equality, their passion is ardent, insatiable, incessant, invincible; they call for equality in freedom; and if they cannot obtain that, they still call for equality in slavery. They will endure poverty, servitude, barbarism; but they will not endure aristocracy.

(Tocqueville, 1964, p. 171)

Tocqueville believed the press also was important for its "watchdog" role on government, but he was somewhat unimpressed with the behavior (such as a lack of manners) displayed by American journalists, who seemed to spend too much time prying into private lives and 
sensationalizing the news (pp. 169-171). Tocqueville found news coverage to be superficial, the papers lacking the French tradition of discourse among the intelligentsia. He found journalists to be rather coarse and "vulgar," and, in many ways, he foretold the devolving of individualism into loneliness and the "mass," uninspired crowd mentality of the following two centuries. As Tocqueville wrote:

The more equal the conditions of men become, and the less strong men individually are, the more easily do they give way to the current of the multitude, and the more difficult is it for them to adhere by themselves to an opinion which the multitude discard.

Contrast that passage, then, with Mill's from On Liberty (1956):

At present, individuals are lost in the crowd. In politics it is almost a triviality to say that public opinion now rules the world. The only power deserving the name is that of the masses.... Their thinking is done for them by men much like themselves, addressing them or speaking in their name, on the spur of the moment, through the newspapers.

By this time, however, the American Victorians had established their commitment "to teaching the public at large in the confidence that they could reach the middle class and direct its energies into the right path" (Hall, 1975, p. 571). That, of course, required "moral and social force" springing from truth in the independent, printed word. Hall (1975) notes, "Not unlike the Puritan ministry, they assumed that the act of sincere speech or writing would secure them the authority needed to accomplish their agenda of reform" (p. 579). But, like at many points to follow, the pulp press, spurred by the Penny Press revolution of the 1830s and 1840 s, was presenting a formidable barrier to using the message of high culture to educate the masses.

Most Americans who could read had become hooked on cheap fiction and newspapers, which, critics claimed, had diminished in quality as their daily price dropped from around a nickel to one penny (Hall, 1975, p. 571). The Victorians optimistically envisaged a social ladder in which the mass readership would ascend to yet higher and higher levels of journalism. The public library system turned to free circulation, and some authors, including Mill, republished their works in cheaper, more accessible volumes. All were wishful ventures, Hall (1975) wrote:

At no point in time, however, did the marketplace lose its power to reduce mass literacy to the lowest level, and it was left to utopian 


\section{Fred Blevens}

writers such as Edward Bellamy to envisage a new cultural order in which serious literature was the only fare desired.

Even so, events such as the Great Moon Hoax, perpetrated by Benjamin Day's New York Sun, showed how the mass marketing of newspapers was changing journalism radically. Unlike the incendiary colonial pamphleteers who incited fervor in the name of revolution, the publishers were creating false narratives to draw in more and more readers. Depending now on advertising rather than subscriptions and political largesse, it was important to boost revenue through dominant circulation numbers. The Moon Hoax, a series of stories that appeared over six days in August 1835, claimed that astronomers had used high-powered telescopes to find bizarre creatures roaming the landscape of the moon (Goodman, 2008). The 6-cent papers first scoffed at the series, then began writing about it as the Sun stole thousands of readers from their subscriber roles. Day's stunt was intended to draw readers, for sure, but the underlying effect was to show that the elitist press really was no more ethical than the penny papers. Other circulation-busting hoaxes would follow, including the Balloon Hoax, authored by Edgar Allan Poe, one of the greatest hoax creators in journalism history (Edemariam, 2009; McLeod, 2014).

By this time, the professional practice of journalism had advanced from an autonomous act to group work. Reporters and editors worked together in corporatized newsrooms where structure and hierarchy emerged. Journalists no longer had to invest in equipment, which was provided by publishers at a fixed business address. Despite the spectacular bouts with "fake news," newspapers, as corporate entities, were moving steadily toward more professionalism and rigor, providing a stabilizing force in society.

Despite their failure at uplifting American culture through the news press, people in the Victorian connection did establish a press of its kind, one dedicated to educating a public, even if that public was nothing more than like-minded gentility. In America, their magazines included Putnam's (1853), Atlantic Monthly (1857), The Nation (1865), and The Galaxy (1866). In England, they included Saturday Review (1855) and The Fortnightly Review (1865). Hall (1975) writes:

Millite in spirit, these intellectuals turned to journalism in order to accomplish two related reforms. The first was to defeat sectarianism by declaring the truth. The second was to present 'the best,' whether in art, politics or literature, and thereby overcome the blight of mediocrity. The higher journalism of these Victorians was synonymous, therefore, with their goal of imparting discipline. 
In the mid-1800s, the intelligentsia had established four avenues for disseminating the cultural goods of gentility and refinement. By exploiting the venues of the theater and opera houses, the rapidly expanding publishing business, the arena of higher education, and the public lecture system, genteel society was able to further solidify its footing as the dominant influence in society (Rubin, 1992, pp. 15-22). By the mid-nineteenth century, then, the division of high and low journalism had developed into a sort of culture war during a period that Daniel Walker Howe (1975) has described as probably the most crucial transformation in U.S. history. The components were emergent, he writes: “...industrialization, knowledge explosion, immigration and vast population growth, urbanization, geographical expansion, changing race relationships, and the greatest armed conflict on American soil” (p. 507).

A key difference between the two components of the transatlantic Victorian connection was the absence in America of a powerful aristocracy. Without the repression from above so prevalent in Britain, the Americans could experience their developing culture "more intensely." Howe (1975) notes, however, that the American Victorians faced a unique and difficult challenge in the increasing cultural diversity carried in by immigrants.

During the last half of the nineteenth century, the developing American intelligentsia was spreading the gospel of gentility and civility in their roles as cultural educators. Most of its members were born into familial and social environments consistent with the development of middlebrow culture. Writes Howe (1975):

Increasingly, in the closing decades of the nineteenth century, as public life became everywhere more fragmented, the concept of culture took on hierarchical connotations along the lines of Matthew Arnold's definition of culture - "the best that has been thought and known in the world ... the study and pursuit of perfection."

It was Arnold's name and its descriptive derivation, Arnoldian, that symbolized a movement in which those in a position to judge would classify and disseminate "the best" in an overall mission to spread the cultural wealth. This approach, according to Lawrence W. Levine (1988), consequently helped develop the cultural division of "high" and "low" brows, the former originating in the 1880s "to describe intellectual or aesthetic superiority," and the latter coming "shortly after 1900 to mean someone or something neither 'highly intellectual' or 'aesthetically refined'" (p. 223). The labels were "derived from the phrenological terms 'highbrowed' and 'lowbrowed,' which were prominently featured in the nineteenth-century practice of determining racial types and intelligence by measuring cranial shapes and capacities" (Levine, 1988, p. 223). 


\section{Fred Blevens}

It was only a matter of a few years before when Van Wyck Brooks adapted the high and low constructs to social criticism, "condemning the division in American life between effete guardians of art and practical, vulgar materialists" (Rubin, 1992, p. iii). Brooks "looked in vain for a 'genial middle ground' on which cultural life could thrive," but it was not until 1933 when Margaret Widdemar, writing in The Saturday Review, identified a middlebrow as "the men and women, fairly civilized, fairly literate, who support the critics and lecturers and publishers by purchasing their wares" (Rubin, 1992, p. xi). Writes Rubin: "Located between the 'tabloid addict class' and the 'tiny group of intellectuals,' middlebrows represented, in Widdemer's view, simply the majority reader" (p. 5).

Arnold, the cultural icon of everything highbrow, bridged the Victorian connection and came to be as popular in America as in his home country of Britain. His "best" phrase became the pledge of allegiance of the literary moral elite who saw as their mission the cultivation and protection of democracy through the diffusion of knowledge.

\section{Advertising and Etiquette after Victoria}

In the transformation of American culture during and immediately following the reign of Victoria, the country was bringing forth the first and second generations of cultural practitioners, those whose spells would fall, consciously or unconsciously, under the dominant cultural influence of Victorianism.

In Fables of Abundance, cultural historian T.J. Jackson Lears (1994) asserts that the profession of advertising presented objects of material abundance as symbols of status and social progress. By doing so, he says, the practice bolstered the nation's puritanical alienation from the magic and carnivalesque hedonism of the pre-industrial age. That set the stage for the subsequent professionalization of a twentieth-century industry that replaced nineteenth-century commodity culture of con men and patent medicine peddlers with scientific-managerial approaches (Lears, 1994). It also was the new engine for journalism, having displaced political funding as the prime source of revenue for newspapers.

The difference, however, ran much deeper. In the nineteenth century, "the rhetoric of control often originated outside the advertising business, issuing from ministers and other moralists" (Lears, 1994, p. 5). As such, it is the final phase in the rise of the isolated self. The duality, Lears writes, spilled over onto consumers, the advertiser's target.

The development of a sophisticated advertising structure from its raucous early stages ran nearly parallel to the rise of civility as a Victorian construct to replace the crudeness associated with the early days of the republic. John Kasson (1990) posits that the switch began in the late eighteenth century and was not complete until the late nineteenth century (pp. 3-7). The process was propelled by a proliferation of etiquette 
books after the revolution of the printed word in the 1830s, roughly the correlative period of journalism's Penny Press. Kasson, in fact, follows that course diligently through a tracing of civility from Benjamin Franklin's early American claim that virtue was primarily a matter of appearance. Franklin "learned to become an expert manager of impressions; first an apprentice, then a master of self-effacement as a means of advancement," Kasson writes (p. 7). In Autobiography, Kasson writes that Franklin established himself an expert on human relations within the emerging capitalist market structure, which already was transforming cultural emphasis from "character" to "personality" and restructuring society's simple rank-order titles (pp. 30-33).

Indeed, for individuals, etiquette became a commodity bought and sold in manuals and tracts published specifically for the genteel middle class. Rubin (1992) writes:

...officially, gentility denoted moral and intellectual qualities that could never be bought. Yet middle-class Americans in the midnineteenth century scrambled to purchase replicas of luxury items (carpets, upholstery, watches) in order to mimic the upper echelons of society.

Making it so accessible, however, created the unavoidable cultural collision of manners and morals, multiple identities or masks, and the core of character so important to the rational constructs of the Enlightenment. Etiquette manuals even presented methods to ferret the charlatans from the genuine types. The center of cultural and social tension and, therefore, the heart of Kasson's (1990) argument seems to be in what he calls a "crisis of social representation" (p 116). Individual privacy, "under new pressures in the brashly inquisitive metropolis and subject to the development of new technologies of intrusion and publicity," had become "sacred" (p. 117). Kasson explains, quoting one writer from the 1800s:

Bluntly formulated, the social command became something very different from the Golden Rule - the Iron Rule of Public Civility, an etiquette of laissez-faire for a capitalist culture: "All rights, and the essence of true politeness, are contained in the homely maxim, MIND YOUR OWN BUSINESS; which means, by a pretty evident implication, that you are to let your neighbor's business alone."

(pp. 116-117, emphasis in original)

By essentially embracing propriety, privacy, and property as the components of ideal conduct, Americans "accepted the boundless market as the model for all exchange, social as well as economic, in urban capitalist society" (p. 117). This "instability of identity" abandoned any prospects 


\section{Fred Blevens}

for friendly encounters or fellowship, forcing those who ventured out to act as if they were in private; etiquette advisers "urged a strategy of self-discipline to the end of self-effacement" (p. 117).

Civility was not limited to evasive public behavior in the tension-filled culture of the democratic market's perpetual motion machine. Middleclass people needed guidance on how to serve a dinner in the spirit of self-restraint and how to attend a concert without drawing the ire of the conductor. On the surface, these appear to be superfluous matters, left to light and secondary treatment in historical texts. Yet, Kasson shows the "increasingly exacting rules governing social conduct and personal expression represented efforts to defend that 'solid, predictable core of self'" (p. 257). As with the paradoxes so common to Victorian constructs, Kasson writes, "such rules pursued a logic that led not toward unity but toward fragmentation" (p. 259). Public and private spheres became more and more segmented, increasing the pressures on individual self.

Kasson notes that the dawning of a new century, as consumer culture broke the barriers into other class structures, brought exponential increases in tension. The advisers were attempting to balance democracy with upward mobility in a fairly homogenous, demanding middle class and to find "equilibrium" in self-denial and consumption (p. 259). These were the macro-issues of the day, embodied in the habits and rules of everyday life. No solution has been found since the vulgar early days of the republic, Kasson concludes (pp. 257-260), but there hardly exists a monumental point in history - particularly in the 1900s - that has not taken blame for the decline of civility in American culture.

\section{Mending a Broken World}

Attempts by antimodernists and the intelligentsia to overhaul Victorian culture at the turn of the twentieth century found accommodation and further rationalization in the emerging social sciences, positivism, romanticism, and collectivism. First Amendment scholar Jay Jensen (1962) says the consequences were dramatic as classical liberal tradition was supplanted by a convergence of those forces that had "begun a wrecking job" on the "theories of reality, social order, law, politics, the self, freedom, and of freedom of the press" (p. 78). If Victorianism had a strong manifestation in the twentieth century, its last vestiges probably were in the rapid rise and fall of the Ku Klux Klan of the 1920s. Stanley Coben (1991) contends that the emergence of this radical organization was a catalyst in the strengthening of an opposing genteel intelligentsia that was adjusting and evolving with the mechanization of society and culture.

Coben, who, like many others, believes that remnants of Victorianism remain etched in contemporary society, lists four developments that fed the growth of this emergent twentieth-century American cultural gentry. First, there was an increase in the number of intellectuals; second, funds 
for research and training were on the upswing, especially for intellectual dissent; third, "intellectual creativity," prompted by "new ideas" in the arts and sciences; and fourth, like-minded leaders rose to positions to mediate between intellectuals and funding sources (pp. 48-49).

Warren I. Susman (1984) says that, during the early decades of the century, culture itself broke apart, perhaps coming very close to the destruction sought by the anti-Puritan movement two decades before (pp. 120-125). Susman, though crediting the emergence of knowledge as important to the cause, was less likely to attribute so much weight to an intelligentsia. His interpretation focused on the demands wrought by what he called "the new world of abundance-leisure-consumer-pleasure orientation" (p. 121). More and more of the workforce was moving into professional and clerical positions, spending more time and spending more money on items for which advertisers created a need or desire.

Strict sexual codes were being replaced by the Freudian ethic and the birth-control movement was being tested as a possible solution to a looming labor market crisis. During the 1920s, heart attack outpaced tuberculosis as the chief killer of Americans. Discovery of the vitamin brought a change in the American diet. Motion pictures developed into middle-class entertainment, and Ford "reordered" American factories. But, of course, all of this exacerbated the persistent, generations-old paradox of community and self. Susman writes:

Community and the advantages of joining a host of organizations were somehow considered an admirable way to sustain individualism. It was important to read all the right books, but since he didn't know what they might be, special services were organized for him; a digest so he didn't have to read all the magazines and, in 1926, a Book-of-the-Month Club.

The decade for Susman (1984) was one of "knowledge and experience and effective use of both. It spent considerable time, energy and talent in trying to mend what had become apparent to many, each often in his own way, as a broken world" (p. 120). It was a time, too, of expanding techniques of communicating knowledge through movies, huge mass circulation newspapers, as well as intellectual reference works. In the end, however, the most troubling aspect of the decade was its inability to pick up the pieces of the fractured culture:

But all of this was part of what amounted to a major debate in which in one way or another the newer mass society of the 1920s, increasingly self-conscious about itself individually and collectively, faced a time of crisis in its world view.

(Susman, 1984, p. 121) 
Some during the decade suggested it was time for a new Enlightenment, while others, following on a familiar path in history, countered with a new Romanticism. Paraphrasing James Burnham, Susman (1984) writes that "those who sought to keep others from destroying the fabric of civilized order devised newer and more effective techniques for the manipulation of men" (p. 91). The most serious of the new developments, Coben (1991) asserts, involved a revitalized Klan, which "emerged as the most visible and powerful guardian of Victorianism during the 1920s" (p. 136; for more see Coben, 1991, pp. 136-157).

Having emerged as a national movement, the Klan was composed of mostly middle-class workers who attended mainstream churches. Although racism remained an important component of Klan philosophy, a new focus was being placed on Americanism, reflecting the decade's tendency toward xenophobia. In the 1930s, the "overcivilization" that Lears attributed to the motives of the early century antimodernists came flush with the development of what became known as "cultural lag." As Susman (1984) explains: "Mankind has entered a new phase of human progress - a time in which the acquisition of new implements of power too swiftly outruns the necessary adjustment of habits and ideas to novel conditions created by their use" (p. 91).

In fact, Susman contends that the battle between "culture" and "civilization" was at its most intense during the 1930s, when the very idea of culture became community-based (pp. 153-156). That is, culture no longer could be considered the "best" in any Arnoldian sense; rather, it was "all the things that a group of people inhabiting a common geographical area do, the ways they do things and the ways they think and feel about things, their material tools and their values and symbols" (p. 154).

\section{How Cultural Divisions Polarized America and Rewarded Donald Trump}

By the middle of the twentieth century, the stage was set for what would happen two and a half decades into the twenty-first century. The preservation of American gentility was a masterful fail, as was the idea that the descendants of the Victorian era could merge high and low culture into some sort of a middlebrow, a stratum populated by a majority that could understand the day's news and make sound decisions in carrying out their civic duties and responsibilities, what many would describe today as news literacy. What have emerged with great rapidity under President Donald Trump are echoes of the past bouts with xenophobia, fear of "the other," immigration, and the enabling (or re-enabling) of Nazism, the Klan, and white nationalism.

Communication scholars Stanley J. Baran and Dennis K. Davis (1995) have posited that such midcentury efforts fell victim to a classic midcult battle over powerful media effects. One group sought "technocratic 
control" while another hoped to head off the elements that threatened to "undermine high culture with trivial forms of entertainment" (p. 75). Under this formula, the authors write, Walter Lippmann would be a leader of the technocrat group, which believes:

the threat posed by (subversive) propaganda was so great that information gathering and transmission had to be placed under the control of wise persons - technocrats who could be trusted to act in the public interest. These technocrats would be highly trained and have professional values and skills that guaranteed that media content would serve socially valuable purposes, for example, stopping the spread of totalitarianism.

Baran and Davis give no name to their other category, but what they define is what we might call cultural guardians, those people who see their cultural mission as one designed to bring the Arnoldian "best" into every living room in America. Baran and Davis say these guardians see the media as the democratic adult education tools with which all citizens can make the correct decisions about their government and society:

In both perspectives, media are viewed as a powerful, subversive force that must be brought under the control of wise people, those who can be trusted to act in the public interest. But who should be trusted to censor media? Social scientists? Religious leaders? The military? The police? Congress? The Federal Communications Commission? ... they couldn't reach consensus on who should do it. Media practitioners were able to negotiate compromises by pointing out the dangers of regulation and by offering to engage in selfregulation - to become socially responsible.

In his own rather mean-spirited way, Dwight Macdonald (1960) warned us about strange bedfellows and what can happen from unprotected cultural intercourse. Despite his elitist and arrogant scoldings of anything at the center or low end of the culture spectrum, Macdonald's 1960 analysis of "midcult" contained an optimistic compromise that, in retrospect, was more enduring than all philosophies and theories put forth in this discourse. He proposed using the cultural diversity inherent in fragmented society to the benefit of all classes of cultural consumers.

With remarkable foresight, he posited that pay television, nothing more than a linear extension of cable as a mere figment of entrepreneurial imagination, could be an answer for those who "would rather pay for bread than get stones for nothing." In the end, Macdonald wrote, the fight is a foolish one: "Which came first, the chicken or the egg, the 


\section{Fred Blevens}

mass demand or its satisfaction (and further stimulation), is a question as academic as it is unanswerable. The engine is reciprocating and shows no signs of running down" (p. 620).

Rubin (1992) asserts that the engine, in fact, may be the power plant driving "what H.G. Wells called the 'race between education and catastrophe" and that the dissipation of the middlebrow leaves American culture naked to further corruption:

Given the widespread disregard for the possession of liberal learning, the popularizers ... appear themselves apostles of a shattered faith. More broadly, while the market remains capable of disseminating the importance of reading - not long ago a cereal box urged breakfast eaters to discover the world of books and libraries - its capacity to subvert genuine understanding and autonomy survives and flourishes as well.

When Donald Trump announced his campaign for president, the table was set perfectly. It is doubtful that he or anyone on his campaign staff were aware that reaching a democratic mean becomes impossible when the middle ground has succumbed to the exponential burgeoning of tenants occupying what avant-garde scholars consider America's cultural slums. Voter awareness, long in a downward spiral, may have hit an all-time low, with many voters not caring enough to vote and certainly not concerned enough to discern, recognize, or accept fact from fiction.

Trump's victory presents a significant challenge to America's news literacy movement, which has been working more than a decade on strategies to help citizens navigate the overpopulated and polluted news agenda. Grounded in those theories and observations of fledgling democracy by Locke, Mill, Tocqueville, and others, the still nascent movement has been struggling with volume or meeting the enormous need to educate the populace whose profile seems close to some of the horrific possibilities feared by those early great thinkers. The more information in the marketplace, the more difficult to ferret good from bad, truth from falsity, real from fake.

Candidates and presidents often have dust-ups with journalists, mostly resulting from conflicted goals over message. Politicians seek to get their version of events or facts into stories while journalists are trying to get a version of events or facts that are closest to the truth. What makes Donald Trump's relationship with the press different is his almost daily use of Twitter to make claims (many false) and attack individuals and groups (many times viciously), all under the guise of creating a modern-day form of what Teddy Roosevelt branded the Bully Pulpit.

In Roosevelt's world, that meant giving speeches to communicate directly to the populace, avoiding filtration by journalists. Trump claims 
his version does the same, but it does not provide the context to inform and educate the citizenry. Roosevelt clearly could do that, even if his message wasn't always a version of truth preferable to journalists. With Trump, the 140-character blasts often are incendiary and false, contradictory or misleading at the very least (PolitiFact, 2017).

Just as earlier technocrats and cultural guardians dreamed of an educable public in need of wizened guidance, today's news literacy proponents are constantly adding layers on the curriculum of news literacy education. Through programs such as the News Literacy Project and the Center for News Literacy, the race is on to get ahead of the galloping culture of "alternative facts," Trump's claims that mainstream media proffer "fake news," and opinion-making based neither in fact nor on the goal of truth.

Howard Schneider (2017), the Pulitzer-winning former editor of New York Newsday who founded the School of Journalism at Stony Brook University, said the shift away from the advertising-based news model created by the Penny Press is putting increasing pressures on media literacy education by driving a new partisan press era. This one, however, is not propelled by political factions as was the case in the early republic, but by cable news, "which continues to have a disproportionate impact on public perceptions of journalistic credibility and fairness," he said in an email interview with the author. The solution, he writes, is "to bake into news literacy education an understanding of why and how the business model is driving change as a cautionary tale." With that context, then, students and citizens need to be equipped with what he calls "evergreen concepts":

Always check the who says, the source of the news and whether there is an ideological dog in the fight; make sure to distinguish between news and opinion; rely on multiple news sources; and finally, yes, there is such a thing as unbiased journalism, and how to spot it.

Schneider, however, worries that the Trump presidency is further eroding public confidence in news media. "Trump didn't start the fire," he writes, "but as president he has become a major accelerant." In almost every meeting Schneider attends - with teachers, students, or the general public - participants are quick to attack media credibility. "The implications are profound for a democracy," he writes. "I worry less now about whether people will believe 'fake news,' and more about whether they won't believe verifiable and reliable ('real') news." Instead of the sporadic attempts in history to moderate or mediate the government-press relationship, Trump has taken a full-on confrontational approach like none seen in history.

Even so, there are those who believe that the Trump presidency actually is doing some favors for the news literacy movement. In an email 


\section{Fred Blevens}

interview, Dean Miller (2017), a veteran journalist and former director of Stony Brook's Center for News Literacy, says that Trump's constant rails on unfairness and bias by the press "provide high-visibility case studies for discussion, sharpening students' understanding of these terms. On his Twitter account, President Trump provides fresh weekly examples of the confirmation bias and other forms of cognitive dissonance" that are in the core of news literacy education courses.

In Connecticut, for example, where Miller lives, "the damage of Alex Jones' InfoWars show is still raw, with Newtown families suffering protracted and vicious harassment by Jones' followers," a reference to Jones' repeated claims that the Newtown school massacre was a hoax. "When Trump praises Jones," Miller explains, "students have a glaring example of the degree to which humans ignore falsehood if an information source affirms their worldview." Such a tool-acquisition strategy descends from early America literacy movements and the predominant founding constructs built on Locke's precepts of moral development and Tocqueville's guarded hopes for participatory democracy.

Miller does not fear a rollback to early partisan press days, however. Though politics certainly drive Fox News and MSNBC, the traditional business model and social media monopolies are doing the most damage. He says that "web advertising is gutting the funding of traditional newsrooms, leading to staff cuts and a lack of economic power required to stand up to powerful special interests." On the upside, Miller is "encouraged by the efforts of legacy newsrooms to change federal law so that they can band together and stand up to Google and Facebook, whose methods are anti-competitive."

Miller also says the cable news narrative is clouded and confused. Developments after the election show that cable news may be getting more of the blame than it really deserves:

People often forget cable news has about one-seventh the audience of broadcast news, so it's a limited phenomenon. Curiously, Trump's ascendancy has coincided with ratings drops at Fox and increases at MSNBC, so the audience's politicization is not necessarily what was predicted.

He also says news practice is being altered by "a dominant political leader who changes his positions rapidly and shows no regard for verification of his statements." That phenomenon, which can be compared quantitatively with Obama's terms in office, has prompted the press to "adopt an unusually confrontational approach" by pushing back. That, in turn, gives educators the opportunity to build "powerful lessons by comparing Trump and Obama statements on similar issues, paying attention to how much time the press has to spend correcting the record before addressing policy.” 
Despite deep concerns from critics of Trump's Twitter rhetoric, Schneider (2017) says news literacy education must remain "agnostic" with respect to platform because skills and values are transferrable:

If students can learn to identify news reports that are verifiable, independent and accountable, they can apply those principles anywhere. Same holds if they can distinguish between assertion and verification, news and opinion, journalism and advertising (think sponsored content) or self-promotion, or an independent, authoritative source from a self-interested source.

In response to changing times, Schneider says the Stony Brook curriculum has developed "interventions": rank (in web searches) does not equal reliability; news consumers should not confuse a message sender's trust and reliability with the source of any attached link; and popularity is not the same as reliability (as in the number of retweets). "Finally," he says, "we emphasize another bedrock principle ... we can't slow down the news cycle or the Twitter sphere, but news consumers can slow how they process and share information."

Miller (2017) agrees, saying Twitter presents "demand-side problems." It's designers "merely internalized what news audiences have long begged for: succinct summaries with links to more depth." Even so, he says, the problem with Trump feeds "is that loyal fans of @RealDonaldTrump are convinced they are getting oracular proclamations direct to their mobile device and he rarely, if ever, supplies links to evidence, context or deeper discussion." Miller continues:

If a person only supplements @RealDonaldTrump with the nonShepard Smith/Chris Wallace shows on Fox, they're likely to believe 45,000 miners went back to work since Trump's inauguration.

Miller says Trump haters are no different, "routinely post(ing) opinion blogger speculations and wishful thinking as 'reporting." A staple of news literacy education is the 48-hour "Schneider News Blackout," which requires students to disengage from news for two days. Instead, Miller says, students should disengage from all news except Trump's feeds, then be assigned subsequently to fact-check against reliable sources. "So, if the president says the U.S. has added 45,000 mining jobs since he took office, you've got to go to the Bureau of Labor (Statistics) to find that's impossible, as there are only about 45,000 mining jobs in total.”

Dana Gold, director of education and strategic partnerships at the Government Accountability Project in Washington, D.C., has been struggling with dramatic changes in politics and journalism since Trump took office. Gold (2017a, 2017b) specifically is tackling the issue of "leaks" 


\section{Fred Blevens}

versus "whistleblowing," a distinction that presidents have traditionally conflated by using the terms interchangeably. Trump's repeated pledge to stamp out "leaks" and pledges by Attorney General Jeff Sessions to carry out the rhetorical and legal prosecutions has Gold concerned about public knowledge and perception in a democracy.

Gold (2017c) says the Trump/Sessions crackdown on information flow could have a serious chilling effect on government employees who have a conscientious need to reveal "evidence of serious abuses of authority, illegality, gross mismanagement, gross waste of funds, scientific censorship, or threats to the public health, safety or the environment" - all forms of whistleblowing:

As the press is demeaned and disparaged, the effectiveness of their reporting in terms of making change diminishes. This has the adverse effect of eroding one of the reasons whistleblowers speak out rather than stay silent, which is because they feel compelled to address a problem.

Regardless, Gold points to a silver lining, one that may illustrate the futility and possible backfire of the information crackdown. Trump's repeated claims of "fake news" and his attacks on individual journalists and journalism organizations with no evidence may be increasing more than ever the currency and credibility of disclosures from government employee whistleblowers.

The evidence, she says, is that the president's attacks have "increased donations, subscriptions and visits to mainstream press outlets such as The New York Times, The Washington Post, and CNN." At the same time, she says, the attacks are "creating new awareness on the part of those who strongly oppose this presidency of the quality, and importance, of verifiable news."

Ironically, she says, the president's allegations of "fake news" by journalists stand in stark contrast because they are made "by the person of whom the journalists consistently expose serial mendacity."

Gold takes some issue with Schneider and Miller on the significance of Twitter as mere "platform," noting that "it has dramatically shortened our attention spans." Trump's use of the vehicle "to communicate everything from his foreign policy positions to displeasure with members of his administrative team, health care legislation, or anyone who crosses him forces the press to essentially read the tea leaves in 140 characters of intent and meaning of the country's leader." She continues:

Because Twitter is a vehicle for opinion and not actual fact or content, the content of reporting revolves around first deciphering the meaning of a tweet and then a more rigorous analysis of the context and consequences of the tweet. Because Twitter is one of the few 
ways Trump communicates with the public, the press necessarily needs to report on the communications, but with the consequence of amplifying the value and power of such a limited, unnuanced [sic], non-fact-based platform as 'news.'

Gold agrees with Miller that Twitter is a platform of communication convenience, but she is not so eager to dismiss it as just another platform because of its amplification effect:

I think of some of the very complicated issues disclosed by whistleblowers, such as risks at nuclear weapons facilities or mortgage fraud, that require in depth research to analyze, report and then read and understand, that would be difficult to communicate in 140 words or a long tweet string. Twitter may dumb down our attention spans with consequences that are not just sad but that are actually dangerous.

Gold also says foreign manipulation of pro-Trump content during the last election has bolstered the importance of audience ethics and news literacy. That and other incidents pushed Google and Facebook to review their algorithms to combat fake news sites (Wingfield, Isaac, \& Bennernov, 2016). Gold sees that as "significant acknowledgment of the ethical responsibility of social media platforms to fill the gaps in news literacy education that created arguably unethical audience behavior." But she cites a downside:

In contrast, however, we also see a seizing on the audience's news illiteracy for political ends. The creation of the Trump propaganda news Facebook video series, "Real News," as well as conservative Sinclair Broadcasting Group's effort to expand its reach beyond the 173 local stations it owns and on which it forces the airing of pro-Trump news segments are clearly aimed at both undermining traditional investigative reporting and exploiting and perpetuating audience news illiteracy.

Countering this trend will require legislative advocacy on media ownership and getting money out of politics, Gold says, but the most important remedy will be "a cultural shift via an advocacy and education campaign that amplifies the role and responsibility of consumers/news audiences to become more news literate, making those skills an expectation of being a responsible citizen." Indeed, that was the Lockean expectation adopted and integrated into the nation's founding documents. What is different, of course, is the role and responsibilities of the news consumer, the reader-viewer-citizen journalist who must become appropriately armed. 


\section{Fred Blevens}

Schneider (2017) says the news literacy curriculum must continue "not teaching students what to think about the news, but how to think about news," empowering them to recognize "actionable" information "what you can use to make a judgment, reach a conclusion, or take an action, including sharing (on social media) with others." He says:

We can't get seduced, whatever the provocation, and become personal or partisan in our teaching. That would be toxic. We already make it abundantly clear that news literacy is not a cheerleading course for journalism. We certainly can use examples from Trump and a range of others, however, to allow students to apply their critical news literacy principles.

What does that mean for the confluence of disrupted media and Trump? What does it mean beyond Trump? Are we truly in a post-truth society?

"The cat is out of the bag in terms of the creation and rapid distribution of false and misleading information," says Schneider (2017). "The tools will only grow more sophisticated. Authenticity will be harder to discern." The game will take on more players "to exploit commercial and political advantages, including bad government actors":

So even if public tolerance for false information dissipates - which it inevitably will as Trump overplays his hand, the consequences become more apparent, partisanship moderates, and news coverage becomes more penetrating and transparent - what I worry about is whether news consumers will know the difference between reliable journalism and junk.

That does not come naturally, he says, and it won't come quickly. He says the real solution is to inoculate every school child in America with a strong grounding in twenty-first century news literacy before they leave middle school.

Miller (2017) believes that people really haven't changed, but

what has changed is our ability to see ourselves as we have always been: seekers of affirmation, avoiders of discomfort, and prone to gossip. Social media have merely provided data that quantify the degree to which we are the same animal Aristotle described in teaching rhetoric.

He says:

While that may seem to be an epochal change for the worse, the very technologies that facilitate the spread of junk information also are powerful in inoculating against untruth. Where a blatant falsehood 
in the 1980s could lie fallow, spreading silently for months, in the social media era it is identified and called out within minutes.

Gold (2017c) believes truth and accuracy will return as a staple of journalism if what she calls the "ethical press" - real investigative journalists and legitimate media outlets - creates accountability and reform:

The tireless and dogged reporting we have seen pre- and postelection has been one of the most important and effective mechanisms to make the clogged gears of democracy turn - reporting (often based on information provided by leaks and whistleblowers) has defeated the nomination of Department of Labor Secretary Andrew Pudzer; helped advance legal challenges to the administration's Muslim travel ban based on public records of discriminatory intent; and driven the appointment of a special prosecutor as well as Senate and House investigations into Russian interference with our elections and the Trump campaign's possible collusion.

When Tocqueville observed America, the news industry was entering a business model that would endure for 175 years, disrupted by rampaging technology and a new communications platform that allowed anyone to become a news provider. Those Penny Press days were impressive to observers foreign and domestic, primarily because that chaotic period came with rapidly advancing levels of literacy. That also armed people with the knowledge to live fuller and more productive civic lives. Anyone surveying that landscape could see that expanding literacy and news in a participatory democracy was far better than the elite, partisan, and politics-driven journalism of early America. The Penny Press was pubescence in the evolution of the news business, a time when more readers meant more content, which meant more and more revenues for newspaper and magazine barons.

At the same time, those same observers were warning of what might happen if the masses, literate as they became, really gained control of culture. As transatlantic genteel culture faded into Macdonald's masscult, news organizations became components of social stabilization, helping technocrats and cultural guardians shape a civil society. Not until the internet did we see cataclysmic disruption of the culture overall and the journalism business model in particular.

In many ways, what we have become is what we were - journalists as entrepreneurs and autonomous practitioners. But instead of doing a solo business with a flatbed press, one can get into today's news game with a laptop and a wireless card. As astute as the eighteenth- and nineteenth-century observers were, they never could imagine the confluence of a disrupted and chaotic media landscape with the raw and make-it-up-as-we-go era of the Trump presidency. Not even the great 
thinkers of last century, save a few like Macdonald, could predict a twenty-first-century frontier this bizarre, a modern-day Wild West with digital gunslingers. We have moved from demand-side media in early America to supply side during the long and now-broken model shaped by the Penny Press to a demand-side structure in search of a new model.

The culture, so delicate when normal along lines of religion, class, race, and gender, is fracturing with repeated episodes of conflict, pitting journalists on Locke's side of reason and morality against a Hobbesian president who prevaricates and changes positions with emotional outbursts on Twitter. The equation gets even more bizarre when we see a president with questionable religious knowledge or experience bonded with an evangelical community that puts its own faith in a casino owner and serial adulterer. Such an unholy alliance is a direct rejection of Mill's and the founders' "safe harbor of liberalism" that prevented doctrine from overtaking rationality and moral authority. The Philosophical Radicals warned that such alliances could be further perverted by the aristocracy (think 1 percenters) to delay or turn back social reform. Those aristocrats, long in the Locke-Hobbes debate for two centuries, are inextricably linked to a president who stands ready to support the business community at all costs to the individual.

While Donald Trump's incessant and irrational fight with the press may make for great theater and very funny late-night comedy, the damage to public perception is horrific. Literacy once powered society toward full-throated democracy, a dynamic that has lost a lot of volume in a short span of time. Perhaps the new cultural guardians and technocrats, the purveyors of news literacy, can help overcome the irrationality and again mend a broken world.

\section{References}

Baran, S. J., \& Davis, D. K. (1995). Mass Communication Theory: Foundations, Ferment, and Future. Belmont, CA: Wadsworth Publishing Company.

Coben, S. (1991). Rebellion Against Victorianism: The Impetus for Cultural Change in 1920s America. New York, NY: Oxford University Press.

Edemariam, A. (2009, October 19). The first great balloon hoax. The Guardian. Retrieved at www.theguardian.com/global/2009/oct/20/edgar-allan-poeballoon-hoax.

Gold, D. (2017a, June 9). James Comey is not a leaker. Slate. Retrieved at www. slate.com/articles/news_and_politics/politics/2017/06/james_comey_is_ not_a_leaker_he_is_a_whistleblower.html.

Gold, D. (2017b, July 27). Blowing the whistle on the Trump Administration's attempt to ignore climate change. Slate. Retrieved at www.slate.com/articles/ news_and_politics/science/2017/07/a_government_scientist_has_blown_a_ whistle_on_climate_change.html.

Gold, D. (2017c). Interview with the author. August 5-8, 2017. 
Goodman, M. (2008). The Sun and the Moon: The Remarkable True Account of Hoaxers, Showmen, Dueling Journalists, and Lunar Man-Bats in Nineteenth-Century New York. New York, NY: Basic Books.

Hall, D. D. (1975). The Victorian connection. American Quarterly, 27, 561-585.

Howe, D. W. (1975). American Victorianism as a culture. American Quarterly, 27, 507-525.

Jensen, J. (1962). Freedom of the press: A concept in search of a philosophy. In Social Responsibility of the Newspress (pp. 75-88). Milwaukee, WI: Marquette University Press.

Kasson, J. (1990). Rudeness and Civility: Manners in Nineteenth-Century Urban America. New York, NY: Hill and Wang.

Levine,L.W.(1988) Highbrow/Lowbrow: The Emergence of a Cultural Hierarchy in America. Cambridge, MA: Harvard University Press.

Lears, T. J. J. (1994). Fables of Abundance: A Cultural History of Advertising in America. New York, NY: Basic Books.

Macdonald, D. (1960). Masscult and Midcult2. Partisan Review, Fall, 589-631.

McLeod,K. (2014).Pranksters: Making Mischiefinthe Modern World.New York, NY \& London: New York University Press.

Mill, J. S. (1956). On Liberty. New York, NY: Liberal Arts Press.

Miller, D. (2017). Interview with author. June 27-30, 2017.

PolitiFact. (2017). The Trump file. Retrieved atwww.politifact.com/personalities/ donald-trump $/$ TB_iframe $=$ true $\&$ width $=921.6 \&$ height $=6297.3$.

Rubin, J. S. (1992). The Making of Middlebrow Culture. Chapel Hill, NC: The University of North Carolina Press.

Schneider, H. (2017). Interview with author. June 27-July 28, 2017.

Susman, W. I. (1984). Culture as History: The Transformation of American Society in the Twentieth Century. New York, NY: Pantheon Books.Tocqueville, A. d. (1964). Democracy in America. New York, NY: Pocket Books.

Wingfield, N., Isaac, M., \& Bennernov, K. (2016, November 14). Google and Facebook take aim at fake news sites. The New York Times. Retrieved at www.nytimes.com/2016/11/15/technology/google-will-ban-websites-thathost-fake-news-from-using-its-ad-service.html? $\mathrm{mcubz}=0$.

Yolton, J. (1985). Locke: An Introduction. New York, NY: Basil Blackwell Inc. 


\section{Trump, Democracy, and the Extension of Journalism Ethics}

Kathleen Bartzen Culver

As the United States' July 4 Independence Day holiday approached in 2017, President Donald Trump took to Twitter in the morning, as he had come to do so many times as a celebrity, candidate, and, now, leader of the world's strongest superpower. His Twitter style was not new. He had long been using the social channel to trash his opponents and thrash his perceived enemies. One such perceived foe was the news media. Trump had been on the attack for quite some time but had stepped up his pressure in the preceding week, going after CNN, The New York Times, and The Washington Post, as well as crudely insulting two anchors from an MSNBC morning talk show. Joe Scarborough, a Republican at the time, and Mika Brzezinski had used their MSNBC Morning Joe platform to criticize Trump after what appeared to be a friendly and collegial rapport early in the campaign. The president responded with personal attacks, aimed particularly at Brzezinski, as June came to a close.

Then on the morning of July 2, 2017, Trump tweeted a video, blasting \#FraudNewsCNN and \#FNN - insinuating one of the nation's leading news outlets, CNN, was the "Fake News Network." The accompanying video was a clip from a 2007 appearance Trump had made at WrestleMania, a televised event in the staged spectacle of professional wrestling. It showed Trump lunging toward and punching Vince McMahon, an executive with World Wrestling Entertainment. But someone had superimposed the CNN logo over McMahon's face, turning the meaning from a long-ago faked event to a current commentary on the president's efforts to beat up on the news network.

Social media response was swift. Users liked and retweeted the post about 600,000 and 350,000 times, respectively. Trump supporters cheered his attack-dog efforts. News media covered the tweet as an apparent attempt to "promote violence against CNN" (Nakamura, 2017), leading some to accuse mainstream outlets of exaggerating a simple joke into something darker and more sinister.

As if it was not enough that Trump - now President of the United States - had previously participated in a staged wrestling event and then used that performance to rail against a news outlet, the story then got even stranger. CNN reporter Andrew Kaczynski, going by the handle 
$@$ KFILE, and other Twitter users began to track the anonymous user who first posted the video clip the president had used. What they found, and the resulting backlash, neatly encapsulate the many challenges to journalism ethics in the time of Trump. The video did not originate with Trump but instead with a Reddit user whose other activities included racist and anti-Semitic memes and chatter.

The story covering these activities, as well as CNN's coverage of its decision not to identify the user, set off a barrage of reaction on social media. The reaction, often fraught with vitriol, misinformation, disinformation, and personal attack, suggests the norms and practices hammered out in newsrooms for more than a century should serve as a clarion call for citizens and public communicators well beyond journalism.

\section{Trump's Rise and Media's Role}

Trump's candidacy promised from the very start to be unlike any other in recent U.S. history. His June 16, 2015, announcement that he was officially running for the presidency unfolded at Trump Tower in New York City. It was the focus of intense media coverage, including documentation that the campaign used paid actors as part of his adoring crowd for the announcement (Federal Election Commission, 2016). Trump almost immediately became a news media obsession. Journalists covered and pundits picked apart every passage of the wide-ranging announcement speech, including Trump's claim that Mexican immigrants were "bringing drugs. They're bringing crime. They're rapists." Some thought the freewheeling, self-aggrandizing, and at-times offensive speech would spell a quick end to the unprecedented candidacy. The Washington Post coined it a "festival of narcissism" and declared, "Donald Trump's 'Mexican rapists' rhetoric will keep the Republican Party out of the White House" (Capehart, 2016).

But rather than fearing negative coverage that would dent his chances at the Republican Party nomination, Trump instead seemed to revel in it. His run dominated news cycles, easily outpacing his fellow Republican contenders. Trump's campaign spent very little in the way of traditional campaigning - such as buying political advertisements on television or setting up field offices in swing states. But he dominated news coverage, known as "free media" or "earned media." By March of 2016, Trump had earned more free media than all his GOP opponents combined, with some experts estimating its value at $\$ 2$ billion. The differential was not lost on those opponents, many of whom complained bitterly that allowing one candidate to so clearly dominate news cycles rigged the game and subverted the primary process. Candidate John Kasich told MSNBC:

The media gave him $\$ 2$ billion worth of free press. I mean, I could be having a press conference and they'd have an empty podium with 
Trump speaking there ... I mean, look, you guys have a lot of responsibility for this. You know it, too. You all know it.

(Gass, 2016)

Kasich pointed to what he appeared to claim was an unfair standard, that he would hold a press conference and take actual questions, but news organizations would instead cover Trump stumping from a podium and not engaging with challenges from reporters. Yet this is exactly what Trump seemed to innately understand that other candidates missed. Trump played to traditionally recognized news values and used them to his distinct advantage. Reporters, producers, and editors often operate with a common understanding of what makes something "news," often referred to in journalism education as "news values." For instance, the thinking commonly goes that "proximity" is an important news value because consumers will care more about news that is close to them than they will about things that happen far away. A reader in Pittsburgh, the thought goes, will care more about a homicide there than she will about one in San Diego.

Three news values in particular proved important in Trump's run: novelty, prominence, and conflict. Novelty is the idea that something new and different will be more appealing to audiences than things they have seen or heard before. Trump often led the morning news shows or front pages of newspapers and websites because he rolled out something new when he got up to the podium. He had consistent themes, to be sure, but every day seemed a different take or a different line. This contrasted with other GOP candidates, including Ted Cruz, who seemed to stump with nearly identical speeches day to day (Perryman, 2016).

Prominence clearly was in Trump's favor. A widely critiqued news value, prominence is the idea that news consumers will care more about celebrities or well-known figures than they will care about everyday people. Prominence fuels coverage decisions because it drives news consumption and traffic. Trump's star power - forged through decades of media interactions through his businesses, as well as his work as a reality television star and social media maven - made him far and away the most famous candidate in the GOP field.

Finally, conflict was the news value Trump seemed to understand beyond all others. Conflict is the idea that people care to read content when sides are in conflict, whether that's Republicans battling Democrats over health care or a man battling cancer. Trump was a figure ready for conflict. His campaign felt at times like a brute-force, manoa-mano affair, from the rhetoric he used to the people he chose to take on. He attacked opponents, such as Rand Paul, once saying, "I never attacked him on his looks and believe me, there's a lot of subject matter there" (Politico, 2016). He attacked then-President Barack Obama, once saying, "I think President Obama has been the most ignorant president 
in our history. His views of the world as he says don't jibe and the world is a mess" (Conway, 2016). He attacked Democratic opponent Hillary Clinton in visceral terms, including giving her the label of "Crooked Hillary."

Those political tussles were to be expected though Trump brought new levels of personalization, specificity, and nastiness. His conflict narratives, however, extended well beyond his opponents in the 2016 campaign. He said U.S. Senator John McCain, who was captured and tortured while serving during the Vietnam War, was less of a war hero because he was captured. He said he would not allow China to "rape our country," alleging the rising global economic superpower was responsible for what he saw as a flagging U.S. economy. He criticized the parents of a Muslim U.S. soldier who died while fighting in Iraq. The parents had appeared at the Democratic National Convention, and Trump asserted that the mother had not spoken because she wasn't allowed to and that he has "made a lot of sacrifices. I work very, very hard." The attack drew immediate rebukes and calls for respect toward "Gold Star" families - those who have lost a son or daughter in U.S. military service (Turnham, 2016).

And Trump courted conflict specifically with the news media. Former Fox News host Megyn Kelly, with whom Trump had a contentious relationship, drew his fire a number of times, including when he tweeted, "I refuse to call Megyn Kelly a bimbo, because that would not be politically correct. Instead I will only call her a lightweight reporter!" (Politico, 2016). He revoked press credentials for The Washington Post, calling the outlet "phony and dishonest" (Politico, 2016). He penned reporters in special areas at rallies and taunted them from the stage. All this conflict, plus other issues like failing to release his tax returns and the explosive Access Hollywood tape of his bragging about groping women without their consent, resulted in coverage that strongly tilted negative (Cillizza, 2016).

Yet Trump seemed to understand that the vast amounts of coverage overall were good for him, and news media faced criticism when they appeared to confirm that such coverage was also a win for them. For instance, CBS CEO Les Moonves told a group of investors that Trump's run for the presidency, "may not be good for America, but it's damn good for CBS, that's all I got to say" (Gass, 2016).

The landslide of traditional news coverage was an important but not sole media factor in Trump's rise to the GOP nomination. It intertwined with a social media presence Trump used to significant advantage. His Twitter persona and posting behavior were legendary before he announced his campaign, as he used the platform to boast about himself or to attack others, including questioning then-President Obama's citizenship from 2011 until the final months of Obama's second term. Trump entered the race with about four million Twitter followers, swamping his 


\section{6}

opponents (Tsur, Ognyanova, \& Lazer, 2016). His distinct and heavy use of the medium led to a hybrid campaign-media approach that was both new and successful.

In their 2016 study, Wells et al. (2016), found that Trump's delegate count during the campaign did not explain the amount of coverage he received. In other words, Trump was not enough of a front runner with voters to account for his front-runner status in the race for news media attention. Instead, they argue, his savvy for courting media attention through staged events, impromptu calls into news and talk shows, and his social media use succeeded in helping him dominate the news agenda during the primary season. In response, they said, journalists should engage in reflection about their practices.

\section{The Trump Presidency and the News}

In the period between Trump's election and inauguration, pundits of all stripes engaged in just such reflection about the role the press played in the primary and general campaigns and what Trump's public disdain for journalism would mean. Some called for a retrenchment into the bedrock ethics that have guided journalistic practice in recent decades while others urged that an unprecedented presidency would require upending some principles. The Washington Post summed the situation up in a widely circulated headline: "A hellscape of lies and distorted reality awaits journalists covering President Trump" (Sullivan, 2017).

And indeed, just days later - Day 1 of the Trump Presidency, in fact reality and the administration collided, with the White House press corps caught in the crossfire. As photos comparing the crowd size at the inaugurations of Trump and Obama clearly showed the latter with far more attendance, then-Press Secretary Sean Spicer used the White House press briefing podium to declare, "That was the largest audience to witness an inauguration, period." Fact-checking service PolitiFact gave the statement its "Pants On Fire!" lie rating (Qiu, 2017). In an ill-fitting suit, a flustered and irritated Spicer read from a prepared statement in a hostile voice. He said recent coverage calling for the press to hold the administration accountable would be a "two-way street," with the White House using its power to hold journalists accountable. Spicer took no questions and left the podium after about five minutes.

The administration then began to make changes that challenged traditional news practices and ethics. Access became a hot-button topic. From a claim by conspiracy-theory website InfoWars that it had been approved for White House press credentials (Concha, 2017) to Secretary of State Rex Tillerson's decision to break longstanding protocol and travel without reporters (Stelter, 2017), journalists accused the White House of keeping them out of important places and robbing the public of key information and context. This came to a head in Summer 2017, when 
Spicer and then-Deputy Press Secretary Sarah Huckabee Sanders all but ended televised White House press briefings, barring reporters from turning cameras on.

Ironically, however, these efforts to shut out reporters in some instances stood in direct relief from a White House awash in leaks that veteran reporters said far outpaced previous administrations from both parties. Some called it the "leakiest White House" and noted that some of the highest-ranking officials, including the president himself, sought out reporters to leak their spin on any number of issues, from the investigation of Russian meddling in the 2016 election to internal staff battles and bad blood (Goldberg, 2017).

The leaks led to impressively sourced stories though sources were almost universally not identified to news consumers. For instance, a Washington Post story on the firing of former FBI Director James Comey cites "the private accounts of more than 30 officials at the White House, the Justice Department, the FBI and on Capitol Hill, as well as Trump confidants and other senior Republicans" (Goldberg, 2017). Leaks appeared central to mainstream news coverage of the administration.

Even though he was known to provide off-the-record information to reporters himself, Trump was enraged by leaks and grew increasingly obsessed with them in public statements throughout his first six months in office. Leaks became part of his public criticism of his own attorney general, Jeff Sessions, when Trump tweeted on July 25, 2017, "Attorney General Jeff Sessions has taken a VERY weak position on Hillary Clinton crimes (where are E-mails \& DNC server) \& Intel leakers!” Trump brought in New York financier Anthony Scaramucci as communications director, and his first priority became rooting out leakers. Scaramucci was loyal, public, and yet erratic as he tackled the issue. In a profanity-laden phone call with New Yorker reporter Ryan Lizza, Scaramucci said revealing Lizza's confidential source on a story was the patriotic thing to do (Lizza, 2017). In a live call with CNN, Scaramucci said, "There are people inside the administration that think it is their job to save America from this President. That is not their job" (CNN, 2017). Scaramucci's tenure lasted ten days.

The decision to do a call-in with CNN, in particular, was a departure for the Trump administration. Already, Trump had been markedly successful with his base in framing the media as opponents of both himself personally and a successful United States more broadly. And no outlet caught more of his ire than CNN. This framing had three main prongs. First, Trump used rhetoric to cast a shadow over journalism generally, such as his February 17, 2017, tweet: "The FAKE NEWS media (failing @nytimes, @NBCNews, @ABC, @CBS, @CNN) is not my enemy, it is the enemy of the American People!" (Grynbaum, 2017).

Second, Trump worked to delegitimize specific reporting unfavorable to his interests and policies, such as in his July 24, 2017, tweet: "So many 
stories about me in the @washingtonpost are Fake News. They are as bad as ratings challenged @CNN. Lobbyist for Amazon and taxes?” (Romm, 2017). Finally, Trump attacked specific journalists and commentators, such as his rail against MSNBC's Joe Scarborough and Mika Brzezinski, hosts of Morning Joe on MSNBC, calling the latter "low I.Q. Crazy Mika" and asserting she once visited one of his properties "bleeding badly from a face-lift" (Thrush \& Haberman, 2017).

The most successful framing element in what some called Trump's war on mainstream news media was his remarkable and almost instantaneous co-opting of the phrase "fake news." Following the election, social media platform Facebook faced blistering criticism over the proliferation of falsehoods, hoaxes, and conspiracy theories on its service. Analysts noted that the top 10 trending fake political stories saw far more engagement - comments, sharing, and the like - than the top 10 trending real news stories focused on the campaign (Silverman, 2016).

This hoax content included such things as the Pope endorsing Donald Trump (he didn't) and Hillary Clinton suffering from Parkinson's Disease (she doesn't, according to her released medical records). The fake content tilted heavily pro-Trump or anti-Clinton, leading to questions about its influence on the outcome of the election (Silverman, 2016). After initially downplaying the impact of such content on election results, Facebook later developed methods for users to flag and slow the spread of this fake news (Culver, 2017).

Yet before Facebook even announced its efforts to control the viral spread of hoax and fake news, Trump took the phrase for his own and used it to contradict an alleged CNN report, tweeting on December 10, 2017, "Reports by @CNN that I will be working on The Apprentice during my Presidency, even part time, are ridiculous \& untrue - FAKE NEWS!" The phrase became an easy go-to for the president, as he used it about 75 times on Twitter in his first six months (Rosen, 2017) and made it a key phrase during a notable press conference featuring a lengthy backand-forth with CNN reporter Jim Acosta (CNN Money Staff, 2017).

\section{Of Wrestling, Reddit and CNN}

Trump's social media activity and vocal antipathy for the press did not drift quietly into an empty public sphere within his first months in office. His statements reverberated resoundingly with both his followers and his detractors. His wrestling video tweet, the CNN coverage of it, and the resulting reaction by social media users make for a useful case study and prompt questions about communication ethics - for journalists and for those responding to them. The video Trump tweeted showed old footage of him in a staged attack on another man at a wrestling event.

The video featured a superimposed CNN logo over the head of the other man. When CNN reporter Andrew Kaczynski tried tracking 
down the source of the video, he discovered it hadn't originated with Trump, his staff, or anyone in the administration. Instead, it came from a user of Reddit, a social aggregation and discussion service that features largely anonymous accounts, who used the handle "HanAssholeSolo" (Kaczynski, 2017). The account also featured racist and anti-Semitic memes, and Kaczynski began trying to track down the actual identity of HanAssholeSolo (Kaczynski, 2017). He succeeded.

After Kaczynski identified the user, but before he published any story, HanAssholeSolo issued an apology to his account on Reddit to the subreddit/The_Donald, a pro-Trump board, and deleted all of his other posts. He wrote that he did not endorse violence against news media and said his posts did not represent who he was:

I would also like to apologize for the posts made that were racist, bigoted, and anti-Semitic. I am in no way this kind of person, I love and accept people of all walks of life and have done so for my entire life. I am not the person that the media portrays me to be in real life, I was trolling and posting things to get a reaction from the subs on Reddit and never meant any of the hateful things I said in those posts. I would never support any kind of violence or actions against others simply for what they believe in, their religion, or the lifestyle they choose to have. Nor would I carry out any violence against anyone based upon that or support anyone who did.

(Berke, 2017)

His post was later removed by the moderators of the subreddit, but after posting the apology, the user called CNN, confirmed his identity, and gave an interview. According to Kaczynski's story, the network made a deliberate decision to withhold the user's identity:

because he is a private citizen who has issued an extensive statement of apology, showed his remorse by saying he has taken down all his offending posts, and because he said he is not going to repeat this ugly behavior on social media again.

(Kaczynski, 2017)

However, an editor then inserted an additional line: "CNN reserves the right to publish his identity should any of that change" (Perlberg, 2017).

It was this line that caught fire, almost immediately, with pro-Trump online and cable outlets, as well as individual users, quickly framing the line as CNN blackmailing the user. Conservative site Breitbart proclaimed, "CNN blackmails source of Donald Trump wrestling video" while WikiLeaks tweeted, "CNN extorts amateur satirist who made video tweeted by Trump: if you make fun of us again we will harm you" (Pollack, 2017). The framing gave rise to the \#CNNBlackmail hashtag, 
which quickly went viral, and pro-Trump posters unleashed a fury of response.

Some of it was incorrect, such as Donald Trump Jr.'s assertion that the allegedly blackmailed user was a 15 -year-old boy. Some of it was hoax, such as conspiracy theorist Mike Cernovich's assertion that Kaczynski's email newsletter involved phishing for user metadata (Tani, 2017). And some of it was ugly, such as the neo-Nazi site Daily Stormer posting that $\mathrm{CNN}$ employees should resign or be targeted:

We are going to track down your parents. We are going to track down your siblings. We are going to track down your spouses. We are going to track down your children. Because hey, that's what you guys get to do, right? We're going to see how you like it when our reporters are hunting down your children.

(Ohlheiser, 2017)

CNN and Kaczynski attempted to clarify that the line was intended to inform readers that they had made no agreement with the source, e.g., "Apologize or we will out you," and that their decision on identification was made after the apology and deletion of the posts and account. According to CNN, the user spoke with Kaczynski after \#CNNblackmail erupted and said he did not feel that he was being extorted or coerced.

\section{The Benefits of Trump}

CBS President Les Moonves' comment that Donald Trump might be bad for the nation but good for his organization was widely derided. But news organizations and the public have, in some ways, benefited from a president who describes the press as the "opposition party" (Fabian, 2017). News subscriptions surged throughout the campaign and after Trump's election, with The New York Times topping three million digital subscriptions, the New Yorker seeing a 300 percent increase over the previous year's period, and The Atlantic setting all-time records (Doctor, 2017). Broadcasters also saw substantial bumps, including CNN earning its second most-watched second quarter in 2017 and a 39 percent spike in the 25-54 age demographic (Coen, 2017).

A good deal of the journalism people were increasingly seeking and paying for was laudable. White House and Washington reporters seemed energized as they ran down important stories like the Comey firing, Russian election meddling, and financial entanglements. Explanatory sites like Vox expanded their staffs as they dug in deep on massive policy proposals like health care and tax reform. And news organizations generally seemed undeterred by efforts to discredit them. Where some feared a press that may be cowed and distracted by a president who attacked them and tweeted bombastically, they instead found many 
journalists with a renewed sense of purpose and plenty on which to report. So, in many ways, Donald Trump did indeed appear to be good for American journalism.

The time also featured many positives for the ethics of American journalism, with three prongs standing out: transparency, participation, and accountability. First, one response to Trump's attempts to delegitimize news was to be more open with the public about decision-making inside newsrooms. Though clumsily handled, CNN's inclusion of its reasoning for not identifying HanAssholeSolo was exactly this kind of transparency. Second, audiences appeared more poised than ever to participate in news practices. From social sharing of content to connecting with reporters directly, people used the affordances of digital media to become part of the conversation of news.

Through June 2017, for example, eight of the top ten comment-generating stories on NewYorkTimes.com involved Trump (B. Etim, personal communication, July 31, 2017). Every time a user engaged with @KFILE - Andrew Kaczynski's Twitter handle - she was engaged in participation. Finally, the combination of transparency and participation increased accountability in news. When members of the public in the Kaczynski case challenged both the decision not to name HanAssholeSolo and the caveat that this might change down the road, the network was accountable to citizens.

All of this served as an opening up of the walled garden of journalism ethics that was long overdue. Guided by codes that are developed without public participation (Culver, 2016) and often seeing the public "not so much to listen to as to speak to" (Brants \& de Haan, 2010), journalists have been rightly criticized as listening more to each other than to the citizens they are supposed to serve.

While journalists revel in their watchdog role - and for good reason that role seldom manifests itself as a critical discussion of press practices and performance. For all that's said and done in the name of accountability journalism, very little is said and done in the name of journalism accountability (Glasser, 2014).

With the possibility of a more open and engaged view of ethics, Ward (2017) argues, journalists should "redefine their ethics from the bottom up" and embrace a view of journalism as central to protecting the functioning of an egalitarian liberal democracy. Advocating for a pragmatic objectivity that engages citizens and advances dialog across social divisions, Ward sees the "time of Trump" as a key moment for journalism:

The problem is not a choice between neutral, objective reporting or a subjective, advocacy journalism. It is not a choice between acting as a journalist or acting as an activist. It is a problem of how to practice an engaged journalism dedicated to democracy while retaining the values of factuality and impartiality.

(Ward, 2017) 


\section{Kathleen Bartzen Culver}

Ward emerges optimistic that journalism can fulfill its role and be a linchpin in preserving democracy in the face of authoritarian instincts in the United States and abroad.

\section{Ethics Beyond Journalism}

None of this is to say that all journalists are operating ethically or that those who try to be responsible do not err. Journalism is a fraught and fast-moving enterprise fueled by human actors who can get things wrong as well as do things for the wrong reasons. But the ultimate question of the moment may be less about ethics at play in producing journalism and more about ethics in consuming and participating in it. It's the classic paradox of a free press operating in a democracy: Even if news media are using their freedom and reporting with courage and responsibility, does that really matter if citizens do not respond in kind? Can you have a system of democratic journalism if citizens reject truth and embrace extreme partisanship?

The foundation of liberal democracy in the United States envisions a free and responsible press as central to its survival, but ethical practice cannot stop with media. In today's society, it's not enough to have journalists reporting ethically. We must not only have free and responsible production of news, but also free and responsible interaction with news. This interaction certainly means consumption of content, including refusing to stay only in an echo chamber of alleged "news" that aligns only with your world view - be that on the left or the right. But it also means responsibly responding to content on social channels, creating content that adheres to principles of truth, and reacting to others in the digital and in-person public sphere with respect.

It is time to ask whether we operate in a public sphere that has gone beyond essential foundational assumptions about democracy and if so, how we return from that precipice to embrace a functional deliberative public sphere. It is important to begin with the very idea of liberal democracy and the kind of social contract that underpins it. In this time of fractured media, increasing partisanship, vicious trolling, and divisive leadership, philosopher John Rawls' theory of justice offers a sound foundation on which to rebuild. Thinking of society as a "system of cooperation," Rawls recognized that competing interests - such as different political, social, or economic ideologies - always exist and can work against that societal cooperation. He writes:

A society is a more or less self-sufficient association of persons who in their relations to one another recognize certain rules of conduct as binding and who for the most part act in accordance with them. Suppose further that these rules specify a system of cooperation 
designed to advance the good of those taking part in it. Then, although a society is a cooperative venture for mutual advantage, it is typically marked by a conflict as well as by an identity of interests.

(Rawls, 1999, p. 4)

Individual efforts matter in this cooperative venture, but Rawls argues that the "basic structure" of society also influences how well its members' lives go. This structure sets the terms under which members operate. Rather than a utilitarian view of maximizing good outcomes for the greatest number of people in the aggregate, Rawls advocates a view of justice as fairness and argues that the most just basic social structure would be freed from individuals pursuing their own greatest good outcomes in their own self-interest.

His idea is better understood by considering a hypothetical. Imagine that two people discover a box of buried treasure and must divide it among themselves. They cannot simply count the items in the booty and split them equally because different items will be of different value. If each tries to grab for items to maximize the value she is taking away, the pair will descend into a battle. The fairest way to split the treasure is for one of them to do the division and then the other to choose first which half she will take. By allowing one to divide and the other to choose, both will maximize fairness yet still serve their interests.

This, in essence, is Rawls' view. People would choose the most just basic structure if they did not know what position they would hold in the resulting social order. The thought experiment Rawls engages in is known as the "veil of ignorance." Theoretically, people behind the veil are ignorant of all aspects of themselves that would put them in a pecking order in the social structure, so such things as race, gender, level of education, or class would not matter. People would arrive at a fair plan for their society because they could hold any place within it. For instance, they would not design something that discriminated on the basis of gender because they would not know whether they end up as a man or a woman. They could either benefit from or be hurt by a biased approach, so they would eliminate that bias.

Rawls does not trample the individual in this theory. Citizens, in his view, are entitled to the greatest amount of liberty as long as that freedom does not interfere with the liberty of others. He acknowledges that inequalities will occur in society but argues that such inequalities should both be to everyone's advantage and be open for anyone to achieve. For instance, a doctor is paid more than a custodian. This inequality can be justified only if the doctor's higher pay advantages all (such as encouraging the doctor to endure the rigorous education needed to properly treat patients or ensuring technological advances) and both positions are open to all (e.g., any child in the society could grow up to be a doctor or a custodian without structural hindrances). For Rawls, the pursuit of 


\section{Kathleen Bartzen Culver}

good - for the self and for the society - is positive but must be wrapped in the constraining cloak of justice and fairness.

As Rawls extends these ideas into liberties of conscience and expression, he expresses a vision of the public sphere that is particularly applicable in the time of Trump and to the question of public participation in news and the ethics of public communication. He explains:

If the public forum is to be free and open to all, and in continuous session, everyone should be able to make use of it. All citizens should have the means to be informed about political issues. They should be in a position to assess how proposals affect their well-being and which policies advance their conception of the public good. Moreover, they should have a fair chance to add alternative proposals to the agenda for political discussion.

(Rawls, 1999, pp. 197-198)

While Rawls certainly could not have envisioned an American president blasting Congress in 140 characters, he articulates the very idea of participation for all in the new media ecology. The public debate should not be controlled by a privileged few with greater private means to communication channels. This ideal participatory vision, however, is sullied when new means to publish publicly are used to humiliate, demean, and distract. The challenge is to stimulate a participatory public sphere where enough of the new media space embraces a dialogic spirit, a commitment to truth, and a dedication to deliberation - where trolls cease to exist because from behind a veil of ignorance, a user does not know whether he will end up the troller or the trollee.

In the end, Reddit user HanAssholeSolo applied the concept of the veil of ignorance in his plea to others to moderate their online behavior:

To people who troll on the Internet for fun, consider your words and actions conveyed in your message and who it might upset or anger. Put yourself in their shoes before you post it. If you have a problem with trolling it is an addiction just like any other addiction someone can have to something and don't be embarrassed to ask for help. Trolling is nothing more than bullying a wide audience. Don't feed your own self-worth based upon inflicting suffering upon others online just because you are behind a keyboard.

(Berke, 2017)

In Rawls' view, we must approach a plural society - where views and values are certain to come into conflict - with a commitment to liberal principles of justice. Individuals rightly have liberty but do not have the right to trample others in pursuit of their own liberties or best outcomes. To ensure this, the social contract requires three things of the public. 
First, citizens must care about justice, not simply naked, individualistic libertarianism. Second, citizens must desire the exchange of ideas and seek compromise, not simply allowing either to be forced upon them.

And, finally, they must embrace a respectful and open-minded dialogue with those with whom they disagree. This requires the use of what Rawls terms "public reason" - an attitude that values objective assessment and evidence in the pursuit of reasoned conclusions. As a leader, Trump is subverting the public reasoning necessary to liberal democracy. His emphasis on creating conflict through social and other media comments, and his supporters' extension of that conflict stature, undermine the system of cooperation that has made the United States a stable social, political, and economic concern for two centuries.

Longstanding principles of journalism ethics could help meet the challenge of forging an effective and egalitarian public sphere if they disperse beyond newsrooms and influence other public communicators. Participants in the public sphere should not be expected to embrace the neutrality we would ask of a news reporter - though the pragmatic objectivity Ward calls for as a response to Trump's rise and authoritarian tendencies would help engender the public reason Rawls highlights.

Partisans can bring their worldviews to deliberation to settle important social debates, as long as they are open to objective assessment and evidence. And other ethics principles - transparency, fairness, minimizing harm, truth-seeking, accountability - should guide anyone participating in the public sphere. Digital media bring new freedom to publish to virtually anyone with an internet connection. What appears unrecognized among many Trump proponents is that new responsibility accompanies that freedom.

In this dialogic space, CNN and reporter Andrew Kaczynski should be transparent about their reasons for not identifying the Reddit user, and citizens should hold them accountable for that choice, as well as the way they described the choice and the possibility it could change. Many did exactly that. But others, led in part by motivated right-wing outlets, polluted the public sphere through doxing, ad hominem attacks, misand disinformation, and threats. In this toxic sludge, a vibrant public sphere - and the democracy it helps ensure - will not stand. Citizens who bear no commitment to truth and no dedication to deliberation too easily fall victim to propaganda and manipulation. As Russian dissident Gary Kasparov tweeted December 16, 2016: "The point of modern propaganda isn't only to misinform or push an agenda. It is to exhaust your critical thinking, to annihilate truth.”

The time of Trump is a time for all to recommit to truth as a necessary foundational condition in a democracy and embrace justice as fairness. Allowing the notions of transparency, minimizing harm, and accountability to guide not just journalists but all public communicators is an important step toward reclaiming a shared social contract and system of cooperation. 


\section{Kathleen Bartzen Culver}

\section{References}

Berke, J. (2017, July 4). Reddit user HanAssholeSolo apologizes for racist posts. Business Insider. Retrieved at www.businessinsider.com/donald-trump-reddithanassholesolo-racist-anti-semitic-cnn-meme-tweet-2017-7.

Brants, K., \& de Haan, Y. (2010). Taking the public seriously: Three models of responsiveness in media and journalism. Media, Culture of Society, 32(3), 411-428.

Capehart, J. (2016, June 17). Donald Trump's 'Mexican Rapists' rhetoric will keep the Republican Party out of the White House. The Washington Post. Retrieved at www.washingtonpost.com/blogs/post-partisan/wp/2015/06/17/ trumps-mexican-rapists-will-keep-the-republican-party-out-of-the-whitehouse/?utm_term=.0da51d0163ff.

Cillizza, C. (2016, December 7). Donald Trump was right. He got incredibly negative press coverage. The Washington Post. Retrieved at www.washingtonpost. $\mathrm{com} /$ news/the-fix/w p/2016/12/07/donald-trump-was-right-he-gotincredibly-negative-press-coverage/?utm_term=.afe416c0a003.

CNN. (2017, July 27). Read: Anthony Scaramucci's full interview on 'New Day.' CNN. Retrieved at www.cnn.com/2017/07/27/politics/scaramucci-new-daytranscript/index.html.

CNN Money Staff. (2017, February 16). Transcript: President Trump's exchange with CNN's Jim Acosta. CNN. Retrieved at http://money.cnn. com/2017/02/16/media/jim-acosta-donald-trump-press-conference/index. html?iid=EL.

Coen, B. (2017, July 3). Trump's war with CNN is failing, new ratings say. The Street. Retrieved at www.thestreet.com/story/14209017/1/is-trump-s-warwith-cnn-helping-or-hurting-its-ratings.html.

Concha, J. (2017, May 22). Questions surround Infowars' claim of White House press credentials. The Hill. Retrieved at http://thehill.com/homenews/ media/334583-questions-surround-infowars-claim-of-white-house-presscredentials.

Conway, M. (2016, November 10). 9 of the nastiest things Trump said about Obama. Politico. Retrieved at www.politico.com/story/2016/11/9-waystrump-insulted-obama-231184.

Culver, K. B. (2016). Disengaged ethics: Code development and journalism's relationship with 'the public.' Journalism Practice. doi: 10.1080/17512786. 2015.1121788.

Culver, K. B. (2017, February 7). The ethics of Facebook's fake news dilemma. The Observatory. Retrieved at https://observatory.journalism.wisc. edu/2017/02/07/the-ethics-of-facebooks-fake-news-dilemma.

Doctor, K. (2017, March 3). Trump bump grows into subscription surge - and not just for the New York Times. The Street. Retrieved at www.thestreet. com/story/14024114/1/trump-bump-grows-into-subscription-surge.html.

Fabian, J. (2017, January 27). Trump blasts media as 'opposition party.' The Hill. Retrieved at http://thehill.com/homenews/administration/316578-trumpblasts-media-as-opposition-party.

Federal Election Commission. (2016, March 7). First general counsel's report. Retrieved at http://eqs.fec.gov/eqsdocsMUR/17044405316.pdf. 
Gass, N. (2016, June 16). Kasich blames media for Trump. Politico. Retrieved at www.politico.com/story/2016/06/john-kasich-trump-media-224413.

Glasser, T. L. (2014). The privatization of press ethics. Journalism Studies, 15(6), 699-703.

Goldberg, J. (2017, May 12). Trump's White House leaks show the President's dramatic personality. National Review. Retrieved at www.nationalreview. com/article/447567/trump-white-house-leaks-show-president-dramaticpersonality.

Grynbaum, M. (2017, February 17). Trump calls the news media the 'Enemy of the American People.' The New York Times. Retrieved at www.nytimes. com/2017/02/17/business/trump-calls-the-news-media-the-enemy-of-thepeople.html.

Kaczynski, A. (2017, July 5). How CNN found the Reddit user behind the Trump wrestling GIF. CNN. Retrieved at www.cnn.com/2017/07/04/politics/kfile-reddit-user-trump-tweet/index.html.

Lizza, R. (2017, July 27). Anthony Scaramucci called me to unload about White House leakers, Reince Priebus and Steve Bannon. The New Yorker. Retrieved at www.newyorker.com/news/ryan-lizza/anthony-scaramucci-called-me-tounload-about-white-house-leakers-reince-priebus-and-steve-bannon.

Nakamura, D. (2017, July 2). Trump appears to promote violence against CNN with tweet. The Washington Post. Retrieved at www.washingtonpost. com/news/post-politics/wp/2017/07/02/trump-appears-to-promoteviolence-against-cnn-with-tweet/?utm_term $=.15570873 \mathrm{da} 81 \&$ wpisrc $=n l_{\text {_ }}$ p1most-partner-1\&wpmm=1.

Ohlheiser, A. (2017, July 5). The Reddit user behind Trump's CNN meme apologized. But \#CNNBlackmail is the story taking hold. The Washington Post. Retrieved at www.washingtonpost.com/news/the-intersect/wp/2017/07/05/ the-reddit-user-behind-trumps-cnn-meme-apologized-but-cnnblackmail-isthe-story-taking-hold/?utm_term=.86be43fea982.

Perlberg, S. (2017, July 5). CNN is standing by its controversial Reddit user story. BuzzFeed. Retrieved at www.buzzfeed.com/stevenperlberg/cnn-isstanding-by-its-controversial-reddit-user-story?utm_term=.luaA8oZA8\#. vcPVO85VO.

Perryman, M. (2016, December 14). Recap: Ethics and election 2016. Center for Journalism Ethics. Retrieved at https://ethics.journalism.wisc.edu/ 2016/12/14/recap-ethics-and-election-2016.

Politico. (2016, November 5). The 155 craziest things Trump said this election. Politico. Retrieved at www.politico.com/magazine/story/2016/11/the-155craziest-things-trump-said-this-cycle-214420.

Pollack, J. (2017, July 4). CNN blackmails source of Donald Trump wrestling video. Breitbart. Retrieved at www.breitbart.com/big-journalism/2017/07/04/ cnn-blackmails-source-donald-trump-wrestling-video.

Qiu, L. (2017, January 21). Donald Trump had biggest inaugural crowd ever? Metrics don't show it. PolitiFact. Retrieved at www.politifact.com/trutho-meter/statements/2017/jan/21/sean-spicer/trump-had-biggest-inauguralcrowd-ever-metrics-don.

Rawls, J. (1999). A Theory of Justice (Rev. ed.). Cambridge: Harvard University Press. 


\section{Kathleen Bartzen Culver}

Romm, T. (2017, June 28). President Trump has attacked Amazon, incorrectly claiming that it owns the Washington Post for tax purposes. Recode. Retrieved from www.recode.net/2017/6/28/15885828/trump-amazon-washington-postattack-jeff-bezos-internet-taxes.

Rosen, C. (2017, July 24). Donald Trump fake news tweets: A complete list. Entertainment Weekly. Retrieved at http://ew.com/tv/2017/06/27/donaldtrump-fake-news-twitter.

Silverman, C. (2016, November 16). This analysis shows how viral fake election news stories outperformed real news on Facebook. BuzzFeed. Retrieved at www.buzzfeed.com/craigsilverman/viral-fake-election-news-outperformedreal-news-on-facebook? utm_term=.rwPxdrNxd\#.mk1K8WmK8.

Stelter, B. (2017, March 10). Journalists outraged by Tillerson's plan to travel without press. CNN. Retrieved at http://money.cnn.com/2017/03/10/media/ rex-tillerson-state-department-no-press/index.html.

Sullivan, M. (2017, January 15). A hellscape of lies and distorted reality awaits journalists covering President Trump. The Washington Post. Retrieved at www.washingtonpost.com/lifestyle/style/a-hellscape-of-lies-and-distortedreality-awaits-journalists-covering-president-trump/2017/01/15/3656a17ed90f-11e6-b8b2-cb5164beba6b_story.html?utm_term=.3ff8a03119dd.

Tani, M. (2017, July 10). CNN's Andrew Kaczynski becomes target of rightwing conspiracies. Business Insider. Retrieved from www.businessinsider. com/conspiracy-theories-andrew-kaczynski-2017-7.

Thrush, G., \& Haberman, M. (2017, June 29). Trump mocks Mika Brzezinski; Says she was 'bleeding badly from a face-lift.' The New York Times. Retrieved at www.nytimes.com/2017/06/29/business/media/trump-mika-brzezinski-facelift.html.

Tsur, O., Ognyanova, K., \& Lazer, D. (2016, April 29). The data behind Trump's Twitter takeover. Politico. Retrieved at www.politico.com/magazine/ story/2016/04/donald-trump-2016-twitter-takeover-213861.

Turnham, S. (2016, July 30). Donald Trump to father of fallen soldier: 'I've made a lot of sacrifices.' ABC News. Retrieved at http://abcnews.go.com/ Politics/donald-trump-father-fallen-soldier-ive-made-lot/story?id=41015051.

Ward, S. J. A. (2017, March 20). How to practice democratically engaged journalism. Center for Journalism Ethics. Retrieved at https://ethics.journalism. wisc.edu/2017/03/20/radical-ethics-in-a-time-of-trump-how-to-practicedemocratically-engaged-journalism.

Wells, C., Shah, D., Pevehouse, J.C., Yang, J., Pelled, A., \& Boehm, F. (2016). How Trump drove coverage to the nomination: Hybrid media campaigning. Political Communication, 33(4), 1-8. 


\title{
15 The Effects of Mediatized Hate Coping with Life in Trumpland
}

\author{
LaTasha DeLoach
}

I will admit that the press irritates me, but mostly only when they are writing things from the angle that they want to see. Since the election, we have had to work much harder to make sure that what we are reading on a daily basis is actually real - and reliable - news.

As a result, I have found myself sharing on social media other media blogs, vlogs, and opinion pieces for my followers to read through, because sorting through the "real" news before posting and sharing was too hectic.

The Russian hacking that happened in the 2016 election was effective psychological warfare. Not just for politicians, but for citizens trying to decipher the daily news, issues, and challenges related to a Trump presidency. Having the floor ripped from under you, multiple times a day, by information that is emotionally unbelievable but real is exhausting: the dog whistling of language to white supremacist groups, investigations into backdoor relations between the White House and Russia, late-night tweets from the president ranting about this and that.

In the previous months, I have found myself having to actually watch the news, which is not a Millennial thing to do. We tend to observe and trust, but with today's news not making sense, I needed to physically look for familiar faces and names of journalists and for news outlets that I know to see if the news I was reviewing on social media was actually "real news."

Still, even if our journalism was reliable, much of the news I was exposed to was dependent on the major owners of the networks. All of this "extra" work to find "the truth" in content that was always told to us to be verified, reliable, and "objective" simply wore me - and others - out.

All the drama of the 2016 election - and even more exhausting, the results of the election and the months after with the drama leading up to taking office - were compounded with painstakingly resonant photos and videos of the outgoing president and his wife. The constant stomach-turning and ache of seeing the keys of the country being turned over to a madman had me asking, "Just what are we doing?" 
As one of the Black women who voted against the current madness, I am glad to be a part of history with other Black women who tried to warn the nation of what was to come. As a woman of color who witnesses the covertness of white supremacy, who understands the coded language and actions of white supremacy, who is an eyewitness to the ugliness of hatred and discrimination in this country, I am ashamed and embarrassed, being knowingly further disenfranchised in a place I am supposed to support, feeling like I just might have wasted time on issues of social justice.

I've witnessed these changing times of increased, approved hatred from our government and mediatized by the press as an elected official that, in the end deflated my feelings of amazement winning my spot on the school board, the first Black woman to do so in 30 years in this predominantly white college-town city. I was elated by this win. Yet, though my victory was historic locally, I felt within myself that it was soon diminished in comparison to seeing hate winning out on the news of Trump's own victory in communities across the country.

I've witnessed the changes as a social worker who must hang on as cuts carve away at funding and mitigate the harm that emerges from new policies that will remove my field - and my position - from being person-centered to being focused on the needs of the institution.

But most of all, I have lived these changes that come with ammunition of rhetoric and photo ops from the White House, that influence our shared culture, as a wife to a Black man and a mother to two babies who have no idea what in the world is going on. My babies don't yet know about the impact this will have on their future education, socioeconomic status, and health. They don't know that the election of the 45th President of the United States has statistically increased their odds of of an early death.

On election night, like many others, the world for me and mine came to a halt. It literally stood still.

The election that was treated in the media as spectacle was a preemptive strike of darkness that would emerge within Trump's first 100 days.

The election foreshadowed the 100-year-eclipse when some of the United States would be in complete darkness in September 2017, when some of us would take the chance to look right at the sun and chance blindness to see if it was just a fluke that Donald Trump actually was the leader of the Free-But-Soon-To-Be-Oppressed World.

But the election happened, and I had to recover quickly because, damn, it was only Tuesday, and I would soon have to face a group of young women and men I work with that next day and explain to them how and why their president hated women and held racist beliefs so openly in public. From all different types of backgrounds, these youths needed a trusted adult with whom to shed tears, to discuss and to cuss, and from whom to receive comfort.

Still, it is this group I am still most concerned with as the Trump era reigns. 
I have the privilege and honor to work with young people professionally. Whether it's counseling or programming, I am surrounded by and work with youth who have had "average" childhoods to those who have been, by federal and state definitions, labeled "at-risk." I refer to this group as "at-promise" children who also have opportunity gaps that I feel responsible for helping to close by creating or recognizing new opportunities.

To be clear, the term “at-promise youth" isn't mine alone. The term has been developed to destroy the term everyone seems to use - "at-risk youth." It is explained this way:

At Promise Youth shows the raw potential that each individual can access within themselves if treated with promise. Society uses "atrisk youth" to describe youth in different situational circumstances that are guiding them towards failure in the educational system, and into the mass incarceration systems or low skilled jobs. "At-risk youth" is used as a label to describe children in lower socioeconomic standings, youth with parents with little education or students from undocumented working class families. "At-risk youth" is used to show the potential number of future youth that are predicted to join the statistics, despite never have been given a chance to prove otherwise. They are never given the same access to resources and guidance, nor are their lives as privileged as other students. Labeling youth as at-risk, often tends to be negative and even damaging. At-promise broadens the perspective, fills in some of the details, and reminds us that we all have natural gifts, positive qualities, and potential for goodness. The act of focusing on strengths is different than the cultural norm of zoning in on what needs "fixing."

(UCSB, 2017)

I share that definition in full with the hopes of creating a movement that changes how we talk about people, especially in today's turmoil. And since I specialize in working with mostly children who are ages 12-18 and their families who are from minority communities, I also wish to challenge the popular use of terms that come from our president and our press in describing "these people."

The children I speak of that are from "minority communities" are not minority because they are less-than in stature but more because of how they compare in sheer numbers to other groups in my small Midwestern state of Iowa and in Iowa City where I live and work.

These children are from families from communities of color that continue to be impacted by not just the campaign for presidency but also the actual presidency. In fact, I have seen the increased stress in their eyes from being uncertain about the future, about what it means to see microaggressions become actual aggressions in daily life. 
They are not just wrestling with the daily drama of being in a microcommunity of a high school or middle school with different social groups. Now they are among new social groups of Trump-supporters who are operating with a new intensity. Students of color seeing an increase in team members in certain sports, such as wrestling and football, where "MAGA" or "Make America Great Again" clothing is secondary to the singlets and gear, and where those wearing the garb laugh - just as our president does - as they walk away from harassing Muslims and Latinos in the hallways.

Our children are waking up to an increased consciousness of recent history unlike that which they read in their history books, where narratives of hatred are playing out on the evening news and on social media, appearing next to their own stories that they share and post.

Their friends weigh in while in classrooms, supporting hate speech, and they vote in mock elections in decorated jars in high school cafeterias for president, with a shocking number voting for a candidate that spews racism and hatred of and for women. Our youth have come to understand and have become accustomed to covert racism that has become overwhelming in its clarity.

\section{Moving to the Trump Era}

From all of this, I can sum up this current presidency into one phrase, "Breaking News!" in which every day brings new challenges captured on the news and propagated online and in our changing social behaviors that elevate hate.

These changes are really disconcerting and heartbreaking. At one point, I believed Trump's rhetoric was hilarious and something I could laugh with my friends about, like the word "covfefe" or his consistent misspellings on Twitter.

But his language and his incessant need to do everything that is the opposite of presidential is a major crisis to people dying by terrorism domestic and abroad.

But here is what is constant: Regardless of who lives at 1600 Pennsylvania Ave. in Washington, D.C., the history of the United States has a tangled story that, despite the many versions, we can all agree is complicated.

Still, the fact that President Donald J. Trump, who was just a man completely unknown to me a few years ago, goes from laughable candidate to the actual 45th President of the Complicated History of the United States (insert groan) is beyond me.

With the presidency comes a specific ideology about who is considered an American and who is Un-American, and the ideas that come with Trump as the president are very dangerous to everyone - even for folks that voted for him.

The anger that people feel is as real as the folks who feel relieved that he is in the White House. 
As I see fear in the eyes of community members, particularly children, at the sound of Trump's name serving as a replacement for other discriminatory terminology, at the destruction and the fear that his name represents as the word/name that should not be spoken out loud, the anger that generates in my heart as a elected official from 2015 to 2017 for our local school board from and a macro social worker working on disparities with youth institutions is overwhelming.

I am constantly reflecting on the times I have had to hear the heartbreaking stories from Latino and Muslim families afraid for their lives and the splitting up of their families due to rhetoric and policy changes, including travel bans and deportation orders, their fear of their children being left with no one to take care of them, the legal issues that this caused and the trauma that they are enduring in their homes. That only speaks to the mainstream media (and, therefore, our politicians and the public) being focused on racist rhetoric connected to people who have come from Mexico or other Central and South American countries.

I live in a community that has large numbers of Latino families who have been here for generations and those who are from African, European, and Asian countries who have been immigrants for years. What of these non-Latino families who were left out of media and public narratives of racist immigration policies that have direct connections to our local communities? What of their fears? What of their experiences when we are left to our own biases of who we will advocate for during these times? How does this speak specifically to our local and national medium, racial bias, and our own racism as a society for believing America consists of binary conversations from topic to topic, one conversation to the next?

This is not a comparison of whose fear has been or will be the greatest since Trump's election, but we should be clear that children who hold legal documentation for residency and who were born here are also terrified - just for being born as a child of color.

In my larger community of Iowa, people responded with pieces of paper and grandiose statements of "It's gonna be alright" and "We are declaring this city as almost a sanctuary city, but not really, because we don't want to be legally that bold" (Hines, 2017).

It's truly sad that community members knew, even before changes to immigration policies and even before the public statements of hate from our president, that they have lived among folk who have been harboring hate in their hearts for years against students and people of color, and that they have done nothing about it before.

Here, like in many places in the United States, children and students who look different due to melanin entering "their" (read, white) schools and "their" (read, white) communities and "their" (read, white) neighborhoods have become susceptible to the intentions and interests of those who knew this new presidency was laying the foundation for how to exterminate whole communities. 
Because the way to be 1940s American Greatness means making sure people of color have little to no rights. But in America, the true America, there has not been one day where AMERICA was great without people of color - and there never will.

\section{Questioning the Role of Allies}

"If you speak for me then I can be heard," I said.

"What?!" she replied.

"If you speak for me then I can be heard," I said.

There continues, even in these times of Trump, a disturbing practice that marginalizes groups, whether it be among ranks of race, gender, or even age: allies.

It seems that there is this need to have allies or accomplices to assist in providing leverage for those in marginalized positions. Unfortunately, this practice actually works in many social situations. Indeed, I have had to utilize this method myself in order to have my voice heard.

Some will look at allyship as advocacy, but in reality, for many of us, this need for leverage for our voices to be heard is painful and exhausting - even with an "ally."

One fight that I continue to see in my work, in my community, and particularly in my state, is the devaluing of the voice and experience of youth - even among those who say they support the experiences of young people. Some would refer to this as adultism when we discount a youth's contributions and input.

Understanding the teen brain is a powerful tool.

They feel deeply, they're controlled by impulses, and they are more willing to be honest with how they see the world, while at the same time they remain quite impressionable. "The adolescent brain is exquisitely sensitive to experience," says Temple University neuroscientist Laurence Steinberg (Schwartz, 2015). "It is like the recording device is turned up to a different level of sensitivity."

Today's youth have endured racism, sexism, homophobia, and other forms of hate early in life, and they have endured this recent hate campaign and the continued discriminatory comments and issues with this presidency, and it is devastating to our communities.

But that doesn't mean that how we talk about allyship, generally, is helpful.

In the world of overt hate many white U.S. residents have found themselves asking, "What can I do?" and wondering, "Am I doing enough to work against overt racism?" A common-enough conversation about standing up for social justice usually begins like this:

I was told to reach out to more people of color when I have questions about social justice issues. People mention your name a lot, and I 
thought I would see if you were interested in meeting with me so I can pick your brain.

But if you haven't been in this active fight against injustice until the 2016 campaign and election, then do not be surprised when people from marginalized groups, mostly people of color, walk away from you to reserve their energy.

We need our energy and quick wits to save us during this time, as another iteration of this country's history of oppression is happening right in our living rooms, in our neighborhoods, and as our country battles with notions of its genesis.

Of course, these new folks who are "opening their eyes" to the terror of living in the United States as a person of color who experiences these issues on a daily basis are needed, and we need more people paying attention and working hard at trying to destroy white supremacy. But we should also remember that these are the same folks who have had years of opportunities to intervene when Cousin Bobby was popping off the "N-word" at the family reunion or when a colleague was discriminating about a hire by saying a person of color "wasn't a good fit." And these people did nothing.

Our new social justice friends have had the opportunity to intervene or ask tough questions and time to get clarification on why they have been complicit in allowing prejudice to grow around them. But now we have neo-Nazism and white supremacists walking across our campuses and marching through our streets.

Now, Cousin Bobby and the Human Resource Manager feel emboldened to speak shameful garbage out loud.

My new social justice friends are wanting to learn how to confront these folks and take up a stance against bigotry. I actually applaud this new desire, even though a part of me wishes that folks would have awoken out of their sleep earlier.

Still, my new friends (including members of the media who attempt to "uncover" racism in public policies and presidential speech) are still working within a white privilege frame. They are not aware of their earned and unearned advantages and how they can be operating as an operative for white supremacy.

Sometimes it is within unconscious bias that they feel the boldness to ask invasive questions or find their need to have answers to old problems provided quickly. So, to them, the solution is to feel just as bold and reach out to random people of color and ask for private lessons on how to deal with intersectional issues.

As I have said, people of color cannot be the guide for everyone's cultural experience when we are navigating the hurricanes of race, power, and privilege as our country is in turmoil over its past. This current presidency has opened a door, and now folks feel motivated and need to be seen as an ally for them to survive. 
Allies are helpful but we need more than allyship. Allies are great for bonding you out of jail in a protest, but we need those folks to go to jail with us and for us. We need accomplices.

Unfortunately, allies need mother's milk in the years of Black Lives Matter and during a Trump presidency. Women of color, especially Black women, need to save ourselves and our energy to continue to protect our children and communities.

However, Trump, like every president before him, will continue the deterioration and genocide of communities of color with rhetoric, policies, and lynchmen in Congress. New allies, particularly White people who are now using terms such as being "woke" and saying that they are taking more action but with a lack of cultural humility, are also professing illuminations of their own white privilege while making such utterances and confessions of their new awareness.

In the moment in which they utter these platitudes to the cause they are inducting white privilege to fill a space that is not meant for them to fill, using these statements as buffers to prove they are not "racist."

These statements and actions are also to show other white folks that "non-allies" are less progressive than others and that they, the newly enlightened, have added value in the conversation of race because of their acquired knowledge.

Current policies that are being reported on from the press about the decisions that federal, state officials, and local officials are signing into law take away our abilities to make choices for our own families. Their choices are informed only by a few folks, but the effects of their choices impact so many of us. These countless policies set forth to police our bodies and our minds is legal, but so was slavery and apartheid.

All of this is rather impressive since the press is supposed to keep us informed about what is happening in the world, and their knowledge should bring about peace and eventual understanding. However, with questionable journalism being put out distracting us from truth, it is difficult to function, especially if you submerge yourself in multiple news outlets.

The press gets so wrapped up in the ridiculous behavior of the president - including his racist hatred speech - that they forget to inform us on the rights that are being lost by the executive orders and laws being voted in to disrupt our lives.

Members of the media know that Trump is watching their every move because we are all feeding into the capitalist social media market of Twitter to see an old man consistently embarrass himself - and our country. Journalists find themselves writing and reporting and chastising an adult because the others around him are failing as pseudo parents for the Big Kid in the Big White House.

The United States, through white supremacist antics, has conditioned marginalized people from infancy that we should be empathetic to white citizens even over others with whom we may have more in common. 
This condition is from slavery to modern day, what Joy DeGruy (2016) refers to as the Post Traumatic Slave Syndrome.

There is this need to protect the bodies and the feelings of white Americans, a task unfortunately dangerous at this historical moment, because we know that we need more (real) allies and folks who will go as far as to be an accomplice in these efforts to work towards equity and to assist in building a better world for the next generation. Beah Richards (1951), in her poem "A Black Women Speaks of White Womanhood," explicates this discussion. An excerpt:

You were afraid to nurse your young lest fallen breast offend your master's sight and he should flee to firmer loveliness. And so you passed them, your children, on to me. Flesh that was your flesh and blood that was your blood drank the sustenance of life from me. And as I gave suckle I knew I nursed my own child's enemy. I could have lied, told you your child was fed till it was dead of hunger.

Discussion about people of color having to take care of white community members as black nursemaids - Black folks taking care of keeping white cops cool when getting pulling over, not speaking up due to fear of white reprisal, managing white anxieties by wearing, speaking, and walking in ways that are white-appropriate - is age-old. Always giving away has been killing us for centuries, and it's hard not to question, "Is this a subtle form of genocide?"

When it comes to our younger generations, they are not open to being nursemaids and supporting white people; they feel anger that it is even being suggested to them to take care of white teachers, white police officers, or officers in general, and of white community members who are complicit in violence against their bodies and the silencing of their voices.

They wear T-shirts with the words, "Dear Racism, I am not my grandparents. \#thesehands."

I completely understand that anger and clarity of thought. It is not that folks are angry due to the complexion of their skin, but they are angry because they are present and concious.

We ask: "How much time did we do it? How long were we sitting and looking for the great hope sometimes referred to as the Great White Hope?" When we found former President Barack H. Obama, we assigned him the title of the Great Black Hope.

It was even his campaign slogan - HOPE.

But Obama was reduced to a sanitized and safe Black man, different than the average Black man that society and our families have taught us to envy and/or fear through language and energy expressed in changing his image that was comfortable for White Americans.

Obama was presented with a shroud of hope and acceptability for liberal white folks. For folks of color who were broken down and 
brokenhearted over the historical conditions of communities and the corresponding maladaptive behaviors and survival strategies gained from surviving slavery, Jim Crow, Civil Rights, a politically inspired and directed heroin and crack cocaine era, homelessness, and the war on drugs, the issues of oppression today are quite clear.

We forgot Obama was just a man and not a god. We put all of our hope in his presidency, and it blinded some of us. He was palatable and likable for white folks. He was extremely intelligent, especially in comparison to his predecessor. He became the new epitome of "acceptable" blackness. Through his years in office, we have seen a rise in such things as a Steve Harvey camp, today's movement of Black men cutting dreads, wearing suits, and "cleaning up" to fit the comfortable notion of Blackness.

Many lived and continue to live in an alternate universe about how Obama's acceptability politics was really commentary about how all Black Americans should act and live. And I get it: as a person who has been a public figure for some time, there is this need to work "twice as hard" as everyone else to be blameless when stacked up against colleagues.

His family was the "No Drama Obamas;" they presented the kind of blackness that white folks preferred and referred to when they mentioned "their Black friends."

Obama's presidency opened the doors for white Americans to feel welcome in allowing "Obama-like" Black men to date their daughters and for "Obama-like" Black people to join their social clubs. Obama became the 1980s Cliff Huxtable of acceptable blackness.

The W.E.B. Du Bois Talented Tenth and these "Obama-like" men and women could shuck and jive in a way that was comforting and reminiscent of yesteryear when deluded people believed "America" was great, when the sweet sounds from the slave quarters on Sunday evening around sunset echoed coded songs of freedom and the demise of the benevolent slave master and his wife.

But the press, with the help of Donald Trump and his Trumpkins who are primarily white residents who basically got emotional that Rock ' $n$ Roll and country music were not playing in the elevator anymore when they were to visit the White House, have come to discuss the terms of an agreement gone wrong.

They were upset that in their moment of weakness, in the comfort of their white privilege, that in the moment they looked away after inviting the nice, non-threatening looking Black man on their lawn, he somehow went in the house and kicked them out.

But we know this is not true, at least to those who pay attention to facts anymore when we now have "alt"ernative facts and even directions such as right and left.

But who wouldn't be mad, one must think, if when you turned your head you'd lost the illusion of ownership and power? They became upset that the Statue of Liberty went back to dating in her own ethnicity, in 
her original form, the history she stood for hundreds of years in silence as she was misrepresented over and over again (for history of Liberty's Blackness via her African roots, see National Parks Service, 2000).

When Obama was first elected in 2008, Liberty found a breath from someone who was reflective of her lived experience and she knew she would be taken care of, protected, and reminded of the melanin from which she came and which she had been denied since she shipped across the sea from France.

Even though Liberty was Black and Obama was Black and she could see the resemblance of herself in the leadership of the country she represented, her people had become fatigued in the days of reckoning that hadn't been reckoned.

\section{Generational Fatigue in an Age of Mediatized Hate}

For many years, therapists and psychologists have written about generational anger. One of the more common generational imprints on DNA is rage that is passed down generation to generation. The other common generational imprints on DNA is trauma.

These imprints lead me to believe that there is generational fatigue from being angry and traumatized among people of color in the United States. So, whether we are working on social justice issues or just dealing with the daily microaggressions from your intersectional identities, we seem to be likely to trigger generational fatigue, which presents itself in feelings of absence from resistance.

To me, then, it also seems that the likelihood of fatigue is increased if folks in our families were active in anyway in historical defiance against structural racism.

These days, everyone who has not in the past activated their imprint are now being activated like rippling dominoes because of our political climate. This only further complicates things for people of color in fighting for social justice because of the onslaught of people of color who wanted to reach out to help - or who are reached out to by the press to talk about these issues.

These complications only further quantify the need for accomplices and for more white people to work with other baby allies, because we have to save our milk this time for our own babies so that they don't die. We must refocus on making choices about where we put our vitality.

If journalists wanted to make the difference, they could report what people need. The press has the ability to bring the country together.

Journalists seem to want to be known for breaking the story, but they have the ability to focus where they want to focus. They can break it.

I am not saying that they should not report on what's happening in the world, but there are daily opportunities to highlight real American leaders who are working to help us understand our past. Journalists can 


\section{LaTasha DeLoach}

report the past and the timeline of moving forward with hope of being a better country, a country that can collaborate and work with others.

I know this all comes down to dollars and cents, but at some point, we all have to be a part of the reconciliation and of the healing that needs to happen in this country.

I hold the free press to a higher standard because there are whole groups of marginalized people who are left out of these stories, headlines, and their amazing contributions to the country go untold. If we work to eliminate the bias that is within media and our country, we will have the opportunity to receive information with a critical eye and ear and move to a more perfect union of states and residents. We all need to do our work, and unfortunately, there is no shift change coming soon, so prepare your heart, mind, and soul.

\section{References}

DeGruy, J. (2016). Post Traumatic Slave Syndrome: America's Legacy of Enduring Injury and Healing. Portland, OR: Joy DeGruy Publications.

Hines, H. (2017, March 28). Plans to support immigrant students enacted by Iowa City School Board. Iowa City Press-Citizen. Retrieved at www. press-citizen.com/story/news/2017/03/28/plans-support-immigrant-studentsenacted-iowa-city-school-board/99747270.

National Parks Service. (2000). Black statue of liberty - summary report. Retrieved at www.nps.gov/stli/learn/historyculture/black-statue-of-liberty.htm.

Richards, B. E. (1951). A Black Woman Speaks: Of White Womanhood, of White Supremacy, of Peace: A Poem. New York, NY: American Women for Peace.

Schwartz, K. (2015, December 21). Harnessing the incredible learning potential of the adolescent brain. KQED. Retrieved at ww2.kqed.org/mindshift/2015/ 12/21/harnessing-the-incredible-learning-potential-of-the-adolescent-brain.

UCSB. (2017). At Promise Youth. Retrieved at www.sustainability.ucsb.edu/ at-promise-youth. 


\section{Epilogue}

\section{Facing Tomorrow in an Age of Trump}

Robert E. Gutsche, Jr.

To say Kayleigh McEnany is a rising star would be putting it mildly. In fact, by the time this book is published, she may very well be a household name, like that of Kellyanne Conway, and at select few dinner tables, Anthony "The Mooch" Scaramucci. Though in Scaramucci's case, his name recognition was short-lived, having been fired as Communications Director by Trump after 10 days at his post after threatening to fire "everyone" under his command and after the appointment of a Trump Chief of Staff John F. Kelly, former U.S. Secretary of Homeland Security under Trump and a retired Marine general (Phillip \& Paletta, 2017). Seems like a lot to digest? That's been the Trump Administration. Every day something new. ${ }^{1}$

But back to McEnany. She's blonde, slim, and light-skinned, educated in Tampa, Florida, and at Harvard. Having interned in several conservative campaigns, McEnany became a staple for defending then-presidential candidate Donald Trump on CNN during the 2016 election. The day after leaving that opportunity in August 2017, McEnany appeared on Trump's Facebook page as host of "News of the Week," a version of Trump TV, what was once an idea early on in the campaign to provide audiences with "the real news" from \#realDonaldTrump.

Positioned as an alternative to the "fake news" of mainstream media, Trump TV was initially questioned as to its effectiveness to motivate voters to become viewers and to maintain a steady stream of millions of viewers that would sustain yet another cable news channel (Stelter, 2016). Silly journalists, cable's for chumps. Trump never intended to join the cable ranks, not with Twitter, Facebook, YouTube, Instagram, and his White House Briefing Room. Even had Trump lost the election, it's unlikely this would be an Al Gore attempt to make something from nothing on cable.

This conclusion positions this volume within a framework of conservative movements against mainstream media that stretch back in recent history to moments of contestation about the values of U.S. society and the role of the press and of politics in daily life. Trump TV represents just another attack against mainstream media that is grounded in unresolved tensions of the past 20 years. 


\section{Robert E. Gutsche, Jr.}

\section{Breaking News: The Making of Trump TV}

On August 6, 2017, months after becoming president, Trump TV became a reality following his administration's innovative communication strategies of lies, deception, and media inclusiveness, such as bringing local, conservative, and/or alt-Right broadcasters into briefings via Skype. Of course, this spectacle of inclusiveness, a nod to media bias by countering bias, was happening at the same time Trump threatened journalists' safety, banned them from briefings, and cancelled briefings altogether. With Trump TV, Trump positioned yet another challenge for mainstream journalists who had been rattled by the election and Trump's unconventional approach to communicating with the public: Journalists were once again no longer the only voice of authority in the political arena.

McEnany's first report for "News of the Week" appeared before the backdrop of Trump's campaign website with a lower third advertising the campaign's (and the presidential office's) social media. Posted to @DonaldTrump on Facebook, the video focused on economic news, immigration policy, the president's naming of a Medal of Honor recipient, and Trump's bid to better the Veteran's Administration system of care (Sheth, 2017). Funded by Trump's reelection campaign and critiqued by some as smacking of "state-sponsored television" that appears in more overtly dictatorial nations (Markay \& Suebsaeng, 2017), "News of the Week" took advantage of the social media hype, the rile of anti-Trump rhetoricians, and the wrath of mediaites who all were likely among the program's intended audience.

Few "real Trump" audience members, such as those who voted for him, either already knew about the minute-thirty show's news or didn't care. They either got the information at Fox News, from a host of other conservative media sites, or from local news coverage of legislation, daily events at the White House, or economic conditions covered by D.C.-based wire services as they always have.

To be clear, Trump TV was designed for the purposes of most Trump-related and Trump-centric communication - to irritate the opposition, to mock the mainstream press, to show that American's don't really need journalists anyway. That McEnany - her looks matching those of George W. Bush's Texas and female family members that surround Trump - announced her show was being taped "from Trump Tower here in New York" removed for conservative audiences the cosmopolitanism that often accompany mainstream media's focus on coastal issues and showed that the presidency need not be in Washington, D.C., just as conservatives need not be bound to the Bible Belt.

That Trump Tower was the central location for Trump TV not only made sense in terms of branding, but to take back conservative meanings of New York that seem only to be associated with Wall Street. 
The location also put this news form into a larger media sphere alongside "liberal" anchors from MSNBC and the networks who speak before Manhattan skylines. How the atmosphere got to be so complicated that it's explained as simply as liberal vs. conservative (much as it was in the mid-1990s during the "Contract with America" days) is the result of conservative politicking that was underway but was interrupted by George W. Bush's War on Terror.

Americans elected Bush in 2001 as a "compassionate conservative," as a means to gain traction outside of a traditional Republican base and to build upon a more sophisticated conservative constituency that was sparked by the successes of Drudge Report and shortly after Fox News. Meanwhile, both sides of Congress became under Republican control and President Bill Clinton was mired in a sex scandal and impeachment. Before his impeachment in 1998, conservatives had had it with a rise in multiculturalism and tolerance in schools, in the military, and in the separation of church and state - all fueled by liberals' wishes for increased Civil Rights.

Hillary Clinton was to blame for much of their ire. Whereas Nancy Reagan and Barbara Bush - both known for sharing their opinions and wishes in the running of White House (and some national) affairs Hillary Clinton had made a name for herself as an advocate for the poor, for children, and for environmental rights. She was also presented in the media and interpreted by conservatives as being too head-strong, involved in a man's political world, hypermasculine in her appearance, and cold in demeanor.

As conservatives tried to pin on the Clintons fraudulent land deals and the destruction of a Christian nation, they pounced on the intern sex scandal and largely on Hillary Clinton's standing by her man. What debauchery, conservatives said, and what evidence of corruption, of the attack against family and an undermining of American democracy and values. The impeachment itself became a sport. In fact, I remember being at a large family event to celebrate the winter holidays as we all gathered around the big screen TV to watch the impeachment proceedings as though it was a Sunday afternoon football game.

Like it or not, the media are just plain silly to many conservatives, and Trump has helped to reveal that possibly media spheres might just be more than silly, but a system of layered interactions that reinforce notions of the power elite (for discussion, see Gutsche, 2017). The undressing of politics and media coverage of politicians and policy appeared in one of Trump's most powerful moments during the campaign, in fact, when he stood with fellow candidates in the first Republican debate in 2015. In the mess of comments, interruptions, and snide remarks bantered between them, Trump dissected a "broken system" of politics in which he addressed his own financial donations that he had made to other candidates' campaigns before he entered the race. He had given 


\section{Robert E. Gutsche, Jr.}

to Hillary Clinton and Nancy Pelosi, he said, something we all knew and facts other candidates thought Trump would want to hide. Instead, Trump reveled in them.

"And you know what," Trump said of his financial support, "when I need something from them two years later, three years later, I call them. They are there for me. That's a broken system." What does he need from them and what does he get? "Well, I'll tell you what, with Hillary Clinton, I said be at my wedding and she came to my wedding" (Time, 2015). Of course, this was code for being in each other's pockets. More from that night's debate:

MODERATOR BRET BAIER: Mr. Trump, it's not just your past support for single-payer health care. You've also supported a host of other liberal policies. You've also donated to several Democratic candidates, Hillary Clinton included, Nancy Pelosi.

You explained away those donations saying you did that to get business-related favors.

And you said recently, quote, "When you give, they do whatever the hell you want them to do."

TRUMP: You'd better believe it.

BAIER: So what specifically did...

UNIDENTIFIED MALE CANDIDATE: That's true.

BAIER: - they do?

TRUMP: If I ask them, if I need them, you know, most of the people on

this stage I've given to, just so you understand, a lot of money.

UNIDENTIFIED MALE CANDIDATE: Not me.

UNIDENTIFIED MALE CANDIDATE: Not me.

(LAUGHTER)

UNIDENTIFIED MALE CANDIDATE: But you're welcome to give me (INAUDIBLE) Donald if you'd like.

TRUMP: Many of them.

But what Trump did in that moment, led one to wonder the degree to which others on the stage had also given in ways that might be questionable at some point in this or in other campaign cycles. It was an unveil focused on the system, not just individual candidates, however, to which audiences responded positively. Finally, conservatives thought, someone speaks the truth.

\section{Decoding Conservative Complaints About Media}

News media walked right into their own battle for authority when they covered Trump so heavily as a spectacle and not as a legitimate candidate. They set the stage for showing not just inside politics what we all knew happened but never talked about, and they revealed in their coverage of Trump's endless talking the inner-workings of an "unfair" and 
"biased" journalism that continues to be ignored by liberals, journalists, scholars, and intellectual elites - to our own demise.

It's important to note that many conservatives think journalistsliberals-academics-educators (we're are all lumped together, really) aren't just hedonists, but are players in a sport for ideological dominance. In my living room once, a family member looked through my library.

"Why do you read about all this driving while Black," she asked. "That doesn't happen."

$\mathrm{Oh}$, really?

So, any news of such a phenomenon becomes distraction from the decline of prayer in schools, of an increased welfare state, of military vulnerability on a global stage, and of a tax and economic system that makes it hard for white Americans (especially men, in their view) to reach The American Dream. Media coverage of systematic and institutionalized racism, militarized police, unconscious bias, identity politics, and human rights is all that mainstream journalists promote and propagate as news, the thought goes.

In effect, the discussion about a liberal media is really a discussion about intellectualism. In August 2017, silliness erupted again across all cable news outlets when journalists wanted to verify history and correct new history-making related to poetry on the Statue of Liberty. History, poetry, monumentalize related to immigration - all of these are triggers for conservative rhetoric.

Asking senior policy advisor Stephen Miller during a White House briefing about Trump's direction related to immigration and the president's proposed policies on traditional thinking about the United States as a haven for those seeking freedom and a fresh start, CNN's Jim Acosta stated the following:

The Statue of Liberty says, "Give me your tired, your poor, your huddled masses, yearning to breathe free." It doesn't say anything about speaking English or being a computer programmer. Aren't you trying to change what it means to be an immigrant coming into this country if you're telling them that you have to speak English?

CNN covered the response this way:

Miller responded that as a requirement to be naturalized, "you have to speak English," and continued, "so the notion that speaking English wouldn't be a part of immigration systems would be very ahistorical."

He went on: "Secondly, I don't want to get off into a whole thing about history here, but the Statue of Liberty is a symbol of American liberty lighting the world. The poem that you're referring to was added later (and) is not actually part of the original Statue of Liberty." 
But talking heads on "mainstream media" used the moment as their own history lesson and as a moment to shame the White House (and Trump) for comments that were considered ahistorical or just plain wrong.

$\mathrm{CNN}$, again:

Lazarus originally wrote the sonnet, entitled "The New Colossus," to raise funds for the statue's pedestal in 1883. The sculpture itself, which sits in the New York Harbor and was visible on the path to the immigration checkpoint at Ellis Island, was a gift from France to the US.

It was not until 1903 that Lazarus's words were inscribed on a bronze plaque and attached to the inner wall of the Statue of Liberty, 17 years after its original unveiling in 1886. (Stark, 2017)

For liberals (I consider myself a progressive), the historical debate represented not only deflection and distraction from the issues by the White House, but an outright rejection by the Trump administration of playing by the strict rules. If someone wants to know the poem, go read it, but don't spend time debating it when there's work to be done, one might say. Moments like these are clashes of expectations of society in which media are to be blamed, conservatives believe, and that further showmanship and bravado of highly paid and underworked news anchors.

For others, the Statue of Liberty coverage, with its focus on intellectual detail and not on information that engages citizens in ways that puts food on the table, was perhaps a less overt example of media bias. But enter "fake news" - again. Conservatives have used moments of "fake news" and general controversy surrounding journalism before, during, and after the 2016 election as specific examples of journalistic "bias" on part of mainstream media to favor liberal agendas, much of which is categorized on the right as fake.

Time magazine's story in January 2017 that the newly established Trump administration had removed a Martin Luther King bust from the Oval Office is a case in point of the conservative side's claim to being ignored, mistreated, and misrepresented by mainstream media "fake news," writes Sharyl Attkisson (2017). The reporter, Zeke Miller, had presented the story to the press pool and, therefore, to a wide range of publications, which quickly became a press tale of a new, racist Trump regime. Miller soon stated upon proof from the administration that the bust was there all along, however, and that he hadn't verified his claim that the bust wasn't there (he just didn't look hard enough, he said). There was little overt, public punishment from his employer for getting the scoop so badly wrong.

Attkisson writes that such moments of journalistic error are not considered by mainstream media to be notions of "fake news," but that "[l] 
iberal commentators defend the acts of fake news, arguing that 'honest mistakes' are far less serious than people knowingly [sic] generating fake news online (like conservatives)." Attkisson says that she could also argue "the opposite" when she writes "mistakes at 'real' news organizations are far more harmful, because more readers are likely to believe them than off-brand online sites" (p. 252).

Sadly, what Miller's reporting did do was lead even the on-the-fence Trump supporter or "non-racist" to believe once again that racism is a made-up movement by the left to validate victimhood, increase the welfare state, and take from white people who work hard for what they have to give to non-white people who don't. And in the end, just as "fake news" becomes more about the political ideologies of the information shared and who shared it (for more, particularly on news of Russia hacking the U.S. election, see Attkisson's discussion pp. 258-264), the controversy also becomes less about the state and the role of everyday journalism as a means by which to indoctrinate.

\section{Where Do We Go from Here?}

Naomi Klein (2017) writes that citizens must ignore the shock of Trumpism, the rhetoric, the change, and respond with measured and calculated resistance to policies and acts that they consider restricting, dictatorial, Orwellian, or simply Trumpish. In an edited volume on resisting Trumpism edited by David Cole and Melanie Wachtell Stinnett (2017), contributors ranging from scholars and activists to journalists and business leaders from across the globe argue for turning the political system on its head, undermining the authority of pollsters, and recognizing the power of populism in the everyday desires and behaviors of the citizenry. Protest, some contributors say. Expect the worst, others note. Watch out for distractions of daily Trump tirades, they write, and focus on the big picture of social justice issues.

Because it seems something a volume like this should do, I present below several approaches citizens, educators, journalists, and scholars could adopt for future action, education, journalism, and research. My thoughts are informed in large part by the works in this book, though I am not extremely confident, I must say, about the degree to which these approaches will be adopted, because each suggestion requires individuals and collectives to relinquish power, to recognize the form and function of agency in others, and to mark for future generations our own inadequacies, our own selfish acts, our involvement in suppression and intentional oppression.

My intent here is not to divide or classify apart our publics to suggest that a journalist is not also a citizen or the researcher not also an educator, for example, but to emphasize actions or approaches that might be more tailored to specific categories to which one might subscribe. 


\section{Citizens: The Need for Reflexivity}

Citizens needs to stop expecting the press to be the Fourth Estate. Perhaps public notions of the Fifth Estate have eroded the former, but still, citizens - to the degree they ever could have or should have - should stop turning to the press to inform and to help engage. Audiences need to radicalize their perspectives about power related to the role of the press in voicing concerns of marginalized populations or to keep the powerful accountable.

Numerous surveys show a decline in trust in the government and in journalism, yet conversations in airports, grocery stores, and in online comments indicate, to some degree, immense public interest in what the press have to say. Perhaps if these TVs are tuned to the news only because of the visual or background noise, or because of the social function of the press to provide "something to talk about," citizens should reflect on why the news is a source of interest.

Indeed, if public interest in the news over the past couple of years is any indication, absent of an international war that captures the public imagination, conflict that has replaced international war with war at home is embedded in masturbatory media coverage of police killings in which white police are killing Black citizens (Steiner \& Waisbord, 2017). The coverage wasn't as much about providing information about daily social conditions of either Black folk, the police state, or general disorder, but to reinforce among fearful white citizens violent actions of order that have become commonplace and seemingly necessary in liberal social and under cultural policies and economies of the United States (Gutsche \& Estrada, 2017).

Reflexivity on part of citizens as to why they are drawn (and why the press itself is drawn) to racialized conflict would further expose the deeply rooted hatred that led to events such as the protests and "counter protests" in Virginia on August 12, 2017, where one person was killed and two police officers on way to the protest died in a helicopter crash. News coverage showed images of a car, driven by a white man from Ohio, plow into a crowd following demonstrations between alt-Right, white nationalists, and "counter protestors" surrounding the removal of a monument to Civil War Confederate General Robert E. Lee (Fortin, 2017).

Trump, speaking in a press conference from his resort in New Jersey, tried to make it seem as though he rebuked the violence by praising why we should all come together - improved employment rates and the work of law enforcement - and said that racial tensions have "been going on a long time in our country. Not [because] of Donald Trump, not [because] of Barack Obama. It's been going on for a long, long time" (Helm, 2017). Instead, Trump's speech only fueled a fire, identifying him as part of the problem and a symptom of the problem at the same time. Just as 
it was ignoring his role, the role of racism today, and the role of his policies in furthering racial divides throughout the country, his intentional silence spoke to the engrained knowledge of his audience. He needn't say what they all know.

Only when a video of the violent act was available, in which white and Black citizens were mowed down, looped over and over again as some sort of "holy shit story" (Berkowitz, 1992), did the clear images of whites holding tiki torches - symbolic of KKK rallies and of an angry suburban backyard racist - make national news. Those images themselves, without the drama and blood, seem too innocent for Americans to recognize the hatred inherent in themselves and in their neighbors (Cullen, 2017). Just as much as images being shown only when they elicit a sexual and sensational rage for Blacks is the fault of news media giving into what they believe is the best they can offer, citizens, too, must question how and why they are drawn to such things (for more, see Berger, 2011; Muhammad, 2010; Shumow \& Gutsche, 2017).

\section{Journalists: Realizing the Cost of Authority}

For years, we may be asking the same question: "Why didn't journalists see Trump coming?" It's the question that won't go away, and one that this very book struggled to resolve. In short, journalists didn't see it coming both because they didn't want to and because they wanted Trump to win. Not only may the Trump candidacy and potential presidency chafe with journalists' own politics and perceptions (for more on political leanings of journalists, see Smith, 2017), but Trump was too good of a "good story" that its appeal fit with desires of and for conflict that revolve around journalism's aims of pandering and promoting conflict and hate (i.e., Ralph, 2017). Without Trump, journalists would have been forced to discuss policy. That's boring and, honestly, journalists lack the authority to adequately present the complexities of law, economics, and governance.

Those of us who have been in the field long enough know that the distance we have from our audiences - behind the locked doors of our newsrooms, in the verisimilitude we demand in our dress, voice, bylines, and brands that lead to our shared sense of power and legitimacy for the benefit of journalistic authority - is to make it seem that we are not part of the citizenry. In turn, journalists will believe almost anything if it is a good enough story - so much so that the distance from citizens who might threaten our beliefs of a story's newsworthiness, accuracy, or believability is held tight and maintained despite calls to provide "community journalism," to "engage with audiences," or to "listen to readers."

Putting aside politics, Tanenhaus (2017) writes that the rise of Trumpish supporters and mediaites Steve Bannon, Andrew Breitbart, and Matt Drudge occurred because "reporters, while often liberal, aren't 
ideological. They want good stories, just as Drudge and Breitbart did, even if they adhere to much more scrupulous standards." Mainstream journalists believed reports of rape in the Superdome during the aftermath of Hurricane Katrina and that police helicopters were subjects of "rioters" bullets, deepening the divide between deserving and undeserving victims, because the story sold to audiences' ideological positions far and wide.

But it wasn't until weeks or months or years later when some journalists were able to report - without the social consequences of police restriction, threats to advertising dollars, and the social ills that malign journalists who speak truth to power that is outside of approved lanes of truth - that the flood waters were the result of racialized policies and were, in many ways, intentionally allowed to drive out the poor and dark-skinned (i.e., Ridgeway, 2009). Questions related to this case remain: Why was it that early in the story journalists found it hard to see racialized intentions of flubbed construction of levees that ultimately failed? Why was it hard for journalists to report without immense skepticism the possibility that the U.S. government had blown the levees in 2005 and in the decades prior? (These questions only smack of "conspiracy theory" because of the term's ability to marginalize "alternative facts." For more on conspiracy theory, see Gutsche, 2017).

The list of questions about the coverage of Trump is equally complicated, a main one being, "Why was it hard for mainstream journalists to believe Trump could - and would - win?” This book has asked these and other questions - and the contributors have provided a myriad answers and suggestions. But perhaps that question is too large, particularly for a mainstream media (of which I have been a proud member for 20 years) to know its neighbors. Those calls for "community engagement" I mentioned above, for instance, lead to nothing more than Tuesday morning coffee shop meet-ups between journalists and readers (promoted by journalists but criticized frequently by reporters when public officials do it since only a select few have Tuesday mornings available), journalists simply don't care about the needs and interests of the Average Joe or even Sarah Palin's “Joe Six Pack.” That's why Pack made sense to so many.

Journalists, by and large, have been trained to serve a higher power to support interests of freedom and democracy. These aims move journalists away from the individual-level interests and needs of the reader and to the aims of collectives and ideologies that gain traction, popularity, and legitimacy by the acceptance of public officials, quantifiable data, and a lineup of sources who can speak plainly and in soundbites. Approved topics of popularity or legitimacy come with a trained constituency with disposable time and money, approved skin colors and tones, the "right" accent - if there is one - and the ability to pass among socialites and to promote archetypes of national pride, or at the very least, 
characters in a story that do not disrupt the overarching narrative of a dominant collective. The real question from the rise of Trump should be, then, "Just how much is the press part of his collective?"

\section{Journalism Educators, Drop the Fourth Estate}

Journalism educators should stop pushing the Fourth Estate. Just as scholars advocate beyond a reason for notions of a public sphere (Hess \& Gutsche, 2017), educators refuse to see that the Fourth Estate is neither accessible nor practical in our part of the system. In an age of populism and rampant racism, the fallibility of our democracy is clear, and educators should emphasize the role of power in journalism and prepare students and future journalists in ways of radicalizing the industry. That said, educators would then be teaching students how to not succeed in the industry of today, in which they will immediately be retrained to professional and capitalistic ideals in the workplace - or be removed.

Perhaps that is what is needed - a generation of journalists able or willing to take one for the team, to work as they did in the days of the Penny Press. Despite the nostalgia assigned to those days of journalism (things weren't necessarily "better"), there was a spirit that seems missing today in terms of comforting the afflicted and afflicting the comfortable. Today, consumerism has become so engrained within our nation's public education system as an intended deliverable of learning itself that citizens are educated to want for themselves and not for others. This is a challenge for industries, such as journalism, that are said to be based on a system of creating outcomes for the public good and balancing those outcomes with financial profit.

To say that journalists writ-large do not care about the public good and only about their own good is perhaps unfair, but it is accurate. Caring too much about the public and not the self for today's journalists would create tension within the news process, the editing and selection of stories, images, and voices and would undermine the very institutional authority that journalists strive for (Schudson, 2008).

Still, journalism educators would benefit from balancing the promotion of normative characteristics of journalism's higher calling with the works of Henry Giroux, bell hooks, Noam Chomsky, and Slavoj Žižek. Other perspectives are equally compelling for complicating how journalists see themselves working within a system of indoctrination and oppression:

- Robert Entman writes about the power of racial narratives in news and on the role of the news media to dismiss presidential misconduct as the cost of doing business (i.e., Entman, 2012).

- John Nichols and Robert McChesney discuss the role of media to increase its own profitability, using politics and policy to commercialize the citizens' information (Nichols \& McChesney, 2005). 
In their individual and collective work, there is a nod to the normative expectations of journalists to serve as a Fourth Estate, but journalistic practices and business models are shown to undermine the ability of the press, without massive change, to meet that aim.

- Ari Rabin-Havt (2016), with the support of Media Matters, connects politicians, special interest groups, and news media as a dangerous combination. Again, the normative expectation of the press as being a watchdog is acknowledged, but it becomes greatly diminished over the desires of business and power interests.

- Jimmie Reeves and Richard Campbell (1994) uncover the news media's knowledge of intersecting interests and acts of politicians, police, and drug-runners that disabled many U.S. communities through the introduction of cocaine during the "Drug Wars" of the Reagan Years.

Expanding students' experiences with journalism beyond writing, reporting, and social media efforts produces a group of professionals with improved critical thinking skills and treats students (and new employees) as more than mere cogs in a media machine but as the future for a society in which its noble tenets are being challenged and eroded.

\section{Increase Research That Exposes Power}

No doubt, titles for papers and panels at the 2017 conference of the Association for Education in Mass Communication, such as the below, are of great importance:

- "Reassessing Issue Emphasis and Agenda Building on Twitter During the Presidential Primary Season"

- "Being Young but Not Reckless: A Study on Young Adults' Social Media Flight-or-Fight to Hostility During the 2016 U.S. Presidential Election"

- "Societal Majority, Facebook, and the Spiral of Silence in the 2016 U.S. Presidential Election”

- "Schadenfreude, Chagrin, and Deliberation: Discussing the 2016 U.S. Presidential Election in Online News Comments"

- "Breaking News Panel: Teaching about Trust in a Fake News World: The Impact of the 2016 Election in Our Journalism Classrooms and Beyond"

- "A Textual Analysis of Fake News Articles on Facebook Before the 2016 Election"

- "Does News Consumption Online and on Social Media Affect Political Behavior? Evidence from a Swing State in the 2016 Elections"

Yet, the focus on social metrics, social media, and the internet by journalism and mass communication scholars indicates a continued attachment 
to the online world that is one of fancy and popularity, not on critical and cultural explorations that place online social behaviors within a greater context of power structures (Gutsche, 2017).

Studies on Twitter as a space for journalistic and political engagement are popular, to a large degree, because they do not tackle the inherent racist and consumeristic tendencies of American Democracy. And with its field in flux over the past two decades, journalism scholars especially turn to quantifiable statements of engagement and power to make interesting scholarship, while ignoring the intentional interactions of business, information, education, and policing and governance that relies on distraction by new technologies, but also to a field that has been in constant flux, trying to find ways to explain how and why society appears as it does.

In covering Trump, the distraction has surrounded his rhetoric - and his modes of communicating via social media. With each day presenting for media and scholars alike new challenges to explaining attacks to the surface of the status quo, scholarship focused on distraction removes critical inquiry from its necessary place in society - at the center. In August 2017, for instance, Trump argued that the United States would fight with fury against North Korea for its government's progress in creating weapons that could reach U.S. coasts. For cable journalists - a social phenomenon of its own - they turned to narratives of Trump being "dangerous" in his threats to North Korean leaders.

But there are likely few Trump supporters (or, as I discussed before, anti-Clinton supporters) who believed that a crazed leader in North Korea would believe a crazed leader in the United States for being anything more than what he is - a big talker. Still, the daily deluge of Trumpisms (for analysis, see Peters, 2017) have posed great concern for those looking at distractions. As conflict rules, mainstream journalists take the news to the extreme: Trump has all but issued a statement of war. But what of the Cold War mode that we have been in since the Cold War?

In 2008, Hillary Clinton attacked President Barack Obama for not being prepared to "answer the phone" in the White House when disaster strikes, as the two battled it out for the Oval Office (Washington Post, 2016). The same questions have been asked of Trump - the major difference being that his late-night tweets and phone transcripts reveal the making of politics in plain language. What hasn't changed, then, is a U.S. fixation on international hegemony. That story, though, is harder to tell U.S. news audiences than metaphors of war (Lule, 2004).

Journalism studies scholars should use this moment of contestation to go deeper, to position themselves as constituents of a power system, to redesign how we think about integrations of news, politics, behavior, and power, returning to the days of newsroom ethnographies, of examining traditional gatekeeping processes and practices of hegemony. And while some of these methods are employed by scholars today, there remains a lack of critical perspectives that engage with whiteness studies, critical 


\section{Robert E. Gutsche, Jr.}

human geography, propaganda studies, and feminist theory, leaving the field stuck in a space of social media studies and the public sphere with scholarship examining just the surface of complexity.

This project is just a first step. It is neither immense social action, nor is it a process of great risk-taking. But it is a form of resistance, and one that is necessary for today and for tomorrow, with or without Donald Trump as president.

\section{Note}

1 In fact, in complete everyday-is-something-new of the Trump administration, as of December 2017, McEnany was less a staple of "News of the Week," with sporadic appearances also made by other young conservatives, including Madison Gesiotto, Katrina Pierson, and Lara Trump, who is married to Donald Trump's son, Eric.

\section{References}

Attkisson, S. (2017). The Smear: How Shady Political Operatives and Fake News Control What You See, What You Think, and How You Vote. New York, NY: Harper.

Berger, M. A. (2011). Seeing Through Race: A Reinterpretation of Civil Rights Photography. Berkeley, Los Angeles \& London, UK: University of California Press.

Berkowitz, D. (1992). Non-routine news and newswork: Exploring a what-astory. Journal of Communication, 42(1), 82-94.

Cole, D., \& Stinnett, M. W. (2017). Rules for Resistance: Advice from Around the Globe for the Age of Trump. New York, NY \& London, UK: New Press.

Cullen, T. (2017, August 12). Tiki torch-wielding white nationalists at UVA rally roastedbycriticson Twitter.Retrievedatwww.nydailynews.com/news/national/ tiki-torch-wielding-white-nationalists-grilled-twitter-article-1.3406056.

Entman, R. M. (2012). Scandal and Silence: Media Responses to Presidential Misconduct. Cambridge \& Malden, MA: Polity.

Fortin, J. (2017, August 13). The statue at the center of Charlottesville's storm. Retrieved at www.nytimes.com/2017/08/13/us/charlottesville-rally-proteststatue.html.

Gutsche, Jr., R. E. (2017). Media Control: News as an Institution of Power and Social Control. New York \& London: Bloomsbury.

Gutsche, Jr., R. E., \& Estrada, C. (2017). Renewing the lease: How news characterizations of Baltimore realigned the white reign of US cities. In L. Steiner \& S. Waisbord (Eds.), News of Baltimore: Race, Rage and the City (pp. 21-40). New York, NY \& London, UK: Routledge.

Helm, A. (2017, August 12). Donald Trump ain't shit, he ain't Barack Obama and he surely doesn't care about black people. Retrieved at www.theroot. com/donald-trump-ain-t-shit-he-ain-t-barack-obama-and-he-s-1797784668.

Hess, K. \& Gutsche, Jr., R. E. (2017). Journalism and the "social sphere": Reclaiming a foundational concept for beyond politics and the public sphere. Journalism Studies. doi: 10.1080/1461670X.2017.1389296. 
Klein, N. (2017). No is Not Enough: Resisting Trump's Shock Politics and Winning the World We Need. Chicago, IL: Haymarket.

Lule, J. (2004). War and its metaphors: News language and the prelude to war in Iraq, 2003. Journalism Studies, 5(2), 179-190.

Markay, L., \& Suebsaeng, A. (2017, August 7). Lara Trump "Running the Show" at "Trump TV." Retrieved at www.thedailybeast.com/lara-trumprunning-the-show-at-trump-tv.

Muhammad, K. G. (2010). The Condemnation of Blackness: Race, Crime, and the Making of Modern Urban America. Cambridge, MA \& London, UK: Harvard University Press.

Nichols, J., \& McChesney, R. W. (2005). Tragedy and Farce: How the American Media Sell Wars, Spin Elections, and Destroy Democracy: And What You Can Do to Change Things. New York, NY \& London, UK: The New Press.

Peters, J. W. (2017, August 5). They're building a Trump-centric movement. But don't call it Trumpism. Retrieved at www.nytimes.com/2017/08/05/us/ politics/building-a-trump-centric-intellectual-movement-trumpism.html.

Phillip, A., \& Paletta, D. (2017, July 31). Anthony Scaramucci removed as White House communications director. Retrieved at www.washington post.com/news/post-politics/wp/2017/07/31/anthony-scaramucci-removedas-white-house-communications-director/?utm_term=.f56d32506f11.

Rabin-Havt, A. (2016). Lies, Incorporated: The World of Post-Truth Politics. New York, NY: Anchor.

Ralph, L. (2017, January 18). Nigger moments. Retrieved at https://culanth.org/ fieldsights/1042-nigger-moments.

Reeves, J. L., \& Campbell, R. (1994). Cracked Coverage: Television News, the Anti-Cocaine Crusade, and the Reagan Legacy. Durham, NC \& London, UK: Duke University Press.

Ridgeway, J. (2009, August 28). The secret history of Hurricane Katrina. Retrieved at www.motherjones.com/environment/2009/08/secret-historyhurricane-katrina.

Schudson, M. (2008). Why Democracies Need an Unlovable Press. Cambridge \& Malden, MA: Polity.

Sheth, S. (2017, August 6). One of Trump's most vocal supporters left CNN to make a pro-Trump news video that's been compared to state TV. Retrieved at www.businessinsider.com/kayleigh-mcenany-left-cnn-to-host-pro-trumpnews-videos-2017-8.

Shumow, M., \& Gutsche, Jr., R. E. (2017). News, Neoliberalism, and Miami's Fragmented Urban Space. Lanham, MA: Lexington.

Smith, J. (2017, January 18). Blind spots of liberal righteousness. Retrieved at https://culanth.org/fieldsights/1044-blind-spots-of-liberal-righteousness.

Stark, L. (2017, August 3). White House policy adviser downplays Statue of Liberty's famous poem. Retrieved at www.cnn.com/2017/08/02/politics/emmalazarus-poem-statue-of-liberty/index.html.

Steiner, L., \& Waisbord, S. (2017). News of Baltimore: Race, Rage and the City. New York, NY \& London, UK: Routledge.

Stelter, B. (2016, August 19). Trump TV may be in the works; but can it turn voters into viewers? Retrieved at http://money.cnn.com/2016/08/19/media/ donald-trump-tv/index.html. 


\section{Robert E. Gutsche, Jr.}

Tanenhaus, S. (2017, August 17). The making of the tabloid presidency. Retrieved at www.nybooks.com/articles/2017/08/17/steve-bannon-donald-trumptabloid-presidency.

Time. (2015, August 11). Transcript: Read the full text of the primetime Republican debate. Retrieved at http://time.com/3988276/republican-debateprimetime-transcript-full-text.

Washington Post. (2016, September 30). Hillary Clinton's 2008 “3 a.m. phone call" ad. Retrieved at www.washingtonpost.com/video/national/hillaryclintons-2008-3-am-phone-call-ad/2016/09/30/a1043ef6-8729-11e6-b57ddd49277af02f_video.html?utm_term=.097a9e8f23dc. 


\section{List of Contributors}

Leon Barkho is founder and editor of the Journal of Applied Journalism and Media Studies. He holds a master's degree in applied linguistics and a doctorate in media and communication science. Previously, he held positions at Reuters News Agency as bureau chief and the Associated Press as staff writer. Barkho, the author of several books, is currently associate professor at Sweden's Jonkoping University and Qatar University.

Katherine M. Bell teaches media, cultural studies, and journalism in the Department of Communication at California State University East Bay. Her research examines celebrity, consumer culture, and identity, as well as gender, race, and sexuality in media. She is a career journalist who worked with The Canadian Press news agency as a reporter, editor and news manager. She holds a Ph.D. in Communication from the University of Washington.

Prashanth Bhat is a Ph.D. student at Philip Merrill College of Journalism at the University of Maryland-College Park. His research interests include online hate speech, right-wing politics and media, and online political expressions. He has worked as a journalist for leading news organizations such as The Times of India and China Central Television.

Fred Blevens is a Professor of journalism at Florida International University. He holds a BA and MA from Ball State University and a Ph.D. from the Missouri School of Journalism. Blevens was a journalist for 20 years and was a 2001 Freedom Forum National Journalism Teacher of the Year. He is co-author of Twilight of Press Freedom: The Rise of People's Journalism.

Brian J. Bowe is an Assistant Professor of journalism at Western Washington University. His research focuses on framing and agenda setting, with particular focus on media coverage of Islam in the United States. He has taught at Grand Valley State University, the Sorbonne, and Michigan State University. 


\section{List of Contributors}

Pam Creedon, Acting Dean of Zayed University College of Communication and Media Sciences, is Professor Emeritus at University of Iowa. Previously director of the School of Journalism and Mass Communication at Kent State and Iowa, her books include The Edge of Change: Women in the Twenty-First-Century Press, Women in Mass Communication: Challenging Gender Values, and Women, Media and Sport.

Al Cross is director of the Institute for Rural Journalism and Community Issues and an associate professor at the University of Kentucky. He reported for The Courier-Journal for 26 years, the last $15 \frac{1}{2}$ as a political writer, and writes a column for the Louisville newspaper. He was president of the Society of Professional Journalists and is a graduate of Western Kentucky University.

Kathleen Bartzen Culver is the James E. Burgess Chair in Journalism Ethics in the University of Wisconsin-Madison School of Journalism \& Mass Communication and director of the Center for Journalism Ethics. Culver focuses on the ethical dimensions of technological advances and networked information in news and other public communication.

LaTasha DeLoach, LMSW, in her position of Community Projects Specialist at Johnson County (Iowa) Social Services, is the Johnson County Disproportionate Minority Contact coordinator and the Community Partnerships for Protecting Children coordinator. DeLoach advocates for families and is a fierce advocate for women and young women of color in Iowa.

Frank Durham is an Associate Professor in the School of Journalism and Mass Communication at the University of Iowa. His research interests include journalism history and media framing analysis. $\mathrm{He}$ teaches courses in journalism history, strategic communication, and cultural satire.

Carolyn Guniss was the first woman to edit The Miami Times, a historically Black newspaper in Miami, Florida. She has worked for the Miami Herald, the Bradenton Herald, and has been a fellow for New America Media, the European Union, the Center for War, Peace and the News Media, and The Gerontological Society of America. Guniss is president of the South Florida Black Journalists Association and was named 2017 Communicator of the Year by The Black Owned Media Alliance.

Robert E. Gutsche Jr. is Senior Lecturer in Critical Digital Media Practice at Lancaster University (UK). He was an assistant professor who taught journalism and digital media at Florida International University in Miami. Gutsche's research focuses on social and cultural meanings of news. He is the author of several books, including Media Control: News as an Institution of Power and Social Control. 
Stephen J. Heidt is an Assistant Professor in the School of Communication \& Multimedia Studies at Florida Atlantic University in Boca Raton, Florida. An expert on presidential rhetoric, his research analyzes American and international public address and the role of presidential rhetoric in the constitution of American foreign policy. His current project focuses on the rhetorical strategies presidents use to depict enemy character at the end of war.

Jennifer Hoewe is an Assistant Professor in the Department of Journalism and Creative Media at The University of Alabama. Her research examines the media's ability to create and perpetuate stereotypes as well as the influence of political orientations on media creation and consumption. Her research has been published in Media Psychology, Journalism \& Mass Communication Quarterly, and New Media \& Society, among others.

Douglas Kellner is George Kneller Chair in the Philosophy of Education at UCLA and is author of many books on social theory, politics, history, and culture. Kellner's latest published books include Cinema Wars: Hollywood Film and Politics in the Bush/Cheney Era (2010); Media Spectacle and Insurrection 2011 From the Arab Uprisings to Occupy Everywhere (2013); American Nightmare: Donald Trump, Media Spectacle, and Authoritarian Populism (2016); and The American Horror Show: Election 2016 and the Ascendency of Donald J. Trump (2017).

Robert E. Pierre is an entrepreneur, author, and award-winning former reporter, editor, and columnist at The Washington Post. He co-wrote A Day Late and a Dollar Short: High Hopes and Deferred Dreams in Obama's 'Post Racial' America. He is president of Bald Cypress Media.

Geri Alumit Zeldes, a tenured professor in Michigan State University's School of Journalism, studies race and gender issues. Zeldes has more than 100 awards and festival screenings, including regional Emmys, an Edward R. Murrow award, national Best of Festival awards, and awards from the Society of Professional Journalists. 


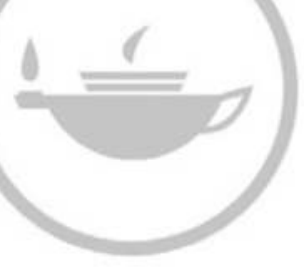

Taylor \& Francis Taylor \& Francis Group

http://taylorandfrancis.com 


\section{Index}

“alternative facts" (see also, alternative explanations and "alternative realities") 8, 19, 26, 27, $37 \mathrm{n} 10,78,181,273,320$

“alternative reality" (see also, "alternative facts" and alternative explanations) 181

“covfefe" 86, 302

"fake news" 8, 11, 13, 25, 27, 33, 34, 39-45, 70, 77-81, 84-86, 89, 157, 159, 169-70, 181-82, 188-90, 200, 249, 264, 272-73, 276-77, 282, 287-88, 311, 316-17, 322; history 41-42, 78-80; and satire 43-44; types 43-44; authority and mainstream press 48-49, 84-86; and audiences 49-51

"inner-city" 2, 5, 12, 52, 140, 143, 147-48, 151-52, 213, 237 see also urban

"Joe Six Pack" 320

"Make America Great Again" slogan 50, 62, 75, 232, 245, 302

"post-fact" 26 see also "post-truth"

"post-truth" 27, 40, 43, 134

\#DumpKelloggs 13, 192-93, 198-201

\#GrabYourWallet 164-66, 172n13

2016 election 1, 7-9, 11-14, 19-20, 23-25, 30-33, 37n10, 39-40, 44-45, 47, 49, 51, 61, 62-68, 71-73, 75, 78-80, 85, 101, 103, 106, 118, 142-43, 146, 149-50, 156-59, 161, 192-93, 197-98, 231, 233-35, 237, 239-41, 243-44, 246-47, 249-50, 252, 274, 277, 279, 286-88, 290, 299-300, 303-04, 311-12, 316-17, 322; Russian involvement in $11,28-34,37 \mathrm{n} 9-10,59,63,68$, 70, 72, 80, 88, 140-41, 149-50, $279,287,290,295,299,317$
9/11 terrorist attacks 73-74, 119, 122, 124-26, 129, 217

$\mathrm{ABC}$ news network 12, 102, 106-13, 130, 166, 171n 4, 216, 219, 287

Acosta, Jim 288, 315

advertising $1,49,50,85,102,165$, 169, 193-96, 198-202, 264, 266, 269, 273-75, 312-20

Affordable Care Act 33, 59, 72, 143, 163 see also Obamacare

African 303, 309

African American 12, 60-63, 72, 118-20, 127-28, 131-32, 134, 142-43, 145-49 see also Black alt-Right 12-13, 34-36, 119-21, $181,188,192,197-98,312,318$

alternative explanations $13,42,53 \mathrm{n} 1$ see also "alternative facts" and "alternative reality"

American Society of Newspaper Editors (ASNE) 182

anti-Semitism 190, 197

Apprentice, The 5, 21, 22, 143, 171,288

Association of Community Organizations for Reform Now (ACORN) 188, 197

ban see Muslim ban

Bannon, Steve 34, 36, 84-85, 148, 192, 197, 202n1, 319

bias, in institutions 70, 79, 102, 105 , 114, 119-20, 125-28, 130-34, 182, 192, 196, 273-74, 293, 305, 310, 312, 315, 316

Black Lives Matter 8, 150, 222, 306

border with Mexico see Mexico

Boston Marathon, bombing of 217

branding 22, 25, 81, 83, 89, 143, 159 , 165, 167-69, 192, 198-201, 272, $312,317,319$ 


\section{Index}

Breitbart News Network 3, 13, 46-47, 69, 82, 84, 119, 134, 148, 187-90, 192-93, 196-202, 289

Breitbart Effect 13, 181

Breitbart, Andrew 181, 187, 188-90, 319-20

Bryan, William Jennings 183-84, 187

Brzezinski, Mika 87-88, 282, 288

Bush, Billy 148, 161, 162

Bush, George H. W. 32

Bush, George W. 124, 131, 169, 211, 216-17, 235, 313-13

Canada 109-10, 127, 211

Carson, Ben 149, 152-53

CBS news network 12, 102, 107-14, $171 \mathrm{n} 4,285,287,290$

Celebrity Apprentice, The 165

Central Intelligence Agency (CIA) 27, 30, 34, 36n7

Central Park Five 144

Charlottesville, Virginia 35, 60, 75, 118-19, 121, 151-52, 171n5, 190

Chicago, Illinois 64, 147, 167, 187

China 45, 89, 211, 286

Christian, Jeremy 120, 121, 132

Christianity 2, 4, 12, 30 62, 65, 181, 185-86, 217, 241-43, 313

Civil Rights 7, 63, 71, 134, 148, 152, 162, 198, 308, 313

Civil War 11, 59, 63-65, 68-69, 73, 151,318

Clinton, William 19, 36n2, 45, 212, 313

Clinton, Hillary 28, 30-33, 37n9, $39,45,49,65,68,70,74,83-86$, $88,103,106,142,149,158,160$, 163-64, 170, 212-14, 216, 218, 220, 231, 233-34, 240, 245-48, $250,285,287-88,313-14,323$

CNN news network 19, 26, 40, 70-71, 81-82, 88, 102, 106, 141, $156,158,160,170,171 \mathrm{n} 4,216$, 219, 221, 276, 282-83, 287-91, 295, 311, 315-16

Cold War 29-32, 34, 211, 216, 261, 323

Comey, James 29, 34, 287, 290

Communism 29-31, 185, 216; anti-Communism 185, 190, 211; see also Red Scare

Confederacy 35-36

Congress, US 8, 29, 31, 34, 36, 39, 72, 103, 126, 129, 141, 149, 150, 164,
170-71, 172n9, 172n10, 193, 242, 271, 294, 306, 313

Congressional Black Caucus (CBC) 141

Conway, Kellyanne 26, 27, 163, 285,311

Darrow, Clarence 183, 187

Democrats 2, 30, 33, 39, 59-61, 67-70, 72, 74-75, 86, 103, 105, 107, 143, 150, 160, 190, 196, 210, $214,218,231,234,242,247,249$, 285,314

Democratic National Committee (DNC) 33, 287

DeVos, Betsy 148, 168

Drudge Report 82, 196, 313

Drudge, Matt 188, 319-20

drugs 2, 4, 23, 104, 118, 124, 146, 164, 206, 209, 210-12, 214-15, 232, 238, 283, 308, 322

Duke, David 62, 75, 119, 129, 151

executive orders, presidential 6, 10 , $34,101,110,112,143,151,163$, 218,306

Facebook 20, 22, 40, 48-50, 52, 59, 67, 84-85, 120, 164, 274, 277, 288, 311-12, 322

Federal Bureau of Investigation 29, $34,121,123,127,132,287$

Feminism 156-57, 165, 171n2

Fields, James Alex 121, 151

Fifth Estate 318

First Amendment 132, 161, 268

Flynn, Michael 29-30, 140

Fourth Estate (see also, watchdog) 6, 27, 134, 194, 210, 318, 321-22

Fox News network 19, 39, 70, 82, 88, 102, 134, 159, 171n4, 189, 190, $196,215,216,274,285,312,313$

fragmentation, media $12-13,43$, 49-51, 188, 200, 265, 268

generational fatigue 309

Google 24, 84, 86, 200, 274, 277

GOP see also Republican Party 2, 4, 246, 283-85

Gore, $\mathrm{Al}$ 36n2, 311

hacking $11,30-33,37 \mathrm{n} 10,40,77-78$, 82-84, 86, 88-89, 93, 299, 317

"hacktology" 11, 68 
Harvey, Steve 308

Heyer, Heather 151

Hispanic 61, 140, 147, 240 see also Latino

Homeland Security, US Department of $66,101,131,169,311$

homophobia 6, 167, 304

Huffington Post 82, 96, 98, 136, 160-61, 175, 187, 223

immigrants 3, 4, 23, 28, 59-60, 62, 67, 101, 103-04, 112, 118, 121, 126, 146, 152, 165, 192, 197, 206-12, 213-17, 218-22, 239-40, $144,265,283,303,315$

immigration $4,10,12,69,83$, 101-04, 106-14, 148, 163, 206, 211-13, 216-17, 220, 238-41, 251, $265,270,303,315-16$

Instagram 20, 22, 70, 168, 311

Iran $30,89,101,109-12,134 n 1$

Iraq 71, 73, 101, 104, 109-12, 124, $131,134 \mathrm{n} 1,285$

Islam $105,118,119,120,122,124$, 126-27, 129, 131, 133, 143, 190, $210,215-17$

Islamaphobia 23, 28

Islamic State in Iraq and Syria (ISIS) 104, 221, 124, 200, 212, 215, 217

Jackson, James Harris 120-21, 132 Jim Crow 63, 119, 308

Jones Alex 70, 134, 274

Justice Department US 34, 72, 123, $129,144,165,287$

Kelly, John F. 311

Kelly, Megyn 159-60, 285

KGB 32

Ku Klux Klan (KKK) 61, 75, 151, $186,190,268,319$

Kushner, Jared 31, 164

Latino 59, 90, 142, 144, 146, 214, 239, 302, 303 see also

Hispanic

leaks $8,11,39,72,77-78,82$, 83-84, 86, 88-89, 93, 275-76, 279,287

Lewis, John 149-51

LGBTQ+ 35, 64, 164, 172n11, 216

Lippmann, Walter 181, 183-84, 187, 189-90, 271
Locke, John 257, 259-62, 272, 274, 277,280

London 60, 121, 122

lone-wolf attacks 121, 129

Loughner, Jared Lee 126

Manafort, Paul 30-31

Mar-a-Lago, Florida 24, 166

McCain, John 107, 285

McEnany, Kayleigh 311-12

McMahon, Vince 282

McVeigh, Timothy 118, 128, 130

memes 7, 48, 77, 85, 158, 161, 169, 220, 283

Merkel, Angela 34

Mexicans 47, 210, 212-13, 218-19, 39

Mexico 2-4, 12, 23, 101, 104, 109-13, 146, 210-13, 303

Miami, Florida 5, 12, 153

Middle East 2, 59, 64, 124, 125, 215,258

military $8,28,35,36,71,110,124$, 129, 131, 161, 170, 172, 209, 271, $285,313,315$

Miller, Zeke 316-17

Mohamud, Mohamed Osman 126-27

MSNBC news network 19, 46, 70, 82, $87,88,102,215,216,282,283$, 288,313

Mueller, Robert 31, 72

Muslims, "ban" 59, 63, 71, 84, $101,110-12,119,163,210,216$, $218-19,279,303$

nationalism 186, 190, 197, 270

Nazism 60, 75, 121, 151, 186, 190 , 210, 270; neo-Nazi 35, 122, 129, $186,192,290,305$

NBC news network 12, 82, 102, $107-14,146,147,161,166,171$, $216,231,250,287$

neoliberalism 4, 7, 8, 9, 11, 190

New York City, New York 5, 20-21, 24, 64, 120, 142, 144, 151, 166, $167,187,198,218,242,287,312$

New York Times, The 1, 32, 34, 39, $44-45,48,50,52,63,70,82,85$, 90-92, 107, 122, 142, 145, 147, $149,157,159,160,162,166,170$, 171n4, 219, 224, 237, 242, 246, $248,249,250,276,282,290$

news literacy 10, 257, 261,270, 272-75, 277-80 


\section{Index}

News of the Week 311-12

North Atlantic Treaty Organization (NATO) 34

North Korea 232

O'Keefe, James 188-90

Obama, Barack 1, 6, 8, 20-22, 25-26, 30, 32, 37n9, 39, 61-63, 66-68, $72,75,101,107,119,131,141$, $143,145-46,149,152,161,166$, 168-69, 188, 199, 213, 215-18, 234, 238-39, 241, 245, 274, 284-86, 307-09, 318, 323

Obamacare see also Affordable Care Act 33, 143

orientalism 123, 125-26

Orlando, Florida, massacre 104, 216-20

Osborn, Darren 122

Page, Carter 30

Palin, Sarah 320

Pelosi, Nancy 150, 314

Pence, Mike 148

Penny Press 14, 193, 201, 261, 263-64, 267, 273, 279-80, 321

Pizzagate 39

Podesta, John 33, 39

police $1,4,7,39,52,62,75,119,120$, 127-28, 129, 131-33, 144, 147, 151, 206, 209, 271, 306-07, 315, $218,320,322$

PolitiFact 147, 152, 286

Priebus, Reince 148

progressivism 181-82, 189-90

protests $8,35,60,67,75,112,113$,

$119,121,133,151,163,165$, 171n2, 172n10, 186, 187, 189, 199, $306,317,318$

Putin, Vladimir 2, 28-33, 36n8, $37 \mathrm{n} 9,90$

Rawls, John 292-95

Reagan, Ronald 20, 24-26, 29-30, $185,196,322$

reality TV 11, 19-21, 25, 61, 134

Red Scare 185 see also Communism

Reddit 283, 288, 289, 294-95

Republicans 19, 23-24, 29-30, 33, 35-36 59-61, 63, 68-70, 72, 74-75, 77, 80-81, 83, 85, 89, 102-03, 105, $107,146,148,159,166,190,192$, 196-97, 206, 217-18, 220-21, 231,
234-35, 239-40, 242-46, 282, 283-84, 287, 313 see also GOP

Riley, William Bell 181, 183-86, 189

Romney, Mitt 21, 107, 231-32, 238, 246

Roof, Dylann 119, 127-28

Roosevelt, Theodore 272-73

Russia 2, 8, 11, 28-34, 37n9, 37n10, 37n11, 59, 63, 68, 70, 72, 80, 85, $88,140-41,149-50,185,261,279$, 287, 290, 295, 299, 317

Ryan, April 140-42, 148, 154

Ryan, Paul 151, 161

San Bernardino, California attack 104, 216-17

Sanders, Bernie 69, 248

Sanders, Sarah Huckabee 287

Scaramucci, Anthony "The Mooch" $88,287,311$

Scarborough, Joe 87, 88, 282, 288

Scopes Monkey Trial 183, 187

Sessions, Jeff 34-35, 148, 276, 287

Skype 20, 312

slavery, of Blacks in US 63, 118, 261-62, 307

social media 7-8, 14, 20, 23, 39, 46, 48-50, 52, 78-81, 84-87, 102, 106, 121, 134, 141, 157, 170, 198, 251, 274, 277-79, 282-86, 288-89, 302, $306,312,322-24$

Soviet Union 29, 31-32

Spencer, Richard 119, 134

Spicer, Sean 25-27, 72, 141, 148, 286-87

Statue of Liberty 308-09, 315-16

Syria 40, 64, 65, 101, 104, 109-12, 134n1, 215, 218

terrorism 12, 105, 118-24, 126-34, $142,211,216-17,220,302$

Tillerson, Rex 29-30, 286

Todd, Chuck 26, 149, 231, 250

travel ban see Muslim ban

Trump Tower 23, 24, 31, 141, 151, $166,167,218,283,312$

Trump TV 311-12

Trump, Ivanka 164-65, 167-68, $172 \mathrm{n} 12$

Trump, Melania 23, 166-67, 172n14

Trumpism 8, 10-12, 51, 85, 146

Turnidge, Joshua 126-27

Twin Towers see World Trade Center 
Twitter 19-24, 33-35, 53n2, 59, $63,71,77,81,86-87,92,141$, $146,150,159,161,164,166-67$, 170, 198, 257, 272, 274-77, 280, 282-83, 285, 288, 291, 302, 306, $311,322-23$

Ukraine 30, 32, 40, 80

urban 12, 14, 34, 147, 152, 172n12, 187, 193, 231-36, 238-41, 243-46, 248, 251-52, 265, 257 see also "inner-city"

victorianism 257-58, 266, 268, 270

Washington, D.C. 5, 9, 30, 35, 49, 61, $64,68,69,90,129,140,156,163$, $167,171,275,290,302,312$

The Washington Post 30, 32, 44-46, 48-50, 63, 70, 82, 84, 157, 160-61, 171n4, 206, 234, 236, 238, 248-49, 251, 276, 282-83, 285-86

Waters, Maxine 149

white supremacy $75,130,300,305$

whiteness 12, 14, 62, 119-20, 122-34, 323

WikiLeaks 33, 39, 158, 289

World Trade Center 2, 118, 131, 216

World's Christian Fundamentals

Association (WCFA) 181, 185-86, 189

xenophobia $13,23,118,121,128$, 132, 134, 161, 192, 200, 207, 222, 270

youth 4, 14, 43, 66, 299-304, 310

YouTube 20, 200, 311

Zehaf-Bibeau, Michael 127 